\title{
BANK ASSET AND LIABILITY MANAGEMENT
}

\author{
by
}

Martin Kusy

B. Comm., Sir George Williams University, 1969

M.B.A., University of Windsor, 1970

A THESIS SUBMITTED IN PARTIAL FULFILMENT OF

THE REQUIREMENTS FOR THE DEGREE OF

DOCTOR OF PHILOSOPHY

in

THE FACULTY OF GRADUATE STUDIES

Faculty of Commerce and Business Administration

We accept this thesis as conforming

to the required standard

THE UNIVERSITY OF BRITISH COLUMBIA

(C) May 1978 : 
In presenting this thesis in partial fulfilment of the requirements for an advanced degree at the University of British Columbia, I agree that the Library shall make it freely available for reference and study. 1 further agree that permission for extensive copying of this thesis for scholarly purposes may be granted by the Head of my Department or by his representatives. It is understood that copying or publication of this thesis for financial gain shall not be allowed without my written permission.

Martin Kusy

Department of Commerce and Business Administration

The University of British Columbia 2075 Wesbrook Place Vancouver, Canada V6T IW5

Date May 16, 1978 


\section{ABSTRACT}

The inherent uncertainty of a bank's cash flows, cost of funds and return on investment, along with the increased variability of economic conditions during the past decade, have emphasized the need for greater efficiency in the management of a bank's assets and liabilities. A consequence has been an increased number of studies on how to structure a bank's assets and liabilities so that an "optimal" trade-off exists between risk, return and liquidity. Except for the Bradley and Crane (BC) mode1, the solution techniques proposed in the literature are computationally tractable only if uncertainty is ignored. Unfortunately, the $B C$ model is not operationally appealing due to severe computational limitations, and a number of undesirable formulation features (such as the restricted feasible region for first period decisions). Given these deficiencies in the literature, the purposes of this dissertation are to develop an asset and liability management model (ALM) that is computationally tractable for large realistic problems and to demonstrate that this model is superior to existing models.

The ALM model developed in this dissertation is a stochastic linear program with simple recourse (SLPR). This model incorporates the following essential features of asset and liability management: 1) the stochastic nature of the problem (by utilizing a set of random cash flows (deposits) with a given discrete probability distribution), 
2) simultaneous consideration of assets and liabilities, 3) transactions costs, and 4) multi-periodicity.

The ALM model was applied to Vancouver City Savings Credit Union's asset and liability management for a five year planning period in order to demonstrate the effort necessary to implement the model. Computational tractability for this large problem was maintained by using Wets' algorithm for solving SLPR. A simulation was run on a real (uncertain) environment to compare the decision making effectiveness of the solutions generated by the SLPR and stochastic dynamic programming (SDP) models.

The findings of this dissertation are: 1) the ALM model is superior to an equivalent deterministic model, 2) the solution of the ALM model is sensitive to the asymmetry of the probability distributions of the cash flows, 3) the effort required for the implementation of the ALM model is comparable to that of an equivalent deterministic model, 4) the SLPR formulation is computationally superior to the SDP formulation utilized by Bradley and Crane, and 5) the simulation indicates that the SLPR formulation results in a better initial period decision than the SDP formulation (this is due to the restrictions imposed by the SDP formulation of maintaining feasibility for all possible forecasted economic scenarios for the first period decision). 


\section{TABLE OF CONTENTS}

Page

Chapter 1 - Introduction

1.1 Overview of Dissertation ........... 1

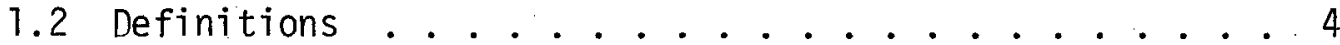

1.3 Theory of Financial Intermediation ....... 5

1.4 Appropriate Criterion for Asset and Liability Management . . . . . . . . . . . 8

1.5 Essential Features of an Asset and Liability Management Model That Maximizes Expected. Net Returns . . . . . . . . . . . . . . 12

1.6 Importance of Asset and Liability Management . . . . 13

1.7 Organization of the Dissertation . . . . . . . 14

Chapter 2 - Review of Literature

2.1 Introduction ............. . . 15

2.2 Deterministic Models . . . . . . . . . 16

2.3 Stochastic Models ............. 22

Chapter 3 - Formal Description of the Asset and Liability Management (ALM) Model

3.1 Introduction ............... . . 32

3.2 Formulation of the ALM Model .......... 34

3.3 Use of the ALM Model . . . . . . . . . . 47

3.4 Appendix One . . . . . . . . . . . . 50

3.5 Appendix Two . . . . . . . . . . . . . 58

Chapter 4 - Implementation of the ALM Model

4.1 Introduction . . . . . . . . . . . 99 93

4.2 Model Details............... . . 97

4.3 Results of the Vancouver City Saving Credit Union Application ............ 108

4.4 Appendix One . . . . . . . . . . . . . 113 
Chapter 5 - A Comparison of Stochastic. Dynamic Programming and Stochastic Linear Programing with Simple Recourse ModeTs as Decision Tools

5.1 Introduction ................. 168

5.2 Scenario for the Simulation . . . . . . . . . 174

5.3 Formulation of the Stochastic Dynamic Programming Model ............... 176

5.4 Formulation of the SLPR Mode1 . . . . . . . . . 181

$5: 5$ Results of the Simulation ........... 183

5.6 Appendix one ................. 186

Chapter 6 - Summary, Major Findings and Directions for Further Research

6.1 Introduction ................. 214

6.2 Summary .................. 214

6.3 Major Findings ................ . . 215

6.4 Directions for Further Research . . . . . . . . . 217

Bibliography ....................... 2 . . . 


\section{ACKNOWLEDGEMENTS}

I would like to thank the Faculty of Commerce for providing the support to facilitate the completion of my dissertation. In particular, I am indebted to my supervisor, Dr. W.T. Ziemba, for his encouragement, acumen and availability, and also for his guidance in al1 aspects of my academic development. I am grateful to Dr. R.W. White, for encouraging me to study bank asset and liability management. I am also grateful to all members of my dissertation committee, Dr. W.T. Ziemba, Dr. R.W. White, Dr. C. Sarndal, Dr. L.G. Mitten and Dr. W.E. Diewert, for providing constructive criticism and advice.

I would also like to thank Dr. R.J-B. Wets for both developing and providing access to an algorithm for solving stochastic linear programs with simple recourse. Also, I would like to thank Vancouver City Savings Credit Union (in particular Mr. Hook and the late Mr. Bentley) for providing me with data for the implementation of the ALM model.

I would like to thank Ms. Chan, Fong, Haller and Miller for the excellent typing of this dissertation.

I would like to thank all my fellow graduate students for providing a conducive academic environment. In particular, I would like to thank A. Amershi, V.V. Baba, D. Kira and S. Larsson. Finally, I would like to thank two special friends Jerry Kallberg and Lawrence Kryzanowski for their encouragement, advice and moral support. 
Chapter 1

\section{INTRODUCTION}

\subsection{Overview of Dissertation}

The inherent uncertainty of a bank's cash flows, cost of funds and return on investments, along with the unsettled economic conditions of the past decade, have emphasized the need for a greater efficiency in the management of a bank's assets and liabilities. A consequence has been an increased number of studies on how to structure a bank's assets and liabilities so that an "optimal" trade-off exists between risk, return and 1 iquidity $[7,11,20,70]$.

These studies focussed on the determination of the use of funds given either deterministic or stochastic economic scenarios. Factors that must be considered in these decisions include: the balancing of anticipated sources and uses of funds to meet liquidity and capital adequacy constraints while concurrently maximizing profitability $[11,20]$, allocating funds among assets based on classification, maturities and rates of return $[5,6]$, and adjusting a bank's financial structure in terms of liquidity, capital adequacy and leverage $[11,20]$.

Current research has stressed two approaches. The first approach, based on Markowitz's theory of portfolio selection, assumes that returns are normally distributed and that bank managers are risk-averse utility 
of wealth maximizers $[59,70]$. In such a world, the value of an asset depends not only on the expectation and variance of its return but also on the covariance of its return with the returns of all other existing and potential investments.

The second approach assumes that a bank seeks to maximize its future stream of profits subject to portfolio mix constraints $[11,20]$.

The solution techniques advanced by the proponents of both approaches are either computationaliy tractable if they do not capture the essential features of the asset and liability management problem $[10,19]$ or computationally intractable if they attempt to capture the essential features of the asset and liability management problem $[5,28,36]$. As an example of the first shortcoming, Cohen and Hammer's [20] 1 inear programming asset management model is computationally feasible for large problems but is neither stochastic in nature nor does it consider the effect of the choice of asset instruments on the total portfolio of the bank's assets and liabilities. As an example of the second shortcoming, Wolf's [98] sequential decision theoretic model includes many of the features inherent in the asset and liability problem, but is computationally infeasible for realistic problems that are stochastic in nature. These two approaches show that the dilemma encountered in developing an asset and liability model is the tradeoff between computational tractability and realism.

The Bradley and Crane $(B-C)$ model attempts in a serious manner to cope with the above dilemma $[5,6,7]$. Essentially, their model is a decision trees that is formulated as a linear program. B-C have developed a decomposition algorithm that takes advantage of the special structure of their formulation. Their model has a number of appealing features: 
it is dynamic in nature; it incorporates the uncertainty of cash flows and interest rates; and it is computationally tractable for problems of $1 \mathrm{imited}$ size. However, there are three major shortcomings of the B-C model. First, the types of distribution functions that may be used in their model are extremely crude - two or three point distributions with cash flows and interest rates being highly correlated. Secondly, their model is unable to handle either a large number of different financial instruments or a planning horizon with more than three time periods without taxing computer capacity. Finally, their model is formulated such that the investment decision made now, has to satisfy ali possible future economic scenarios. That is, the decision will be overly influenced by the worst possible scenario.

Given these deficiences in the literature, the primary purpose of this dissertation is to develop an asset and liability model (ALM) that is computationally tractable for large realistic problems.

In the remainder of this thesis, the following principle areas of research will be discussed in turn: the reasons for the existence of financial intermediaries, the reasons for the use of the net present value approach as opposed to the expected utility approach as a rationale for bank management, a critical survey of the net present value models currently in the financial literature, the presentation of a stochastic linear program with simple recourse model to solve the asset and liability management problem, the application of the proposed model to a local financial institution (Vancouver City Savings Credit Union), and the demonstration of the 'superiority' of the proposed model to existing models using a simulation of economic scenarios.

The remainder of this chapter will consist of the definitions of financial terms used in this dissertation, the economic rationale for the 
existence of financial intermediaries, the features that an asset and liability management model must have, and the justification for using the net present value approach in preference to the expected value approach.

\subsection{Definitions}

The Ziquidity of a financial asset will be defined in terms of marketability and capital certainty. According to Van Horne [83, p. 7]

- liquidity has two dimensions: (1) the length of
time and transaction cost required to convert the
asset into money, (2) the certainty of the price
realized. . . . The two factors are interrelated. If
an asset must be converted into money in a very short
period of time, there may be more uncertainty as to
the price realized than if there were a reasonable time
period in which to sell the asset.

Financial Intermediaries will be defined as entities involved in the business of holding and dealing in financial instruments (which can be expressed in terms of money). They issue financial instruments (indirect securities) in order to purchase the financial instruments of others (primary securities). Financial intermediaries include such institutions as chartered banks, credit unions and life insurance companies. Since this dissertation is concerned with banks and credit unions, this is the sense in which the term financiaj. intérmediary will be used.

Portfolio risk is the risk associated with the rate of return earned by a bank. Fund risk is the risk associated with the ability of the bank to meet its commitments. Risk independence occurs when the following two conditions are satisfied: (1) the aggregate value of mutually exclusive investment proposals is equal to the sum of the values of the proposals considered separately (no synergism), and (2) the financial 
instruments under consideration are physically independent [61]. Risk interdependence is said to occur if either of the necessary conditions for risk independence are not met

A financial market is any mechanism or institution used to bring together buyers and sellers of financial instruments. A perfect financial market satisfies the following conditions: (1) many buyers, sellers and issuers, all of whom are price takers, (2) transaction costs (including volume discounts, pooling of independent risks of default and imputed costs for inconvenience resulting from indivisibility) and taxes do not exist, and (3) all investors have access to all relevant information at no cost [52]. An imperfect financial market does not meet one or more of the above conditions.

\subsection{Theory of Financial Intermediation}

In order to develop the objectives and behaviour of a financial intermediary, it is essential to discuss the role of financial intermediaries in the economy. Unfortunately, the theoretical rationale for the existence of financial intermediaries has not been resolved in the economic literature. 1 For example, financial intermediaries have not been incorporated into a general equilibrium model. Economic rationale for the existence of financial intermediaries is presented next.

The underlying framework for such a theory is Hirshleifer's interpretation of Fisher's theory of the investment decision $[45,46,47]$. The theory assumes:

$[9,30,70,80]$.

${ }^{1}$ Contributions have been made to such a theory. See for example 
1) perfect markets,

2) certainty,

3) no borrowing or lending with the auctioneer,

4) two time periods, the present (0) and the future (1),

5) J individuals, where $j<\infty$

6) $U_{j}\left(C_{0 j}, C_{1 j}\right)$ where $U_{j}$ is the $j$ th individual's utility function and $C_{i j}$ is the consumption of individual $j$ in period $i$ (these are the objectives of choice for the individual investor), and

7) each individual attempts to maximize his utility function subject to his opportunity set, which consists of his initial endowment $\left(Y_{0}, Y_{1}\right)$, financial opportunities ( $f$ inancial assets) and productive opportunities (real assets).

Financial opportunities along the market line permit an individual to transform his initial endowment into alternative $\left(C_{0}, C_{1}\right)$ combinations. By investing or borrowing with other individuals, an individual can attain the optimal point, $\mathrm{P}^{*}$, on the production possibility locus, $\mathrm{PP}^{1}$, which is tangent to the highest market line, $\mathrm{NN}^{1}$ (șee Figure 1).

The individual attains the optimal point as follows. First the individual moves to $P^{*}$ from his initial endowment $\left(Y_{0}, Y_{1}\right)$. Then he borrows or lends to attain his utility optimum $\left(C_{0}^{*}, C_{1}^{*}\right)$. In the particular case illustrated in Figure 1 , the individual first invests $\left(Y_{0}-P_{0}\right)$ and then borrows $\left(C_{0}^{*}-P_{0}\right)$ to replenish current consumption.

An individual is defined as a surplus (deficit) unit when $\left(C_{0}^{*}-P_{0}\right)$ is negative (positive). The existence of surplus and deficit units is a necessary condition for both direct and indirect financing. However, it is 


\section{Figure 1}

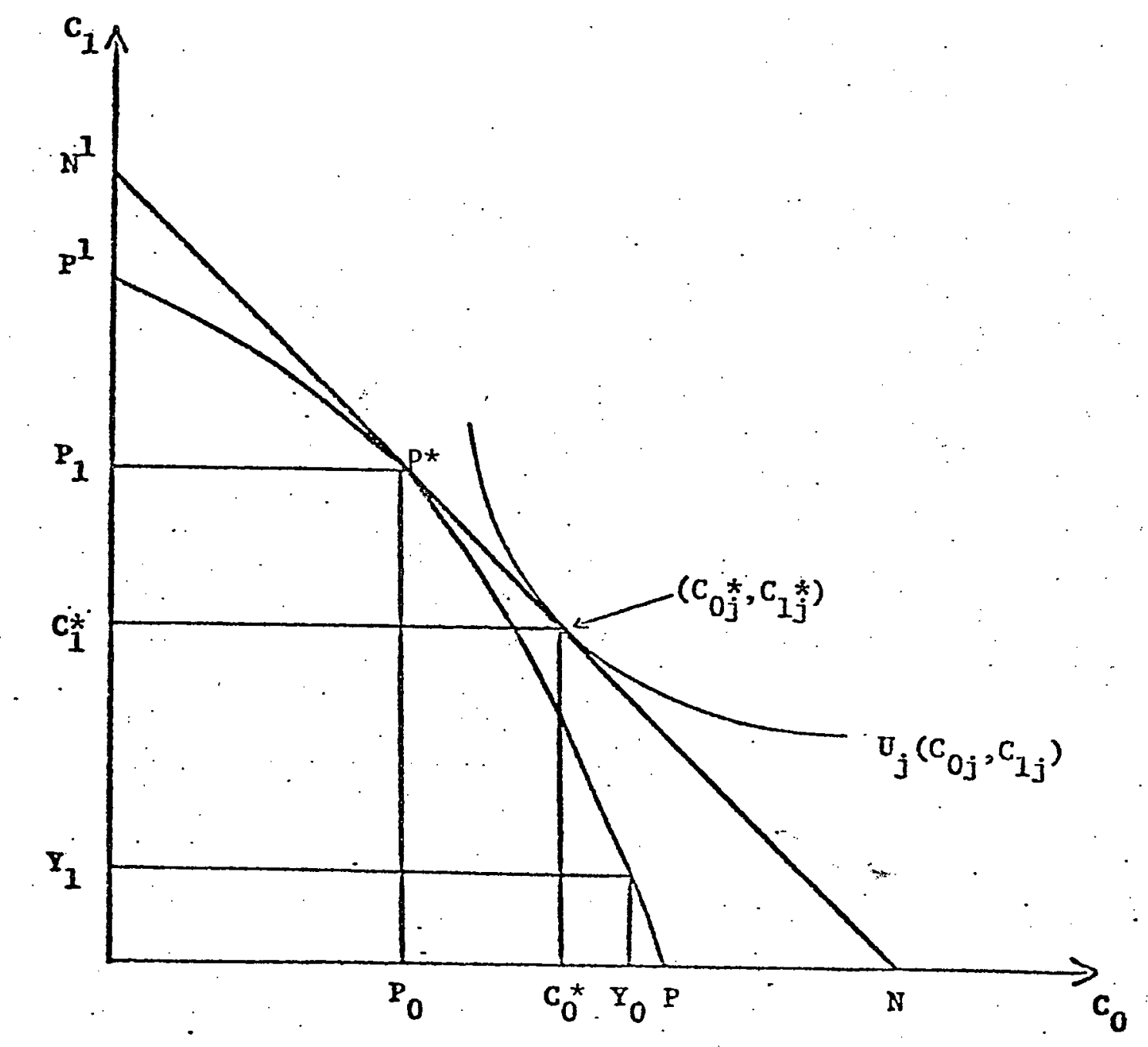

not a sufficient condition for the existence of financial intermediaries since all financial transfers can take place directly.

Extensions of this model by Arrow [1] and Hirshleifer

$[45,46]$ to incorporate uncertainty, still do not justify the existence of financial intermediaries. Therefore, the existence of uncertainty, per se, does not justify the economic existence of financial intermediaries.

Relaxing the assumption of perfect capital markets does suggest two potential reasons why financial intermediaries may interpose themselves between ultimate borrowers and lenders. These are cost economies in trading 
(especially in a world of negotiated commission rates), cost economies in the gathering and processing of information, and the benefits of portfolio diversification (of minor importance for pure financial institutions).

The premise behind the second reason is that surplus units may not buy primary securities because they cannot economically evaluate the borrower's credit standing. Furthermore, economies of scale in gathering and processing information may enable the financial intermediary to develop superior informational expertise in a subset of primary securities. This could enable the financial intermediary to formulate more accurate probability distributions of potential outcomes for the same dollar expenditure than surplus units. As a result the required risk premium for a financial intermediary may be smaller than that required by a surplus unit.

In summary, the necessary conditions for the existence of financial intermediaries are the existence of surplus and deficit units, and the imperfection of capital markets. Whether these conditions are also sufficient is at present unresolved.

Also, at this point in time, it is unresolved whether or not the assets of financial intermediaries are risk independent. If financial intermediaries cannot create assets that investors cannot duplicate on their own account, such as perfect inflation hedges, then the assumption of risk independence is reasonable.

\subsection{Appropriate Criterion for Asset and Liability Management}

A principle constraint on the management of bank funds is the need to meet deposit withdrawal claims on request. To illustrate the nature of the resulting problem, consider the following simplified example from Tobin [79]: 
1) certainty,

2) transaction costs, and

3) two assets, one of which is illiquid and cannot be liquidated for two periods (infinite transactions costs up to the end of the second period), and the second which can be liquidated at the end of the first period. The returns on the assets are $r_{1}$ and $r_{2}$, respectively, where $r_{1}>r_{2}$.

Although the allocation of initial funds between the two assets is trivial, the example does emphasize that to make realistic decisions the planning horizon cannot be infinitesimally short.

This multi-period nature of asset and liability management results from the existence of assets with different degrees of liquidity, maturity and yield. The essence of the liquidity management problem is to allocate resources in a least cost (transactions costs and opportunity costs) manner. The essence of the asset and liability management problem is not just to manage cash but to consider all assets and liabilities simultaneously.

Relaxing the assumption of certainty results in two additional problems - uncertain future market rates and uncertain timing and volume of cash flows. In viewing a bank as an ongoing entity, it is often argued that a bank must satisfy demand requests or face the prospect of losing customers [27]. In anticipation of these uncertain (e.g. loan) requests a bank must be prepared to provide large amounts of funds on relatively short notice.

In the current financial and economic literature, two criteria are used in modelling asset and liability management. The first criterion is developed from the Markowitz mean-variance framework. It assumes that an intermediary possesses a utility function; which the intermediary 
attempts to maximize. The second criterion is to maximize the net present value of returns subject to a number of constraints.

Pyle's paper [70] is an example of the use of the first criterion. It is the most general of such applications since it considers assets and liabilities simultaneously. However, a fundamental question arises..Is is possible to operationalize portfolio theory for corporations? In particular, what utility function is appropriate for a corporation?

Furthermore, the first criterion leads to a static one-period model. This implies that the intermediary can select the amount of assets and liabilities to be maintained over the period and be certain of having those amounts at a11 times during the period. Or, stated somewhat differently, Pyle's paper ignores fund risk except to the extent that it is reflected in portfolio risk. An adverse synchronization of cash flows could result in trading costs that more than offset market returns and in the extreme case solvency. Other problems such as the transaction cost incurred in the sale of a security prior to maturity are ignored. ${ }^{2}$ Thus the oneperiod nature of the model precludes the ability of the bank to exercise any matching (synchronization) of maturities of assets and liabilities and makes it difficult to insert adequate terminal conditions.

An example of the use of the second criterion, maximizing net present return, to mode 1 the asset and liability management problem is given by Chambers and Charnes [1]. Although a review of such literature will be done in Chapter 2; a few general statements are in order here. First, models using the second criterion assume risk independence

${ }^{2}$ Chen, Jen and Zionts have included transactions costs in a similar model [18]. 
(defined earlier) as opposed to the Markowitz type models which treat risk dependence. Second, the types of models range from linear formulations, which can solve relatively large problems, to stochastic dynamic formulations which can solve limited sized problems because of computational intractability. However, neither type of model is generally considered or accepted as being the 'best'.

Thus the question remains: which of the two criteria results in the model which is most suitable for solving the asset and liability management problem? Myers [61] attemots to resolve the controversy. Myers has shown that: 1) risk independence is a necessary condition for the existence of security market equilibrium, 2) if security market equilibrium exists, then this implies the risk independence of securities, and 3) if risk independence of investment opportunities exists then the maximization of the expected net present value is the appropriate objective criterion.

In the case of financial institutions it is observed that: 1) a state of equilibrium exists for the securities which are held by financial institutions, and 2) securities purchased do not have a synergetic effect (implying the risk independence of securities). Therefore, the implication from (1) and (2) is that the appropriate objective function for a financial institution is the maximization of the expected net present value.

A further test of the two approaches is their applicability as a normative tool to the actual problem solving. The risk dependent (Markowitz) approach does not lend itself to solving large (decision variables) multiperiod problems. On the other hand, the risk independent approach, given certain assumptions, can solve problems of a more realistic size. If the 
assumptions (underlying risk independence) can be relaxed and if it can be shown in an operational sense that the risk independent approach yields as good or better solutions than the risk dependent approach, then this would imply that using the maximization of net present value is a superior modelling approach.

\subsection{Essential Features of an Asset and Liability Management Model That}

\section{Maximizes Expected Net Returns}

The asset and liability management problem is analyzed in this dissertation using a constrained optimization model which mazimizes the expected net returns. A general discussion of the relevant constraints follows.

The major constraint on the management of a bank's funds is the capacity to meet withdrawal claims on demand. Since this capacity must be maintained across time, the following five features should be incorporated in the ideal optimization model.

1) multi-periodicity - in order to incorporate:

a) the changing yield spreads across time,

b) the transaction costs associated with selling assets prior to maturity, and

c) the synchronization of cash flows across time by matching maturity of assets with expected cash outflows.

2) simultaneous consideration of assets and liabilities - in order to satisfy basic accounting principles and more importantly to match the liquidity qualities of assets with those of the liabilities. 
3) transaction costs - in order to incorporate:

a) brokerage fees, and

b) other expenses incurred in buying and selling securities.

4) uncertainty of cash flows - in order to incorporate the uncertainty inherent in the depositers' withdrawal claims and deposits. (The model must ensure that the structure of the asset portfolio is such that the capacity to meet these claims is maintained by the bank.)

5) uncertainty of market rates - in order to incorporate fluctuating interest rates into the decisionmaking process so as to avoid lending and borrowing decisions which may ultimately be detrimental to the financial well-being of the bank. (For example, if the bank lends (borrows) Tona when the interest rates are relatively low (high)).

While there are other constraints that can be incorporated into the optimization model, these constraints are not universal.

\subsection{Importance of Asset and Liability Management}

As was stated previously, there have been many attempts to model asset and liability management. The conclusion derived from this literature is that much work remains to be done on the problem since not one of the models proposed, thus far, incorporates all the essential features of the real world problem while maintaining computationally tractability.

The asset and liability management (ALM) model developed in this dissertation is an attempt to rectify the above deficiencies. The ALM model includes: 
1) the stochastic nature of the problem - by incorporating a set of random cash flows (deposits) with a given discrete distribution,

2) simultaneous consideration of assets and liabilities,

3) transaction costs, and

4) multi-periodicity.

These features will be incorporated into the model while maintaining computational tractability for large problems.

\subsection{Organization of the Dissertation}

In Chapter 2, the literature on the asset and liability management models using a net present return "criterion is reviewed. In Chapter 3 , the the ALM model is developed as a stochastic linear program with simple recourse (SLPR). The appendix to Chapter 3 gives a brief summary of relevant stochastic programming techniques and the theoretical development of SLPR. Chapter 4 presents the results of an application of the model to one of Canada's largest credit unions. Computer information about the algorithm used to solve the problem is also presented. In Chapter 5, the SLPR formulation is compared to an equivalent stochastic dynamic formulation to determine if the SLPR approach results in better operational solutions for a decisionmaker. This is accomplished by a simulation of the same data (economic scenarios) for both the SLPR and stochastic dynamic formulations. In the final chapter, the conclusions and possible extensions of this research are presented. 


\section{Chapter 2}

\section{KEVIEW OF LITERATURE}

\subsection{Introduction}

Before proceeding to a discussion of the normative analytical models dealing with asset and liability management, a brief summary of the results of a study on positive models is in order. Hester and Pierce, in a recent study [42], use cross-sectional data to analyze the validity of a number of portfolio selection models in bank fund management. Their main conclusion is that there is an optimal method of managing a bank's portfolio. The objective function utilized by Hester and Pierce was either the maximization of net discounted returns or the maximization of a two variable function (where net discounted returns was dominant).

As a result of the arguments presented in Chapter 1 and the empirical evidence obtained by Hester and Pierce, the maximization of expected net discounted returns is taken as the appropriate objective function for a bank in this dissertation. Therefore, only the asset and liability management models using this objective function are discussed in this chapter.

Asset and liability management models fall into two broad categories The first category consists of deterministic models. These models use linear programming, assume particular realizations for all random events, 
and are computationally tractable for large problems. Furthermore, these models have been accepted as a useful normative tool by the banking industry [20].

The second category of asset and liability management models are the models that are stochastic in nature. At best these models have achieved very modest success due to the inherent computational difficulties or to the oversimplifications needed to achieve computational tractability. The stochastic models include the use of the following techniques: 1) chanceconstrained programming, 2) dynamic programming, 3) sequential decision theoretic approach, 4) linear programming under uncertainty, and 5) dynamic linear programming.

The next two sections will review the deterministic and stochastic modelling techniques.

\subsection{Deterministic Mode1s}

The models discussed in this section are important because they can and are used to solve real portfolio problems.

The 1961 seminal work by Chambers and Charnes (CC) [11] produced a linear programming model to optimize bank portfolios. The utilization of linear programming (LP) was deemed to be acceptable given the number of trade-offs between large numbers of variables, the intertemporal nature of the problem and the large number of constraints. Furthermore, it was feasible to structure the problem in a linear format and efficient algorithms were readily available to solve large scale problems. Since the subsequent development of other deterministic models was either a slight extension or an application of the CC model, a summary of their article is essential. 
The CC model maximizes net discounted returns, subject to budget (sources and uses of funds) and liquidity constraints. These constraints are developed from the capital adequacy formula as put forth by the American Federal Reserve Board (FRB) [27]. These constraints are presented below (in a somewhat different form from those originally used by $\mathrm{CC}$ ) because they are utilized later in the ALM model

A bank's liquidity under 'normal' economic conditions is said to be adequate when

$$
\underset{\text { Market Value }}{\text { of Assets }} \geq \underset{\text { Liabilities }}{\text { Total }} \text { - (Equity + Surplus) }
$$

The value of the total liabilities is defined as their book value and the market value of assets is defined as their liquidation value as given by:

$$
A_{t}=\sum_{i=1}^{n}\left(1-\beta_{i}\right) x_{i t}
$$

where, $A_{t}$ is the market value of assets, in period $t, \beta_{i}$ is a parameter contained in the capital adequacy formula used to measure the shrinkage in the value of asset $i$ from book value if the asset has to be liquidated quickly, and $x_{i t}$ is the book value of asset $i$ held in period $t$.

If only a single bank were liquidated, then equation (1) would ensure no loss of principal to depositors. However, in the event of severe recession (or financial disintermediation), other financial intermediaries are also likely to be in financial distress. Consequently, according to the FRB, the discount required to liquidate assets is expected to be greater (except for cash and treasury bills) than the value used to compute $A_{t}$ [27]. 
This additional loss is a: function of both the anticipated deposit withdrawals and the asset structure. The functional relationships, for the additional loss, is defined by inequalities (4), which are developed as follows. The dollar value of the expected deposit withdrawal under adverse economic conditions is

$$
w_{t}=\sum_{i=1}^{m} \gamma_{i} Y_{i t}=
$$

where $w_{t}$ is the anticipated withdrawal of liabilities in period $t, \gamma_{j}$ is the parameter contained in the capital adequacy formula to measure the contraction of liability $i$ under adverse economic conditions, and $\gamma_{i t}$ is the book value of liability $i$ in period $t$.

In order to determine how the asset structure affects liquidation under severe financial disintermediation, the assets are classified as per the FRB's capital adequacy formula [27] as follows: 1) "Primary and Secondary Reserves" $\left(K_{1}\right)$ which includes cash $\left(k_{1}\right)$, treasury bills $\left(k_{2}\right)$, and government bonds of less than five years maturity $\left(k_{3}\right)$; 2) "Minimum Risk Assets" $\left(K_{2}\right)$ which include government bonds with more than five years maturity $\left(k_{4}\right)$, municipal bonds $\left(k_{5}\right)$; 3) "Intermediate Assets" $\left(K_{3}\right)$ which includes mortgage loans $\left(k_{6}\right)$; and 4) "Portfolio Assets" $\left(K_{4}\right)$ which consist primarily of personal loans $\left(k_{7}\right)$.

Based on this asset classification, liquidity reserves $P_{i}$ are constructed with the property that they increase as the assets become more illiquid and/or the liabilities become more liquid.

The extra liquidity required as reserves for possible adverse economic conditions is determined as follows: 


$$
P_{i} \geq q_{i}\left(w-k_{k \in K_{1}} \cup \cdots \cup K_{i} \alpha_{k} k\right), \quad i=1,2,3,
$$

where $\alpha_{k}$ are the parameters contained in the capital adequacy formula used to measure the shrinkage in. the value of asset $k$ from book value if the asset has to be liquidated quickly under adverse economic conditions, and $q_{i}$ is a measure of the reserves required by the bank for excess liquidity of liabilities over assets in $K_{1} \cup \cdots \cup K_{j}$. Finally, the FRB's capital adequacy formula is

$$
\sum_{i=1}^{k} \beta_{i} x_{i} \leq \text { Net Worth }-P_{1}-P_{2}-P_{3} \text {. }
$$

Since decision-makers, operationally, manage assets and liabilities (and not net worth), an intuitively more appealing manner of stating (5) is

$$
A=\sum_{i=1}^{K}\left(1-\beta_{i}\right) x_{i} \geq P_{1}+P_{2}+P_{3}+\left\{\begin{array}{l}
\text { Total right } \\
\text { hand side of }- \text { surplus - equity } f \\
\text { balance sheet }
\end{array} .\right.
$$

Thus the general formulation of the CC-type model may be stated as

$$
\begin{gathered}
\max _{x_{j} \geq 0} \sum_{u=1}^{n} c_{j} x_{j} \\
\text { s.t. } \sum_{j=1}^{n} s_{t j} x_{j}=s_{t} \\
P_{i t} \geq q_{i t}\left(w_{t}-x_{j} \in K_{1} \cup \cdots \sum_{i} k_{i} \alpha_{x_{j}} x_{j}\right) \\
\sum_{j=1}^{n}\left(1-\beta_{t j}\right) x_{j} \geq \sum_{i=1}^{3} P_{i t}+L_{t}
\end{gathered}
$$




$$
\sum_{j=1}^{n} a_{t k j} x_{j}=b_{t k}
$$

where $i=1,2,3 ; t=1, \cdots, T ; k=1, \cdots, K ; c_{j}$ is the net present return on asset $j$; $x_{j}$ is the amount of the $i$ th financial instrument: $s_{t j}$ is the per dollar flow of funds for financial instrument $j$ in period $t: S_{t}$ is the external flow of funds in period t, $T$ is the number of time periods; $a_{t k j}$ is the initial, policy; or terminal technological coefficient type $k$ in period $t$ for instrument $j ; b_{t k}$ is the resource available for policy or terminal constraint type $k$ in period $t$; and $K$ is the number of initial, policy, and terminal constraints.

The input necessary for the above formulation is an initial portfolio and an economic scenario of the future. The linear program yields an optimal course of action that is presented by a series of ( $T$ ) balance sheets. However, only the immediate changes in the portfolio are of consequence to the decision-maker since more information will be available at the next decision point. Before implementing the portfolio generated by the solution, the linear programming technique can be used to test the sensitivity of the optimal solution to policy changes and changes in the expectations of the economic environment.

The dual variables and the reduced costs have important economic implications for asset and liability management. The binding constraints can be identified through the (nonzero) dual variables. The value of the dual is interpreted as the incremental improvement (worsening) of the objective function by releasing one unit of resource. This is of practical importance since costs can be attached to the procurement of additional resources. For instance, in their case study, Cohen and Hammer [20] found the duals of the capital adequacy constraints to be high, which suggested 
that additional capital (assuming the marginal cost of procuring funds is less than the dual), would result in greater profitability for the firm. In the same manner, the opportunity costs of bank policies can also be determined from the dual variables.

Reduced costs also provide useful information to the decisionmaker. If a portfolio manager wanted to purchase an asset, not currently in the optimal solution, then the reduced cost is interpreted as the per unit profitability forgone in diverting funds from the optimal portfolio to this new portfolio.

There are two other important uses of the linear programming model. The first is to observe the effects of any policy change by the bank on the optimal portfolio. This is accomplished by inserting additional constraints in the linear programming formulation. The second is to observe the effects of any changes in the bank's expectations of the economic environment on the optimal portfolio. This is accomplished by changing the returns and costs of financial instruments and the resources available. Thus the changing expectations are reflected in the new optimal solution generated.

Despite the fact that the literature contains many examples of successful applications $[20,50,53]$ of the $C C$ model, criticism continues to be levelled at the model: (see for example $[7,21,34]$ ). The major source of the disenchantment is the omission of uncertainty in the model. Prob-. ability distributions can be obtained for different economic scenarios and a linear programming formulation can be applied to each scenario in order to generate optimal solutions. However, this will, not generate an optimal solution to the total problem but rather act as a deterministic simulation to observe portfolio behaviour under various economic conditions. Another criticism 
of the model is its use of the Federal Reserve Board's capital adequacy formula which is likely to be too conservative and could lead to portfolios that are too 'safe' and thus not profitable enough.

\subsection{Stochastic Models}

The major weakness of the CC modelling approach to asset and liability management, as perceived by most researchers, is the inability of the model to cope with the inherent uncertainty in the problem. The majority of the models discussed in this section are concerned with the above shortcoming and thus are more occupied with technique than with capturing the essence of a realistic asset and liability management.

One of the initial attempts to incorporate uncertainty utilized chance-constrained programming. Charnes and Thore [16] and Charnes and Littlechild [15] were the pioneers in this area. The capital adequacy formula was replaced by chance-constraints on meeting withdrawal claims. Future deposits and loan repayments were expressed as joint normally distributed random variables. Though both papers enabled the decision-maker to explicitly incorporate uncertainty in a manner that was computationally tractable, the chance-constrained procedure does not have the facility to handle a differential penalty for either varying magnitudes of constraint violations or different types of constraints. Also in a multi-period model, there are conceptual difficulties, as yet unresolved in the literature dealing with the treatment of infeasibility in periods $2, \cdots, n[32] .1$ In other

\footnotetext{
? See the appendix at the end of Chapter 3 for additional clarification.
} 
words, the principal weakness of chance-constrained programming is that the economic consequences of violating a constraint are considered only indirectly.

A second approach was dynamic programming. This technique solves the problem of asset and liability management only for very limited numbers of financial instruments. Eppen and Fama $[34,35,36]$ modelled two and three asset problems, and their work was extended by Daellenbach and Archer [28] to include one liability. The virtues of these models are that they are dynamic and that they take into account the inherent uncertainty of the problem. However, albeit these are useful tools in practice, their applic-.. ability is limited by the small number of financial instruments that can be analyzed simultaneously.

A third alternative, proposed by Wolf [98] for approaching the problem, is a sequential decision theoretic approach. The essential notion of his model is to employ sequential decision analysis to find an optimal solution through the use of implicit enumeration. The flaw with this technique is that it does not find an explicit optimal solution to problems with a time horizon beyond one period, because it would be necessary to enumerate al1 possible portfolio strategies for periods preceding the present decision point in order to guarantee optimality. In an effort to explain away this drawback, Wolf makes the dubious assertion that the solution to a one period model would be equivalent to a solution provided by solving an $\mathrm{n}$ period model. (He thus avoids the problem of synchronizing the maturities of assets and liabilities.)

A fourth approach, suggested by Cohen and Thore [21] and Crane [24], is stochastic linear programming with simple recourse [SLPR]. Although relatively efficient solution algorithms existed for solving SLPRs [91,92]. 
both models were solved by using 'extensive representation. ' 1 This technique explicitly characterizes each realization of the random variables in the model formulation by a constraint. So large (realistic) problems were computationally infeasible. This handicapped the modellers greatly, in fact Cohen and Thore viewed their model more as a tool for sensitivity analysis (in the aggregate) rather than a normative decision tool. Thus the computational intractability and the perceptions of the formulation precluded consideration of problems other than those which were limited both in terms of time periods (Cohen and Thore used one and Crane used two), and in the number of variables and realizations. There was an attempt to apply this formulation by Booth [4]. He limited both the number of possible realizations and the number of variables considered in order to incorporate two time periods.

In this dissertation a comprehensive and systematic asset and liability management model will be developed using SLPR and the most efficient algorithm [95] available will be used to solve it.

The final stochastic approach was proposed by Bradley and Crane (B-C) $[5,6,7]$. This model has many of the desirable features essential to a bank portfolio model. The model has as its conceptual origins the Wolf [98] formulation. Recall that Wolf's model became computationally intractable as the number of time periods increased. In order to overcome this shortcoming, they reformulated the asset and liability problem and developed a general linear programming decomposition algorithm that alleviates the computational difficulties.

'See appendix at the end of Chapter 3 for further comments. 
The B-C model depends upon the development of economic scenarios. These economic scenarios are considered to include the set of all possible outcomes. The economic scenarios can be thought of as a tree diagram where each element (economic conditions) in each path has a set of cash flows (varying amounts of deposits) and a set of interest rates. The problem is then formulated as a linear program. The objective function is the maximization of the expected terminal wealth of the firm. There are four types of constraints: 1) cash flow constraints, which do not allow the firm to purchase more assets than it has funds available; 2) inventory balancing constraints, which ensure that the firm cannot sell and/or hold more of an asset at the end of a period than it held at the beginning of a period; 3) capital loss constraints, which do not allow the net realized capital losses in a period to exceed some pre-specified upper bound; and 4) class composition constraints, which limit the holding of a particular asset. Their formulation is

s.t.

$$
\begin{gathered}
\max \sum_{e_{N} \varepsilon E_{N}} p\left(e_{N}\right) \sum_{k=1}^{K}\left\{\sum_{m=0}^{N-1}\left[y_{m}^{k}\left(e_{m}\right)+v_{m, N}^{k}\left(\bar{e}_{N}\right)\right] h_{m n}^{k}\left(e_{N}^{N}\right)^{\prime}+\right. \\
\left.\left[y_{N}^{k}\left(e_{N}\right)+v_{N N}^{k}\left(e_{N}\right)\right] b_{N}^{k}\left(e_{N}\right)\right\}
\end{gathered}
$$

Cash Flows

$$
\text { 1) } \begin{aligned}
\sum_{k=1}^{k} b_{n}^{k}\left(e_{n}\right) & -\sum_{k=1}^{k}\left[\sum_{m=0}^{n-2} y_{m}^{k}\left(e_{m}\right) h_{m, n-1}^{k}\left(e_{n-1}\right)+y_{n-1}^{k}\left(e_{n-1}\right) b_{n-1}^{k}\left(e_{n-1}\right)\right] \\
& -\sum_{k=1}^{k} \sum_{m=0}^{n-1}\left[1+g_{m, n}^{k}\left(e_{n}\right)\right] s_{m, n}^{k}\left(e_{n}\right)=f_{n}\left(e_{n}\right)
\end{aligned}
$$


2) Inventory Balance

$$
\begin{gathered}
-h_{m, n-1}^{k}\left(e_{n-1}\right)+s_{m, n}^{k}\left(e_{n}\right)+h_{m, n}^{k}\left(e_{n}\right)=0, \text { for } m=0, \cdots, n-2, \\
-b_{n-1}^{k}\left(e_{n-1}\right)+s_{n-1, n}^{k}\left(e_{n}\right)+h_{n-1, n}^{k}\left(e_{n}\right)=0, \\
h_{0,0}^{k}\left(e_{0}\right)=h_{0}^{k},
\end{gathered}
$$

3) Capital Losses

$$
-\sum_{k=1}^{k} \sum_{m=0}^{n-1} g_{m, n}^{k}\left(e_{n}\right) s_{m, n}^{k}\left(e_{n}\right) \leq L_{n}\left(e_{n}\right)
$$

4) Category Limits

$$
\sum_{k \in K^{i}}\left[b_{n}^{k}\left(e_{n}\right)+\sum_{m=0}^{n-1} n_{m, n}^{k}\left(e_{n}\right) \quad\left(\frac{\leq}{s}\right) c_{n}^{i}\left(e_{n}\right) \text {, for } i=1, \cdots, I\right. \text {, }
$$

5) Nonnegativity

$$
b_{m, n}^{k}\left(e_{n}\right) \geq 0, s_{m, n}^{k}\left(e_{n}\right) \geq 0, h_{m, n}^{k}\left(e_{n}\right) \geq 0, m=1, \cdots, n-1,
$$

where $e_{n} \varepsilon E_{n} ; n=1, \cdots, N ; k=1, \cdots, K ; e_{n}$ is a set of economic condition from period 1 to $n$ having probability $p\left(e_{n}\right) ; E_{n}$ is the set of possible economic conditions from period 1 to $n$; $K$ is the number of assets; $N$ is the number of time periods; $y_{m}^{k}\left(e_{n}\right)$ is the income yield per dollar of purchase price (period $m$ ) of asset $k$ (conditional on $\left.e_{m}\right) ; v_{m, N}^{k}\left(e_{N}\right)$ is the expected terminal value per dollar of purchase price (period $m$ ) of asset $k$ and held at horizon (period N) conditional on $e_{N} ; b_{n}^{k}\left(e_{n}\right)$ is the dollar amount of asset $k$ purchased in 
period $n$ conditional on $e_{n} ; h_{m, n}^{k}\left(e_{n}\right)$ is the dollar amount of asset $k$ purchased in period m...and still held in period $n$ conditional on $e_{n} ; s_{m, n}^{k}\left(e_{n}\right)$ is the dollar amount of asset $k$ purchased in period $m$ and sold in period $n$, conditional on $e_{n} ; g_{m, n}^{k}\left(e_{n}\right)$ is the capital gain (loss) per dollar of purchase price (period $m$ ) of asset $k$ sold in period $n ; f_{n}\left(e_{n}\right)$ is the incremental increase (decrease) of funds available for period $n ; L_{n}\left(e_{n}\right)$ is the dollar amount of maximum allowable net realized capital losses in period $n$; and $c_{n}^{k}\left(e_{n}\right)$ is the upper (lower) bound in dollars on the amount of funds invested in asset type $i$ in period $n$.

The $B-C$ formulation is dynamic in nature. The first decision (immediate revision, $h_{01}^{k}\left(e_{1}\right), b^{k}\left(e_{1}\right), s_{01}^{k}\left(e_{1}\right)$ ) has as $i t s$ feasible set the intersection of all possible realizations (that is the current solution must be feasible for the set $E_{N}$ ). This decision is conditional on the realization of economic events in the first period. The feasible set for the second decision is the intersection of all possible realizations from the second decision point to the horizon of the model. In other words, the final solution generated has decisions at each point in time conditional on the states of nature that have occurred up to the current decision point.

There are a number of advantageous features to this model including its dynamic nature and computational tractability However, the B-C formulation has a number of features that detract from its practicability. The capital loss and category limit constraints have as upper (or lower) bounds amounts (resources) generated arbitrarily by portfolio managers rather than through a systematic procedure. For example, no consideration is given to the portfolio mix in the development of bounds (except in the sense that upper (or lower) bounds are placed on asset categories). At some point in 
time, this may imply that the bank has invested a disproportionate amount of its available funds in long-term bonds when compared to the amount of short-term liabilities held. Also the formulation does not utilize either the Federal Reserve Board's recommended capital adequacy formula or any other statistically generated systematic procedure in the development of bounds for the constraints. Since the capital loss and category limit constraints actually determine the composition of the solution, the arbitrary nature of the choice may unsystematically bias the solution.

Another shortcoming of the model is that the solution to the immediate revision problem has to satisfy all future economic events. In the B-C formulation some constraints may have a very small probability of occurring; these constraints may turn out to be binding and this would unduly constrain the problem. ${ }^{1}$ Thus the net effect is to restrict the feasible region for the immediate revision problem to the most pessimistic possible set of economic events. These two shortcomings may be corrected by replacing the capital loss and category limit constraints with others that are systematic in nature.

However, it may not be possible to correct another shortcoming of the B-C formulation - computational intractability for large problems. B-C state $[7 ;$ p. 112]

Unfortunately, taking uncertainty explicitly into account will make an asset and liability management model for the entire bank computationally intractable, unless it is an extremely aggregated model. The complexities of the general dynamic balance sheet management problem are such that the number of constraints and variables needed to accurately model the environment would be very large.

${ }^{1}$ See Chapter 5 for evidence of this undue constraint. 
In an effort to gain computational tractability they consider only bonds in their model. However, even limiting their model to these assets, the B-C model still has computational problems. Consider the following four asset and liability management problems: 1) eight assets, three time periods and three possible realizations per period; 2) thirty assets, five classes of assets, three time periods and three possible realizations per period; 3 ) thirty assets, five classes of assets, three time periods and five possible realizations per period; and 4) thirty assets, five classes of assets, five time periods and five possible realizations per period. The number of constraints and decision variables necessary to solve each problem using the B-C formulation is: 319 constraints and 656 variables for (1); 1141 constraints and 2460 variables for (2); 2827 constraints and 6120 variables for (3); and 116,827 constraints and 246,120 variables for (4). These numbers were calculated in the following manner: the number of variables is $\left(4+5 D+7 D^{2}+\cdots+(2 n+7) D^{n-1}\right)$, the number of constraints is equal to the sum of the cash flow constraints $\left(1+D+D^{2}+\cdots+D^{n-1}\right)$ the capital loss constraints $\left(1+D+D^{2}+\cdots+D^{n-1}\right)$, the category limit constraints $(I)\left(1+D+D^{2}+\cdots+D^{n-1}\right)$, the inventory balance constraints $(K)\left(L+2 D+3 D^{2}+\cdots+n D^{n-1}\right)$, and the initial conditions $K$. $D$ is the number of possible realizations per period, $n$ is the number of time periods, $I$ is the number of asset classes: and $K$ is the number of assets.

Bradley and Crane state that (1) has a running time of 68 seconds on an IBM 360/65 [5]. A model, of the same size as (1), would not be of much benefit to a decision-maker in the selection of an actual portfolio, one reason being that the aggregation of investment opportunities into eight categories would not allow for the selection of the best opportunities 
within a group of assets. Another potential problem is the inadequate number of time periods to match maturities (of assets and liabilities). In fact the exclusion of liabilities makes any matching of assets and liabilities impossible. Another shortcoming is the limited number of possible realizations. Despite the fact that uncertainty is incorporated in the model, the probability distribution of economic events is crude and thus does not allow the model to exploit much of tho inherent uncertainty of the model. These deficiencies would be diminished if a model of the size of problem four were utilized. However, the size of (4) $(116,827 \times$ $246,120)$ would make its use difficult as a decision-making tool. The B-C formulation can be decomposed [5]; but even by decomposing (4) the basis of the master has dimension 5467. When this is compared to (1). withra' master basis of dimension 39 and needing 68 seconds of running time, the computational difficulties of solving (4) are evident. Also (1) has in the order of 2200 nonzero elements and (4) has in the order of 850,000 nonzero elements. The computational and data handling difficulties of (2) and (3) may be less striking but nevertheless, they remain formidable.

Although initially the B-C formulation may appear to be a sound approach to asset and liability management, computational tractability and problem formulation seem to possess undesirable features. In Chapter 5 closer analysis will be made of the inherent problems in the B-C formulation. In conclusion, the stochastic models presented thus far in the literature are not satisfactory for decision-making purposes. The proposed models lack computational tractability for large problems and in addition in certain cases the formulation has been developed to fit the technique 
rather than reflect the actual asset and liability management problem faced by the bank. 
Chapter 3

\section{FORPAL DESCRIPTIOH OF THE ASSET AND LIABILITY MAAAGEMENT (ALM) MODEL}

\subsection{Introduction}

The size and structure of an asset portfolio that a bank can acquire is constrained by the uncertainty of its cash flows. In particular, deposit withdrawals must be satisfied on demand. It is usually disadvantagous and sometimes impossible for banks to liquidate earning assets in order to meet unexpected shortages in cash requirements. Thus a bank must hold a sufficient portion of its assets in cash and liquid assets to meet unanticipated cash drains as they arise. It is in this environment that a bank must function. This involves a trade-off between the opportunity cost of holding lower yielding liquid assets and the potential loss incurred in selling assets prior to maturity.

To insure an 'optimal' synchronization of the maturities of assets and liabilities and an 'optimal' return on investment, certain features must be included in an asset and liability management model. The first feature is multi-periodicity in order to capture the shifting yield spreads across time, to incorporate the transaction costs associated with calling and selling assets prior to maturity and to incorporate a smoothing of net cash flows across time by matching the maturity of assets with anticipated 
cash outflows. The second feature is environmental uncertainty in order to include the uncertainty of cash flows (deposits) and interest rates. The third feature is the simultaneous consideration of assets and riabilities in order to satisfy basic accounting principles and to match the liquidity qualities of the assets with those of the liabilities. The final feature is that transaction costs should be included in order to incorporate brokerage fees and other expenses associated with the purchase and sale of financial instruments.

The approach taken in this dissertation to the asset and liability management problem has as its motivation the Chambers and Charnes formulation [11]. However, there are certain inherent weaknesses in their formulation. For example, the exclusion of uncertainty $[7,15,21,28]$, the exclusion of Tiabilities as decision variables $[7,20]$, the use of conservative liquidity constraints (as prescribed by the Federal Reserve Board [27]) [20], the availability of funds for investment purposes only at the end of a period [20], the holding of investments to maturity and the omission of differentiating between the costs of various types of deposits, have been well documented in the literature. Nevertheless, the model has served as a starting point for many applications to actual problems. However, as the literature survey in Chapter 2 demonstrated, no existing model handles these problems well.

The incorporation of uncertainty in an efficient manner was the main difficulty of researchers attempting to extend the CC model. Many stochastic optimization methods were unsuccessfully used to approach the problem. ${ }^{1}$ Computational tractability was the obstacle that could not be overcome.

${ }^{1}$ For a review of stochastic programming see the appendix at the end of this chapter. 
As wäs already noted, the Wets algorithm [95] (see appendix) wi1l be used as the solution technique to solve the asset and liability management model (ALM) presented in the next section. The ALM model will allow a bank to address the question of uncertainty of its cash flows in a systematic manner. A11 of the features necessary for a comprehensive asset and liability management model enumerated earlier will be incorporated in the model. Techniques to overcome the other shortcomings of the $\mathrm{CC}$ model will also be included in the ALM model.

\subsection{Formulation of The ALM Model}

The asset and liability manaqement- (ALM) model is an intertemporal decision-making optimization tool to determine a portfolio of assets and liabilities of a bank, given deterministic rates of returns and costs (interest rates), and random cash flows (deposits). Ailthough the ALM problem is essentially a continuous decision problem as portfolios are constantiy being revised over time, the computations and analysis involved with a continuous time process are infeasible for a normative tool. Therefore, the ALM model is developed as a multi-period decision problem in which portfolios are determined at consecutive discrete points in time (for example, the end of each accounting period).

The ALM model is developed in a mathematical programming framework. The general formulation can be stated as:

I. Objective function maximize the net present profits of a bank minus the expected penalty costs for infeasibility. 
2. Constraints
a. legal, which are a function of the bank's jurisdiction,
b. budget, which are the initial condi- tions and the sources and uses of. funds,
c. liquidity and leverage, to satisfy deposit withdrawals on demand, (the FRB's capital adequacy formula form the basis of these constraints).
d. policy and termination, which consist of constraints unique to the bank and condi- tions to ensure the bank's continuing existence after the termination of the model, and
e. deposit flows.

Constraints (a) and (b) are deterministic, (c) consists of both deterministic and stochastic constraints, (d) can consist of either deterministic or stochastic constraints, and (e) contains only stochastic constraints.

Chambers and Charnes [11] and Cohen and Hammer [20] have justified the use of linear functions to model a bank's asset and liability management problem, Thus from the point of view of linearity, the appropriateness of using LPUU ${ }^{1}$ is established. The uncertainty aspect of LPUU is justified with the following argument. In the banking business, constraint violations do not imply that the intermediary is put into receivership. Rather the bank is allowed to restructure its portfolio of assets to regain feasibility at some cost (penalties). The ALM problem fits well as a stochastic linear program with simple recourse model.

As was stated previously, the formulation is a multiperiod model. However, the model is a zero order decision rule model in that decisions

'Linear programming under uncertainty. 
for period $1, \cdots, n$ are made as an instant revision in period 1 in such a way that total profits minus expected penalty costs in period $1, \cdots, n$ is maximized. It should be noted that the decision-maker is essentially interested in the immediate revision of the bank's assets and liabilities. The ALM mode 1 incorporates immediate revision by setting times 0 and 1 an arbitrarily small time period apart. The point 0 , in time, refers to the bank's initial position and the point 1 refers to the bank's position immediately after running the model. In practice the model should be 'rolled over' continuously. Also to partially overcome the drawbacks of a static model, the decision variables are defined in such a manner that a security can be purchased in one time period and sold in one or more subsequent periods.

In addition, the recourse aspect of the model gives it a dynamic flavour. The model being two-stage, means that initially the decision variables are chosen. Next the stochastic variables are observed. This determines the recourse variables (in order to recover feasibility) and their corresponding penalties. The penalty is a function of both the constraint violated and the magnitude of violation. The recourse cost has the effect of restraining 'aggressive' choices of decision variables if the costs involved with regaining feasibility outweigh the benefits. Thus, the 'rolling over' of the ALM model, defining the variables so as to give them flexibility and the recourse aspect of SLPR, are the dynamic features of the ALM model.

The ALM model can now be presented (see pages 39, 40, 41, 42). 


\section{Notation for ALM Mode 1}

$x_{i j}^{k}-\underset{j=0}{a s s e t} k$ purchased in period $i$ sold in period $j ; k=1, \ldots, k$;

$x_{00}^{k}$ - initial holdings of security $k$,

$x_{i \infty}^{k}$ - security purchased in period $i$ and to be held beyond the horizon of the model,

$y_{i}^{d}-$ new deposits of type $d$ in period $i ; d=1, \cdots, D$,

$y_{00}^{d} \quad$ - initial holdings of deposit type $d$,

$b_{i} \quad-$ funds borrowed in period $i$,

$y_{j s}^{+}-$shortage in period $j$ of stochastic constraint type $s$,

$y_{j s}^{-}$- surplus in period $j$ of stochastic constraint type $s$,

$P_{j s}^{+}-$proportional penalty cost associated with $y_{j s}^{+}$,

$P_{j s}^{-}-$proportional penalty cost associated with $y_{j s}^{-}$,

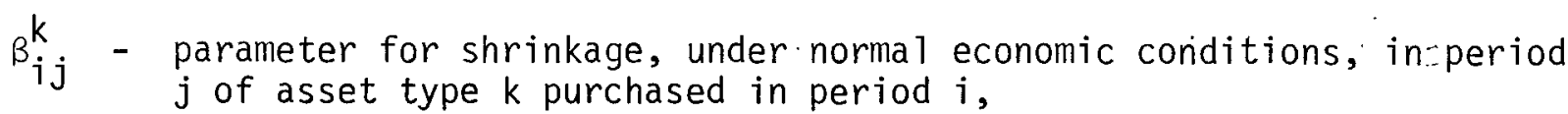

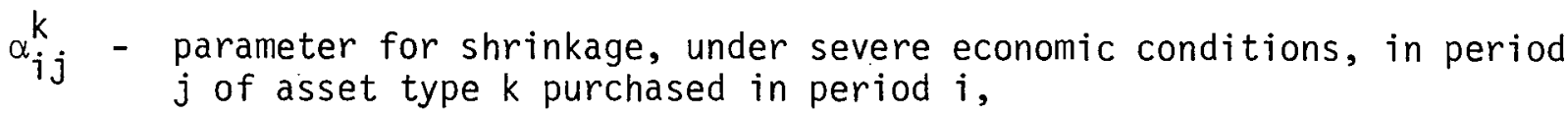

$t_{i}^{k}$ - proportional transaction cost on asset $k$, which is either purchased or sold in period $i$,

$r_{i}^{k}$ - return on asset $k$ purchased in period $i$,

$T_{j} \quad$ - tax rate on capital gains (losses) in period $j$,

$\tau_{j} \quad$ - marginal tax rate on income in period $j$,

$z_{i j}^{k}$ - proportional capital gain (loss) of security $k$ purchased in period 
$\gamma_{d}$ - the anticipated fraction of deposits of type $d$ withdrawn under adverse economic conditions,

$c_{i}^{d} \quad$ - rate paid on deposits of type $d$,

$p_{i} \quad$ discount rate from period $i$ to period 0 ,

$K^{1}$ - set of current assets as specified by the British Columbia Credit Union Act,

$\mathrm{K}_{1}$ - set of primary and secondary assets as defined in the Capital Adequacy Formula,

$\mathrm{K}_{2}$ - set of minimum risk assets as defined in the Capital Adequacy Formula,

$K_{3}$ - set of intermediate risk assets as defined in the Capital Adequacy Formula,

$q_{j}$ - penalty rate for the potential withdrawal of funds, which are not covered by assets in $k_{1} \cup \ldots \cup k_{i}$,

$P_{i} \quad$ - liquidity reserves for the potential withdrawal of funds not covered by assets in $K_{1} \cup \ldots \cup K_{j}$,

$k_{m i}-$ mith mortgage, and

$\xi_{j s}$ - discrete random variable in period $j$ of stochastic constraint type $S$ where $S \& S$. 


\section{The ALM Mode 1}

$$
\begin{aligned}
& \operatorname{Max}_{x, y, b}\left\{\sum _ { k = 1 } ^ { k } \left[\sum_{j=2}^{n} x_{0 j}^{k}\left(\sum_{\ell=2}^{j} r_{0}^{k}\left(1-\tau_{\ell}\right) p_{\ell}+z_{0 j}^{k}\left(1-T_{j}\right) p_{j}\right]+x_{01}^{k}\left[z_{01}\left(1-T_{j}\right)\right]\right.\right. \\
& +\left[\sum_{i=1}^{n-1} \sum_{j=i+1}^{n} x_{i j}^{k}\left(\sum_{\ell=i+1}^{j} r_{i}^{k}\left(1-\tau_{\ell}\right) p_{\ell}+z_{i j}^{k}\left(1-T_{j}\right) p_{j}\right]+x_{0 \infty}^{k} \sum_{\ell=2}^{n} r_{0}^{k}\left(1-T_{\ell}\right) p_{\ell}\right. \\
& \left.+\sum_{i=\tau_{1}}^{n} \sum_{\ell=i+1}^{n} x_{i \infty}^{k} r_{i}^{k}\left(1-\tau_{\ell}\right) p_{\ell}\right)=\sum_{d=1}^{D}\left[\sum_{j=1}^{n} y_{0}^{d}\left(1-\frac{\gamma_{d}}{2}\right)\left(1-\gamma_{d}\right)^{j-1} c_{j}^{d} p_{j}\right. \\
& \left.+\sum_{j=1}^{n} .5 y_{j}^{d} c_{j}^{d} p_{j}+\sum_{i=1}^{n-1} \sum_{j=i}^{n-1} y_{i}^{d}\left(1-\frac{\gamma_{d}}{2}\right)\left(1-\gamma_{d}\right)^{j-i} c_{j}^{d} p_{j}\right] \\
& \left.-b_{0} c_{0}^{b} p_{1}-\sum_{j=1}^{n} b_{j} c_{j}^{b} p_{j}-E_{\xi}+\min _{y^{+} y^{-}} \sum_{j=1}^{n} \sum_{s \varepsilon s}\left(p_{j s}^{+} y_{j s}^{+}+p_{j s}^{-} y_{j s}^{-}\right)\right\} .
\end{aligned}
$$

Subject to:

(a) Legal constraints

$$
\begin{gathered}
\sum_{k \in K^{1}} \sum_{i=0}^{l}\left(\sum_{l=2}^{n} x_{i \ell}^{k}+x_{i \infty}^{k}\right)-.1\left[\sum_{d=1}^{D}\left(\frac{y_{0}^{d}+\left(1-\gamma_{d}\right) y_{0}^{d}}{2}+\frac{y_{1}^{d}}{2}\right)+b_{0}+b_{1}\right] \geq 0, \\
j=1, \\
\sum_{k \varepsilon K^{1}} \sum_{i=0}^{j}\left(\sum_{\ell=j+1}^{n} x_{i \ell}^{k}+x_{i \infty}^{k}\right)-.1\left[\sum_{d=1}^{D}\left(\sum_{i=0}^{j-1} y_{i}^{d}\left(1-\frac{\gamma_{d}}{2}\right)\left(1-\gamma_{d}\right)\right]^{j-i-1}\right. \\
\left.\left.+\frac{y_{j}^{d}}{2}\right)+b_{j}\right] \geq 0, j=2, \cdots, n,
\end{gathered}
$$


(b) Budget constraints

(i) Initial holdings

$$
\begin{aligned}
\sum_{j=1}^{n} x_{0 j}^{k}+x_{0 \infty}^{k} & =x_{00}^{k}, k=1, \cdots, k, \\
y_{0}^{d} & =y_{00}^{d}, d=1, \cdots, D,
\end{aligned}
$$

(ii) Sources and uses

$$
\begin{aligned}
& \sum_{k=1}^{k}\left[\left(\sum_{\ell=2}^{n} x_{1 \ell}^{k}+x_{1 \infty}^{k}\right)\left(1+t_{1}^{k}\right)-x_{01}^{k}\left(1+z_{01}^{k}\left(1-T_{1}\right)-t_{1}^{k}\left(1+z_{01}^{k}\right)\right)\right] \\
& +\sum_{d=1}^{D}\left[\frac{\gamma_{d} y_{0}^{d}}{2}-\frac{y_{1}^{d}}{2}\right]-b_{1}=0, \quad \ldots . \quad j=1, \\
& \sum_{k=1}^{k}\left(\sum_{\ell=j+1}^{n} x_{j \ell}^{k}+x_{j \infty}^{k}\right)\left(1+t_{j}^{k}\right)-\sum_{i=0}^{j-1}\left[\left(\sum_{\ell=j}^{n} x_{j \ell}^{k}+x_{j \infty}^{k}\right)\left(r_{i}^{k}\left(1-\tau_{j}\right)\right)+\right. \\
& \left.\left.+x_{i j}^{k}\left(1+z_{i j}^{k}\left(1-T_{j}\right)-t_{j}^{k}\left(1+z_{i j}^{k}\right)\right]\right]\right] \\
& -\sum_{d=1}^{D}\left[\sum_{i=0}^{j-2} y_{i}^{d}\left(1-\gamma_{d}\right)^{j-i-2} f\left(-\gamma_{d}\left(1-\frac{\gamma_{d}}{2}\right)\right)+\frac{\left(1-\gamma_{d}\right) y_{j-1}^{d}}{2}+\frac{y_{j}^{d}}{2}\right. \\
& \left.\left.-\left(1-\frac{\gamma_{d}}{2}\right) c_{j-1}^{d}-\frac{y_{j-1}^{d} c_{j-1}^{d}}{2}\right\}\right]+b_{j-1}\left(i+c_{j-1}^{-b}\right)-b_{j}=0, \quad j=2, \cdots, n
\end{aligned}
$$


41

(c) Liquidity constraints

(i)

$$
\begin{gathered}
-\sum_{k \varepsilon K_{1}} \sum_{i=0}^{j}\left[\sum_{\ell=j+1}^{n} x_{i \ell}^{k} \alpha_{i j}^{k}+x_{i \infty}^{k} \alpha_{i j}^{k}\right]+b_{j}+ \\
\sum_{d=1}^{D} \gamma_{d}\left[\sum_{i=0}^{j-1} y_{i}^{d}\left(1-\gamma_{d}\right)^{j-i-1}\left(1-\frac{\gamma_{d}}{2}\right)+\frac{y_{j}^{d}}{2}\right] \leq \frac{1}{q_{1 j}} p_{1 j},
\end{gathered}
$$

(ii).

$$
-\sum_{k \varepsilon K_{1} \cup K_{2}} \sum_{i=0}^{j}\left[\sum_{\ell=j+1}^{n} x_{i \ell}^{k} \alpha_{i j}^{k}+x_{i \infty}^{k} \alpha_{i j}^{k}\right]+b_{j}+
$$

$$
\sum_{d=1}^{D} \gamma_{d}\left[\sum_{i=0}^{j-1} y_{i}^{d}\left(1-\gamma_{d}\right)^{j-i-1}\left(1-\frac{\gamma_{d}}{2}\right)+\frac{y_{j}^{d}}{2}\right] \leq \frac{1}{q_{2 j}} p_{2 j},
$$

(i ii)

$$
\begin{aligned}
& -\sum_{k \varepsilon K_{1} \cup K_{2} \cup K_{3}} \sum_{i=0}^{j}\left[\sum_{\ell=j+1}^{n} x_{i \ell}^{k} \alpha_{i j}^{k}+x_{j \infty}^{k} \alpha_{i j}^{k}\right]+b_{j}+ \\
& \sum_{d=1}^{D} \gamma_{d}\left[\sum_{i=0}^{j-1} y_{i}^{d}\left(1-\gamma_{d}\right)^{j-i-1}\left(1-\frac{\gamma_{d}}{2}\right)+\frac{y_{j}^{d}}{2}\right] \leq \frac{1}{q_{3 j}} p_{3 j},
\end{aligned}
$$

(iv) $-\sum_{k=1}^{k} \sum_{i=0}^{j}\left[\sum_{\ell=j+1}^{n}\left(1-\beta_{i j}^{k}\right) x_{i \ell}^{k}+\left(1-\beta_{i j}^{k}\right) x_{i \infty}^{k}\right]+y_{j s}^{+}-y_{j s}^{-} \geq$

$$
\begin{array}{r}
P_{1 j}+P_{2 j}+P_{3 j}+b_{j}+\sum_{d=1}^{D}\left[\sum_{i=0}^{j-1} y_{i}^{d}\left(1-\gamma_{d}\right)^{j-i-1}\left(1-\frac{\gamma_{d}}{2}\right)+\frac{y_{j}^{d}}{2}\right]+\xi_{j s}, \\
j=1, \cdots, n,
\end{array}
$$


(d) Policy constraints

$$
\begin{aligned}
-.1 & \sum_{i=0}^{j}\left[\sum_{\ell=j+1}^{n} x_{i \ell}^{k}+x_{j \infty}^{k}\right]+\sum_{i=0}^{k}\left[\sum_{\ell=j+1}^{n} x_{i \ell} k_{m 2}+\right. \\
& \left.x_{i \infty}^{k}\right]+y_{j s}^{+}-y_{j s}^{-} \leq \xi_{j s}, \quad j=1, \cdots, n
\end{aligned}
$$

(e) Deposit Flows

$$
y_{j}^{d}+\sum_{i=0}^{j-1} y_{i}^{d}\left(1-\gamma_{d}\right)^{j-i}+y_{j s}^{+}-y_{j s}^{-}=. . \xi_{j s}, \quad j=1, \cdots, n ; d=1, \cdots, D .
$$


The objective function consists of five expressions. The first expression is the discounted returns (net of taxes) and capital gains and losses (net of taxes) on assets. The second expression refers to the net discounted costs of deposits. The third and fourth expressions refer to the cost of direct borrowing either from other banks or from a central bank. The final expression is the sum of the expected penalties for violating the stochastic constraints.

There are no discount factors incorporated into the constraints since each constraint refers to conditions in only one period. The ALM model treats the first two types of constraints, legal and budget, strictly as deterministic. The legal constraint shown states that the current assets cannot be less than $10 \%$ of the total liabilities less reserves, surplus and equity. 1 The legal constraints are, of course, peculiar to the locale of the institution being studied. The budget constraints include the initial conditions and a statement of the accounting identity - uses of funds are equal to sources of funds.

The liquidity constraints, as developed in Chapter 2, follow from the Federal Reserve Board's capital adequacy formula. The requirement that the market value of a bank's assets is adequate to meet depositors' withdrawal claims during adverse economic conditions is the principal constraint in the capital adequacy formula. In order to develop this constraint, liquidity reserves (for adverse economic conditions) are first defined. ${ }^{2}$ The first three Tiquidity constraints in the ALM mode 1 are

\footnotetext{
'As defined by the British Columbia Credit Union Act [8].

${ }^{2}$ The same notation is used às in Chapter 2 , Section 2.2.
} 


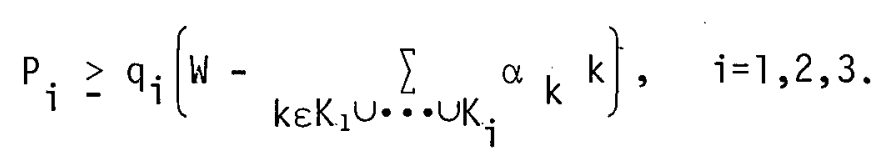

The principal constraint of the capital adequacy formula is

$$
\sum_{i=1}^{k}\left(1-\beta_{i}\right) x_{i} \geq \sum_{i=1}^{3} P_{i}+\left\{\begin{array}{l}
\text { total right hand } \\
\text { side of balance - surplus - equity } \\
\text { sheet }
\end{array}\right) .
$$

The constraint states that the market value of the bank's assets should be equal or greater than the liquidity reserves for disintermediation under severe economic conditions plus all liabilities. This constraint is in fact the last liquidity constraint in the ALM model. Although this constraint is not stochastic in nature, a bank portfolio manager may violate it because the capital adequacy formula as set forth by the FRB is a suggested guideline for 'sound' bank management rather than a strict regulation. The penalty for a violation of this constraint is $\sum_{i=1}^{3} q_{i}$ (as prescribed by the FRB). This 'psuedo-stochastic' treatment of the FRB's regulation allows the constraint to be violated when the benefits of violation exceed the costs. In this manner, the criticism, levelled at modellers using FRB's conservative constraints, can be resolved in a systematic manner.

The fourth set of constraints is also psuedo-stochastic. These constraints are introduced to capture the internal operational policy of the institution modelled. In reality minor constraint violations of bank policies are usually tolerable while more severe violations are increasingly less tolerable. The introduction of a piece-wise linear convex penalty function (via additional constraints) can capture the dependency between the penalty costs and the extent of the policy violations. 
This is accomplished by the addition of supplementary constraints to reflect the increased seriousness in the magnitude of constraint violations.

The final set of constraints, deposit flows, are stochastic. Since deposit flows are continually turned over and bear various rates of interest (term deposits), the model has to reflect the actual (and not net) flows during an accounting period. This property of the problem was incorporated in the model by having a proportional outflow $(\gamma)^{1}$ of 'old funds' during each period.

The three types of liability expressions in the ALM formulation will now be developed. First, consider the deposit flow constraints. These constraints represent the total amount of new deposits in the jth period. The total amount of new deposits of type $d$ generated in period $j$ is

$$
y_{j}^{d}=B S_{j}^{d}-\sum_{i=0}^{j-1} y_{i}^{d}\left(1-\gamma_{d}\right)^{j-i}
$$

or

$$
y_{j}^{d}+\sum_{i=0}^{j-1} y_{i}^{d}\left(1-\gamma_{d}\right)^{j-i}=B S_{j}^{d} .
$$

where $y_{j}^{d}$ is the total amount of new type d deposits $j, \gamma_{d}$ is the annual rate of withdrawal of type d deposits, and $\mathrm{BS}_{j}^{d}$ is the discrete random variable representing balance sheet figure of type d deposits at the end of the jth period.

The second type of liability expression represents the total amount of deposits outstanding during a period. Since the model is discrete, an approximation to the continuous flows is made by assuming that half of a

IStatistically calculated by the FRB and corroborated for use in British Columbia in [25]. 
period's net flows arrive at the beginning of the period and the other half arrive at the beginning of the next period. Thus during the first period, the funds available are equal to

$$
\frac{y_{0}^{d}+\left(1-\gamma_{d}\right) y_{0}^{d}}{2}+\frac{y_{1}^{d}}{2}
$$

for period $j$

$$
\sum_{i=0}^{j-1} \frac{(1-\gamma)^{j-i-1} y_{i}^{d}+(1-\gamma)^{j-i} y_{i}^{d}}{2}+\frac{y_{j}^{d}}{2}
$$

or

$$
\sum_{i=0}^{j=1} y_{i}^{d}\left(1-\frac{\gamma_{d}}{2}\right)\left(1-\gamma_{d}\right)^{j-i-1}+\frac{y_{j}^{d}}{2}
$$

The above expression is used in the objective function, legal constraint and liquidity constraints. The third liability expression is the incremental increase (decrease) of deposits from one period to the next. This incremental difference is used in the sources and uses constraint. For period $j$ the incremental difference is

$$
\begin{aligned}
{\left[\sum_{i=0}^{j-1} y_{i}^{d}\left(1-\frac{\gamma_{d}}{2}\right)\left(1-\gamma_{d}\right)^{j-i-1}+\frac{y_{j}^{d}}{2}\right]-\left[\sum_{i=0}^{j-2} y_{i}^{d}\left(1-\frac{\gamma_{d}}{2}\right)\left(1-\gamma_{d}\right)^{j-i-2}+\frac{y_{j-1}^{d}}{2}\right) } \\
=\sum_{i=0}^{j-2} y_{i}^{d}\left(1-\gamma_{d}\right)^{j-i-2}-\gamma_{d}\left(1-\frac{\gamma_{d}}{2}\right)+\frac{\left(1-\gamma_{d}\right) y_{j-1}^{d}}{2}+\frac{y_{j}^{d}}{2}
\end{aligned}
$$




\subsection{Use of the ALM Model}

Before implementing the ALM model, various inputs to the model have to be determined. The data required by the model include:

1) the identification of the assets in which the bank can potentially invest (or at least a representative group of assets),

2) the point estimates of the returns on these assets,

3) the point estimates of capital gains (losses) as a function of the time the bank holds the assets,

4) the identification of the liabilities which the bank can potentially sell,

5) the point estimates of the costs of these liabilities,

6) the rate at which deposits are withdrawn,

7) an estimated weighted cost of funds to determine the discount rate,

8). the pertinent legal constraints,

9) the parameters used in the development of the liquidity constraints,

10) the policy constraints used by the bank,

11) the estimates of the marginal distributions of the stochastic resources, and

12) the unit penalties incurred for having a shortage or a surplus in the stochastic constraints.

Remarks, are in order, about the characteristics of certain of the above inputs.

Since the SLPR model has a separable objective only the marginal distributions of the components of the resource vector are needed to find the optimal solution. This characteristic of SLPR is most important since in most problems tine correlations of the components of the random vector would have to be incorporated in the solution technique ${ }^{1}$ 
The shortage $\left(y^{+}\right)$and surplus $\left(y^{-}\right)$variables have very specific meanings in the ALM formulation. Consider a realization $\xi_{j s}^{d^{\prime}}$, of the random deposit $\xi_{j s}^{d}$. If

$$
y_{j}^{d}+\sum_{i=0}^{j-1} y_{i}^{d}\left(1-\gamma_{d}\right)^{j-i}<\xi_{j s}^{d^{\prime}}
$$

then this would impiy that $y^{+}>0$ and $y^{-}=0$, if $p^{+}+p^{-}>0 . y^{+}$would be interpreted as the amount of funds that could have been used for investment purposes in the ALM. Since the cost of deposits is usually lower than the returns on assets, the bank would want to utilize all available funds. A penalty $\mathrm{p}^{+}>0$ for the opportunity cost can be determined by assuming that the funds not used can be invested in earning assets. The $y^{+}$dollars would be available at some rate $c$ and could then be invested in some asset at a rate $r$. The penalty, $p^{+}$, would be equal to $(r-c)$ discounted to point 0 plus the net discounted returns on $y^{+}(r-c)$ to the horizon of the model (that is the profits that could, have been generated).

On the other hand, if

$$
y_{j}^{d}+\sum_{i=0}^{j-1} y_{i}^{d}\left(1-\gamma_{d}\right)^{j-i}>\xi_{j s}^{d^{\prime}}
$$

then this would imply that $y^{-}>0$ and $y^{+}=0$, that is that a surplus would occur. In this case, the bank would have to divest itself of some earning assets. The cost, $p^{-}$, of this action would be equal to $(r-c)$ discounted to point 0 plus the net discounted returns on $y^{-}(r-c)$ to the horizon of the model (that is, the profits that would have been generated with unavailabie funds). 
One point to notice is that in the above case, both $\mathrm{p}^{+}$and $\mathrm{p}^{-}$ are greater than 0 . In other words, profit is forfeited if either not enough or too much is invested. A key issue is what $r$ and $c$ should be used to determine the penalties. This point will be addressed in Chapter 4, where a case study of the ALM formulation will be presented.

The Federal Reserve Board's parameters used in its capital adequacy examinations of a bank's portfolio of assets and liabilities are well known, see for example [27]. Before utilizing their figures in the ALM formulation, estimates of these parameters should be made in order to test their applicability to the problem at hand.

When using the Wets' algorithm to solve an actual problem, two additional numbers are required for each stochastic constraint, $\alpha_{i}$ and $\beta_{i}$. The realizations are ordered $\xi_{i 1}<\xi_{i 2}<\cdots<\xi_{i k_{j}}$. The $\alpha$ and $\beta$ are chosen such that $\alpha_{i}<\xi_{i 1}$ and $\beta_{i}>\xi_{i k_{i}}$. Also the $\alpha$ and $\beta$ are chosen so that optimality is in this region.

The Wets' algorithm solves a special type of linear program. So at any point in time the duals generated correspond to the duals of a deterministic linear program. The dual of a stochastic constraint, at optimality, may be negative. This implies that an increase in the value of the right hand side would result in a decrease in the value of the solution (benefit). However, the reason that the stochastic resource component does not increase is that the marginal penalty cost exceeds the benefits accrued from the increase. 


\subsection{Appendix 1}

A most important aspect of asset and liability management optimization models is the inclusion of uncertainty. There have been a number of techniques developed to solve stochastic optimization models. This appendix serves to highlight the major stochastic linear programming solution approaches (stochastic with respect to right hand sides). Also, since the ALM formulation presented in this dissertation uses the stochastic linear programming with simple recourse (SLPR) approach, particular emphas is is placed on SLPR, its characteristics and the Wets' algorithm used to solve it.

Let $(\Omega, F, \mu)$ be a probability space. Let $\xi$ be a random variable defined from $\Omega$ to a finite subset of $R^{m}$. The distribution function of $\xi$ is denoted by $F$,

$$
F(z)=\mu(\{w: \xi(w) \leq z\})=P\{\xi \leq z\}
$$

where $z \in R^{m}$ and $P$ is the induced measure on $R^{m}$.

The model to be considered in this appendix assumes $\xi$ is a discrete random variable with possible realizations $\xi^{1}, \cdots, \xi^{L}<\infty$. A general abstract formulation is $\left.\min _{x>0} E_{\xi}[f(x, \xi)] \mid g(A x-\xi) \geq 0\right\}$ where $A$ is $m \times n, x \in R^{n}$ is the decision variable, $f: R^{n} \times \Omega_{\Omega} \rightarrow R$ and $g: R^{m} \rightarrow R^{k}$. Four basic approaches have been suggested in the mathematical literature to solve this model.

1. The Fat Formulation [55].

This procedure is to solve

$$
\begin{aligned}
& \min _{x>0} c^{\prime} x \\
& \text { s.t. } A x=\xi^{j} \quad j=1, \cdots, L,
\end{aligned}
$$


the feasible set is

$$
K=\left\{x: x \geq 0, x \in \bigcap_{i=1}^{L}\left\{x: A x=\xi^{i}\right\}\right\},
$$

where $K$ is the intersection of the feasible sets for each realization (that is the safest region). One advantage of the fat formulation is that it is deterministic. A major disadvantage is that $K$ mav be empty or unduly restricted. "The fat formulation leads to "verv large deterministic equiv-" alents. Since the Bradley and Crane $[5,6,7]$ model's solution to the immediate revision problem has to satisfy the constraints for every possible realization, it is a fat formulation.

\section{Chance-Constrained Programming [12, 13$]$.}

This technique defines $x$ to be feasible if it satisfies the constraints, $A x \geqq \xi$, with a certain prespecified probability. There are several types of chance-constraints which may be formulated. The following discussion focuses on two types of constraints:

1) marginal chance-constraints:

$$
P\left\{A_{i} \cdot x \geq \xi_{i}\right\} \geq \alpha_{i}, \quad i=1, \cdots, m,
$$

where $A_{i}$. is the $i^{\text {th }}$ row of $A, \xi_{j}$ is the $i^{\text {th }}$ component of $\xi$, and $\alpha_{j} \varepsilon$ $[0,1]$ are given, and

2) joint chance-constraints:

$$
P\left\{x: x \in \bigcap_{i=1}^{m}\left\{x: A_{i}, x \geq \xi_{i}\right\}\right\} \geq \alpha,
$$

where $\alpha \varepsilon[0,1]$. 
The deterministic equivalent of the marginal joint constraints

$$
P\left\{A_{i} \cdot x \geq \xi_{i}\right\} \geq \alpha_{i}
$$

is

$$
A_{i} \cdot x \geq F_{\alpha_{i}} \quad \text { for } i=1, \cdots, m
$$

where $F_{\alpha_{i}}$ is $\inf \left\{y: y \in Y_{i}\right.$ where $\left.Y_{i}=\left\{y: F_{i}(y) \geq \alpha_{i}\right\}\right\}$, the smallest $\alpha_{i}$-fractile of $F_{i}$ (where $F_{i}$ denotes the marginal distribution of $\xi_{j}$ ). See [67] for a discussion of deterministic equivalents for joint chanceconstraints.

The shortcomings of this approach include the difficulty in specifying the probabilities $\alpha_{j}$ and $\alpha$ in a systematic method. Secondly, there is no differential penalty for: 1) small versus large infractions of constraints, or 2) the type of constraint violated. Also the treatment of a multistage problem has not been adequately conceptualized. The problem of handling constraint violations from period $n$ to period $n+1$, has not been resolved. Eisner, Kaplan and Soden [32] have discussed three alternative approaches to this problem: 1) total chance-constrained, 2) safetyfirst, and 3) conditional-go, and have provided some preliminary results on this difficult problem.

\section{Stochastic Linear Programming [7.8] .}

Generally stated, this technique studies the distribution of the objective function, by solving a linear program for each realization of the resource vector. For each $i=1, \ldots, L$ the following linear program is solved. 


$$
\begin{aligned}
& z_{i}=\min _{x} c^{\prime} x \\
& \text { s.t. } A x=\xi^{j} \\
& x \geq 0
\end{aligned}
$$

This sequence of linear programs generates the distribution of $z$ based on the distribution of $\xi$. Clearly this approach has little application as a normative tool, for static problems. However, since recourse models contain distribution problems as subproblems their use in recourse models is quite important [78].

4. Stochastic Linear Programming with Simple Recourse $[3,29,103]$.

A SLPR can be expressed as

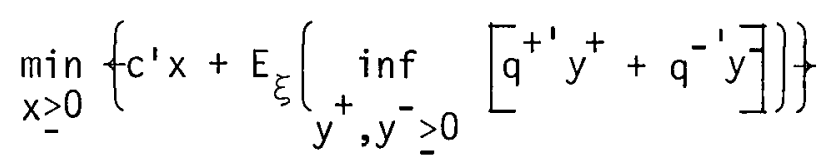

$(\mathrm{P} 1)$

$$
\begin{aligned}
& \mathrm{Ax}=\mathrm{b} \\
& \mathrm{Tx}+\mathrm{Iy}^{+}-\mathrm{Iy}^{-}=\xi
\end{aligned}
$$

where $c \varepsilon R^{n}$ is the cost vector, $x \in R^{n}$ is the decision vector, $\xi$ is a random variable defined on $R^{m_{2}}, b \varepsilon R^{m_{1}}$ is the known resource vector, $y^{+}, y^{-} \varepsilon R^{m_{2}}$ are the recourse variables, $q^{+}, q^{-} \varepsilon R^{m_{2}}$ are the unit penalty 
costs, $A$ is a $m_{1} \times n$ known matrix, $T$ is a $m_{2} \times n$ known matrix, and $I$ is a $m_{2} \times m_{2}$ identity matrix.

Usually $y^{+}$is the 'shortage' variable and $y^{-}$is the 'surplus' variable. The objective is to minimize the sum of $c^{\prime} x$ and the expected linear penalty cost. This problem may be viewed as a two-stage problem. In stage one an $x$ is determined. Then in the second stage the recourse variable $y^{+}$and $y^{-}$are determined in such a manner as to retrieve feasibility with the given $T x$. The recourse problem is always feasible and bounded from below if $q^{+}+q^{-}>0$. Parikh [67] shows that if $q_{j}^{+}+q_{i}^{-}=0$, row $i$ can be eliminated. Clearly if $q^{+}+q^{-}<0$ the problem is unbounded.

In this dissertation, $\xi$ is restricted to be discrete. This allows (PI) to be expressed as a linear program.

$$
\begin{aligned}
& \min _{x,\left\{y^{+i}, y^{-i}\right\}>0}\left\{c^{\prime} x+\sum_{i=1}^{L} \cdot P_{i}\left(q^{+1} y^{+i}+q^{-1} y^{-i}\right)\right\} \\
& \text { s.t. } \quad A x \quad=b \\
& T x+I y^{+i}-I y^{-i}=\xi^{i} \quad i=1, \cdots, L
\end{aligned}
$$

where $P_{i}=P_{r}\left(\xi=\xi^{i}\right), i=1, \ldots, L$.

This form, (P2), is known as the 'exterisive represéntation' of the discrete form of $(P 1)$. Couhault [23] uses this formulation directly, but it is clear that for reasonably sized problems, the number of constraints quickly becomes unmanageable. El-Agizy [33] uses this representation to reduce (decompose) the problem to a smaller separable convex program. However, the most satisfying treatment of this problem is aiven by Wets. [95] . In this paper, he modifies techniques similar to those developed for 
generalized upper bounding (notably the working basis concept [30!,31]) to reduce the problem to one that is tractably comparable to a linear program with $m_{1}+m_{2}$ rows and $n$ variables.

Consider the second stage problem

$$
\begin{gathered}
Q(x, \xi)=\min _{y^{+}, y^{-} \geq 0}\left(q^{+\prime} y^{+}+q^{-1} y^{-}\right) \\
\text {s.t. } I^{+}-I y^{-}=\xi-x,
\end{gathered}
$$

where $x \equiv T x$. It follows that

$$
Q(\ddot{x}, \xi)=\sum_{i=1}^{m_{1}} E_{\xi_{i}} Q_{j}\left(x_{i}, \xi_{j}\right)
$$

where $Q_{i}\left(x_{i}, \xi_{i}\right) \equiv \underset{y_{i}^{+}, y_{i}-00}{\min ^{-}}\left\{q_{i}{ }^{+} y_{i}^{+}+a_{i}{ }^{-} y_{i}{ }^{-} \mid y_{i}^{+}-y_{i}^{-}=\xi_{i}-x_{i}\right\}$, $i=1, \ldots, L$. Hence the recourse problem is separable. Thus only the marginal distributions are of importance.

To illustrate the Wets algorithm [95] write (P2) as the separable convex program

$$
\begin{aligned}
\min _{x \geq 0} c^{\prime} x+\sum_{i=1}^{m_{2}} E_{\xi_{i}}\left\{Q_{j}\left(x_{i}, \xi_{j}\right)\right\}=\min c^{\prime} x+\sum_{i=1}^{m_{2}} Q_{j}\left(x_{i}\right) \\
\text { s.t. } A x=b \\
T x=x .
\end{aligned}
$$

The $Q_{j}\left(x_{i}\right)$ have the useful representation [95]: 


$$
\begin{aligned}
& Q_{i}\left(x_{i}\right)=q_{j}^{+}\left(\bar{\xi}_{i}-\alpha_{i}\right)+\left.\operatorname{minf}_{y_{i \ell}} \sum_{l=-1}^{k_{i}+1} P_{i \ell} y_{i \ell}\right|_{\ell=-1} ^{k_{i}+1} y_{i \ell}=x_{i}-\alpha_{i}, \\
& \left.y_{i-1} \leq 0,0 \leq y_{i, k_{i}+1} \text { and } 0 \leq y_{i \ell} \leq d_{i \ell} \text { for } \ell=0, \cdots, k_{i}\right\},
\end{aligned}
$$

where $P_{i \ell}=-q_{i}^{+}+q_{i} F_{i \ell}, \quad \ell=0, \ldots, k_{i},\left(q_{j}=q_{j}^{+}+q_{j}^{-}\right)\left(F_{i \ell}=\operatorname{Pr}\left(\xi_{i} \leq \xi_{i \ell}\right)\right)$, $P_{i,-1}=P_{i 0}, p_{i, k_{i}+1}=P_{i, k_{i}}, d_{i \ell}=\xi_{i, \ell+1}-\xi_{i \ell}, d_{i 0}=\xi_{i l}-\alpha_{i}, d_{i, k_{j}}=$ $\beta_{i}-\xi_{i, k_{i}}$ and $\alpha_{i}<\xi_{i 1}<\xi_{i 2}<\cdots<\xi_{i, k_{j}}<\beta_{i}$, and where $k_{i}$ is the number of possible values of $\xi_{j}$ and $\bar{\xi}_{j}$ is the mean of $\xi_{j}$.

This representation is useful because it greatly simplifies the solution of the recourse problem. Increase each of type $y_{i \ell}$ to its upper bound or until the sum of the $y_{i \ell}$ reaches $\left(x_{i}-\alpha_{i}\right)$ since the $P_{i \ell}$ are increasing in $\ell$. The algorithm needs to record the value of only the first $y_{i \ell}$ (in each row) which is not at its upper bound, say $y_{i m}$. (Since $y_{i \ell}$ for $\ell<m$ is at its upper bound and $y_{i \ell}$ for $\ell>m$ is zero). This resembles the usual modified simplex algorithm for upper bounded variables. Note that the $y_{i \ell}$ do not explicitly appear in the (working) basis, again this means that the working basis is of dimension $m_{1}+m_{2}$, the same size as if $\xi$ were replaced by its mean, $\bar{\xi}$.

The pivoting rules can be thought of as examining the values of the reduced costs and the duals (adjusted for penalties) and the selecting the 'largest' marginal value. If it is a reduced cost, then the usual simplex pivot is performed. On the other hand, if it is a dual, then the right hand side is brought to its upper bound. Appendix 2 contains the flow chart, computer code and details of the implementation of the code. Since chance-constrained programming (CCP) has been the most widely used stochastic programming technique in the literature, a comparison 
of the solutions generated by CCP and SLPR is in order. Recall that a CCP is of the form.

(CCP1)

$$
\begin{aligned}
& \min _{x \geq 0} c^{\prime} x \\
& \text { s.t. } \operatorname{Pr}\left[A_{i} x \geq \xi_{i}\right] \geq \alpha_{i}, \quad i=1, \cdots, m,
\end{aligned}
$$

and the certainty equivalent of (CCP1) is

(CCP2)

$$
\begin{aligned}
& \min _{x>0} c^{\prime} x \\
& \text { s.t. } A_{i} x \geq F_{\alpha_{i}} \quad i=1, \cdots, m .
\end{aligned}
$$

It has been shown [67] that if $x^{*}$ is an optimal solution to (CCP2) and $\mathbb{I}^{\star}$ is the corresponding dual solution to (CCP2), then with

$$
q_{i}^{+}=\frac{\Pi_{i}^{*}}{1-\alpha_{i}} \text { and } q_{i}^{-}=0 \text {, }
$$

$x^{*}$ is an optimal solution to the corresponding SLPR.

Suppose $x^{*}$ is an optimal solution to (P2), the SLPR formulation, and that for all $i, F_{j}$ is strictly increasing at $x_{i}^{*}$ then $x^{*}$ solves (CCP2) and (CCP1) with a cost vector

$$
c+q^{-} A
$$

and

$$
\alpha_{i}=\frac{q_{i}^{+}-\pi_{i}^{\star}}{q_{i}^{+}-q_{i}^{-}}, \quad i=1, \ldots, m,
$$

where $\pi^{*}$ is the dual from the SLPR solution. 


\subsection{Appendix Two}

This appendix consists of three parts: 1) a flowchart of the algorithm to solve SLPR, 2) a FORTRAN-IV code for the algorithm, and 3) a user's guide for the code. The first page of the flowchart gives an overall view of the algorithm. The following pages explain in detail each part. The computer code was originaliy written by Collins [23] and modified by Kallberg and Kusy [49]. 


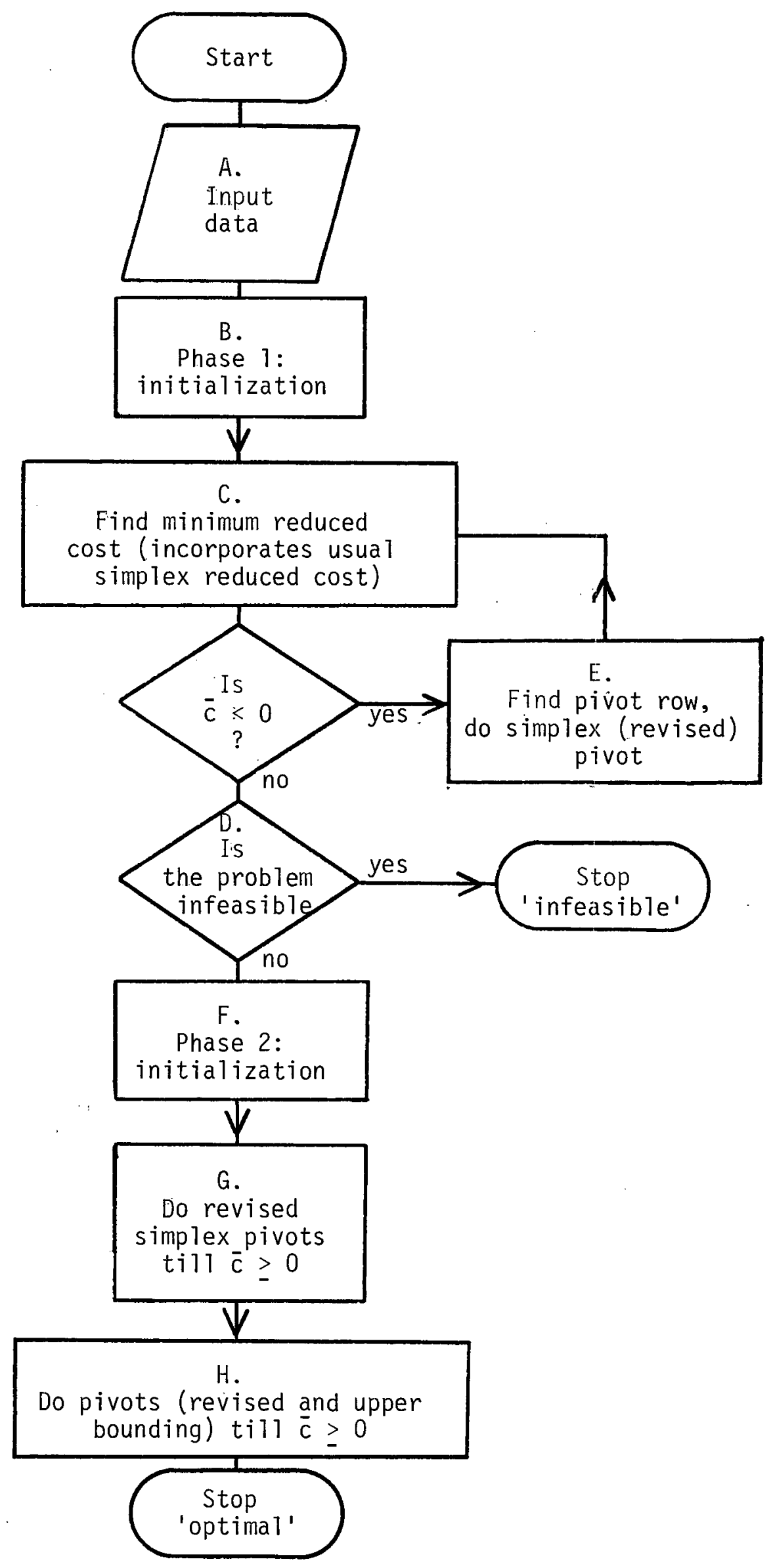



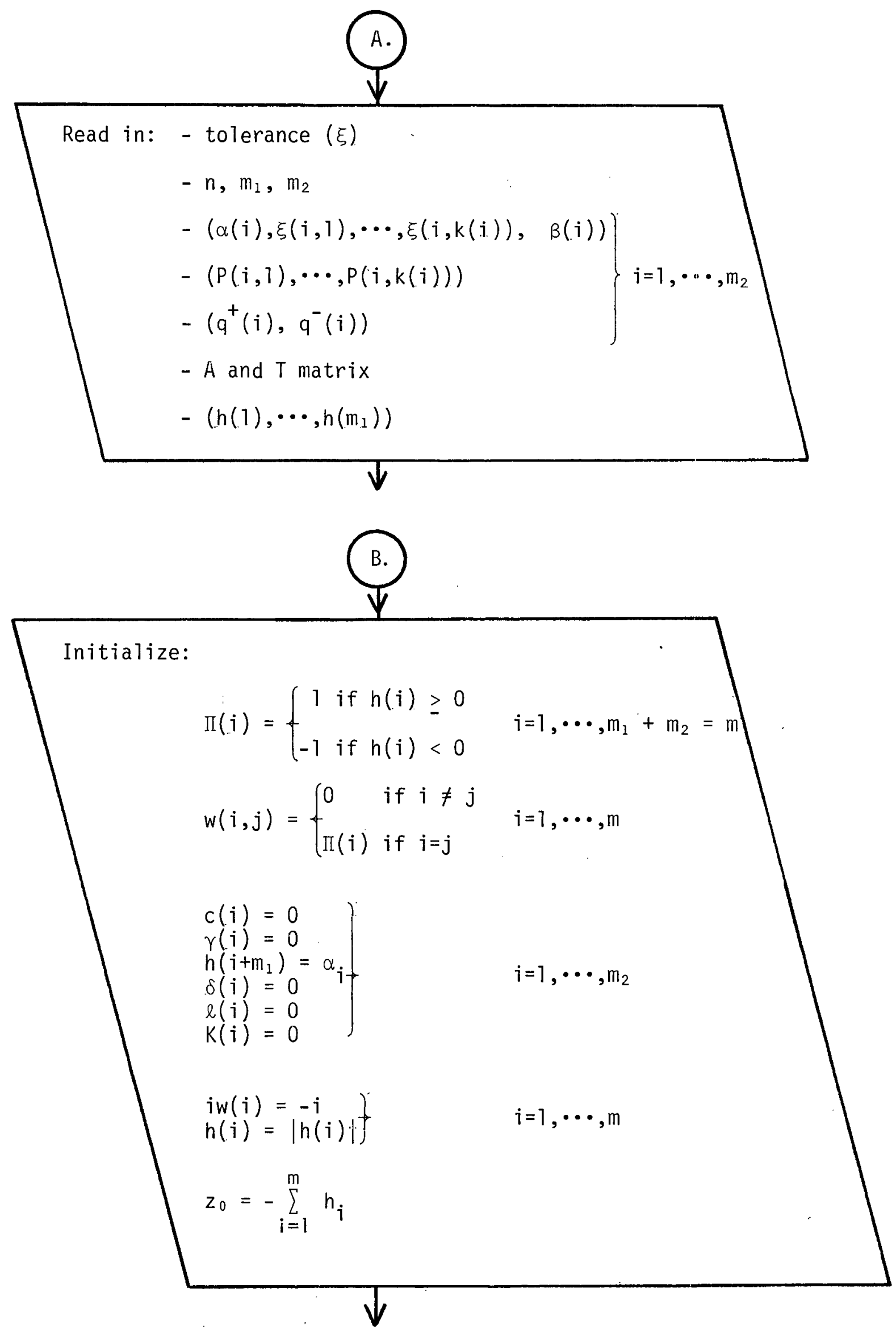
c.

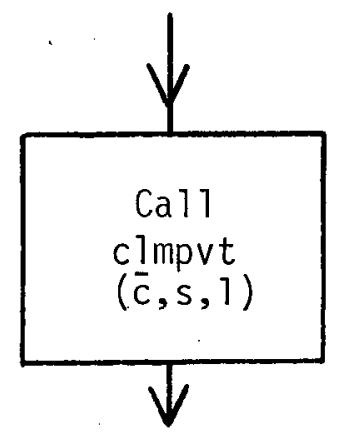

D.

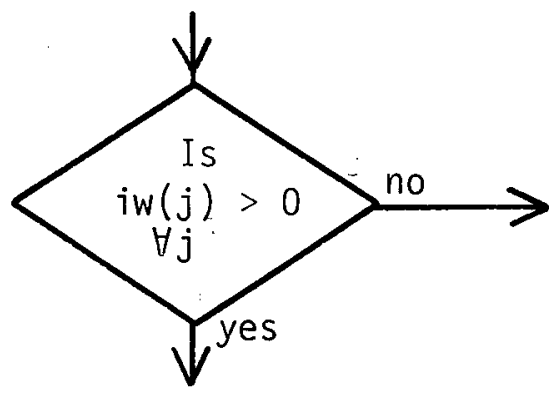

E.

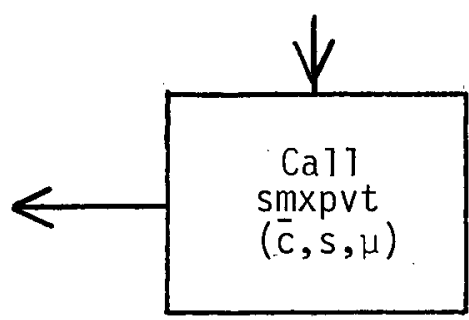


F.

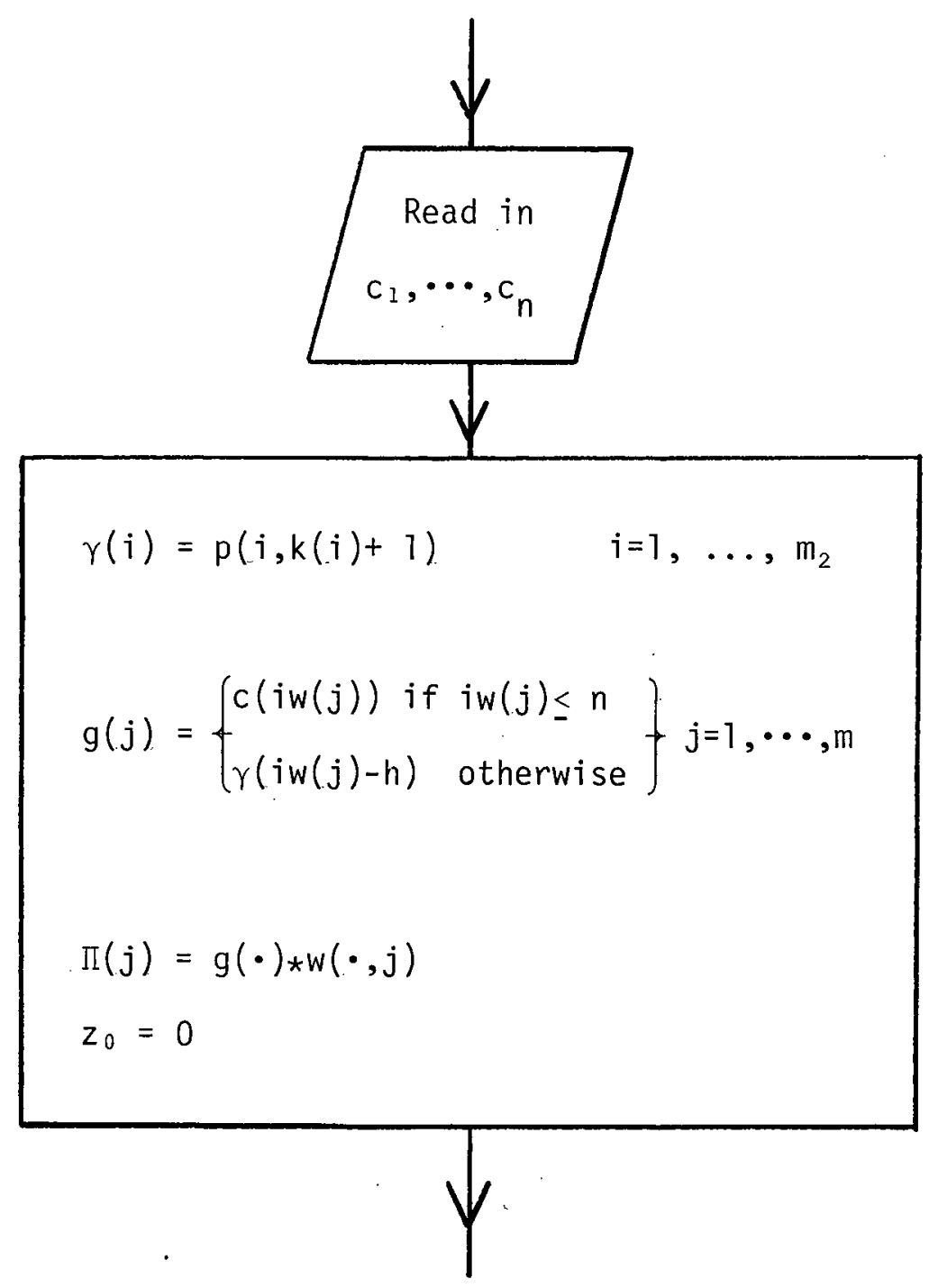




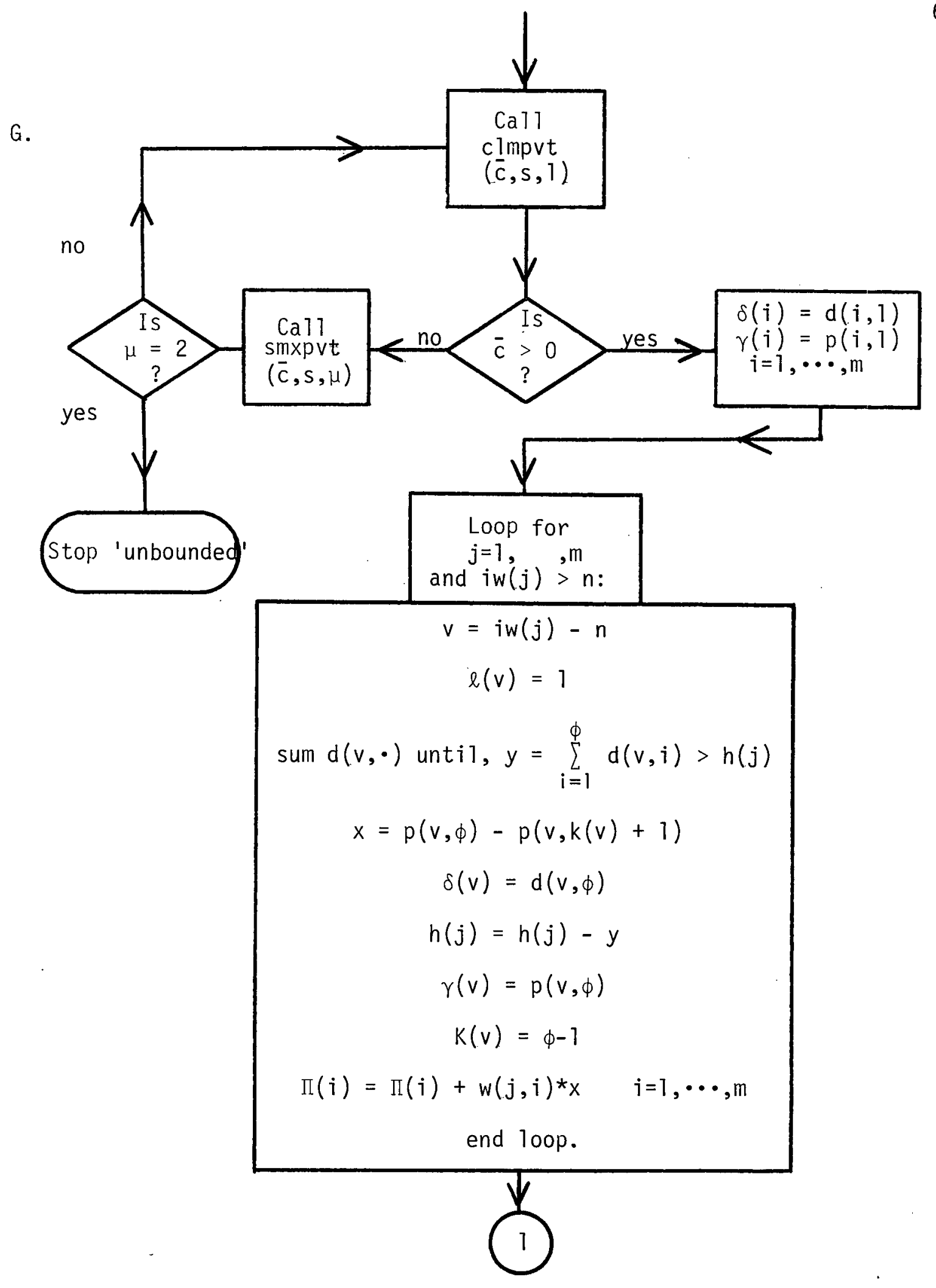


$\operatorname{CLMPVT}(\bar{c}, \mathrm{~s}, \mathrm{mau})$

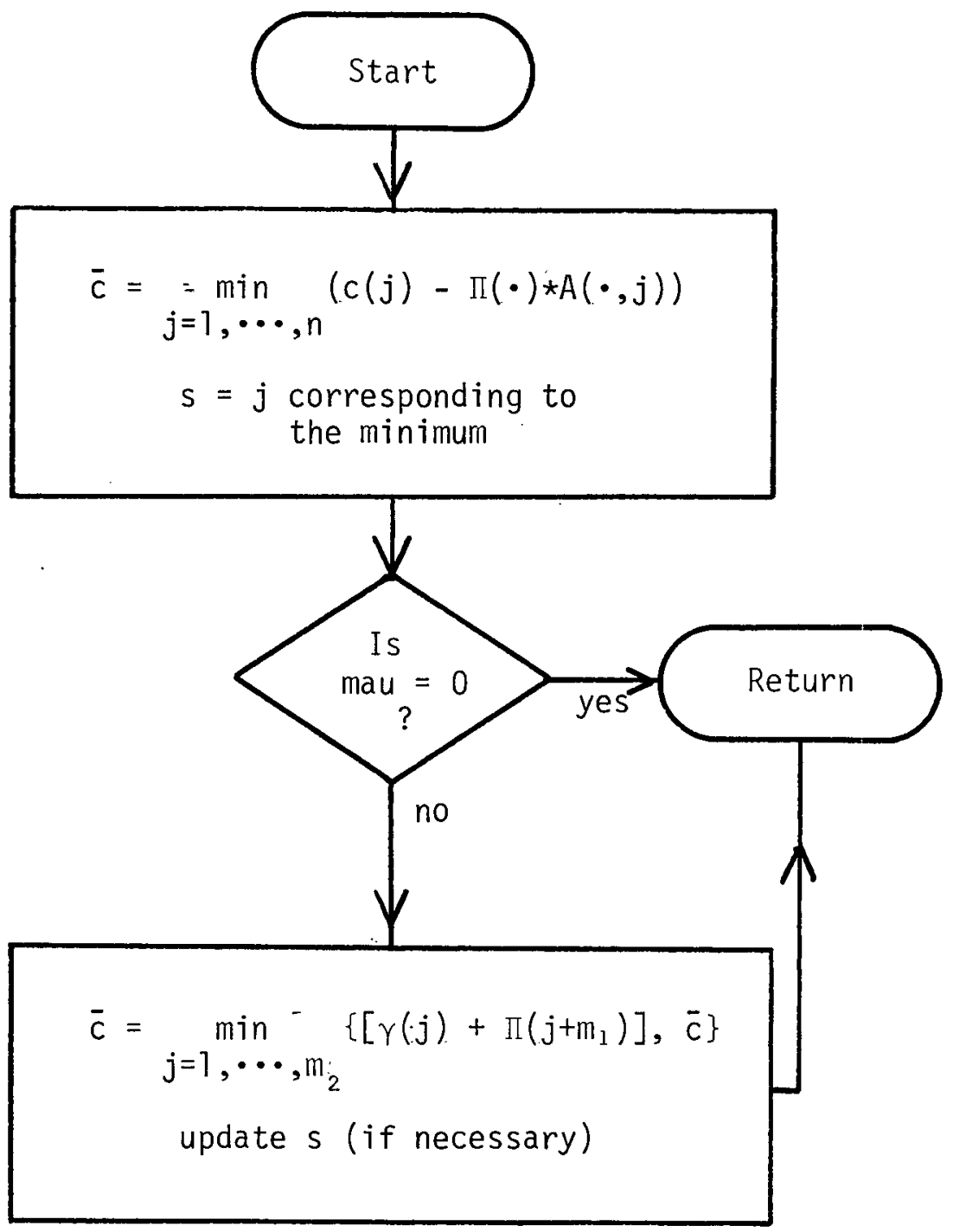




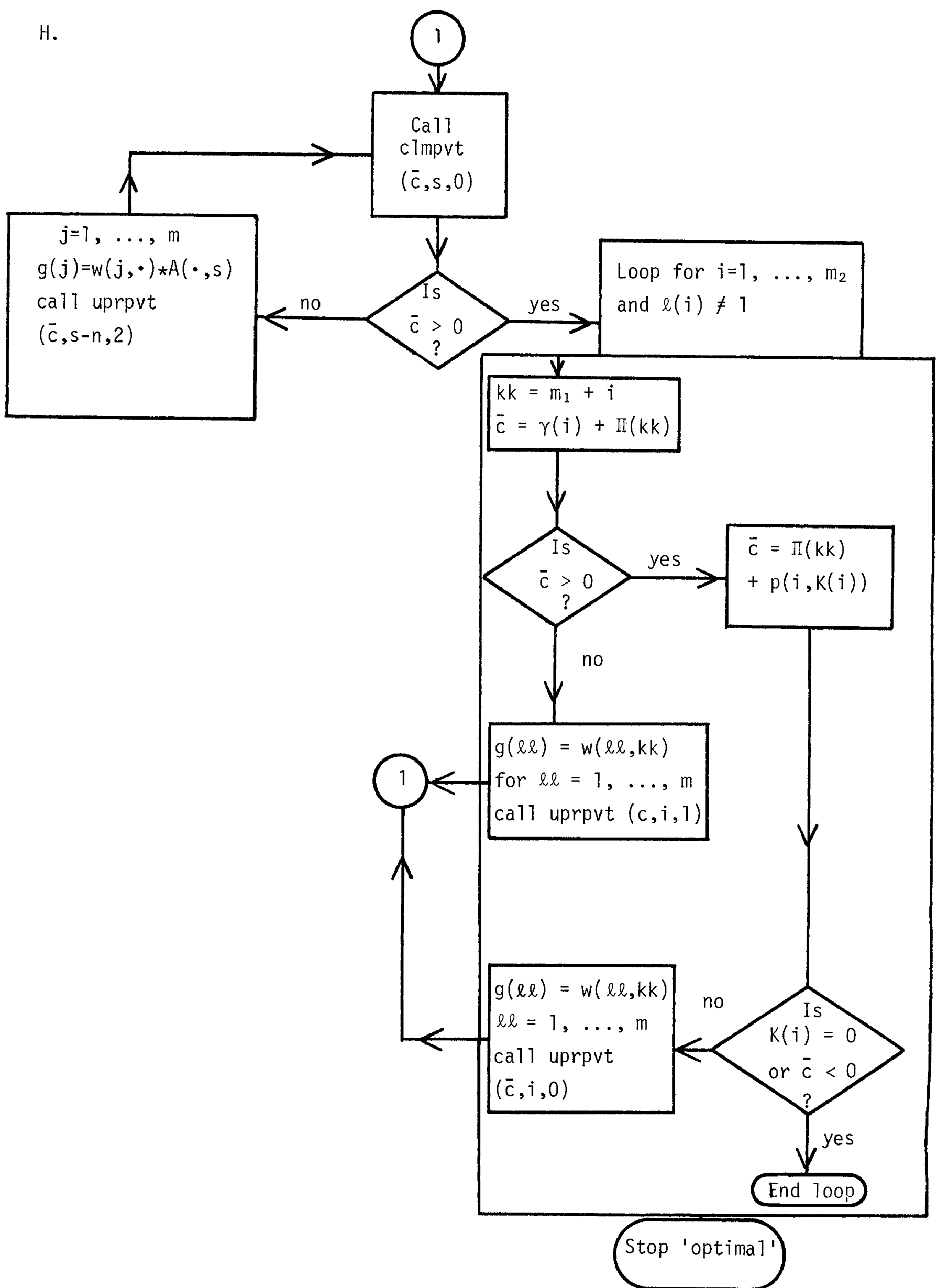




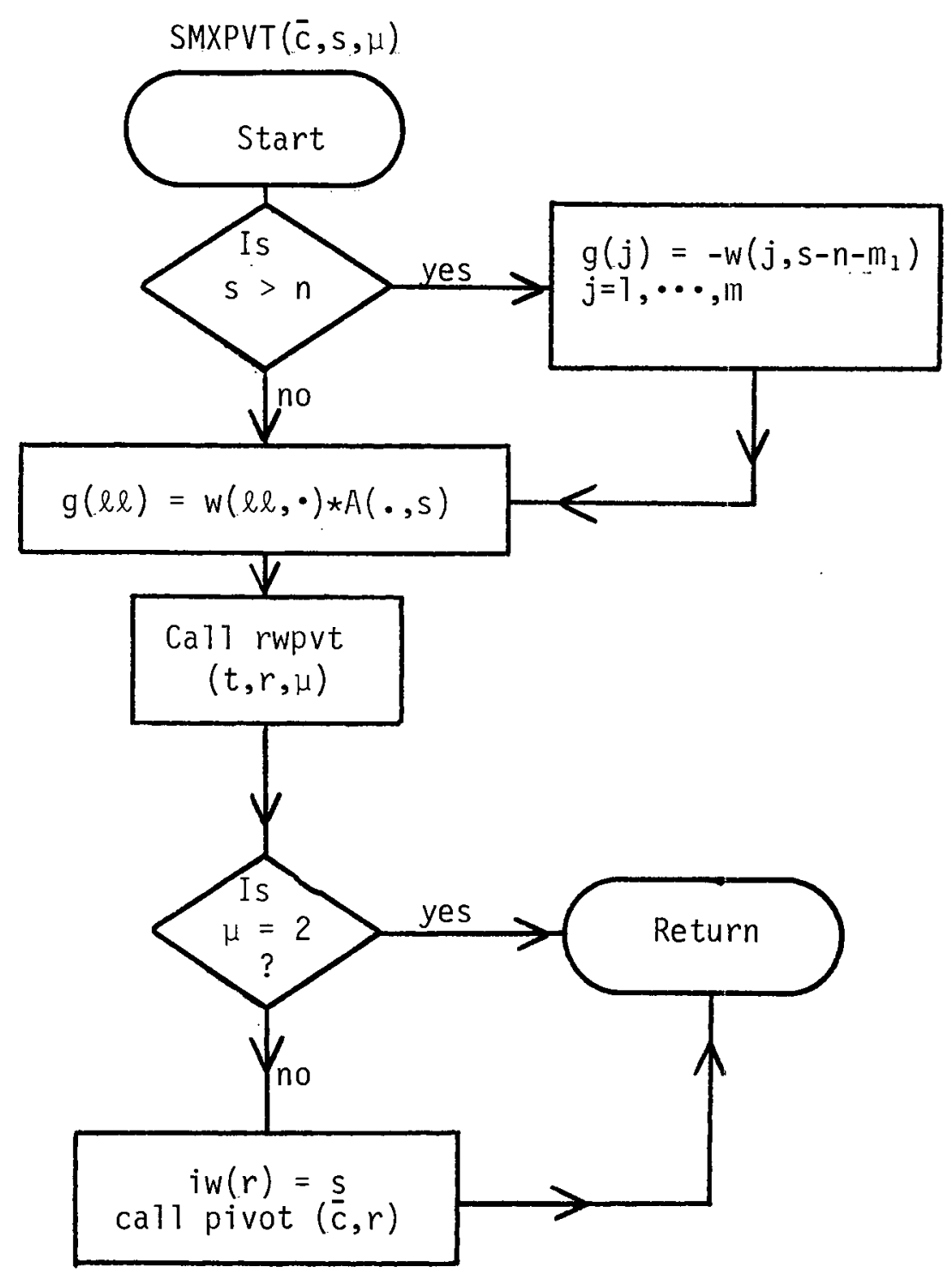


$\operatorname{RWPVT}(t, r, \mu)$

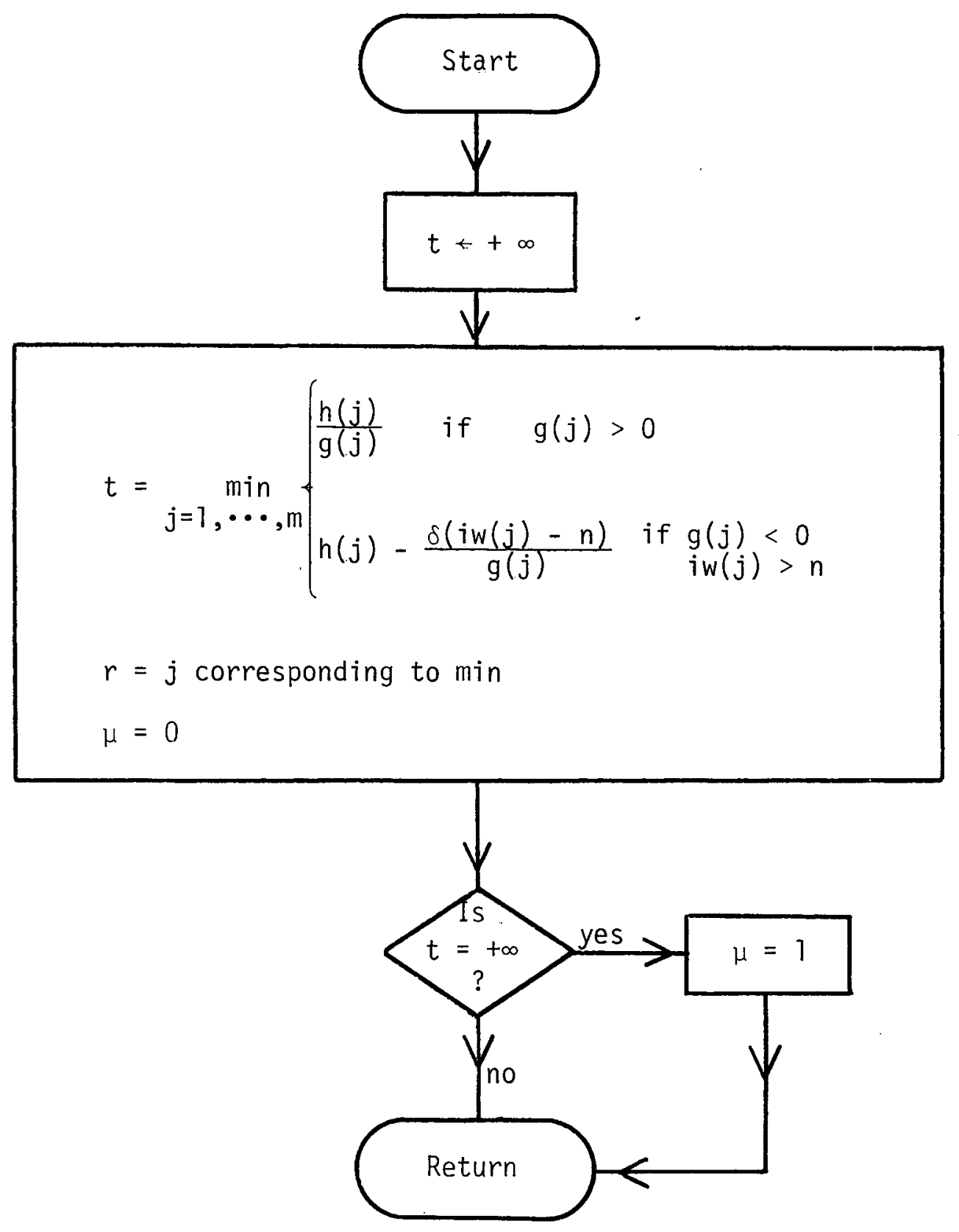


PIVOT $(\bar{c}, r)$

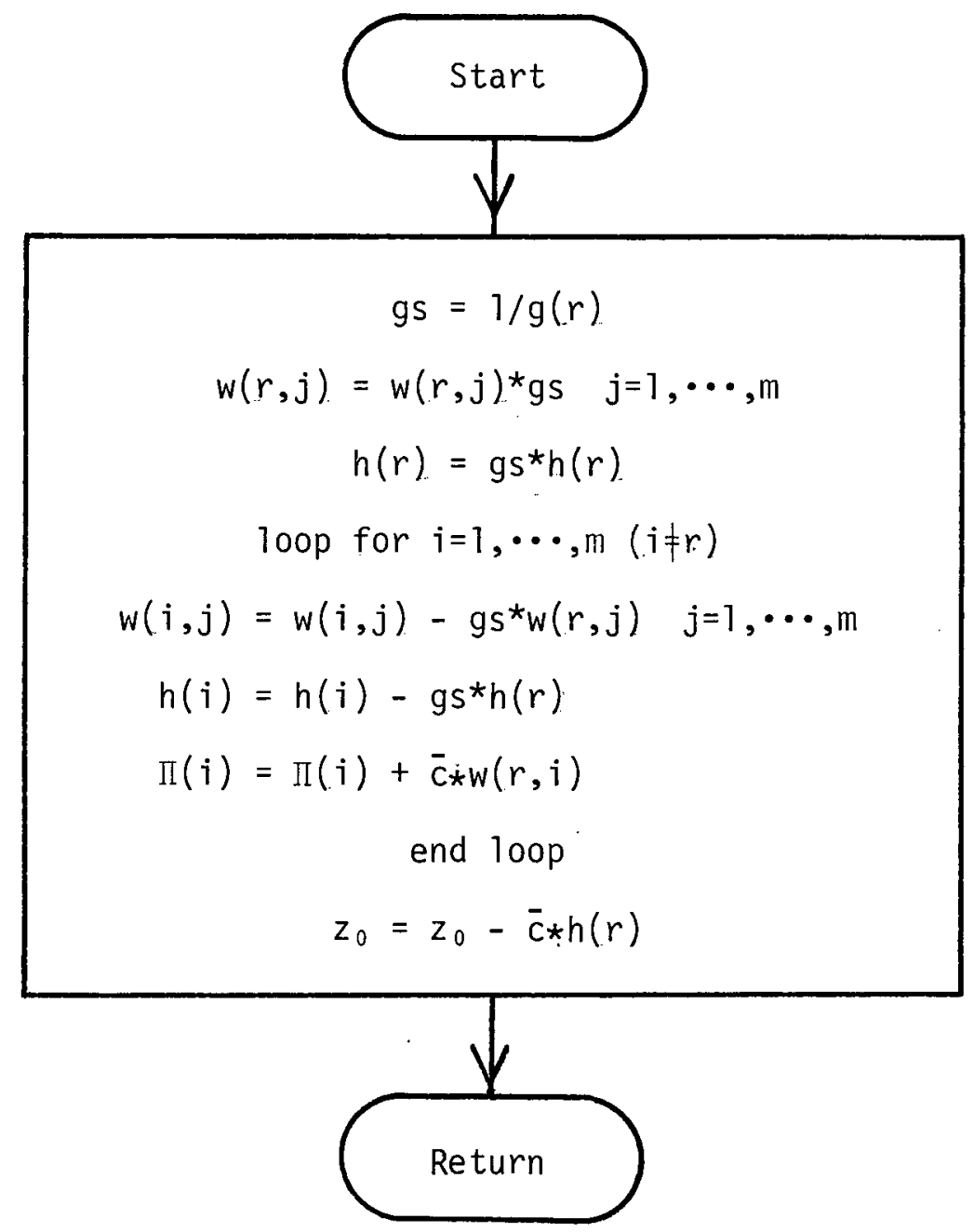


UPRPVT $(\bar{c}, i, k i k)$

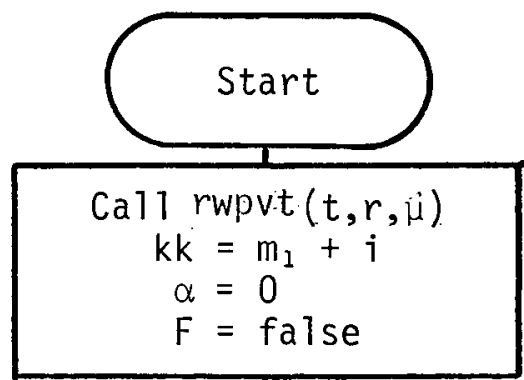

v

Let $\alpha$ be the sum of $d(i, K(i)-j+1)$ over

$$
j=1, \cdots, K(i) \text { unti } 1
$$

(if kik=0) $p(i, k(i)-j+1) \leq-\Pi(k k)$

(if kik=1) $p(i, k(i)-j+1) \geq-\Pi(k k)$

$$
\begin{gathered}
- \text { or }- \\
t<\alpha,
\end{gathered}
$$

then $l s=$ last value of $j((-j)$ if $k i k=0)$

$$
F=\text { true }
$$

(if neither condition holds go to $A$ )

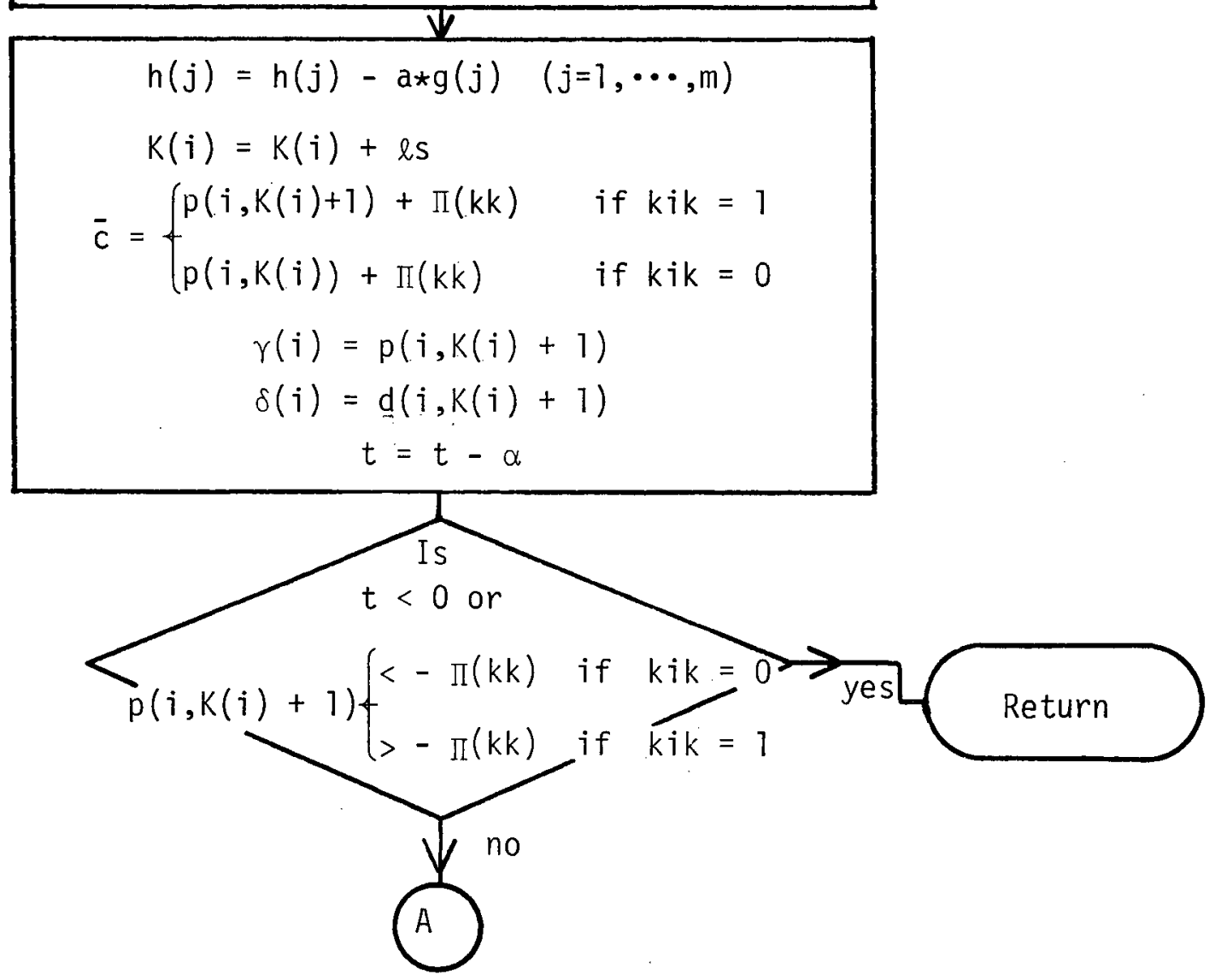




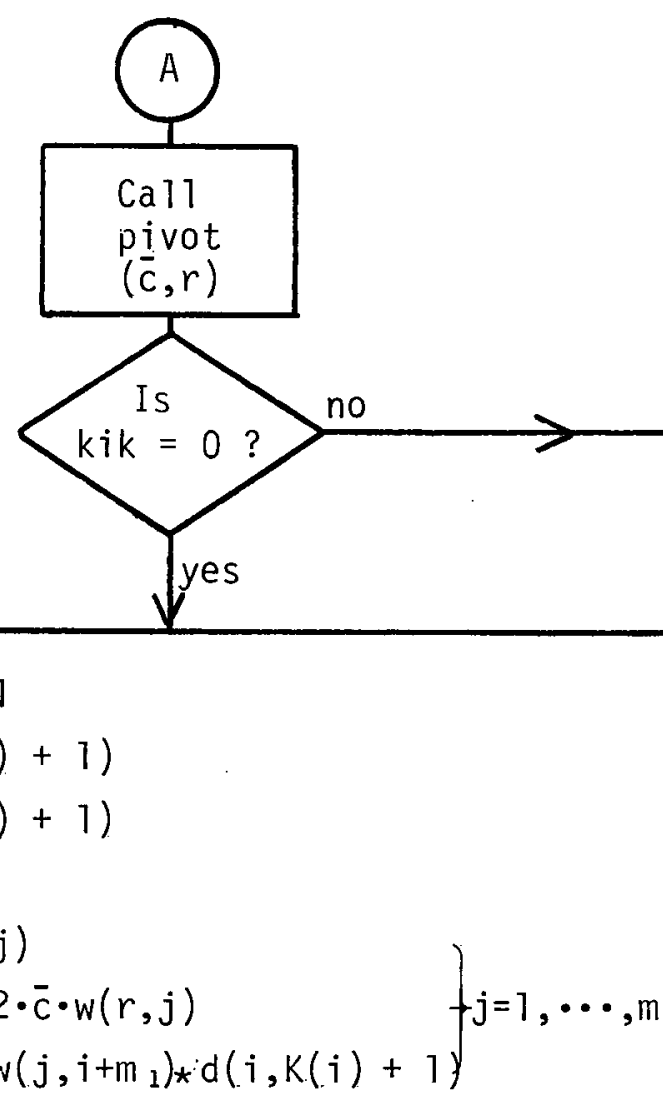

$K(i)=K(i)-1$

$\delta(i)=d(i, k(i)+1)$

$\gamma(i)=p(i, K(i)+1)$

$h(r)=-h(r)$

$w(r, j)=-w(r, j)$

$\Pi(j)=\Pi(j)+2 \cdot \bar{c} \cdot w(r, j)$

$h(j)=h(j)-w\left(j, i+m_{1}\right)_{*} d(i, k(i)+1)$

$$
\begin{aligned}
\because v & =i w(r) \\
i w(r) & =n+i \\
\ell(i) & =1 \text { if } i>0
\end{aligned}
$$

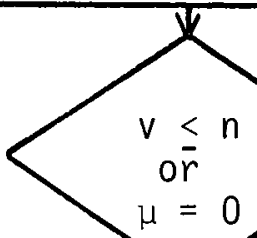

no

$$
\begin{aligned}
& v=v-n \\
& \ell(v)=0 \\
& i v=m_{1}+v \\
& h(j)=h(j)+w(j, i v) * \delta(v) \quad j=1, \cdots, m \\
& K(v)=K(v)+1 \\
& \delta(v)=d(v, K(v)+1) \\
& \gamma(v)=p(v, K(v)+1)
\end{aligned}
$$


DPOCDAM KUTV IINDUT, BUTSUT, TADES=TNOUT, TAOEG=OUTPUTI

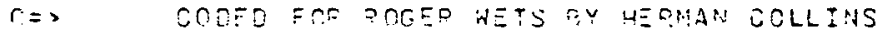

WORTETCAT TONO OY J KALLO PO \&

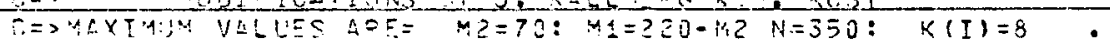

i-

IMITEIT OEAL $(A-H, O-7)$

TNTEGEA S,F,OHT, WARTY

PEAL TP(70,16), TU(70.10)

DEAL $0(78,1: 1,0(70,10), 0(1) 2,260), 4(120), 0(263)$

=EAL H(103,10U),G(100), DELTA(70), GAMMA(70),PI(100)

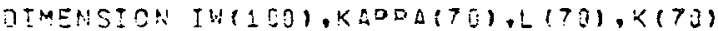

DEAL OCI7G1,OM(TO)

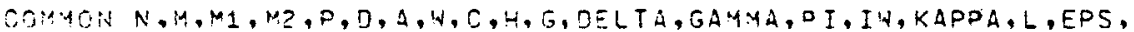

$5 \quad K, \cap P, O N, 2 G, M A R K E Z$

COMMON IEDINTOI TP,TO

SPNOTICE THAT IN THE DOCUMENTATION THAT P.ANO O USE J-ORIGIN INDEXING.

$r=S$ JH THE FDETPAN ROOE ALL SUCH INOEXES HAVE BEEN INCREMENTED BY 1 . $=E A D(5,9 \geq 2)=05$

?32 = OPHAT (F:0.5)

WPITE (E.17E) EDS

1.7E FOPNAT(1H1,T1O,"TOLFEANCE IS SET AT “,F3.5)

$r=2 \cdot 2 \leq \triangle D I N$ N.MI.MI, KI.

QEAD (5, IES) K, MI, M?

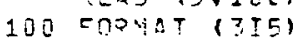

WPITE (E, $139,1 \mathrm{~N}, M 1, M 2$

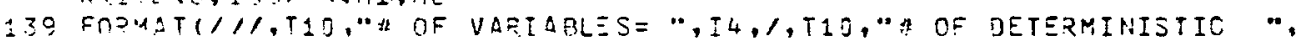
C $\cdots$ OONSTOAIUTS $=\cdots, I 4,1, T 10, \cdots \#$ OF STOCHASTEC CONSTRAINTSE

$C=>P E A O$ IN $\triangle N D$ WPITE OUT THE XT-VALUESTPOSSIBLE VALUESI ANO ALPHA ANO BETA

$C=$ LLONEP. ANS UPPER BOUNOS T:NTO D. HDITE 6,110$)$

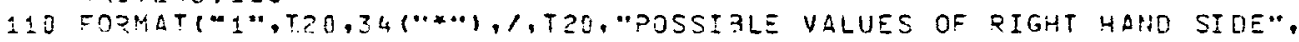

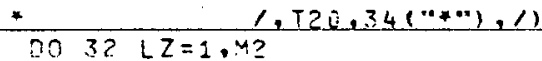

$0 . E 4(5,8,0) \times(L Z), 0(L Z, 2), P(L 7 ., 2)$

$T \supset(L Z, 1)=P(L ?, 2)$

$T \cap(L Z, 1)=0(L Z, 2)$

$I=(K(L Z) \cdot 15.1), 00 T 03 ?$ $K D=K(L Z)$

$7031: 0=2, \mathrm{KO}$

READ $(5.8$ E i) D(L7. LA+1), P(LZ.LA+1)

$T D(I Z, L A)=0(1,-L \Delta+1)$

$31 T P(1, T \cdot L A)=P(L 7, L A+1)$

37 PE $90(5,602)$, $(L Z, 1), 9(L Z, V,(L Z)+2)$

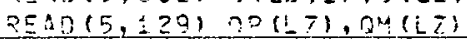

306 FOPMAT(I3,F19.2,FG.4)

P.SI EOPUAT(FIO.2,FG.4)

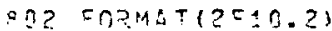

129 FOPAATI2F1E.t? $K I=K(L Z)+1$

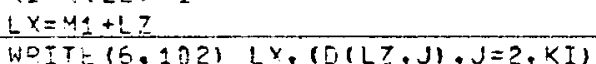

102 FOPMET(TS," "OOW ". I3,T 15,4(F14,2,6X), , 


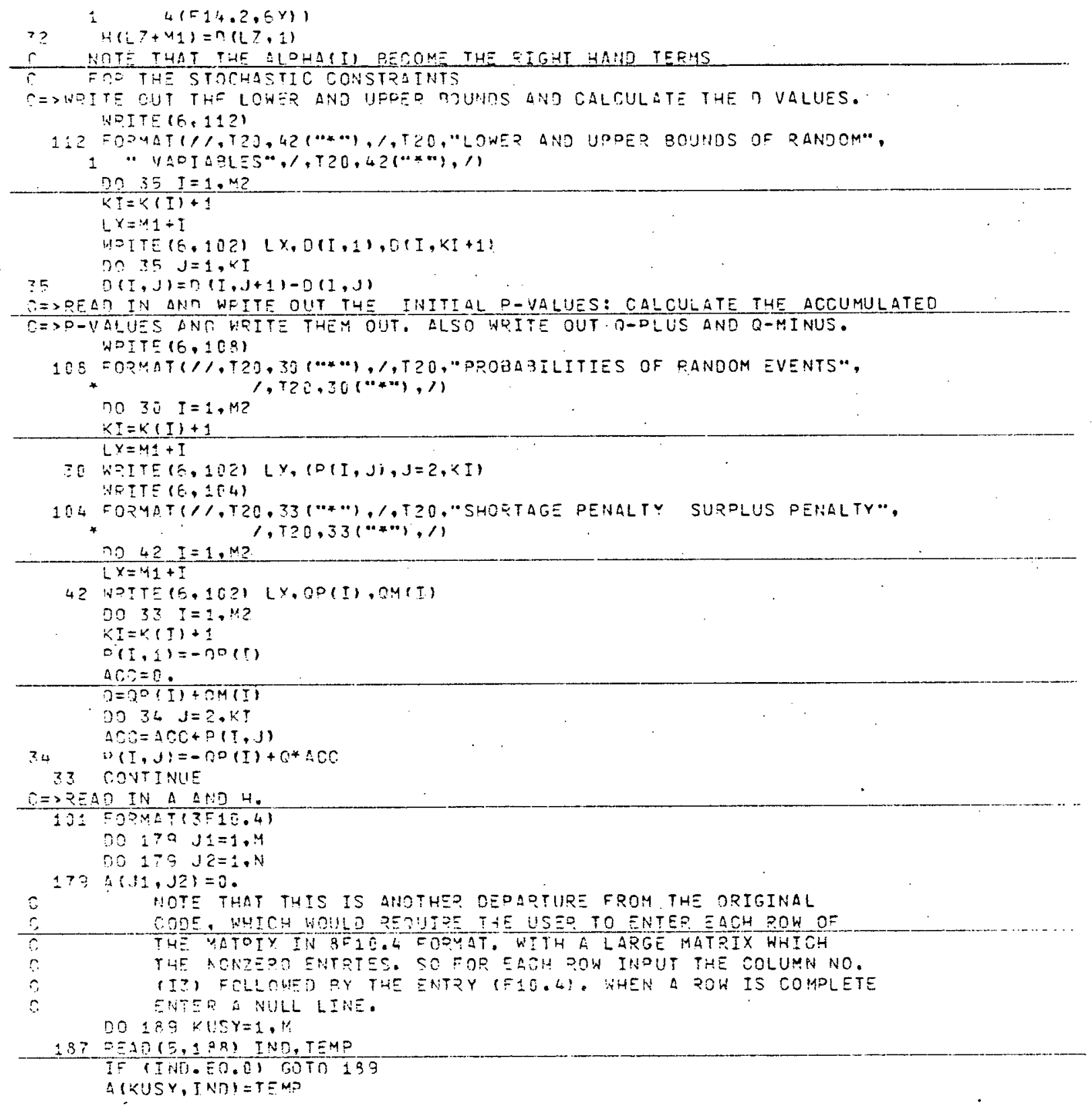


$\operatorname{roton}: 37$

239 COUT TNUE

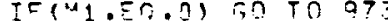

$P=40(5,1 ! 1)(4(I), I=1, M 1)$

273 COUTINUE

WRITE 16,1051

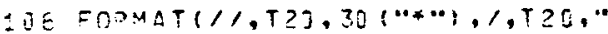

a - mATRIX“,

Q3 =0PMAT (II.,F1J.4)

Ni. $43=N / 10+1$

IF $(M O Q(N, 10), 5 \cap .0) N U: 13=N U M R-1$

กO $224 \mathrm{~J}=1$. NUMP

$L 1=1+10 *(\mathrm{~J}-1)$

$L 2=M I N D(O+L 1, N)$

WRITE $(6, ? 27)$

WRITE $(5,228) \quad(I, I=L 1, L 2)$

D० $224 \times 9=1.4$

WRTTE $(6,222) \mathrm{K},(A(K 9, K Q), K Q=L 1, L 2)$

224 CONTINUE

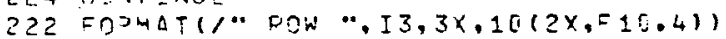

$202=08 M \triangle T(11 / 30 x, \cdots * * * * * * * * * * * * * * * * * * * * * * * * * * * * * * * * * * * * * * * * * * * * * \cdots)$

2:? FOPMAT $(/ /, T 10)$

228 FOPMAT " COLUMNS", $10 I 12\}$

HDITE (E. 109$)$

139 FOPNAT $(1 /, T 20,30(\cdots 4 \cdots), /, T 20$, INITIAL RIGHT HANO SIDE VECTOR",

* $1,720,30(\cdots \times), 11$

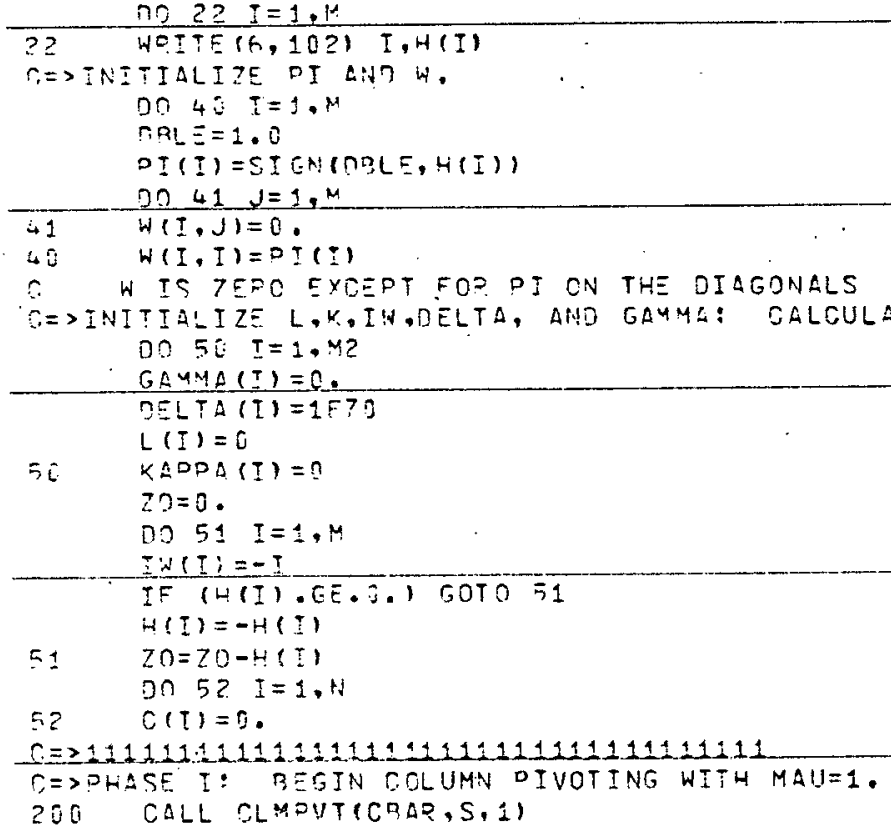


IECOAS.LT.-EOS) GO TO $20 ?$

$I=(70.6 E .-E O S) r O T O 203$

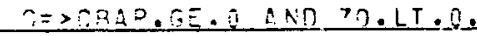

$N=T T E(5,207)$

?Q7 = OPHAT (" INFEASI PLE"*)

CBIL TUMP

$C=>C . A P \cdot G E \cdot 0$ ANO $70.6 E \cdot 0$.

2E? $09204 \mathrm{~J}=1, \mathrm{Q}$

IF (IW(J).LT.I) GO TO 205

504 CONTINUE

205 WRTTF(6.209)

208 FOPMAT (. DHASE I DEGENEOACY")

SALL DUMF

$r=P C, 2 \triangle P<0$

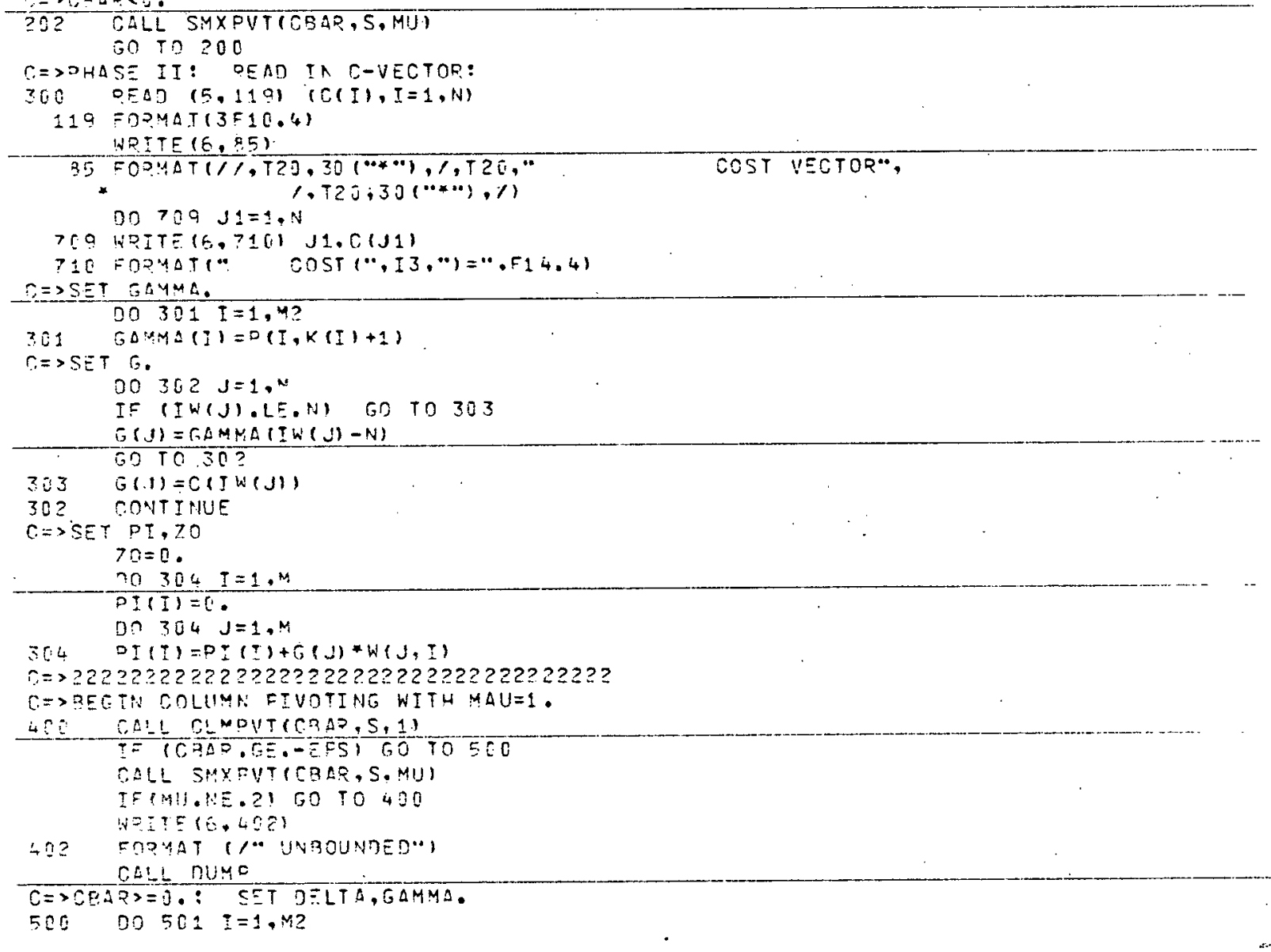


TELTA I $=$ OIT,I)

$501 \quad$ GAMA $A(I)=0(T .1)$

$r: \equiv S E I$ L.KA $=04, H, C A 4: 44,0 I$.

$00502 \mathrm{~J}=1 . \mathrm{M}$

IF (IW(J).LE.H) GO TO 50?

NUI $=I W(J !-N$

$L(N U)=1$

$Y=3$.

PHT $=1$

$k !=K .(N !))+1$

$00503 k K=1 . k !$

DHT $=K K$

IF $(Y+D(N U, K K)+E P S \cdot G T \cdot H(J) !$ 30 TO 504

$503 \quad Y=V+0(N), K K)$

$504 \quad X=P(N U, D H I)=0(N U, K(N U)+1)$

DELT L $(N U)=D(N U$. PHI $)$

$H(\|)=H(J)-V$

$G A M M \triangle(N U)=D(N U, D H I)$

$K A D D A(N U)=P H T-1$

Q0 $505 \quad I=1, Y$

$505 \quad 3 I(I)=P I(I)+x * H(J, I)$

502 CONTINUE

$r=2333333 \geq 3 \geq 3333333333333333333333333333$

$C \Rightarrow$ PEGIN COLUMN FIVOTIHG AGAIN WITH MAU $=3$.

70 CALL CLMFVTCOBAR,S, OI

IF ICQAP.TE.-EFS GO TO 500

$7[1 \quad 0070 ?]=1 . M$

$r(j)=0$.

$00.703 \quad I=1.4$

$703 \quad G(J)=G(J)+W(J, I) * \Delta(I, S)$

DALL IIPOOVT (CEAT,S-N, 2$)$

ro To ?o?

$C=>T E R$ IN UPDEF DCUND PIVOTING.

$20601 I=1 . M ?$
$T E(L(I) . E Q .1)$, 0 TO EOI
$K K=M I+I$

$C=>T E S T 1$.

COSA $=6 A M M A(I)+F I(K K)$

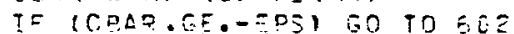

$00603 L L=i, N$

$503 \quad G(L L)=-W(L L, K K)$

OALL UPRPVT (COAPAT, I)

00 Tก 700

$C \Rightarrow$ TEST2.

Ge? IF (KADEA(I) EE. (j) 60 TO 601

CQAR $=P I(K K)+O(I, K A P D A(I))$

TF (COAD.1E.EPS) SOTO601.

$02504 L L=1,4$

504 $\quad 6(L)=,W(L,, \% k)$

CALL UPEPUT (CBAR, I, 3 ,

БO TO ?0:

SQI CONTTHUE

COWHEN THE LOOF IS SATISFIED, WPITE OUT THE OPTIMAL SOLUTTON ANO STOP 
WPITE 16,752$)$

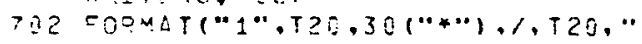

DPTIMAL SOLUTION $"$, CALL PSINT

STคO

$1,120,30(\cdots * \cdots), 11$

EN? 


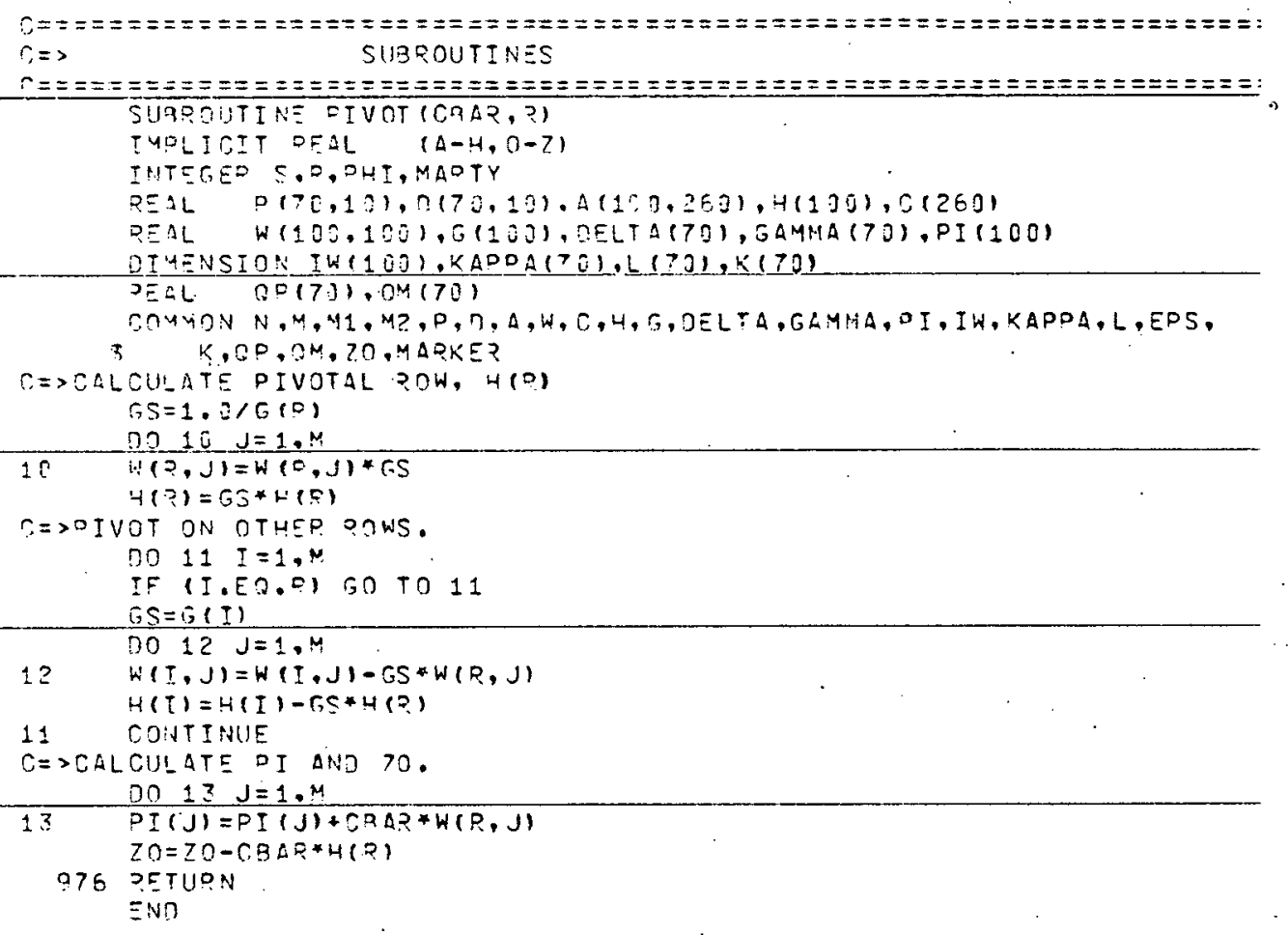




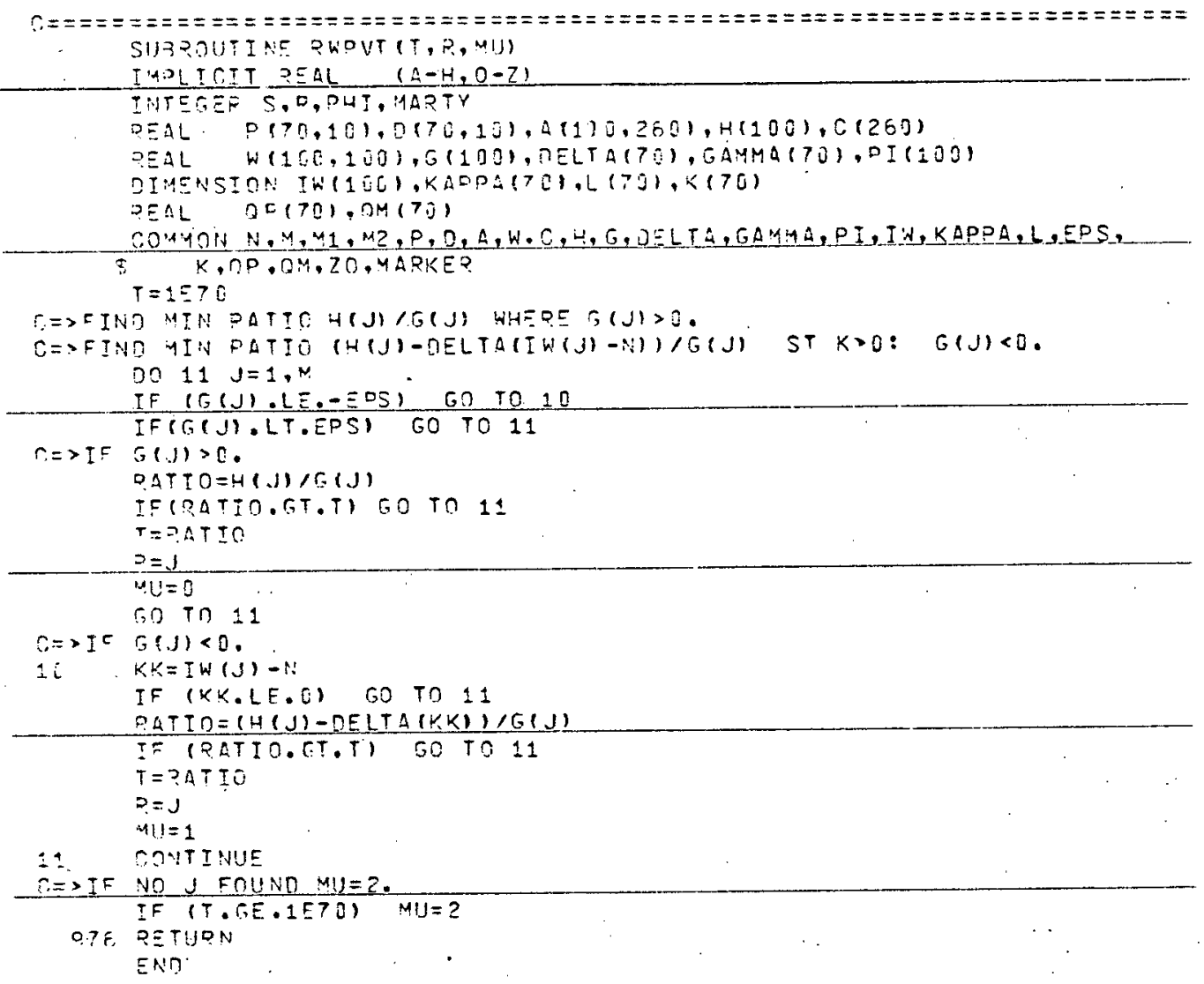




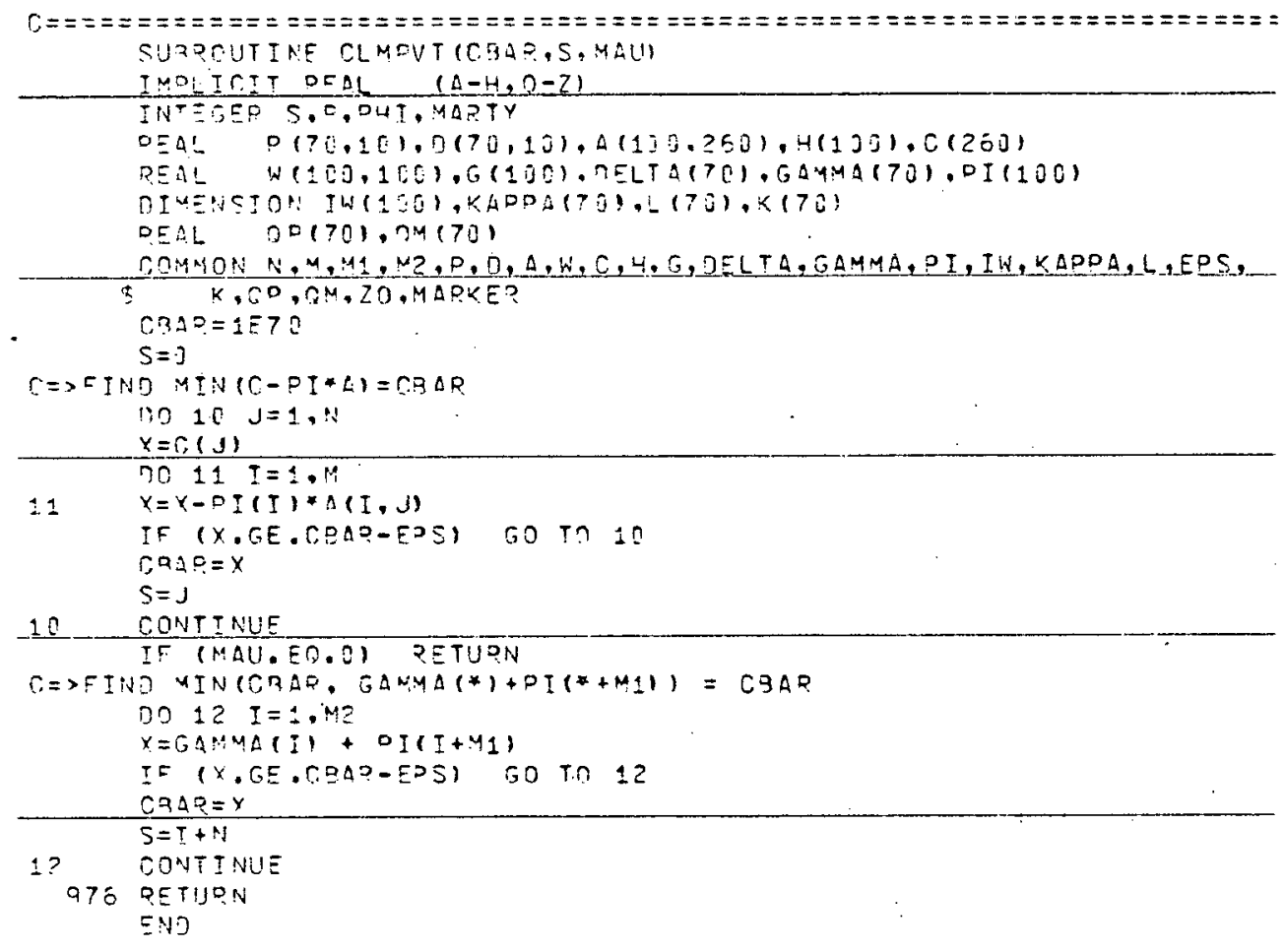




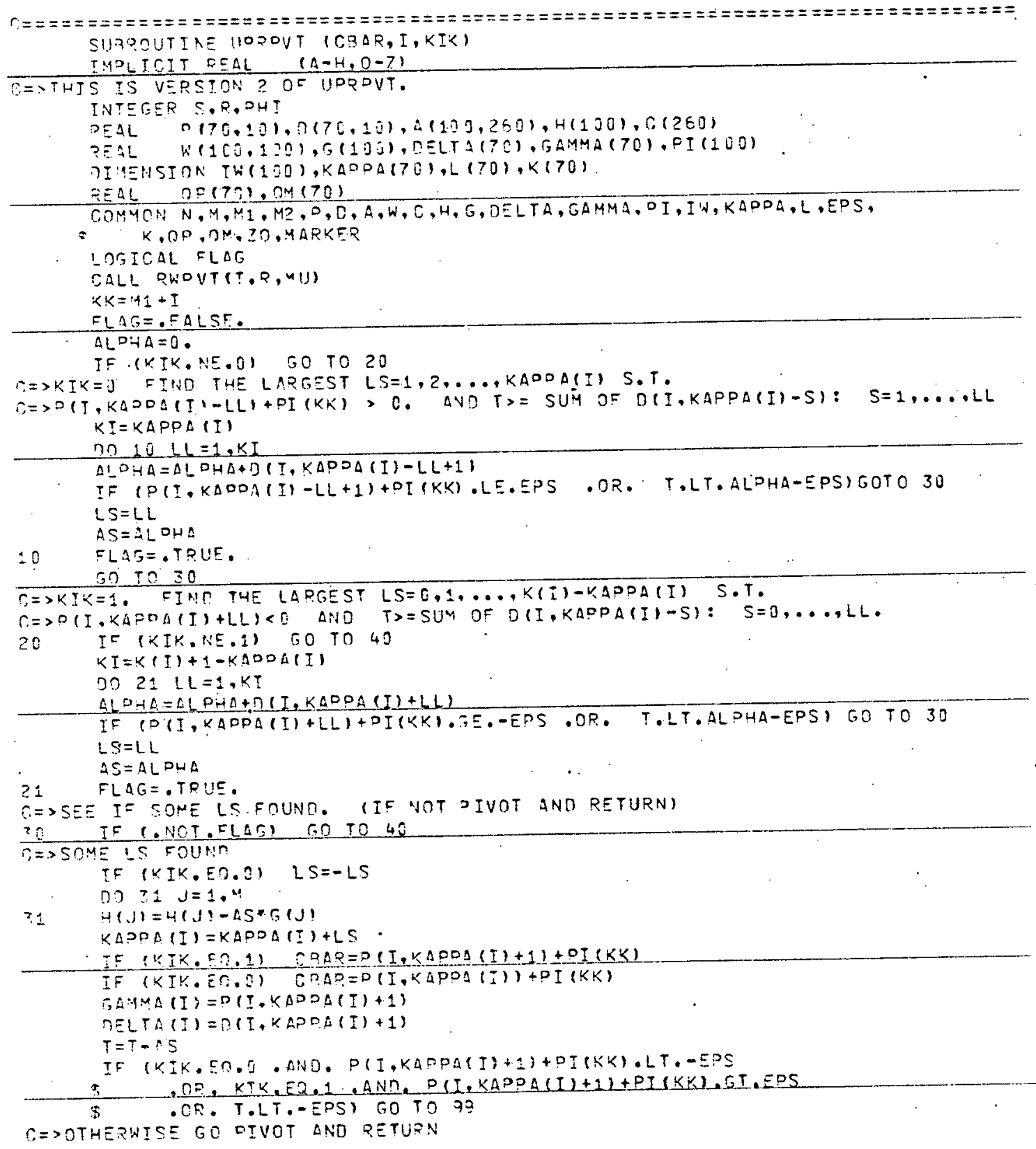




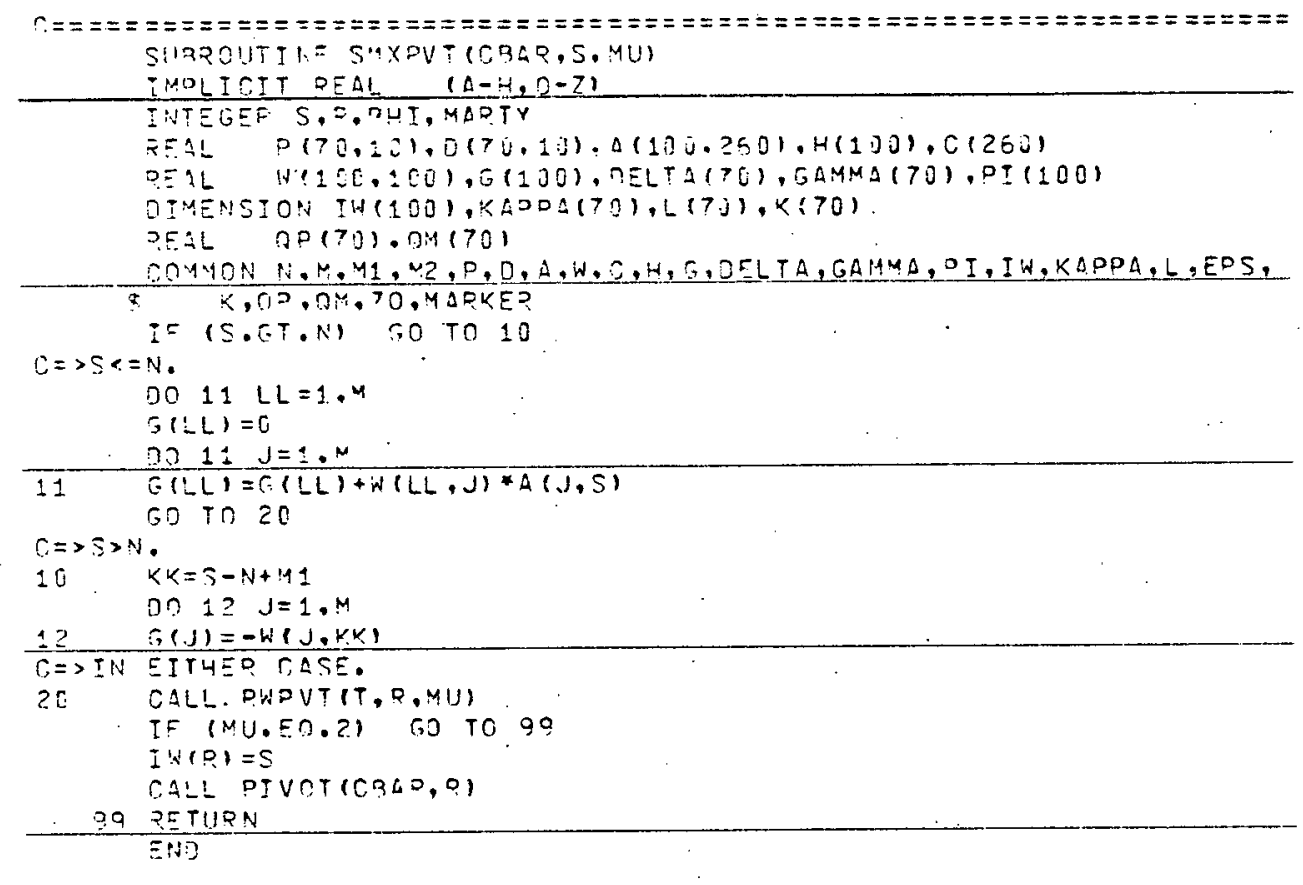




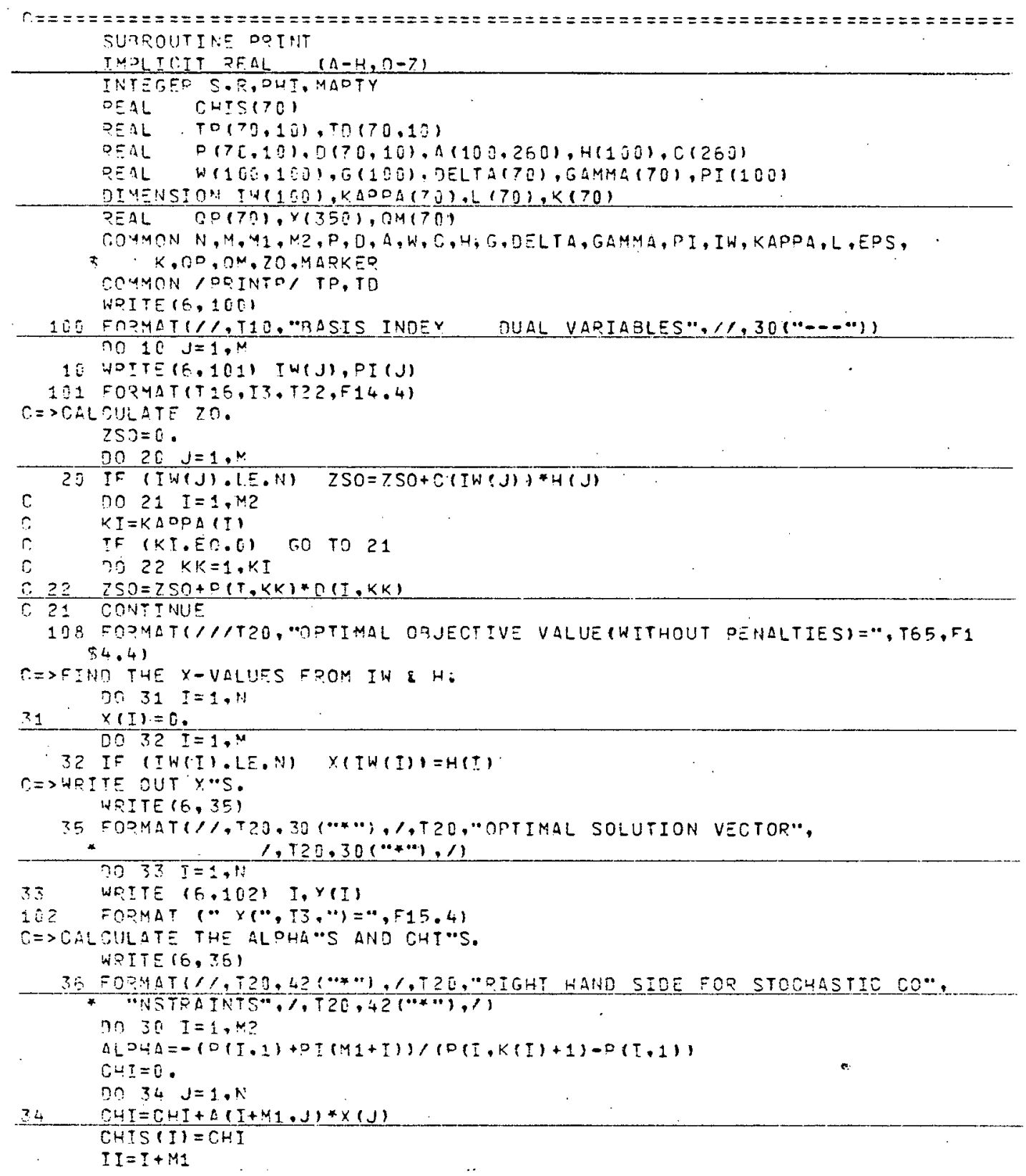




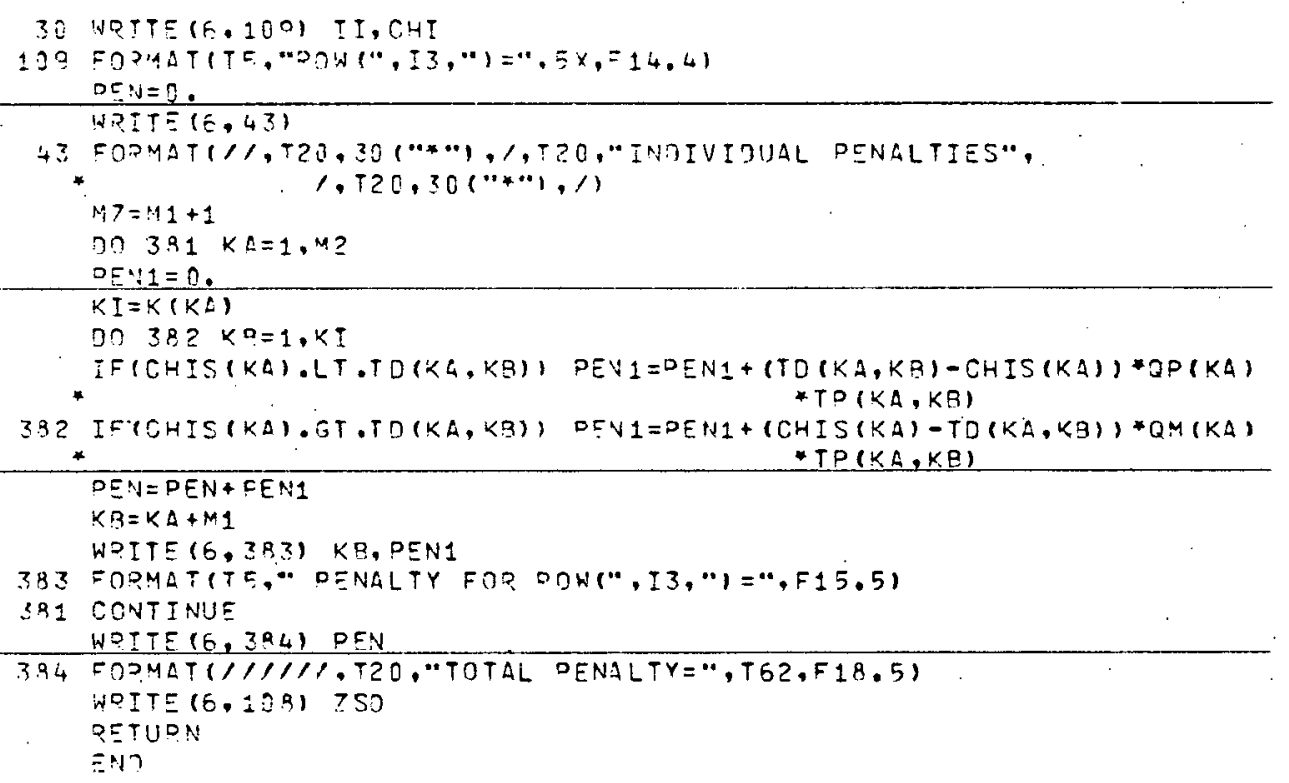




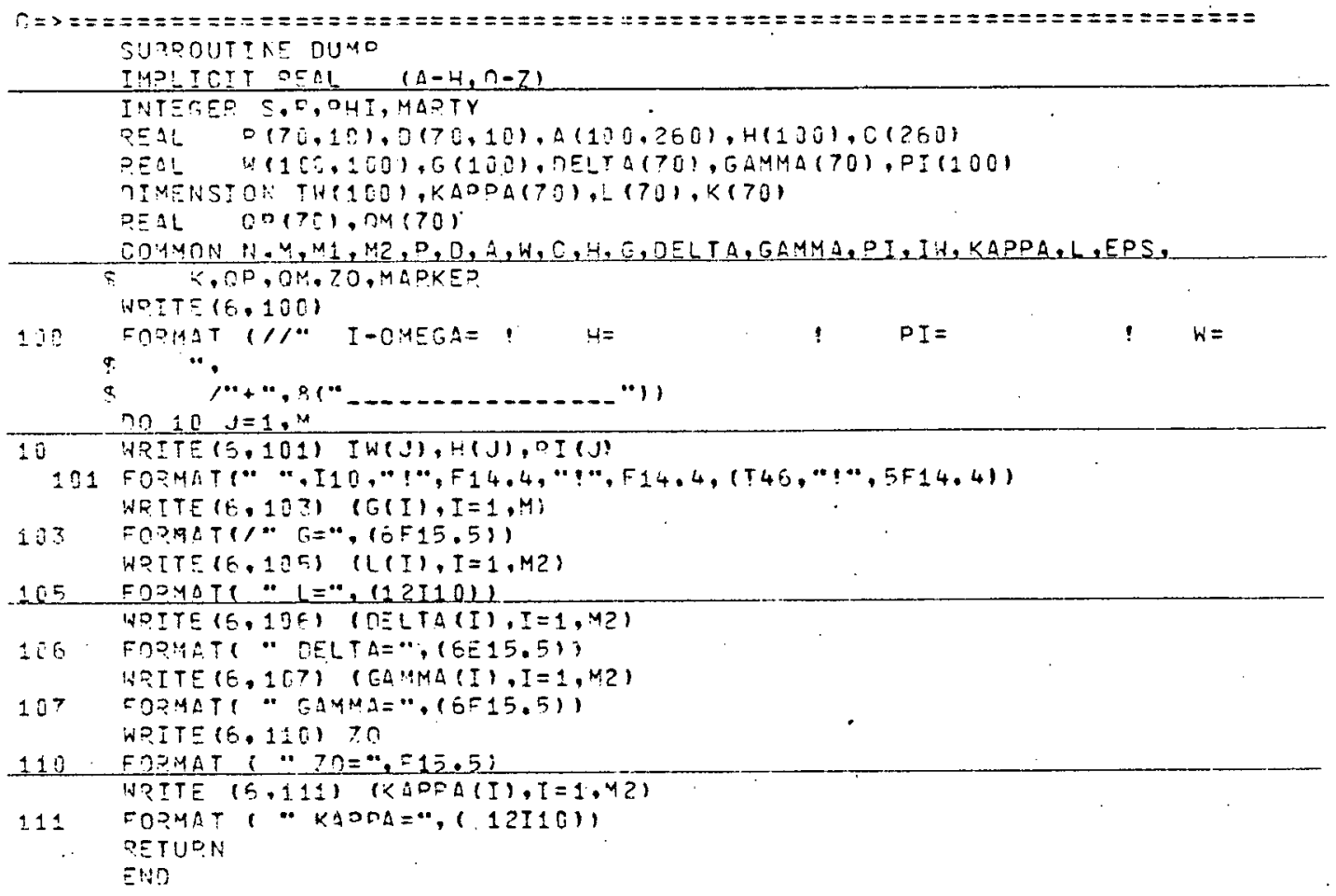




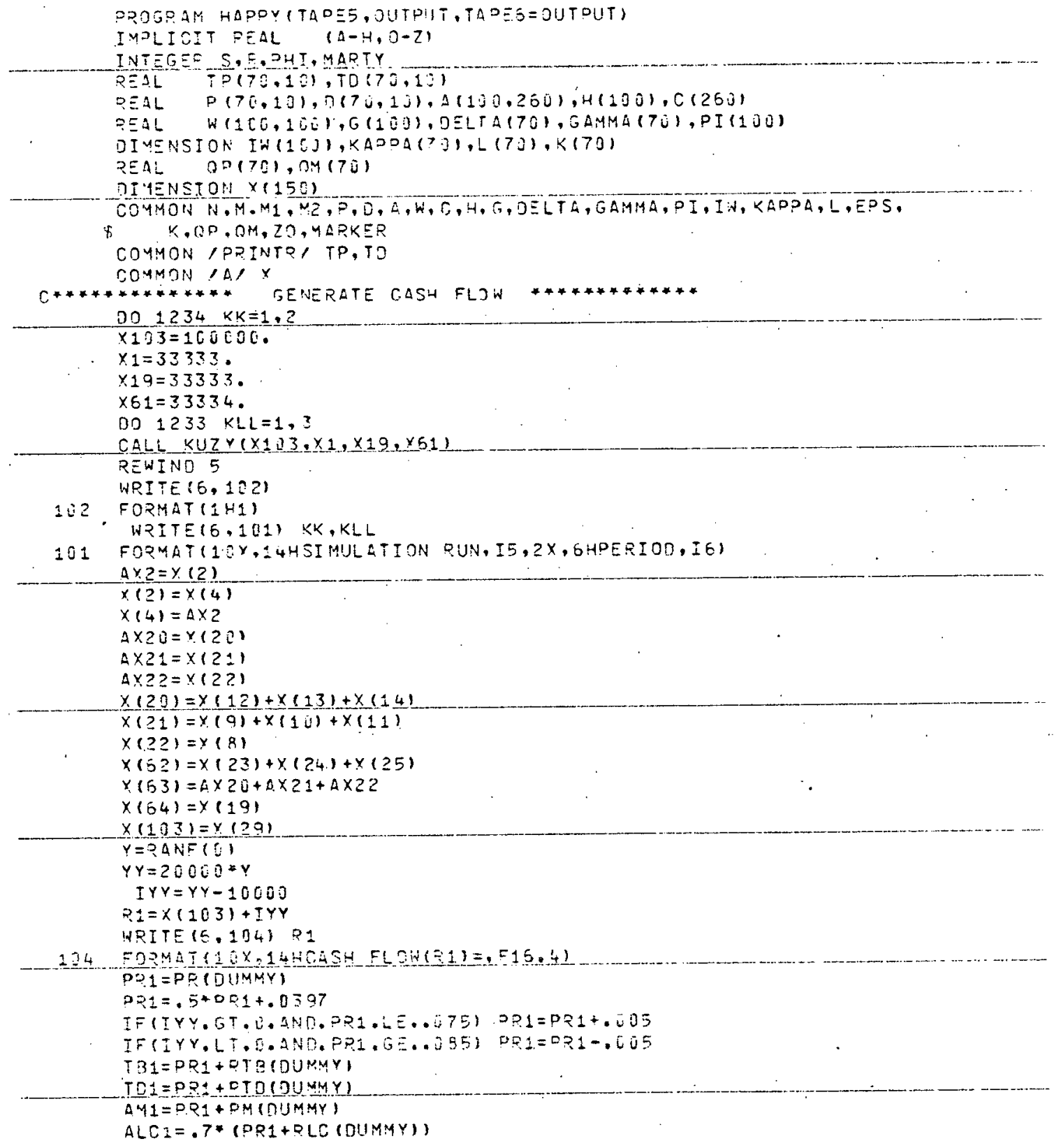


WPITE $(6,156)$ TEI

150 =OPMAT(12X,134TREASURY ETLL RATE=,2X,F15.6)

HPITE $(6,151)$ TN1

151 FORMAT (16X.19H TERM DEPSST RATE $=22 \times, F 10.61$

WOITE $(6,152)$ AM 1

152 FОР:1T(1:X.13H

MOPTAGE PATE $=, 2 \times, F 16.61$

WP.ITE $(6,153)$ ALZ1

153 OQPपT $110 \times, 19 H$

LIMBILITY २ATE $=, 2 \times, ? 16.0)$

$v_{1}=x(2)+x(20)+x(6,2)+x(3)+x(21)+x(53)+.005 * x(4)$

$\$+.014 \times(22)+.05 * \times(54)$

$22=.035 * x(4)+.04 * x(22)+.36 * x(54)$

$A R: 1=Z 2$

IF $(Y 1 \cdot L T \cdot P:) \times(2)=X(2)+P_{1}-Y_{1}$

IF $(Y 1 . L T . R 1) \quad 60 \quad$ TO 79

$X ?=X(2)-(Y 1-P 1) *(.2)$

IF $(x 2 . G T \ldots 0) \quad Z z=z 2+(x(2)-x 2)+(.005)$

IF ( $Y 2 . L E \ldots(j) \quad Z 2=Z 2+(x(2)) *(.005)$

$x(2)=x 2$

$\times 20=0.0$

IF $(x(2) \cdot G E \ldots 0) \quad 30 \quad$ TO 7.7

$X 3=x(3)+x(2)$

$x(2)=3.0$

$I F(x 3 . G E \ldots .01 \quad Z 2=z .2+(x(3)-x 3) *(.005)$

$I F(x 3 . L T \ldots .0) Z Z=22+(x(3)) *(.0) 5)$

$x(3)=x 3$

$I \equiv(X 13) . G E \ldots 0) \quad 50$ TO 77

$\times 2]=-x(3)$

$x(3)=0.0$

77 CONTINUE

$\times 231=x(20)-x 20-\left(Y_{1}-0.1\right) *(.4)$

IF $(\times 201.0 T .00) 72=Z 2+(x(20)-x \geq 01) *(.04)$

IF $(\times 201 . L E \ldots 0) 72=72+(\times(20) 1 *(.04)$

$x(201=x \geq 01$

$\times 52=0.0$

$I F(x(20) . G E \ldots 0) 60$ TO 78

$x 21=x(21)+x(20)$

$x(20)=0.0$

If $(x \geq 1.0 F .012 .2=72+(x(21)-x .21) *(.04)$

IF $(X 2 \pm . L T \ldots .0) 72=Z 2+x(21) *(.0+1$

$x(21)=X 21$

IF $(x(21) .6 E \ldots 0) \quad 60$ TO 78

$\times 62=-x(21)$

$x(21)=0 . j$

78 CONTINUE

$\left.x_{6} 21=x(52)-x 5 ?-\left(Y_{1}-R_{i}\right) * i .4\right)$

IF $(\times 621.6 T .09) 72=22+(x(62)-\times 521) *(.06)$

IF $(x 621 \cdot(T \ldots O) Z Z=Z 2+(x(52)) *(.06)$

$x(52)=x \in 21$

IF $\{x(62) .5 E \ldots 01$ GO TO 79

$\times 53=\times(63)+\times(62)$

$x(52)=0.8$

IF $(x 63.6 E .0122=22+(x(63)-x 63)+(.05)$

IF $(x \in 3 . L T \ldots 0) Z 2=Z 2+(x(53)) *(.05)$ 


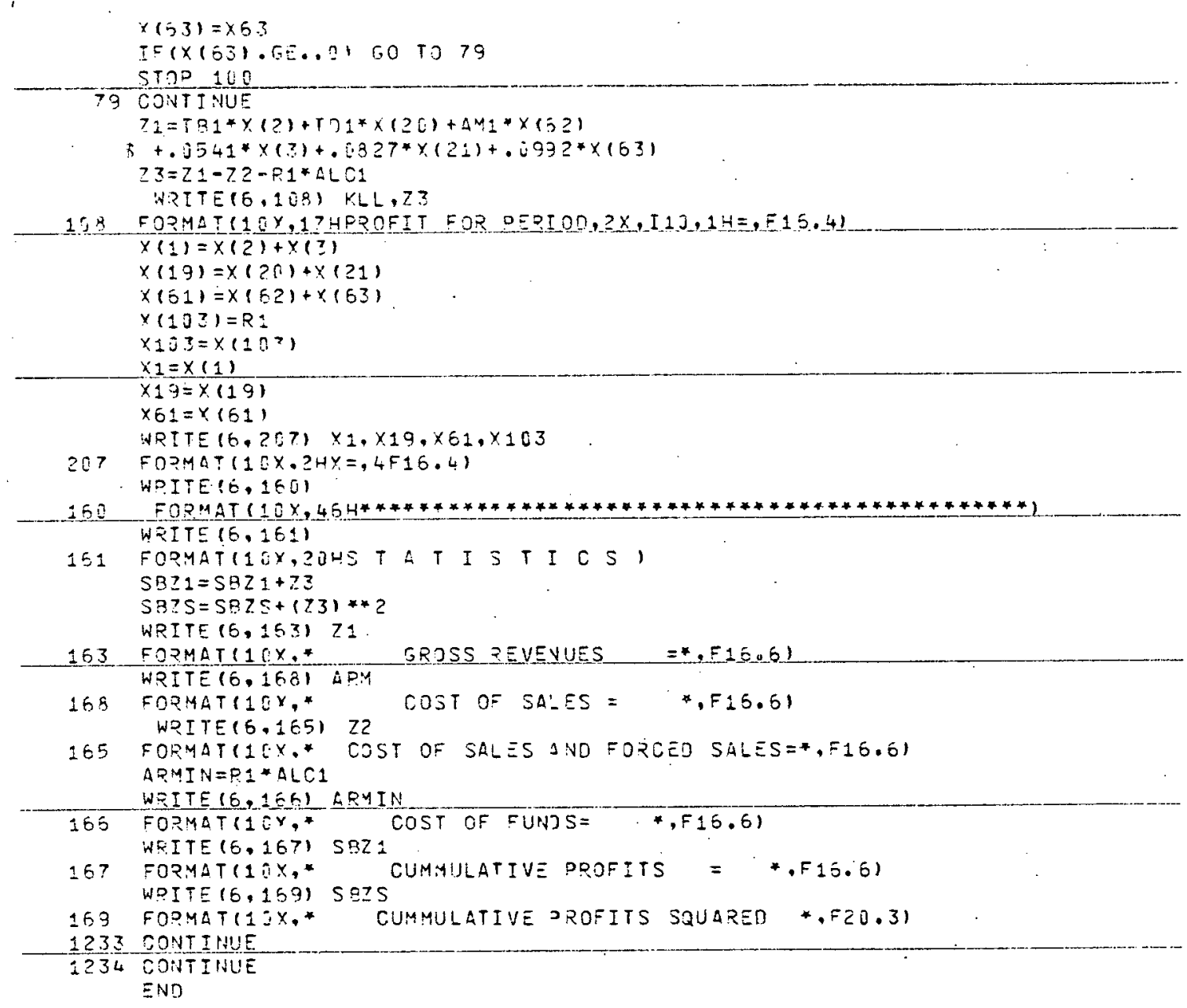


The purpose of the code is to solve in-core a stochastic linear programs with simple recourse. The problem to be solved is of the type

$$
\left.\min _{x_{j}}\left\{\sum_{j=1}^{n} c_{j_{j} x_{j}}+E_{\xi_{i}} \operatorname{lmin}_{y_{i}^{+} y_{i}^{-}} \sum_{i=1}^{m_{2}}\left(p_{i}^{+} y_{i}^{+}+p_{i}^{-} y_{i}^{-}\right)\right\}\right\}
$$

subject to

$$
\begin{aligned}
& \sum_{j=1}^{n} a_{i j} x_{j} \quad=b_{i} \quad \text { for } i=1, \cdots, m_{1} \\
& \sum_{j=1}^{n} t_{i j} x_{j}+y_{i}^{+}-y_{i}^{-}=\xi_{i} \quad \text { for } i=1, \cdots, m_{2} \\
& x_{j} \geq 0 \quad \text { for } j=1, \cdots, n \\
& y^{+}{ }_{i}>0 \quad \text { for } i=1, \cdots, m_{2} \\
& y_{i}^{-} \geq 0 \quad \text { for } i=1, \cdots, m_{2}
\end{aligned}
$$

where: $c_{j}$ - is the $j$ th element of the given cost vector

$x_{j}$ - is the $j$ th element of the decision vector $x$

$a_{i j}-i_{A}$ the $(i, j)$ th element of the given technological matrix

$t_{i j}-i_{T}$ the $(i, j)$ th element of the given technological matrix

$b_{i}$ - is the $i$ th element of the given resource vector $b$

$\xi_{j}$ - is the $i$ th element of the random resource vector $\xi$

$y_{\bar{i}}^{-}$- is the ith element of the surplus vector $y^{-}$ 


$$
\begin{aligned}
& y_{i}^{+}-\text {is the } i \text { th element of the shortage vector } y^{+} \\
& p_{i}^{+}-\text {is the } i \text { th element of the penalty vector } p \text { (for shortage) } \\
& p_{i}^{-}-\text {is the } i \text { th element of the penalty vector } p^{-} \text {(for surplus) }
\end{aligned}
$$

a) so define

$\xi_{i}^{(j)}$ - to be the $j$ th smallest possible realization $\left(j=1, \cdots, J_{i}\right)$
of the $i$ th element of $\xi$

$$
\begin{array}{ll}
p_{i}^{(j)}-\text { is the } p_{r}\left\{\xi_{j}=\xi_{i}^{(j)}\right\} & \\
\text { and } \sum_{j=1}^{j} p_{i}^{(j)}=1 . & \text { for } i=1, \cdots, m_{2}
\end{array}
$$


The input data are:

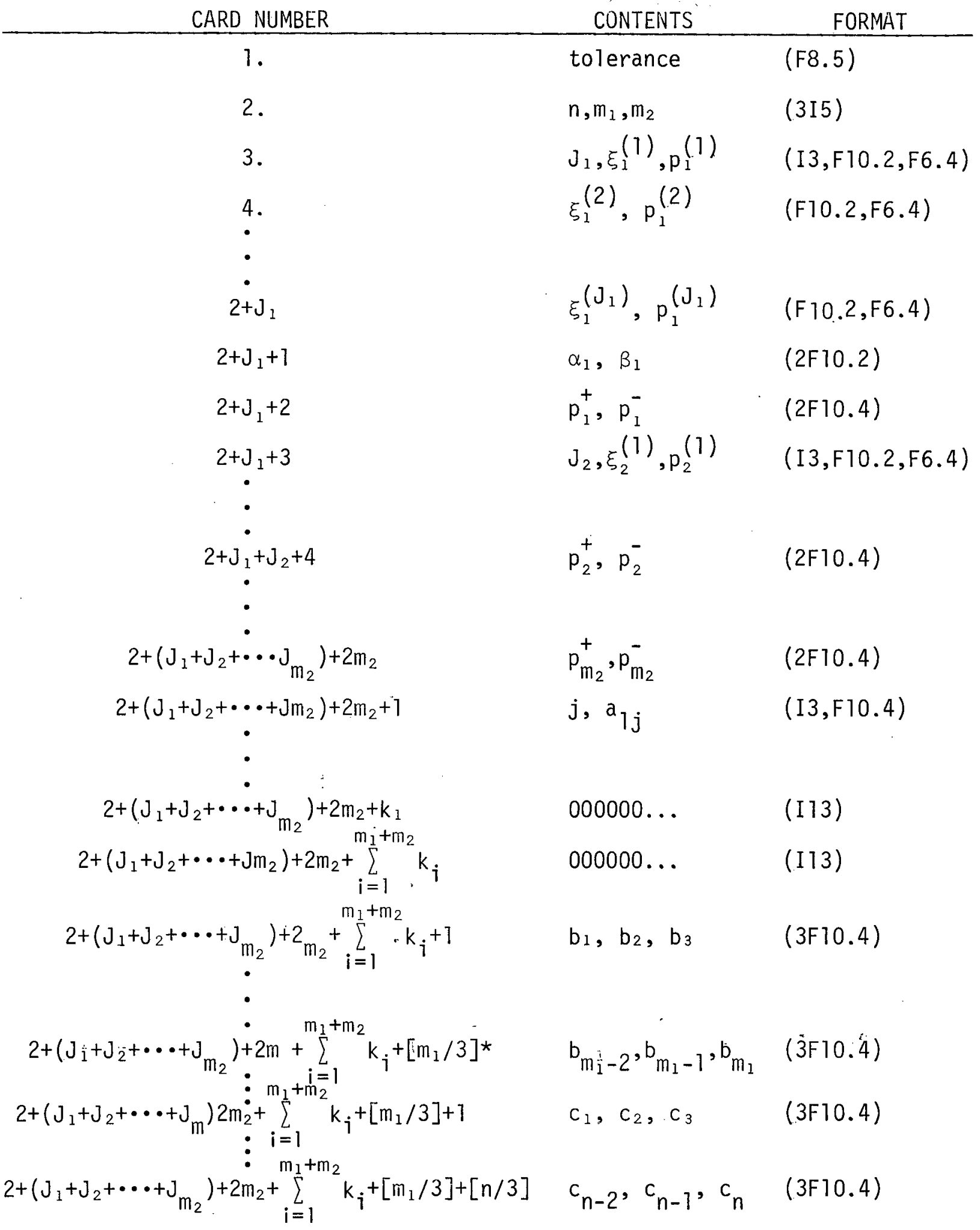

* $\left[\frac{m_{1}}{3}\right]$ is the minimum of all integers not less than $\frac{m_{1}}{3}$. 
Card 1

The user may provide his own tolerance level,

$\underline{\text { Card } 2}$

$n$ - The number of variables (not including surplus and shortage variables).

$m_{1}$ - The number of deterministic constraints.

$m_{2}$ - The number of stochastic constraints.

Card 3 (first stochastic constraint)

$\mathrm{J}_{1}$ - The number of realizations of RHS of the first stochastic constraint (with positive probability).

$\xi_{1}^{(1)}$ - Smallest possible realization of RHS of 1 st stochastic constraint.

$p_{1}^{(1)}$ - Probability of $\xi_{1}^{(1)}$ occurring.

$\underline{\text { Card } \mathrm{J}_{1}+3}$

$\alpha_{1}-$ A real number equal or less than $\xi_{1}^{(1)}$ (i.e. a lower bound on the realizations).

$\beta_{1}$ - A real number equal or greater than $\xi_{1}\left(J_{1}\right)$ (i.e. an upper bound on the realizations).

Card $2+\mathrm{J}_{1}+2$

$p_{1}^{+}$- A per unit penalty, for a shortage on the left hand side of the first stochastic constraint.

$p_{1}^{-}$- A per unit penalty, for a surplus on the left hand side of the first stochastic constraint.

Card $\left[2+\mathrm{J}_{1}+3\right]$ to $\left[2+\left(\mathrm{J}_{1}+\mathrm{J}_{2}+\cdots+\mathrm{J}_{\mathrm{m}}+2 \mathrm{~m}_{2}\right]\right.$

- Sequentially repeats process of cards 3 to $2+J_{1}+2$ for each constraint. 


\section{Cards $2+\left(\mathrm{J}_{1}+\cdots+\mathrm{J}_{m_{2}}\right)+2 m_{2}+1$}

- Now starting to input the technological coefficients -rows are listed in order and separated by a string of 0 's or blanks (at least 13) -- al1 the deterministic constraints must precede the stochastic constraints -assume $k_{j}-1$ nonzero coefficients in row $i$-- (unspecified coefficients default to 0 ).

j - Column number.

$a_{1 j}$ - Coefficient for first row and $j$ th column.

$\left.\underline{\text { Card } 2+\left(J_{1}+J_{2}+\cdots+J_{m}\right.}\right)+2 m_{2}+\sum_{i=1}^{m_{1}+m_{2}} k_{i}+1$

$b_{1}$ - Right hand side of first deterministic constraint.

$b_{2}$ - Right hand side of second deterministic constraint.

$b_{3}$ - Right hand side of third deterministic constraint.

$\underline{\text { Card } 2+\left(\mathrm{J}_{1}+\mathrm{J}_{2}+-+\mathrm{J}_{m}\right)+2 \mathrm{~m}_{2}+\sum_{i=1}^{m_{1}+m_{2}} k_{i}+\left[\mathrm{m}_{1} / 3\right]+1}$

$c_{1}$ - Cost coefficient of first variable.

$c_{2}$ - Cost coefficient of second variable.

$c_{3}$ - Cost coefficient of third variable.

Additional notes on input data and restrictions.

1. Al1 constraints must be equalities, so slacks must be added or subtracted (sign of RHS is not important).

2. The number of deterministic constraints $m_{1} \leq 150+\left(70-m_{2}\right)$.

3. The number of stochastic constraints $m_{2} \leq 70$.

4. The number of possible realizations for $\xi_{j}$ is $J_{j} \leq 8$. 
Chapter 4

\section{IMPLEMENTATION OF THE ALM MODEL}

\subsection{Introduction}

This chapter is concerned with results of an application of the ALM model to the asset and liability portfolio problem of Vancouver City Savings Credit Union (VCS). In addition to these results, some of the procedural aspects of implementing the model for this and related problems are discussed. This thesis, in fact, was prompted by the real life problem continuously facing this particular credit union a liquidity problem.

Some of the salient characteristics of VCS during the five year planning period studied, 1970 to 1974, are: 1) the firm's assets grew at a compound rate of $57 \%$ from $\$ 26$ million to $\$ 160$ million, and 2) the firm adopted an aggressive policy of investing in high yielding assets (predominantly mortgages). In 19774, vCS realized that the combination of their aggressive investment policy and changing market conditions was creating serious liquidity problems. Investors were trading their low yielding term deposits for higher yielding deposits. At the same time the outstanding mortgage loans of VCS were still : earning returns on the basis of the lower interest rate structure. It was at this moment that the first version of this study was initiated. 
The approach first taken was to construct a five year linear programming planning model based upon the Chambers and Charnes formulation [11]. The objective of the VCS formulation was to maximize net discounted returns which are given by the total discounted returns minus the total discounted costs. There were four types of constraints:

1) the legal constraints as prescribed by the Credit Unions Act of British Columbia [8], 2) the liquidity constraints which are similar to inequalities (4) and (5) in chapter 2, 3) the budget constraints that include the initial conditions and a statement of the accounting identity - the uses of funds are equal to the sources of funds, and 4) the policy constraints which include the internal operating policies of VCS and the terminal conditions to insure that the structure of the final portfolio of assets and liabilities maintains continuity of operations.

The basic shortcoming of the above formulation is that it does not incorporate the inherent uncertainty of unknown cash flows and interest rates. As an initial attempt to overcome this drawback, a decision theoretic approach was taken. The procedure was to first make point estimates of future interest rate structures and potential growth rates of VCS'S assets. Then, for each possible combination of interest rate structure and growth rate, the linear program was executed. This would then yield a set of solutions. The steps necessary to find the 'best' solution can be summarized: 1) finding the optimal solution vector for each state of nature, 2) computing the resulting net 
present values for each optimal solution from step 1) for each of the remaining states of nature, (This can be accomplished by forcing the solution to be the same as in step 1) for each state of nature. If infeasibility is reached then the debt constraints are relaxed to attain feasibility), 3) using subjective probabilities for the likelihood of each state of nature, an expected value for each decision in step 1) was computed, and 4) from step 3) selecting that action which has the highest expected net present value. Mathematically, steps 3 ) and 4) are represented by

$$
E\left(N P V_{k}\right)=\sum_{i=1}^{m} \sum_{j=1}^{n} N P V_{i j k} P\left(\theta_{i j}\right)
$$

and choosing $k^{*}$ such that $E\left(N P V_{k^{*}}\right) \geq E\left(N P V_{k}\right)$ for all k. Where $\theta_{i j}$ is the state of nature with the $i$ th interest rate structure and the $j$ th growth rate and $i=1, \ldots, m$ and $j=1, \ldots, n ; P\left(\theta_{i j}\right)$ is the probability of $\theta_{i j}$ occurring; $N P V_{i j k}$ is the net present value of choosing strategy $k$ when $\theta_{i j}$ occurs for $k=1, \ldots,(n \times m)$; and $k^{*}$ is the optimal strategy.

Alternative criteria such as minimax can be used to find a 'best' solution instead of steps 3) and 4). However, in general, this approach is not very appealing for the following reasons: 1) the $k^{*}$ chosen is in no way optimal, for there may exist a solution $k$ which is not optimal for any particular state of nature, but has a higher expected net present value; and 2) the model does not incorporate any means of 
evaluating the economic consequences of infeasibility, for example there may be a particularly disastrous realization that results in insol vency.

As described in Chapter 2, a number of other approaches have been proposed to model the problem, but, at best these models have only limited applicability. Hence a different approach to the problem was necessary. This led to the ALM formulation. The ALM model does incorporate uncertainty while maintaining computational tractability for large problems.

As already stated the purpose of this chapter is to demonstrate the applicability of the ALM model. Specifically, there are three major domains where it can be demonstrated: 1) the usefulness of the model in terms of the results to be used by management, increased profitability and superiority of the equivalent deterministic problem; 2) the ease of application, and 3) that this model does in fact have the features attributed to $i t$, before comparing it to the 'best' alternative solution technique - the Bradley and Crane model. Hence the remainder of this chapter is concerned with the implementation and results of the ALM model to VCS for the planning period 1970-74. 


\subsection{Model Details}

The aim of this section is to describe the input necessary for the implementation of the ALM model to Vancouver City Savings Credit Union. It will include the method of data collection, the choice of decision variables, and the actual constraints and objective function used in the application. The purpose is to indicate the effort required to implement the ALM model rather than to demonstrate the very difficult problems of estimation. The actual data used are given in Appendix 1 at the end of this chpater. Since presenting the data in matrix form would be rather cumbersome (the matrix is 92 by 257), they are presented in input form (as described in Chapter 3, Appendix 2).

The ALM model being a SLPR model implies that there are first and second stage decision variables. The first stage variables are divided into assets, $x_{i j}^{k}$, and liabilities, $y_{i}^{d}$ and $b_{j}$ (as defined in Chapter 3). Eleven types of assets are considered in this application. They are: 1) cash, 2) British Columbia Credit Union shares,

3) federal government bonds maturing in $i$ years $(i=1, \ldots, 4)$,

4) federal government bonds maturing in five to ten years, 5) provincial government bonds maturing in more than ten years, 6) first and second mortgages with a three year term, and 7) personal loans. Six types of liabilities are considered. They include: 1) demand deposits, 2) share capital of VCS, 3) borrowing from banks, and 4) term deposits maturing in $i$ years $(i=1,3,5)$. Specifically, if a 
four year federal government bond is purchased at the beginning of the third time period, this will generate decision variables $x_{34}^{6}, x_{35}^{6}$ and $x_{3 \infty}^{6}$, where $x_{34}^{6}$ and $x_{35}^{6}$ are the portions of the initial investment to be sold in periods four and five, respectively and $x_{3 \infty}^{6}$ is the portion to be held at the horizon of the model. The eleven types of assets generate 136 variables (including the initial positions) and the six types of liabilities generate an additional 36 variables (including the initial positions) for the five year planning period. The choice of these assets and liabilities was based on VCS's historical portfolios of assets and liabilities [85]. The reason for such a choice was to maintain a basis of comparison between the actual portfolios and the portfolios yielded by the ALM formulation.

Before detailing the specifics of the model, it is important to note that although the cash flows are continuous over time, the model assumes that all transactions occur at the beginning of periods. Cash flows during any period are treated assuming that half the cash flows occur at the beginning of the present period and the other half at the beginning of the next period. The constraints will now be described. 


\section{a. Legal Constraints}

The source for the legal constraints is the Credit Union Act of British Columbia [8]. This act places three operational restrictions on the composition of the portfolio of assets and liabilities. The first constraint is that credit unions maintain at least $10 \%$ of the total assets, $\sum_{i \varepsilon I} x_{i t}$, in highly liquid assets, $\sum_{i \varepsilon I_{L}} x_{i t}$, that is

$$
\sum_{i \in I_{L}} x_{i t} \geq .1 \sum_{i \in I} x_{i t} .
$$

The second requirement is that credit unions maintain at least $1 \%$ of their total debt, $\sum_{i \in D} Y_{i t}$, in cash and term deposits, $X_{1 t}$ and $x_{2 t}$, respectively,

$$
x_{1 t}+x_{2 t} \geq .01 \sum_{i \varepsilon D} Y_{i t}
$$

The final constraint restricts the credit union's borrowing, $\sum_{b \in B} Y_{b t}$ to one half of the total liabilities,

$$
\sum_{b \in B} Y_{b t} \leq .5 \sum_{i \varepsilon D} Y_{i t}
$$

Since the planning horizon is for five periods, the legal requirements account for fifteen constraints in the formulation. 


\section{b. Budget Constraints}

Of the twenty-two constraints in this set, the first seventeen establish the initial positions of the eleven types of assets and six types of liabilities, while the other five constraints require the sources of funds to be equal to the uses of funds in each period. These constraints were constructed directly from the budget constraints in the ALM formulation, as in Chapter 3 . The way in which the actual numbers utilized in these equations were determined, will be part of the discussion on the objective function.

\section{c. Liquidity Constraints}

The function of the liquidity constraints is to ensure that the firm has sufficient capital reserves to meet severe withdrawal claims under adverse economic conditions. The constraints follow from the Federal Reserve Board's capital adequacy formula [27]. The application of the FRB's capital adequacy formula to British Columbia's credit unions is justified in a study published by the Credit Union Reserve Board [25].

The first three constraints establish capital reserves based upon the structure of the portfolio of assets and liabilities.'

$$
P_{i} \geq q_{i}\left(W-k_{k \in K_{j} \cup \ldots \cup K_{i}}{ }_{k} k^{k}\right) \quad i=1,2,3
$$

1 The same notation is used as in Chapter 3, Section 2. 
where $W$ is the dollar value of the expected withdrawal. claims under adverse economic conditions, $w=\sum_{i=1}^{m} \gamma_{i} y_{i}$, where $\gamma_{i}$ measures the contraction of liability $y_{i}$ under adverse economic conditions. The $\gamma_{j}$ 's used were .47 for demand deposits, . 36 for term deposits and 1.0 for borrowing. The parameters are justified in [25]. The $\alpha_{k}$ in (1) is a parameter that measures the realizable portion in the value of asset $k$ if the asset is to be liquidated quickly under adverse economic conditions. The $q_{j}$ measures the reserves required for potential withdrawal claims that exceed the realizable portion of the assets contained in $K_{1} \cup \ldots \cup K_{j} . P_{j}$ is the required reserve necessary to meet the excess withdrawal claims.

Finally, the principal constraint in the capital adequacy formula can be stated as,

$$
\sum_{i=1}^{K}\left(1-\beta_{i}\right) x_{i} \geq \sum_{i=1}^{3} P_{i}+\left\{\begin{array}{l}
\text { total right hand - equity - surplusi } \\
\text { side of balance } \\
\text { sheet }
\end{array}\right\}
$$

where $\beta_{j}$ is a parameter to measure the shrinkage of asset $i$, when the asset is to be liquidated quickly. The actual numbers used for $\alpha_{k}, q_{j}$, and $\beta_{j}$ are the same as those prescribed by the FRB [27]. Since the purpose here is not to develop an operational model for VCS, but rather to demonstrate the applicability of the ALM model, the numbers used for the above parameters provide an adequate proxy. However, in the development of an operational model it would be necessary to estimate the parameters. 
Since these constraints have to hold for all five periods, it is implied that there are twenty liquidity constraints.

\section{d. Policy Constraints}

Two types of policy constraints are included: 1) personal loans made in period $t\left(x_{t L}\right)$ should be equal to or less than .2 of the first mortgage loans made in period $t\left(x_{t m}\right), x_{t L} \leq .2 x_{t m}$, and 2) second mortgages made in period $t\left(x_{t s}\right)$ should be equal or less than .125 of first mortgages, $x_{t s} \leq .125 x_{t m}$.

The rationale for such investment policies is that the returns on the first mortgages are less risky (smaller deviations), compared to second mortgages or personal loans even though the latter may yield a better return. This is consistent with management's preference may be violated without any legal implications. These features are readily incorporated by treating the constraints as though they were stochastic. Since the objective here is merely to demonstrate the applicability of the ALM model, in this application $\left(\mathrm{p}^{+}, \mathrm{p}^{-}\right)$is $(0,1.0)$, which suggests that the constraints will not be violated. For the five periods, the above two policy conditions generate ten constraints.

\section{e. Deposit Flows}

The variable $y_{j}^{d}$ represents the new deposits of type $d$ $(d=1, \ldots, 5)$ generated in period $j(j=1, \ldots, 5)$ and $\xi_{j d}$ is a discrete 
random variable representing the balance sheet figure of deposit type $d$ at the end of the $j$ th period. The amount of $y_{j}^{d}$ generated is established in the deposit flow constraint as follows:

$$
y_{j}^{d}+\sum_{j=D}^{j-1} y_{i}^{d}\left(1-\gamma_{d}\right)^{j-1}+y_{j d}^{+}-y_{j d}^{-}=\xi_{j d} .
$$

The $\gamma^{\prime}$ 's used were 1.0 for demand deposits and .36 for term deposits. The $\gamma^{\prime} s$ are included to reflect the actual (and not net) flow of deposit funds. The distribution of $\xi_{j d}$ was estimated by using the actual balance sheet figures of VCS for 1970-74 as the mode of the distribution and constructing a distribution of values around this mode. $\xi_{j d}$ had different probability distribution assumptions for varying runs of the VCS application. The first distribution used is shown in Appendix 1.

The penalties for shortages associated with these constraints are: 1). for demand deposits and share capital, $\mathrm{p}^{+}$is the total discounted returns on a one year term deposit minus the discounted cost of the funds calculated to the horizon of the model, 2) for term deposits maturing in one or three years, $\mathrm{p}^{+}$is the total discounted returns on a five year term deposit minus the discounted cost of the funds calculated to the horizon of the model, and 3) for term deposits maturing in five years, $\mathrm{p}^{+}$is the total discounted returns on a ten year provincial government bond minus the discounted cost of the funds calculated to the horizon of the model. The penalties $\mathrm{p}^{-}$, for surpluses associated with 
the deposit flow constraints are the total discounted returns on first mortgages minus the discounted costs of funds calculated to the horizon of the mode1. The $\mathrm{p}^{+}$and $\mathrm{p}^{-}$attempt to reflect a conservative strategy, on the part of management, as to what policy decisions to make: 1) with the surplus funds available when realized sources exceed uses, and 2) with the shortage of funds when uses exceed realized sources, respectively.

\section{f. Objective Function}

The objective is to maximize the expected total discounted revenues minus the expected total discounted costs and minus the expected penalty costs. The data were gathered from a number of sources. The source for the returns on the federal and provincial government bonds was [10]. The source for the returns on BCCU shares, mortgages and personal loans and the cost of the term deposits, demand deposits and share capital was [85].

The discount rate used was the time value of money. To obtain $i t$, the risk free rate (the average yield on three month treasury bills) was used. These rates are as follows [10]:

\begin{tabular}{|c|c|c|c|c|c|}
\hline & 1970 & 1971 & 1972 & 1973 & 1974 \\
\hline $\begin{array}{l}\text { Average yearly } \\
\text { yield }\end{array}$ & .0599 & .0356 & .0356 & .0547 & .0782 \\
\hline \multirow[t]{3}{*}{ discount factor } & 1 & .9435 & .911 & .8797 & .8341 \\
\hline & 1.0599 & 1.0356 & 1.0356 & 1.0547 & 1.0782 \\
\hline & .9435 & .911 & $=.8797$ & $=.8341$ & $=.7736$ \\
\hline
\end{tabular}


The returns on the assets are as follows $[10,85]$ :

Returns on Asset in Year

$\begin{array}{llllll}1969 & 1970 & 1971 & 1972 & 1973 & 1974\end{array}$

Type of Asset

1 year federal government bond

\begin{tabular}{|c|c|c|c|c|c|c|}
\hline$(\mathrm{fgb})$ & .0725 & .0620 & .0450 & .0510 & .0610 & .0800 \\
\hline 2 year fgb & .0749 & .0657 & .0490 & .0550 & .0654 & .0803 \\
\hline 3 year $f g b$ & .0758 & .0684 & .0525 & .0590 & .0680 & .0807 \\
\hline 4 year fgb & .0767 & .0710 & .0555 & .0626 & .0698 & .08 \\
\hline 5 year fgb & .0776 & .0758 & .0615 & .0674 & .0717 & .08 \\
\hline $\begin{array}{l}10 \text { year provin- } \\
\text { cial government } \\
\text { bond }\end{array}$ & .0840 & .0904 & .0803 & .0813 & .0836 & .09 \\
\hline first mortgage & .0938 & .1040 & .0943 & .0921 & .0959 & .1124 \\
\hline second mortgage & .1050 & .1220 & .1108 & .1083 & .1123 & .7321 \\
\hline personal loans & .1040 & .1170 & .1075 & .1050 & .1075 & .12 \\
\hline B.C.C.U. shares & .0600 & .0600 & .0600 & .0600 & .0700 & . \\
\hline
\end{tabular}

If one were to purchase a five year federal government bond in 1970 , the decision variables $x_{12}^{7}, x_{13}^{7}, x_{14}^{7}, x_{15}^{7}$, and $x_{1 \infty}^{7}$ would be generated. The returns would be calculated as follows: 
Decision

Variable

$$
\begin{array}{ll}
\frac{x_{i j}}{x_{12}^{7}} & \frac{\text { Return } r_{i j}^{7}}{(.0758)}(.9435)=.0720 \\
x_{13}^{7} & (.0758)(.9435+.9110)=.1410 \\
x_{14}^{7} & (.0758)(.9435+.9110+.8797)=.2070 \\
x_{15}^{7} & (.0758)(.9435+.9110+.8797+.8341)=.2700 \\
x_{1}^{7} & (.0758)(.9435+.9110+.8797+.8341+.7736)=.3290
\end{array}
$$

The return is the interest earned every year discounted back to the beginning of the planning horizon. The returns on all assets were determined similarly.

The costs of the liabilities are as follows [85]:

Type of

Liability

$\begin{array}{lcccccc} & 1969 & 1970 & 1971 & 1972 & 1973 & 1974 \\ \begin{array}{l}1 \text { year term } \\ \text { deposit }\end{array} & .0712 & .0780 & .0720 & .0680 & .0780 & .0990 \\ \begin{array}{l}\text { year term } \\ \text { deposit }\end{array} & .0712 & .0820 & .0760 & .0690 & .0820 & .0980 \\ \begin{array}{l}\text { year term } \\ \text { deposit }\end{array} & .0785 & .0850 & .0800 & .0800 & .0850 & .0975 \\ \begin{array}{l}\text { demand deposit } \\ \text { share capital }\end{array} & .0400 & .0460 & .0410 & .0420 & .0560 & .0770 \\ & .0500 & .050 & .050 & .055 & .0575 & .0800\end{array}$

The cost of a five year term deposit $\left(y_{1}^{3}\right)$ sold during 1970 would be determined as follows: 
Year $\mathrm{i}$

1970

1971

1972

1973

1974
Cost Incurred in Year $\mathrm{i}$

$$
\text { (.5) }(.0850)(.9435)=.0401
$$

(.82) $(.0850)(.9110)=.0635$

$(.82)(.64)(.0850)(.8797)=.0392$

$(.82)(.64)^{2}(.0850)(.8341)=.0238$

$(.82)(.64)^{3}(.0850)(.7736)=.0141$

The total discounted cost of $y_{1}^{3}$ is .1807.

In an actual implementation further refinements would be required. Firstiy, although the time value of money was utilized as the discount rate, a risk adjusted discount rate should be used to reflect varying degrees of riskiness of investments, see for example [84]. Secondly, liability management, for example "controlling" the deposit flows, cannot be directly included in the framework of the ALM model. In contrast to the linear treatment of asset management, liability management might typically involve alternative interest rate structures inducing alternative distributions of deposit flows. Finally, most asset and liability management models do not include any systematic approach to liquidity constraints, but rather make use of the judgement of bank managers in prescribing maximum levels for either capital losses or limits on the amount of investment in assets. It is desirable to maintain some level of consistency in matching the liquidity characteristics of assets and liabilities across banks. Thus although the parameters utilized by the Federal Reserve Board may not be valid, the general structure of these constraints are, and these would have to be more carefully estimated. 
4.3 Results of The Vancouver City Savings Credit Union Application

It will be recalled that there are two purposes of this application: 1) to demonstrate the applicability of the ALM model, and 2) to test the sensitivity of the solution generated. To accomplish these goals, the model was run initially with the data given in Appendix I (basic mode1), secondly by replacing all random variables with their expected values (deterministic equivalent), and finally with variants of the basic model (with respect both to the penalty costs and the probability distributions).

Before presenting the detailed results of the application, several general statements can be made concerning the ALM model in particular and SLPR models in general: 1) the initial portfolio held by VCS violates the liquidity constraints (a situation which was known to management), 2) the stochastic models yielded solutions that were superior to the deterministic equivalent, ${ }^{1}$ and 3) the nature of the probability distributions and the penalty costs markedly affects the optimal solution.

The basic model has symmetric three point probability distributions $(.2, .6, .2)$ for $a 11$ the deposit flow constraints and degenerate probability distributions for the liquidity and policy constraints. The penalties for all stochastic constraints are asymmetric. The optimal

1 Madansky in [56] has shown that the 'deterministic equivalent' provides a lower bound on the optimal value of a SLPR. 
value of the basic model is $\$ 2,520,316.01 \quad(\$ 8,288,941.53$ in expected profits minus $\$ 5,768,625.52$ in expected penalties). The deterministic equivalent model has an optimal value of $\$ 2,278,187(\$ 8,565,068$ in expected profits minus $\$ 6,286,885$ in expected penalties). Thus the bound provided by the deterministic equivalent is $10.6 \%$ below the optimal value of the basic model. The structure of the two portfolios is similar in the initial period. However, the investment patterns differ beyond the first time period. The basic model did not invest as heavily in the less liquid assets (namely mortgages).

The deterministic equivalent model also had an empty feasible set when it was first run. The reason was that VCS's initial portfolio did not satisfy the liquidity constraints. In order to secure feasibility, variables were added to each of the liquidity constraints. The objective coefficients of these variables were the same as the penalties associated with violating the stochastic liquidity constraints in the basic model. As a further insight into the operations of VCS, the penalties could be set arbitrarily high so that the model would violate the liquidity constraints only to attain feasibility. The amount by which the constraints are violated will be the amount of liquid reserves that the firm needs to meet the FRB's liquidity requirements.

Variants of the basic model were run in order to ascertain the effects of different probability distributions, various penalty cost and parameter changes. The initial change instituted in the basic model 
was the alteration of the first legal constraint from the requirement that current assets be equal to or greater than $10 \%$ of the liabilities to equal or greater than $1 \%$ of the liabilities. The effect of this change was to increase the optimal value to $\$ 2,906,773.53(\$ 8,657,619.24$ in expected profits minus $\$ 5,750,845.71$ in expected penalties). For the initial two periods, the investment pattern deviated substantially from that of the basic model in that more of the incremental funds were allocated to longer term assets. After the first two periods there did not seem to be any generalized behavior in the investment patterns of the two models. However, there was a larger total amount invested in longer term assets in the modified formulation.

The basic model was then further altered to include a change in the probability distribution $(.05, .50, .45)$ of the cash flows. The increase in the optimal value was much more dramatic in this case. The optimal value jumped to $\$ 3,256,500.65(\$ 8,872,911.53$ in expected profits minus $\$ 5,661,410.80$ in expected penalties). The expected net profit rose with respect to both the basic model and the model with the parameter change while at the same time the expected penalty costs decreased with respect to both models. This is explained by: 1) all the violations of stochastic constraints are now infeasible only with a probability .05 instead of .2 (that is the penalties decreased) and 2) constraints which were not previously violated because of excessive penalties are now violated by 15\% (implying more profits). This demon- 
strates the need for accurate estimates around the values on the left hand side of a stochastic constraint.

Although it is not possible to make definitive generalizations from the runs of the ALM model described above, some general conclusions may be inferred. First, the asymmetry of the probability distributions may have a substantial effect on the optimal solutions and values. Also an important point to note is the sensitivity of the estimate of the probability distribution around the value on the left hand side of the stochastic constraints. Second, the solutions are sensitive to changing penalty costs. Third, the various stochastic models have substantially different solutions than the equivalent deterministic models. This indicates that reliance on the deterministic models as normative tools can lead to erroneous solutions. Fourth, the implementation of this model is not more difficult than the implementation of a similar deterministic model. Finally, the computations necessary to solve the ALM formulation are of the same order as the computations necessary for an equivalent deterministic problem. All the runs were computed on the University of British Columbia's IBM 370/ 168. It will be recalled, that the ALM formulation is 92 by 257 with 40 stochastic constraints. Using the SLPR code, the solution of the ALM model took about 37 seconds of CPU time. To solve an equivalent sized deterministic problem using the SLPR code took about 30 seconds of CPU time. The same deterministic linear program was also solved on 
a standard L.P. code, UBC LIP which took 17 seconds of CPU time. These and a number of other runs indicate that CPU times for stochastic models are generally about double that of equivalent deterministic models. 
4.4 Appendix One

The following is the input data for the basic model. 


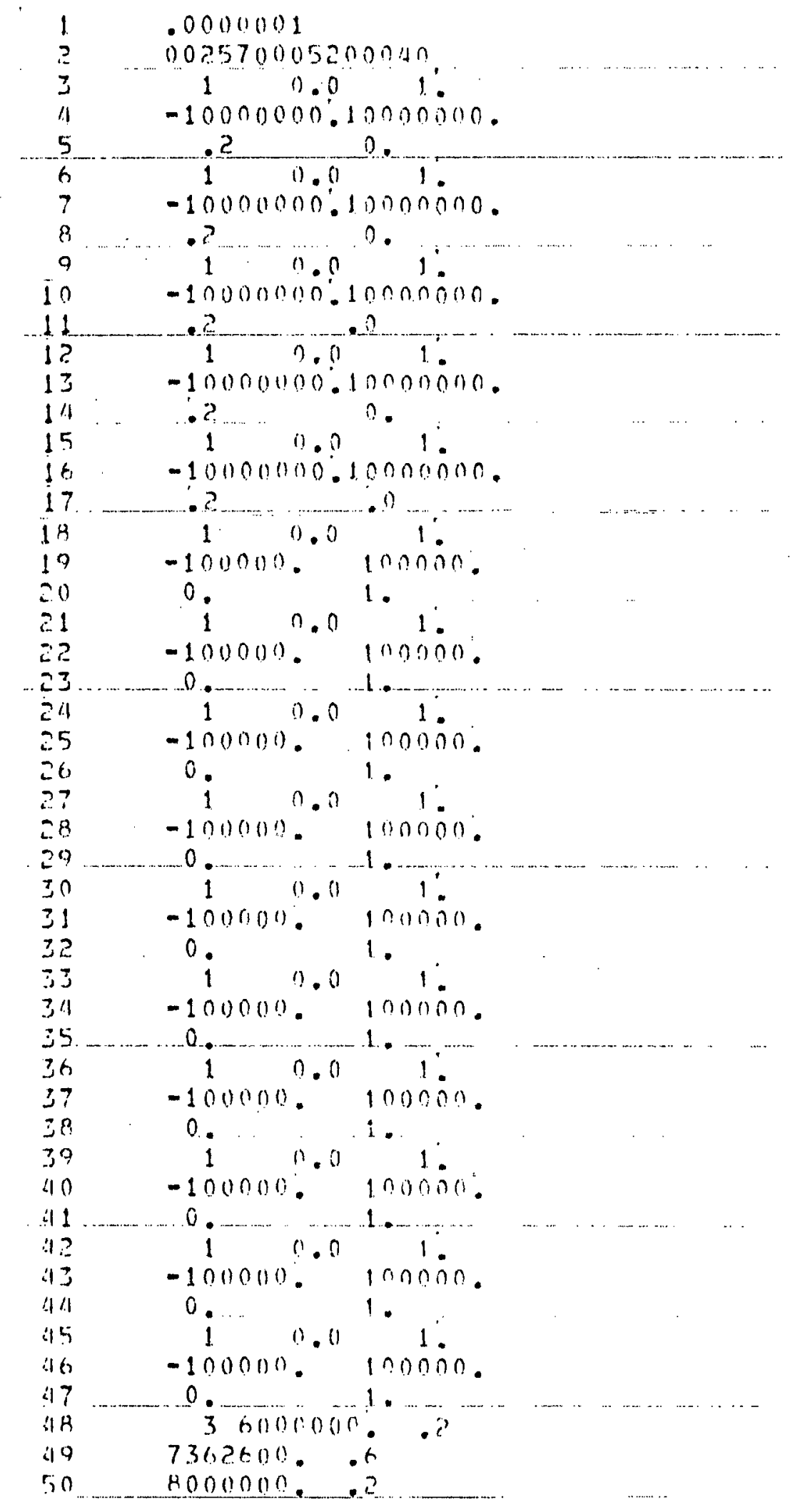




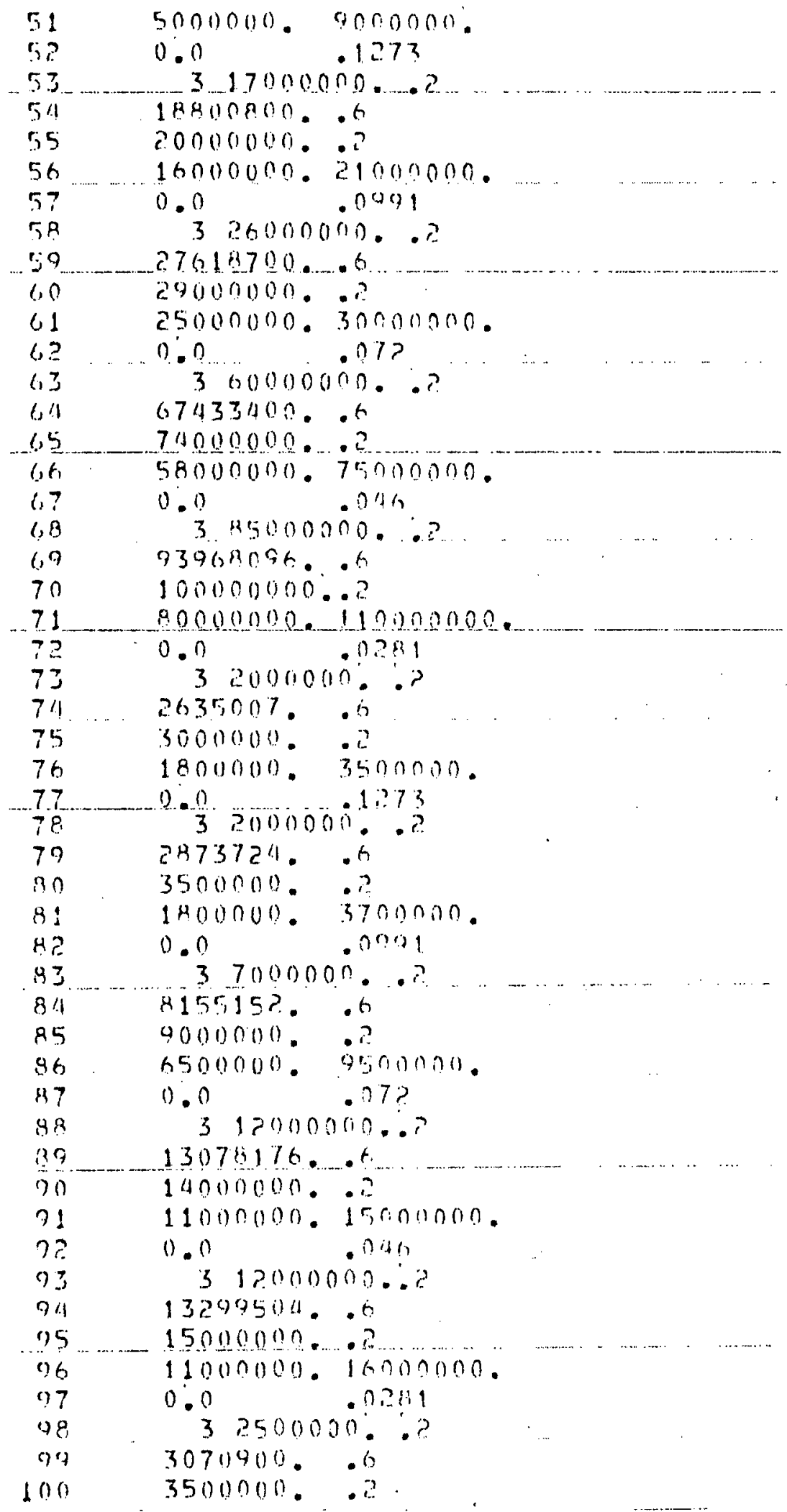




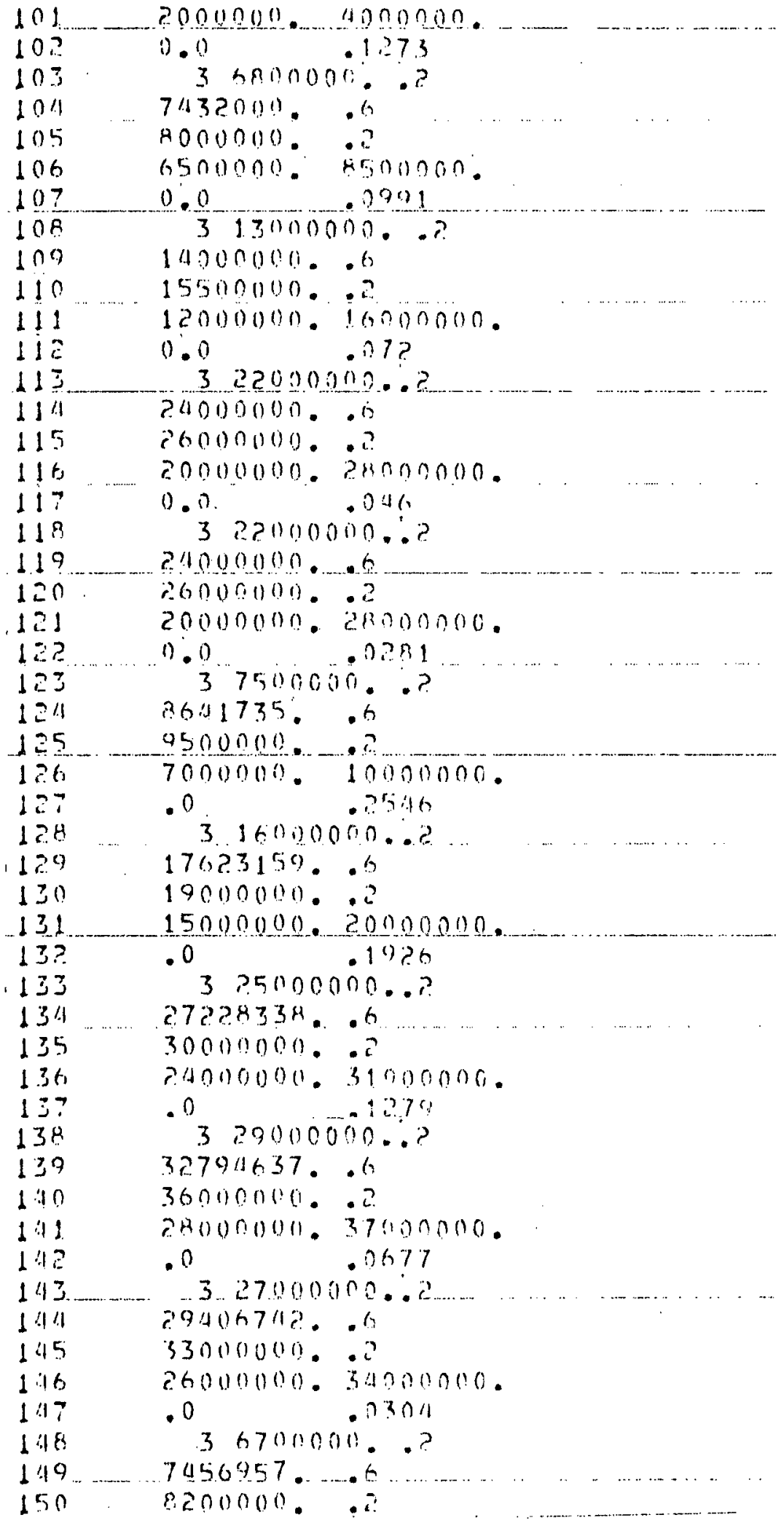




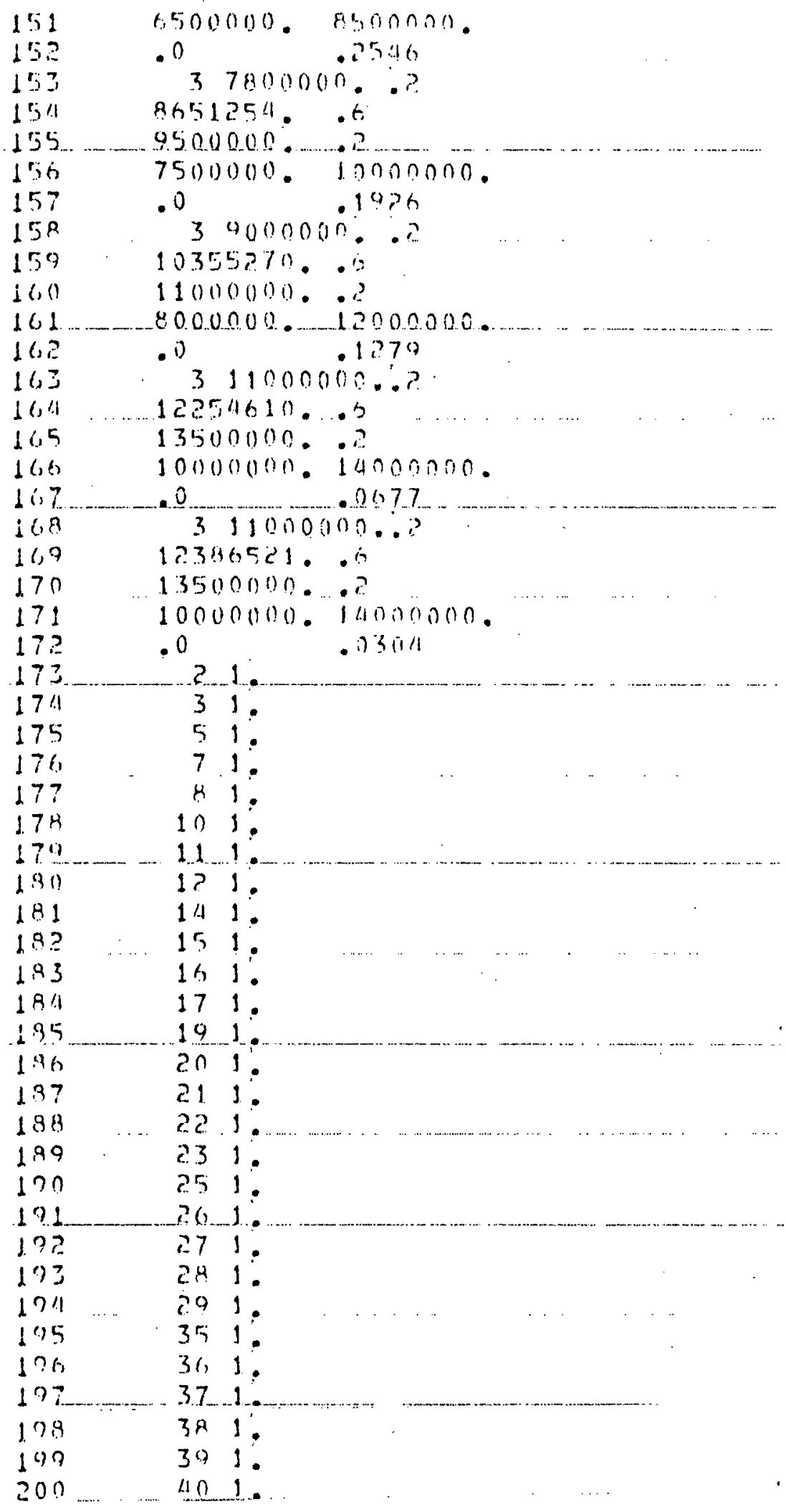




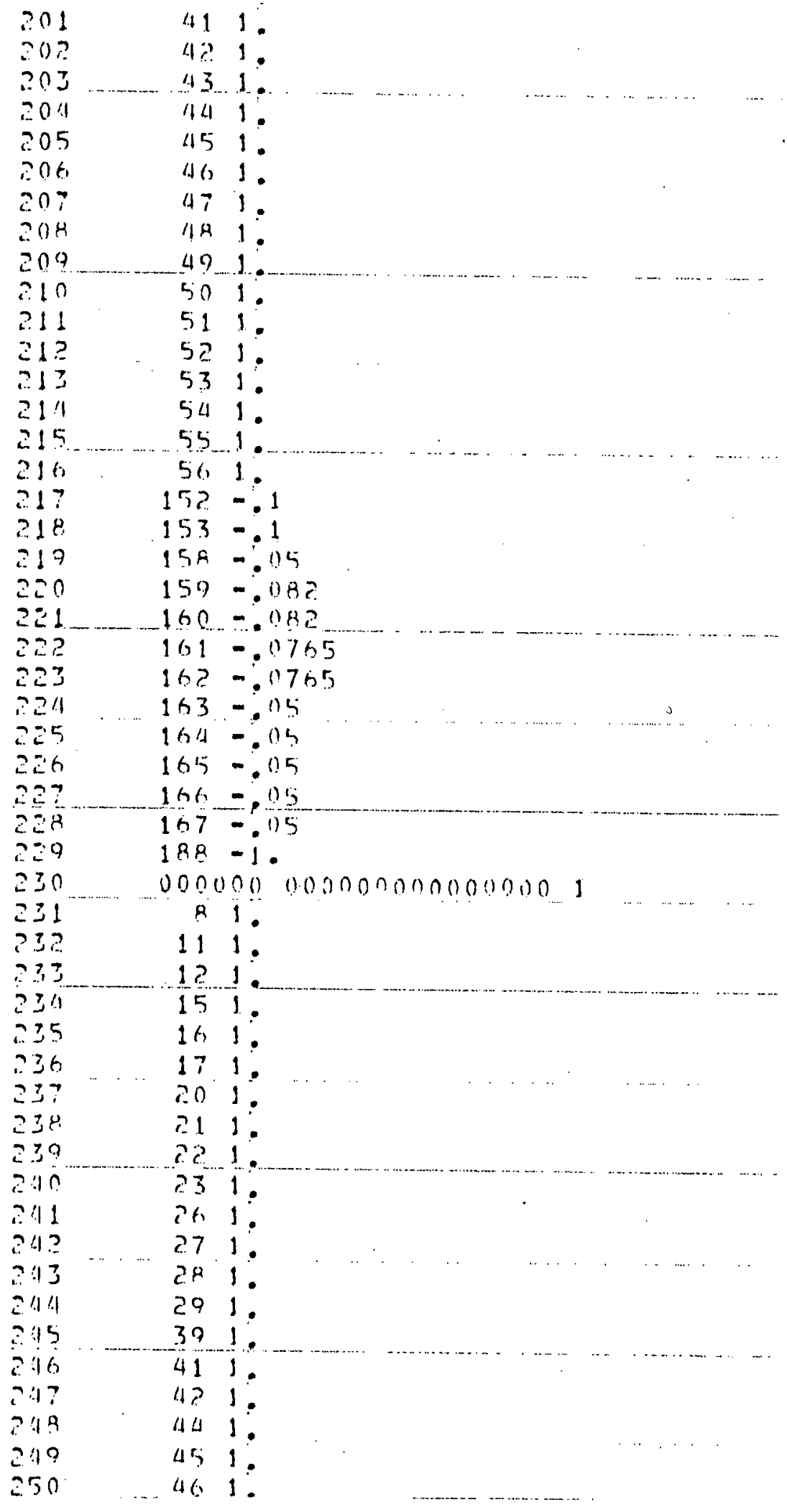




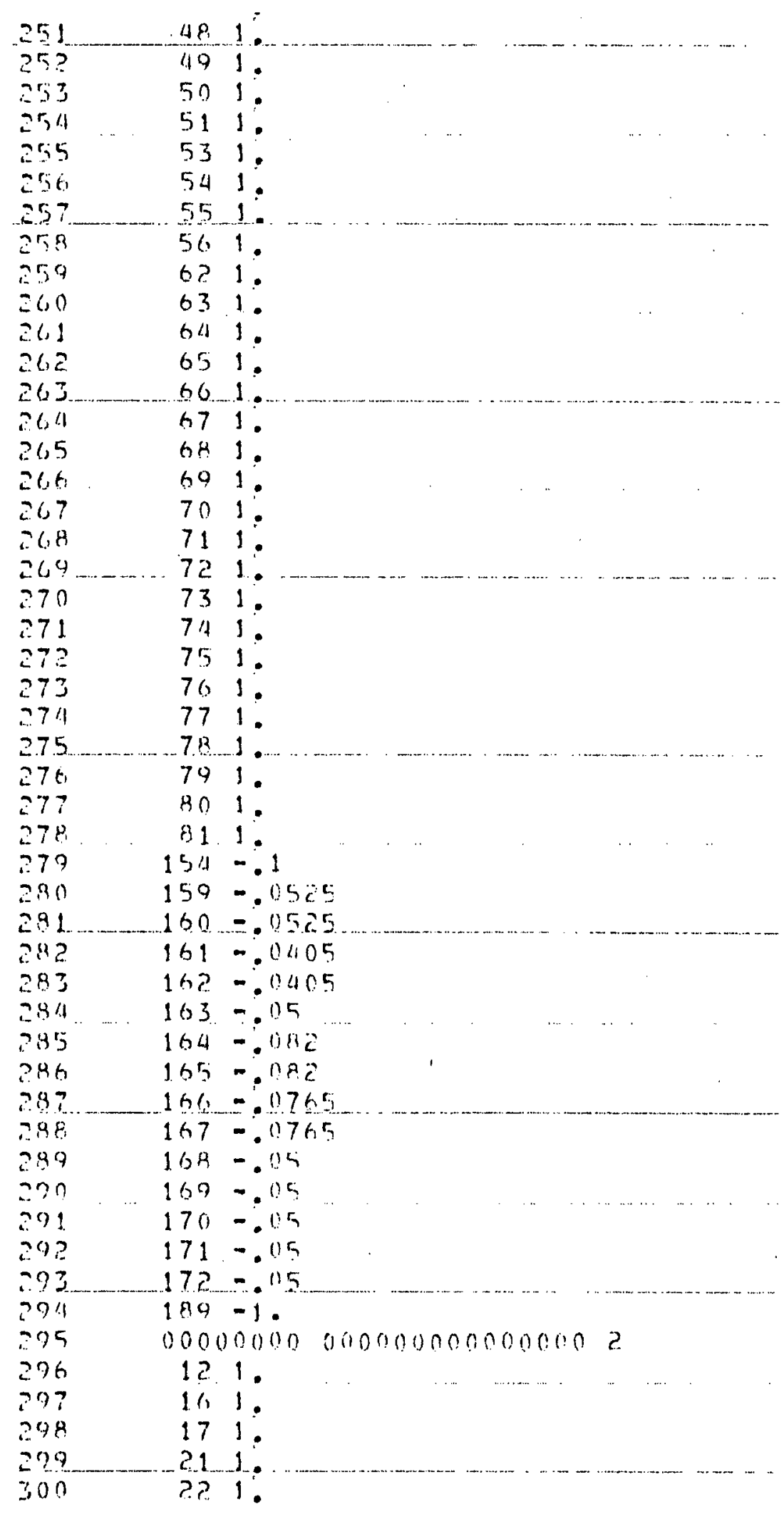




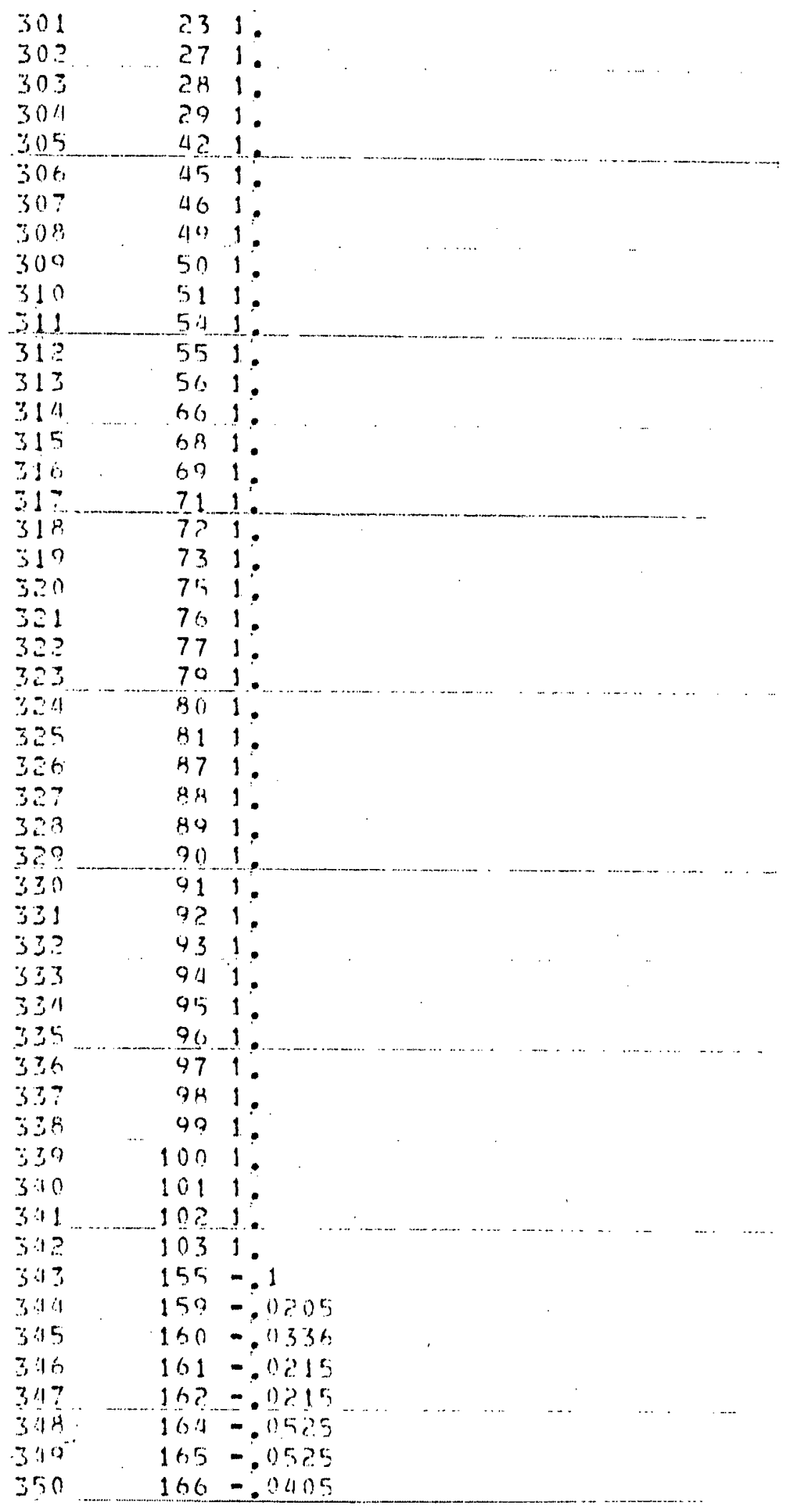




$$
\|
$$




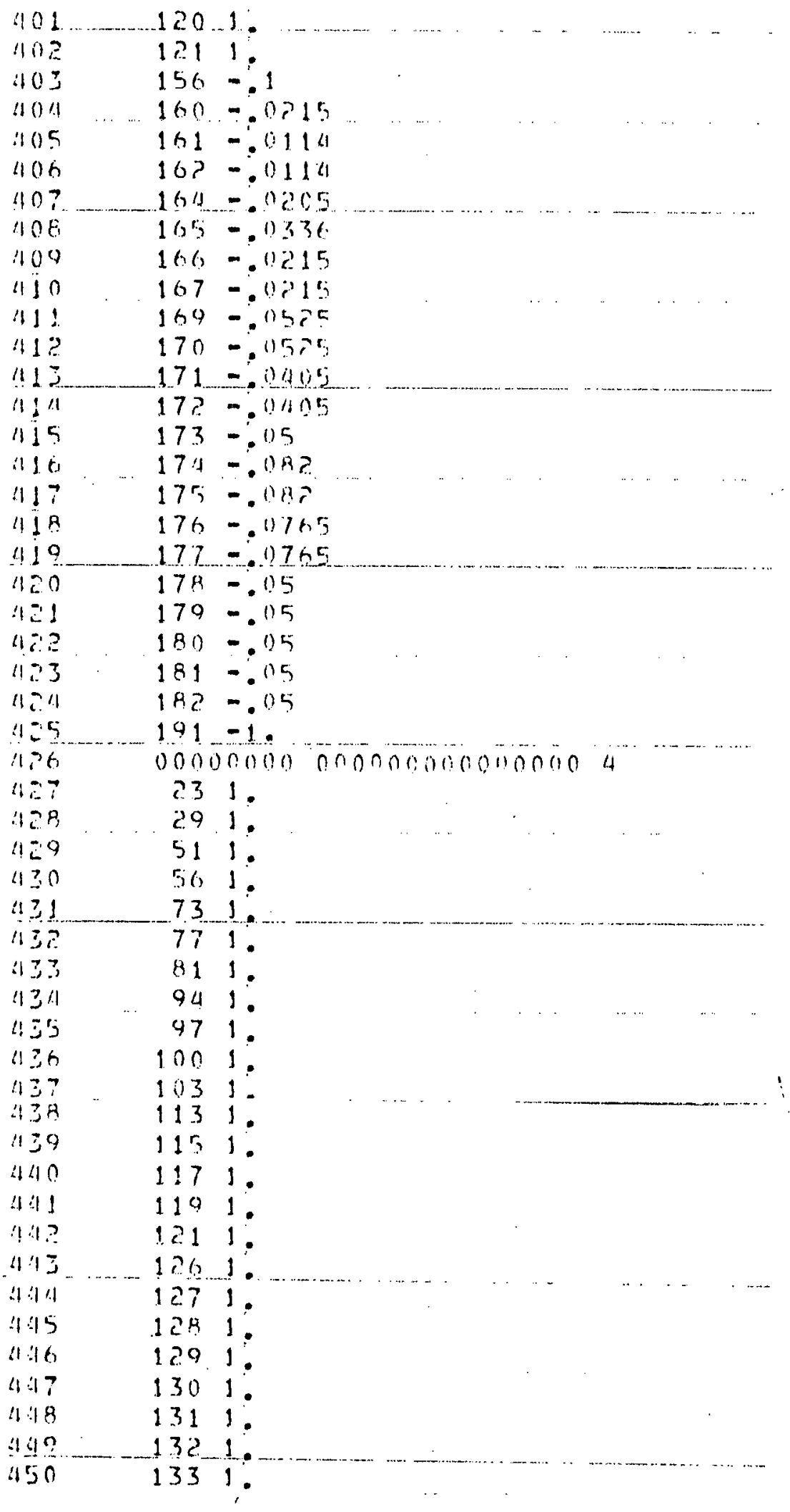




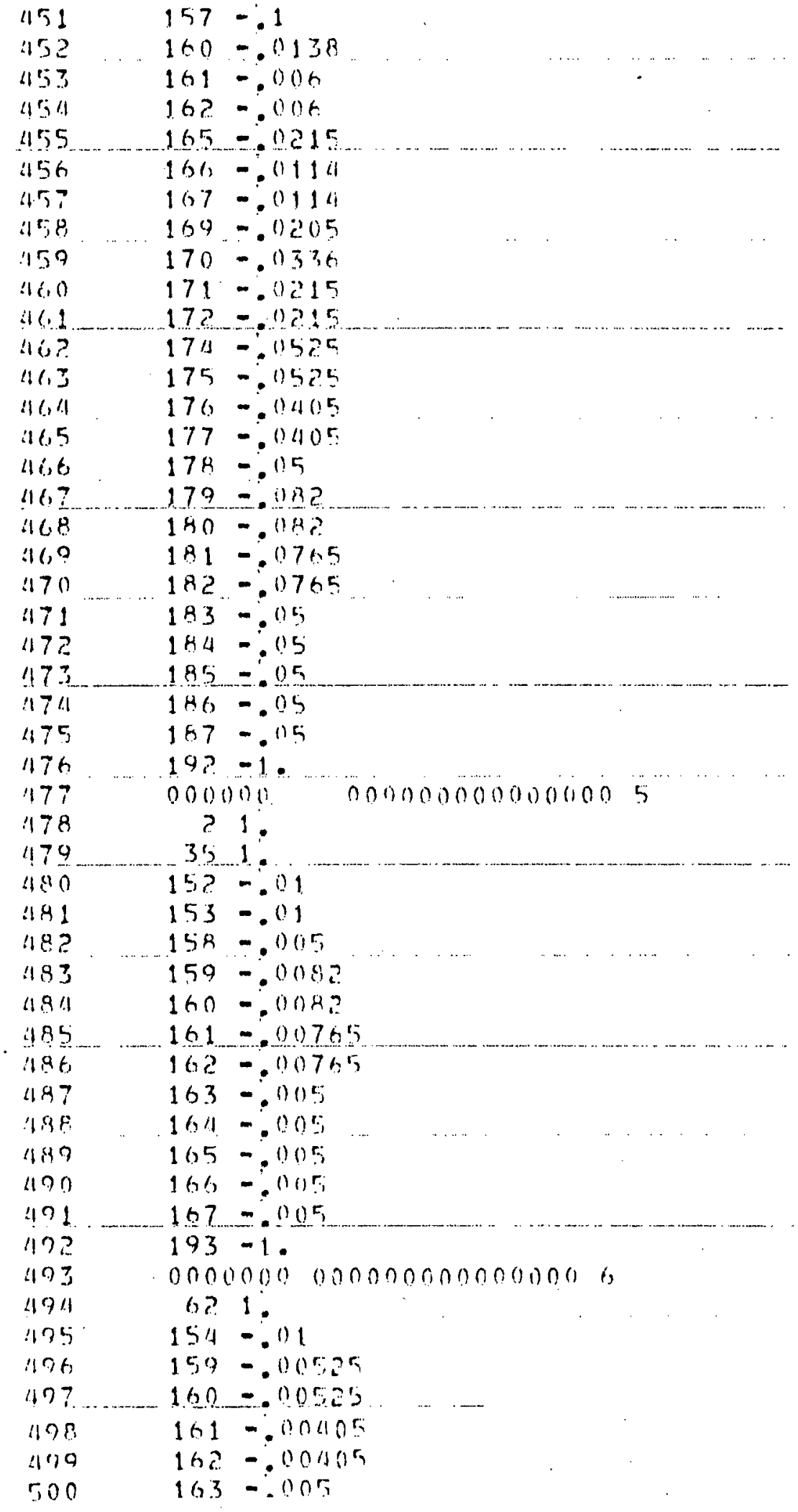


124

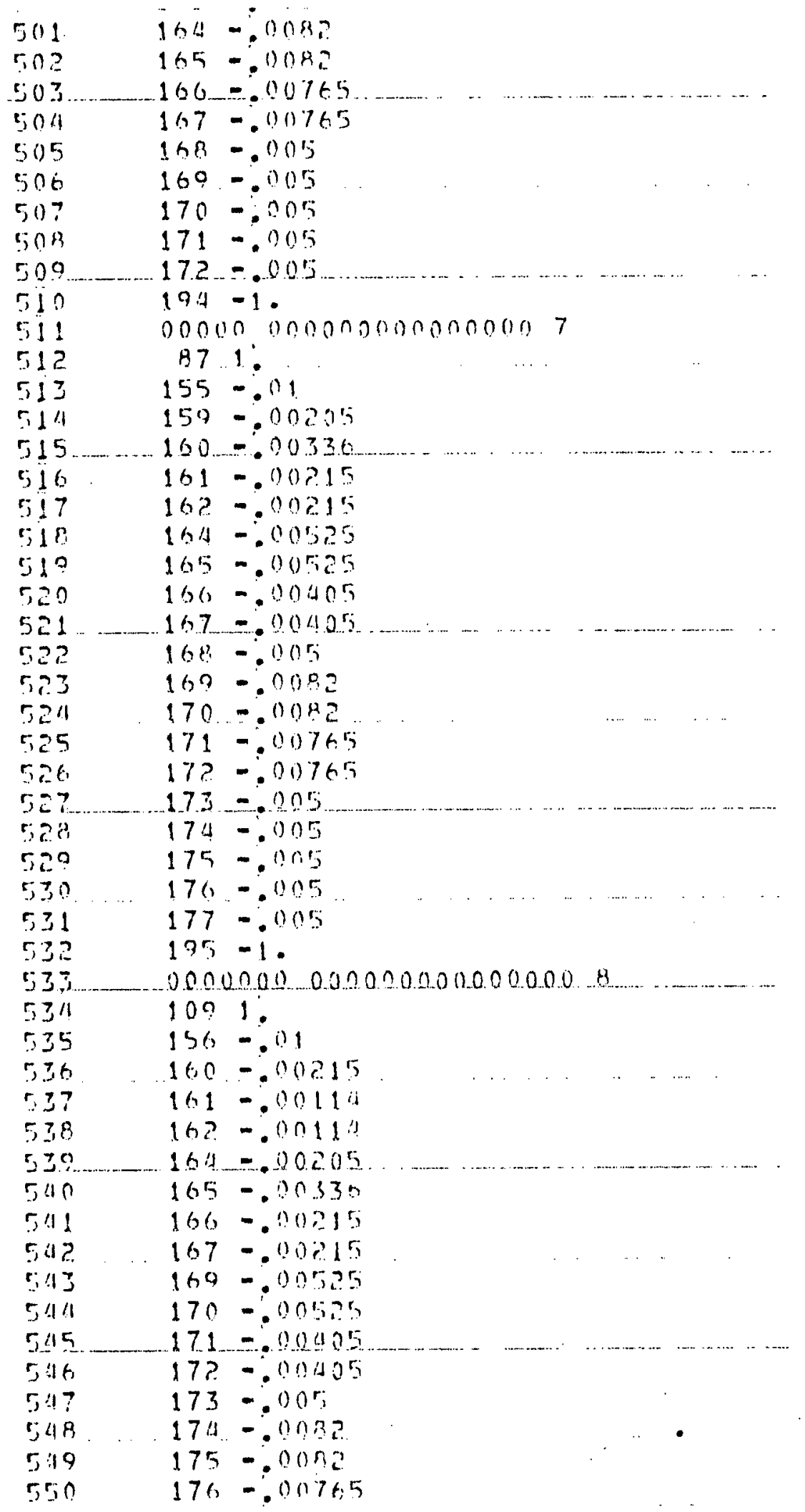


is 0000000000000001000000

$00 \%$

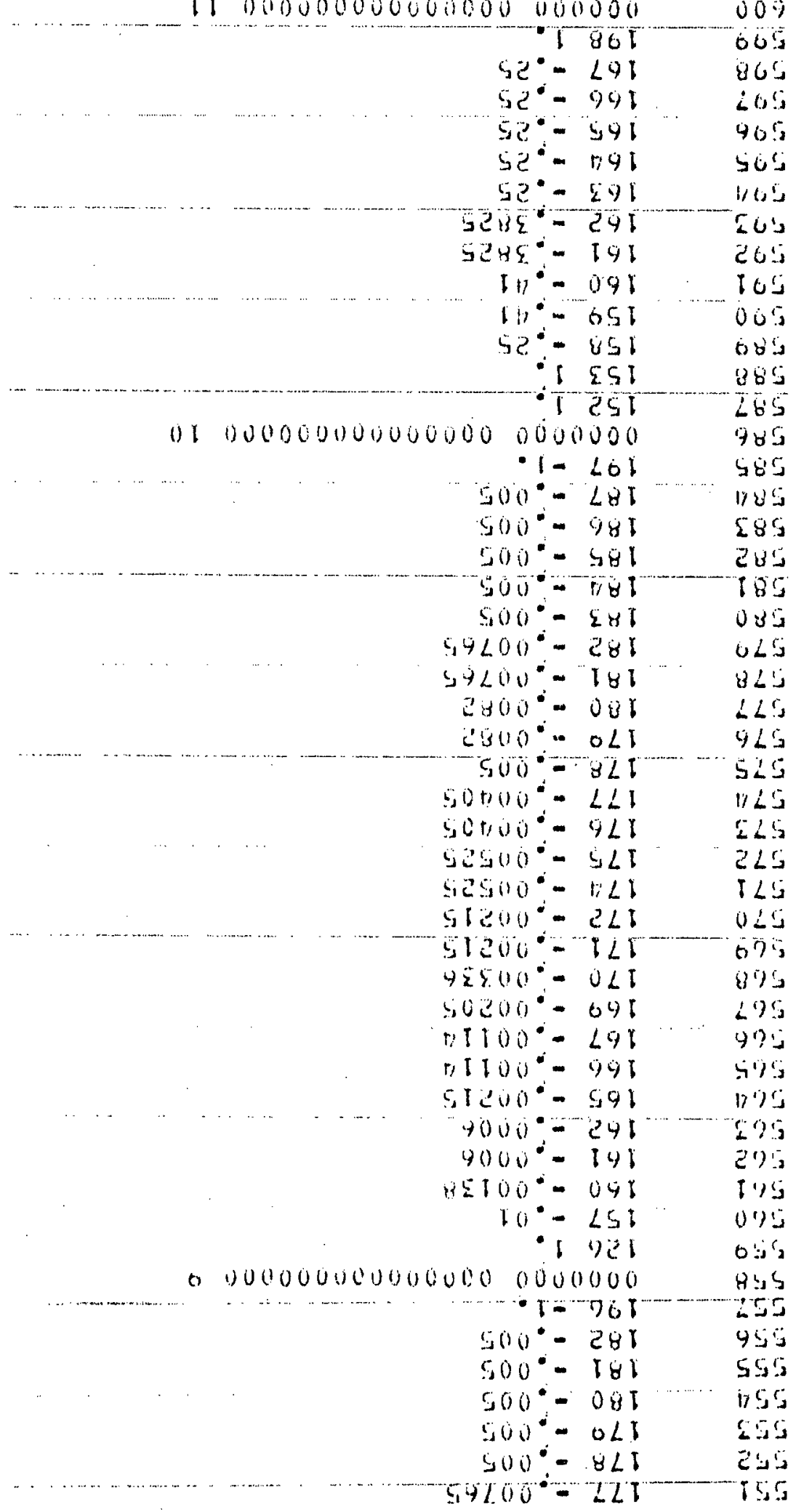




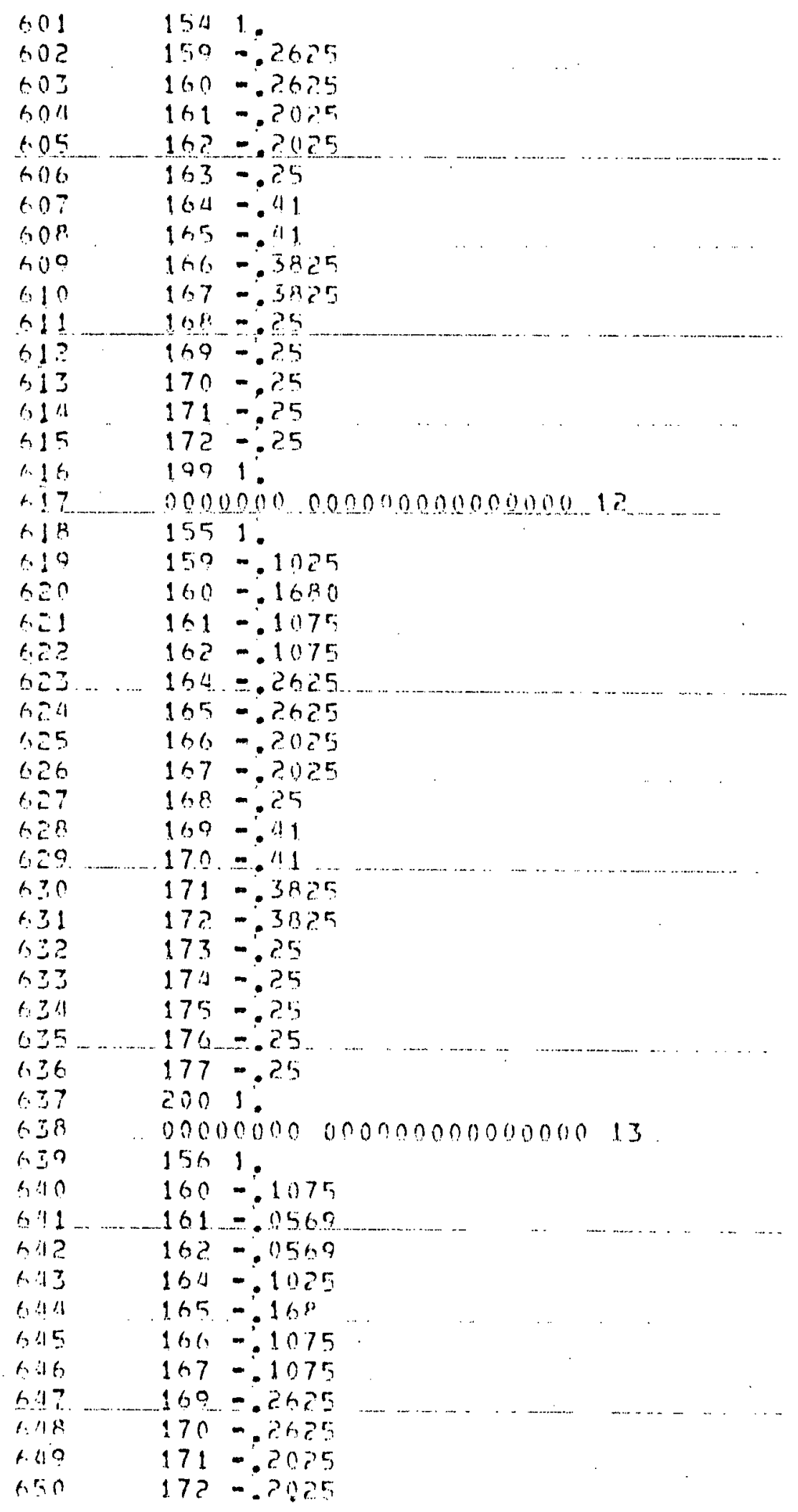




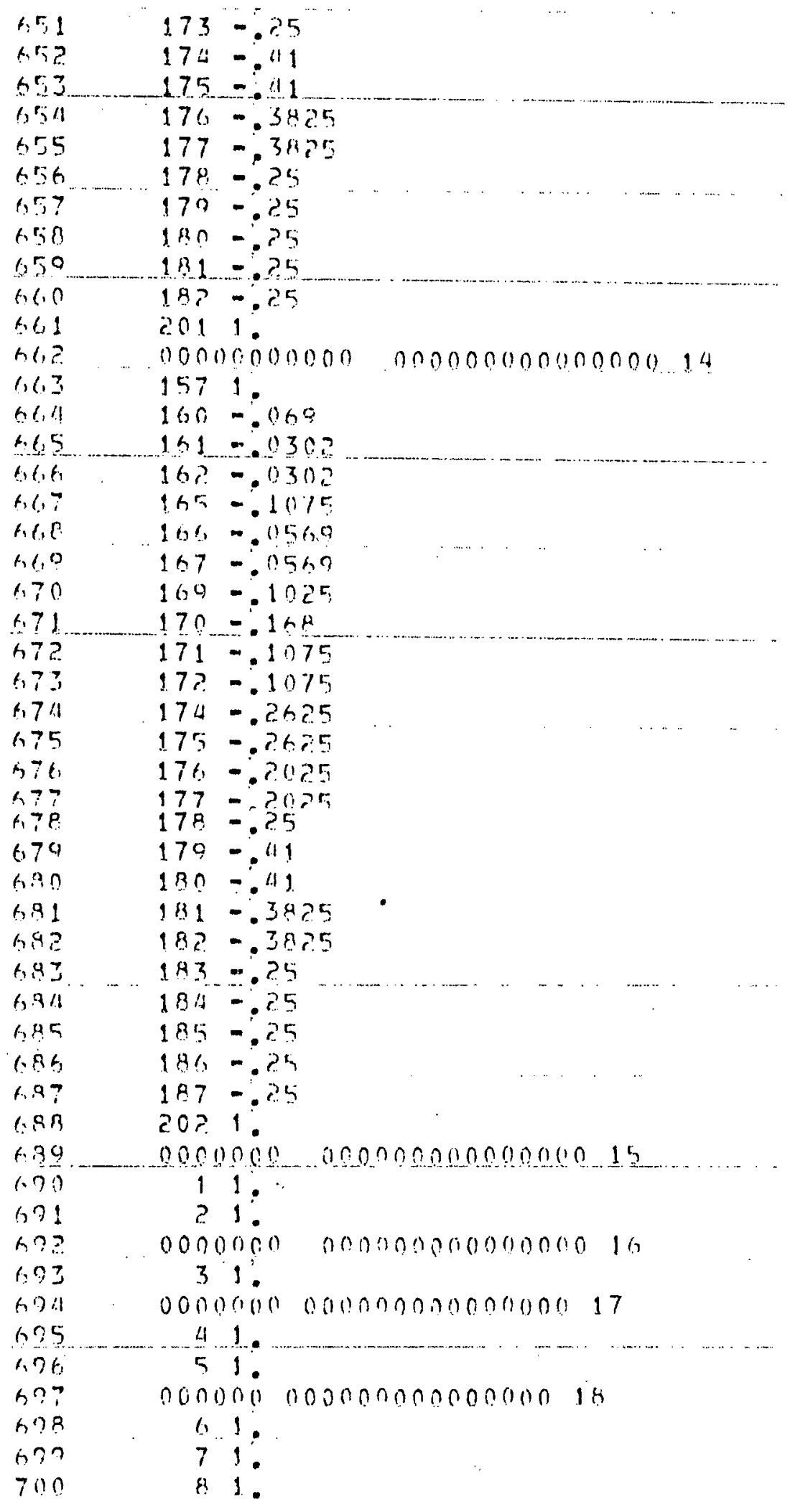


.701

70 ? 703

7111

705

700

707

708

70 ?

710

$7 ! 1$

712

7.13

7111

715

716

$7 ! ?$

718

7.9

$7: 0$

$7=2$

723

724

725

726

$72 ?$

728

729

730

731

732

73.

734

735

736

$7 \mathrm{i}$ ?

738

730

710

7 :1

742

7 . 3

7.111

$7: 15$

716

717

$7: 18$

7419

00000 nono0nonogono0n 19

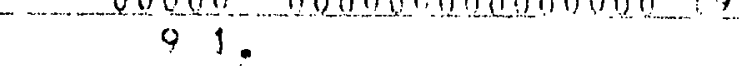

$10 \%$

(... 111 .

0.? 1.

$-131$

$151 \%$

-.... 16 $1:$

$17 \mathrm{j}:$

00000000000000020

00000000 000000000000000 31

- 181.

101

201

211

2?. 1 .

a1 1 .

$000000000000000000000 ? 2$

241

251

$201:$

77 3.

दR 1

?2 1

000000

301 .

00000.00000000000000024

311.

0000000000000000000025

$32 \ldots 1$.

341 .

1) 0000000.000000000000000 .26

$15 \times 1$.

000000000000000000000027

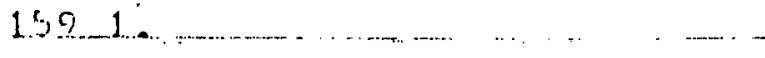

0000000000000000000028

16n 1 .

00000000000000000000029

1611.

00000 000000000000000 30

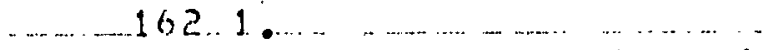

00000000000000000000031

750

15? 1.

0000000000000000000.32

$1-1$.

$4-3975$

$6 . .9975$
$9-.7975$ 


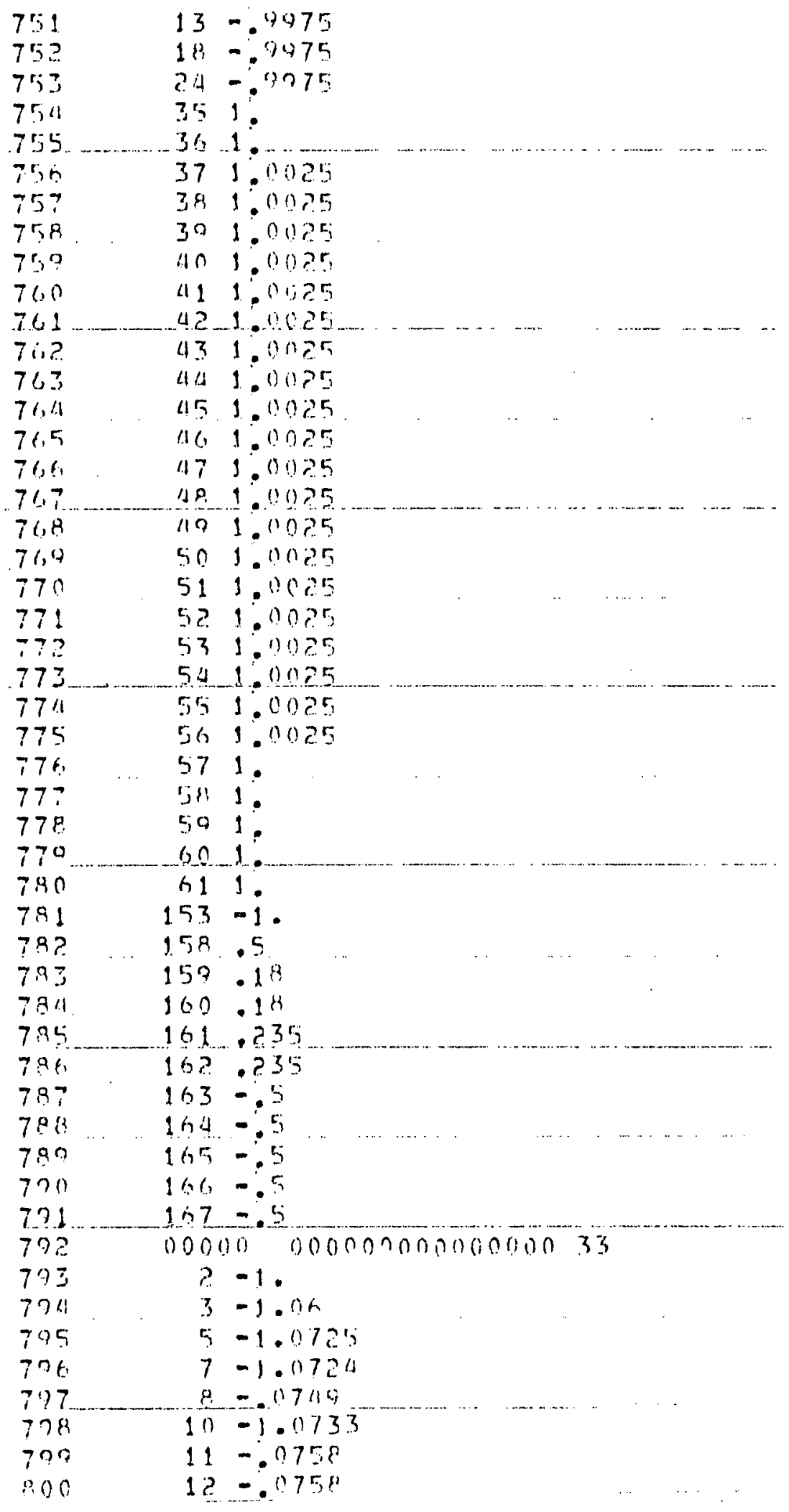




\begin{tabular}{|c|c|c|}
\hline $\begin{array}{l}801 \\
80 ? \\
803 \\
\end{array}$ & $\begin{array}{l}14 \\
15 \\
16 \\
\end{array}$ & $\begin{array}{l}-1.0742 \\
\therefore 0767 \\
-0.0767\end{array}$ \\
\hline $80 !$ & 17 & -0767 \\
\hline $\begin{array}{l}805 \\
806\end{array}$ & $\begin{array}{l}19 \\
20\end{array}$ & $\begin{array}{l}-1.0751 \\
-.0776\end{array}$ \\
\hline $\begin{array}{l}807 \\
808 \\
809 \\
\end{array}$ & $\begin{array}{l}21 \\
22 \\
23 \\
\end{array}$ & $\begin{array}{l}.0776 \\
=0776 \\
.0776\end{array}$ \\
\hline $\begin{array}{l}810 \\
811 \\
812\end{array}$ & $\begin{array}{l}25 \\
26 \\
27\end{array}$ & $\begin{array}{l}-1.0815 \\
-0841 \\
-.0841\end{array}$ \\
\hline 813 & 28 & $=0841$ \\
\hline $9 \underline{1}$ & 29 & $\because 0841$ \\
\hline 815 & 30 & $=.0938$ \\
\hline $\begin{array}{l}816 \\
817\end{array}$ & $\begin{array}{l}31 \\
32\end{array}$ & $\begin{array}{l}-105 \\
-1.104\end{array}$ \\
\hline 818 & 33 & -104 \\
\hline 819 & 34 & .104 \\
\hline 920 & 35 & -1. \\
\hline$\frac{821}{82 ?}$ & $\frac{36}{37}$ & $\frac{-1.06}{-1.0595}$ \\
\hline $\begin{array}{l}822 \\
323\end{array}$ & 38 & -1.0632 \\
\hline 824 & 30 & -0657 \\
\hline 825 & 40 & -1.0659 \\
\hline 826 & $\Delta 1$ & $=0634$ \\
\hline 827 & 42 & $=0694$ \\
\hline 828 & 43 & -1.0685 \\
\hline 829 & 44 & $=.071$ \\
\hline 830 & 45 & -.071 \\
\hline 831 & 46 &. .071 \\
\hline 832 & 47 & $=1.0733$ \\
\hline 833 & 48 & -00758 \\
\hline 834 & 49 & -.0758 \\
\hline 335 & 50 & -.0758 \\
\hline 836 & 51 & -.0758 \\
\hline 837 & 52 & -1.0875 \\
\hline 838 & 53 & .09 \\
\hline 829 & 54 & -00 \\
\hline 840 & 55 & .09 \\
\hline 841 & 56 & -.090 \\
\hline 842 & 57 & $=.104$ \\
\hline 843 & 58 & .122 \\
\hline 844 & 59 & -1.117 \\
\hline 305 & 60 & - \pm 117 \\
\hline 846 & 61 & .117 \\
\hline $8: 17$ & 62 & $1:$ \\
\hline 840 & 63 & 1: \\
\hline 849 & 64 & 1.0025 \\
\hline 850 & 65 & 1.0025 \\
\hline
\end{tabular}




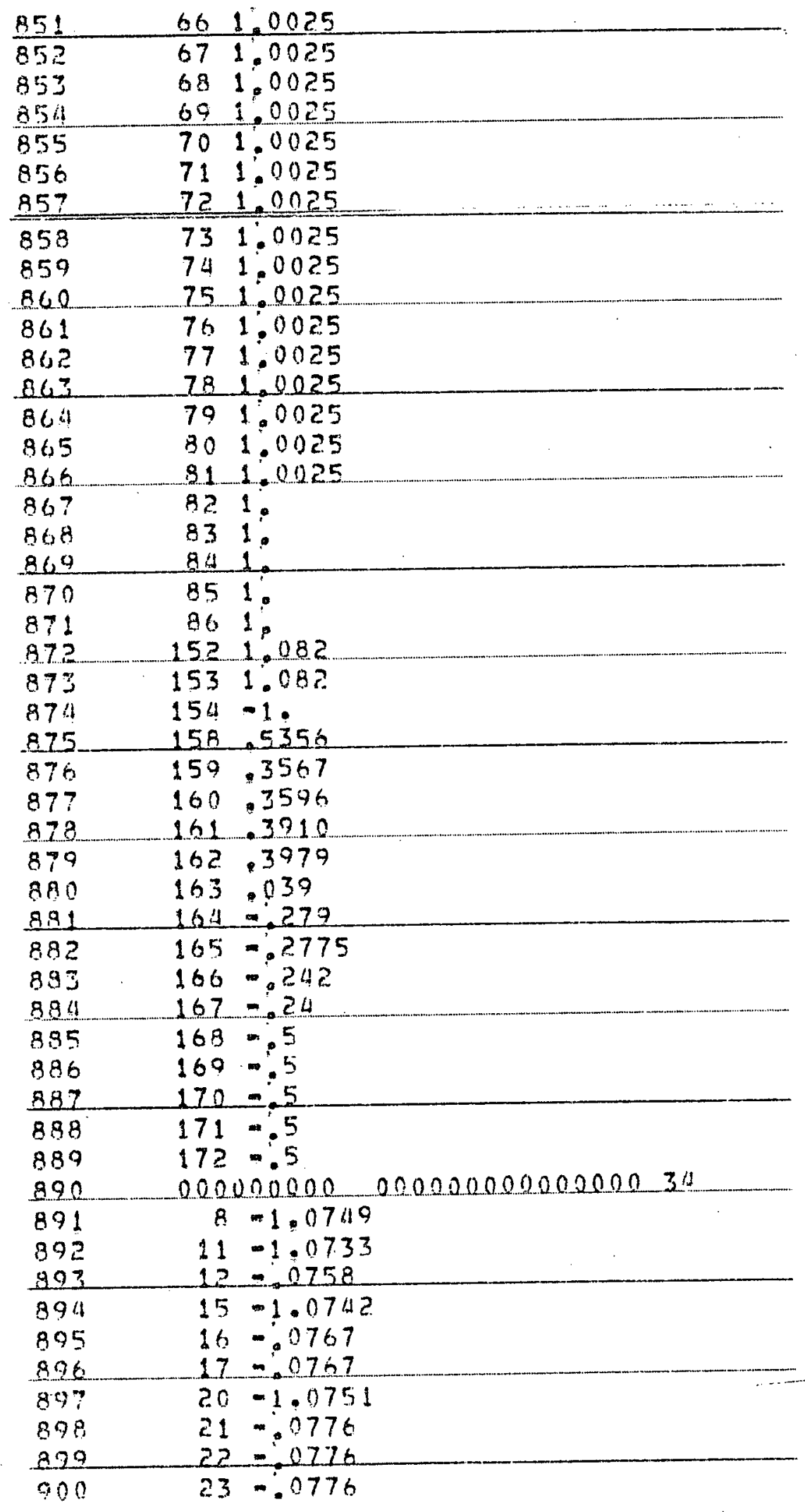




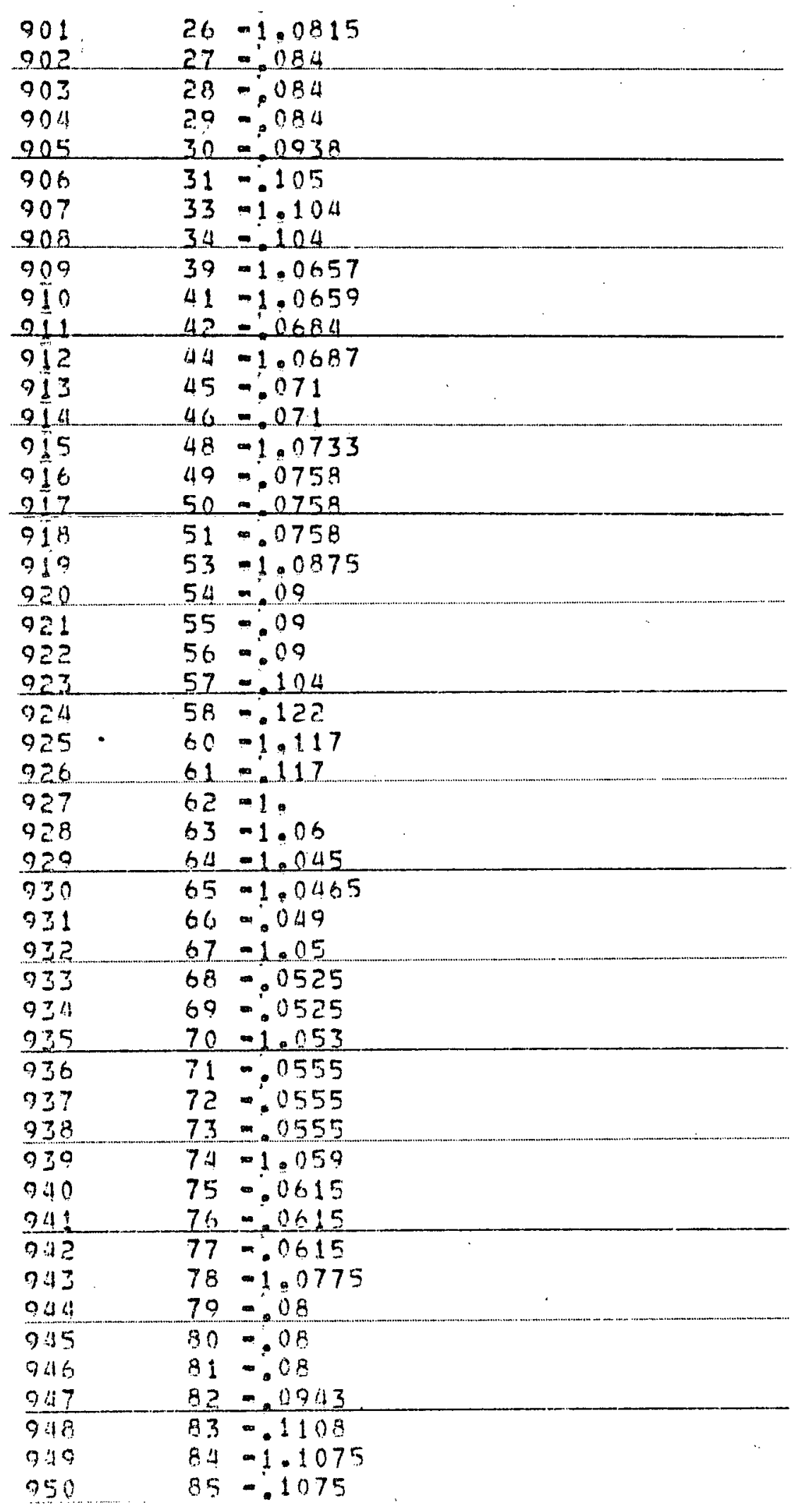




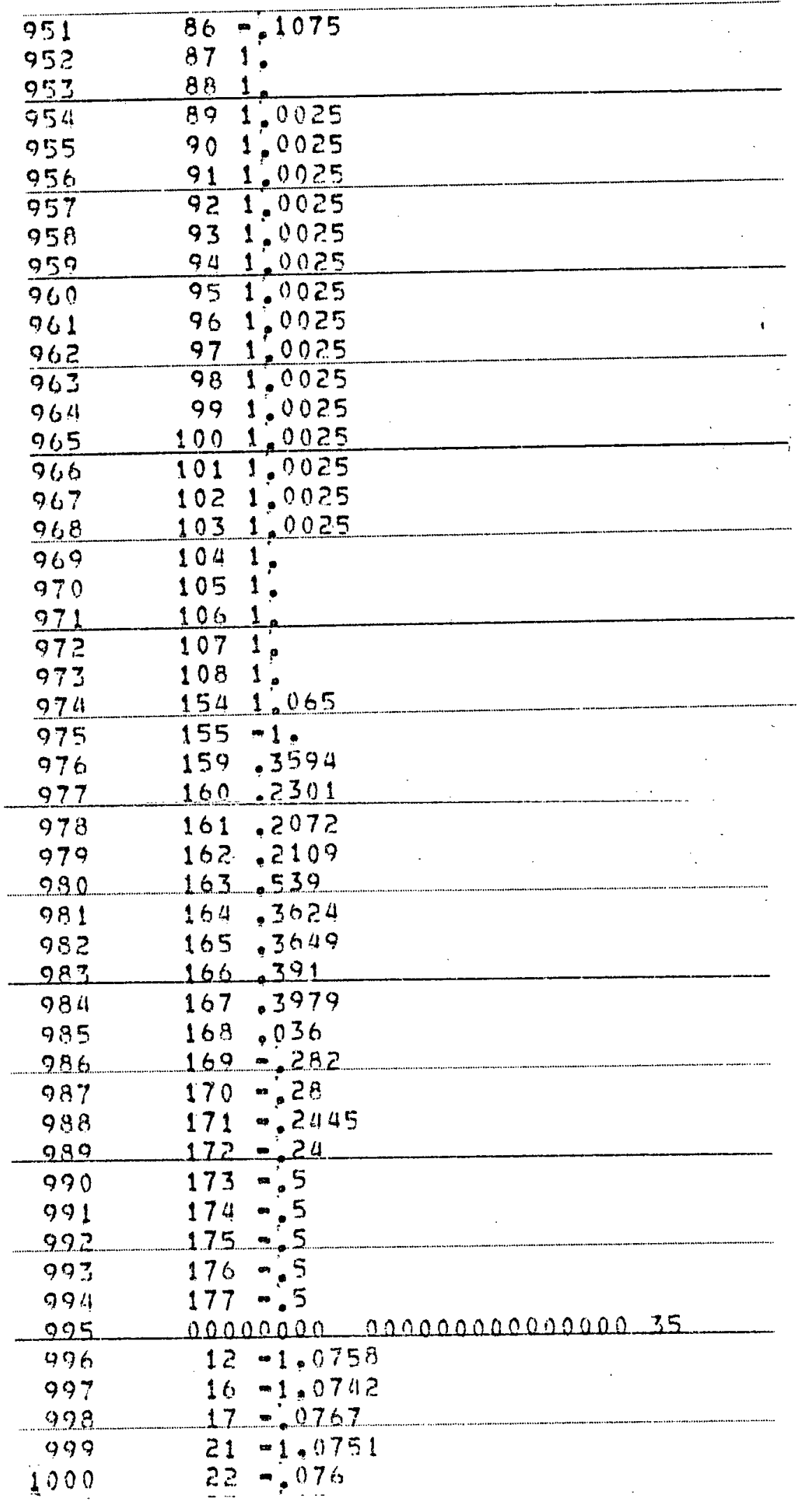




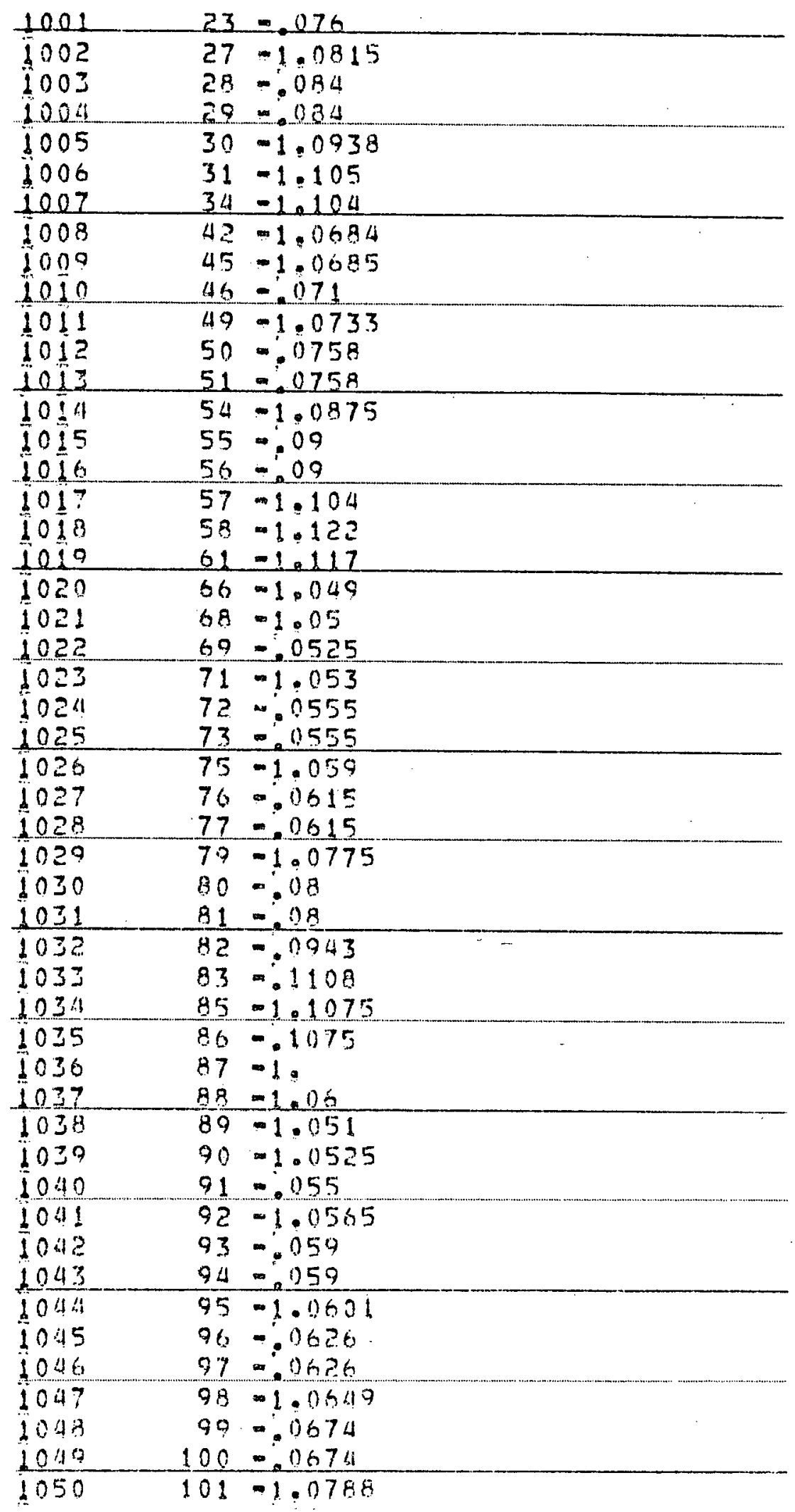




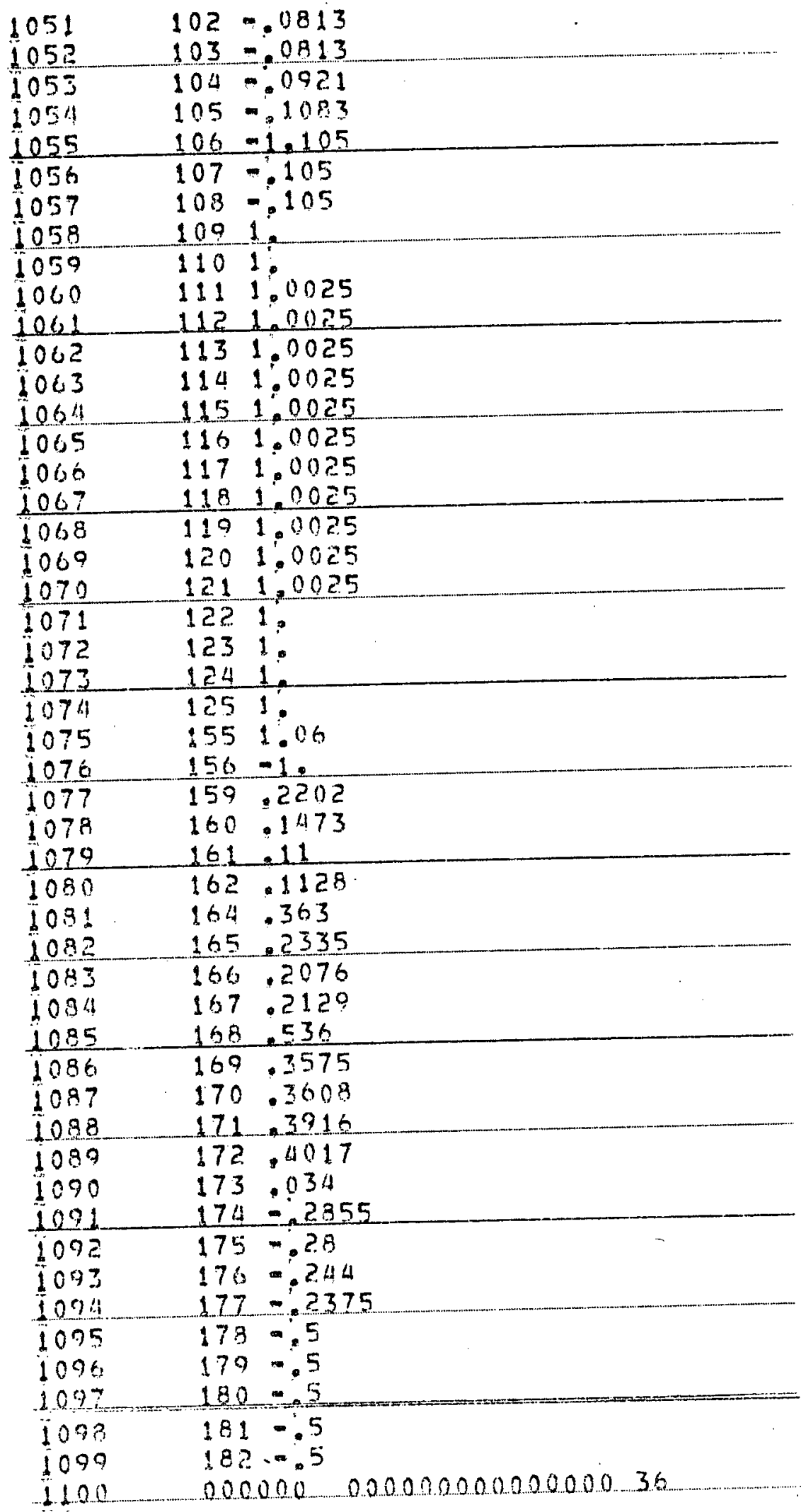




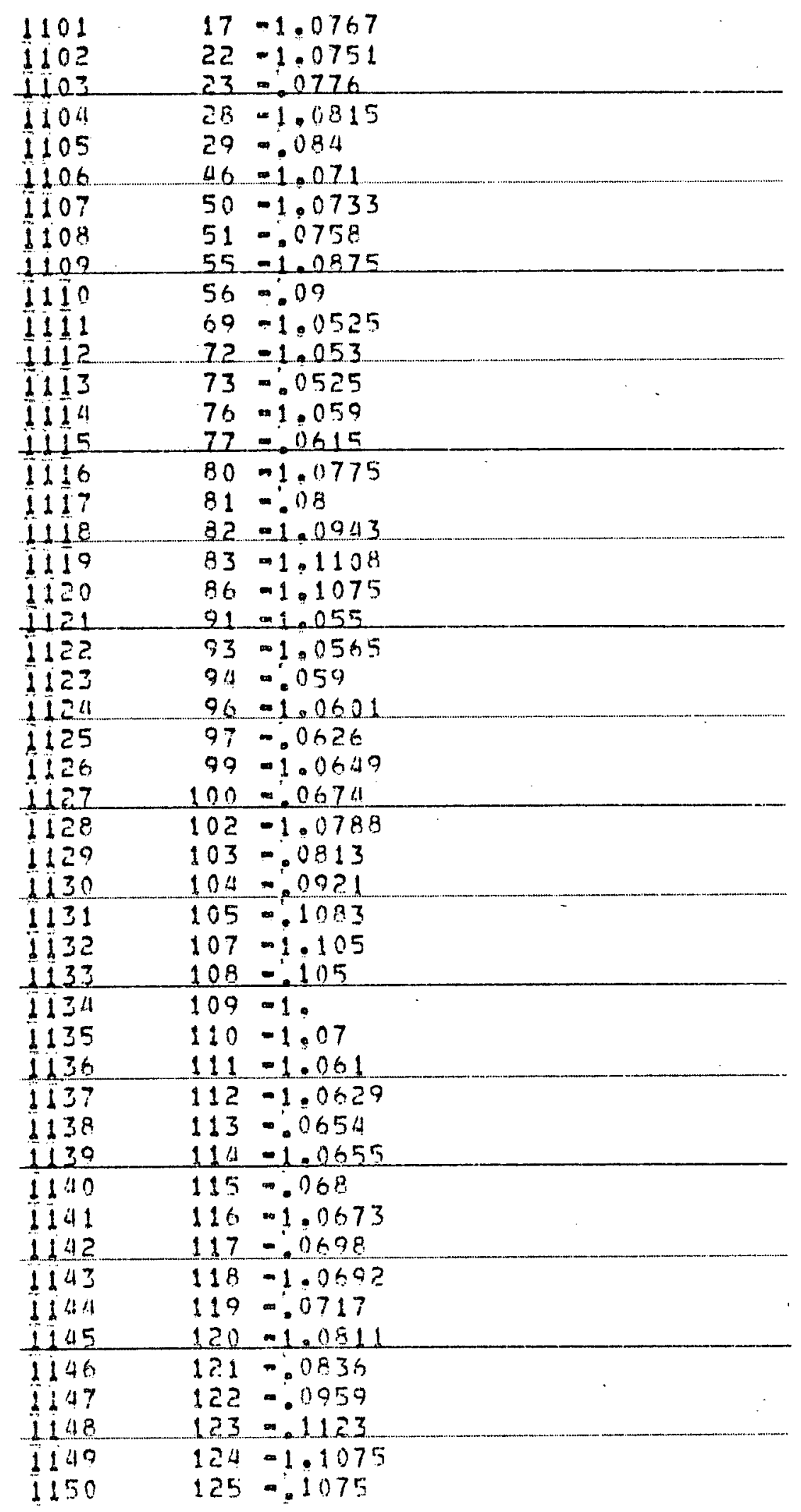




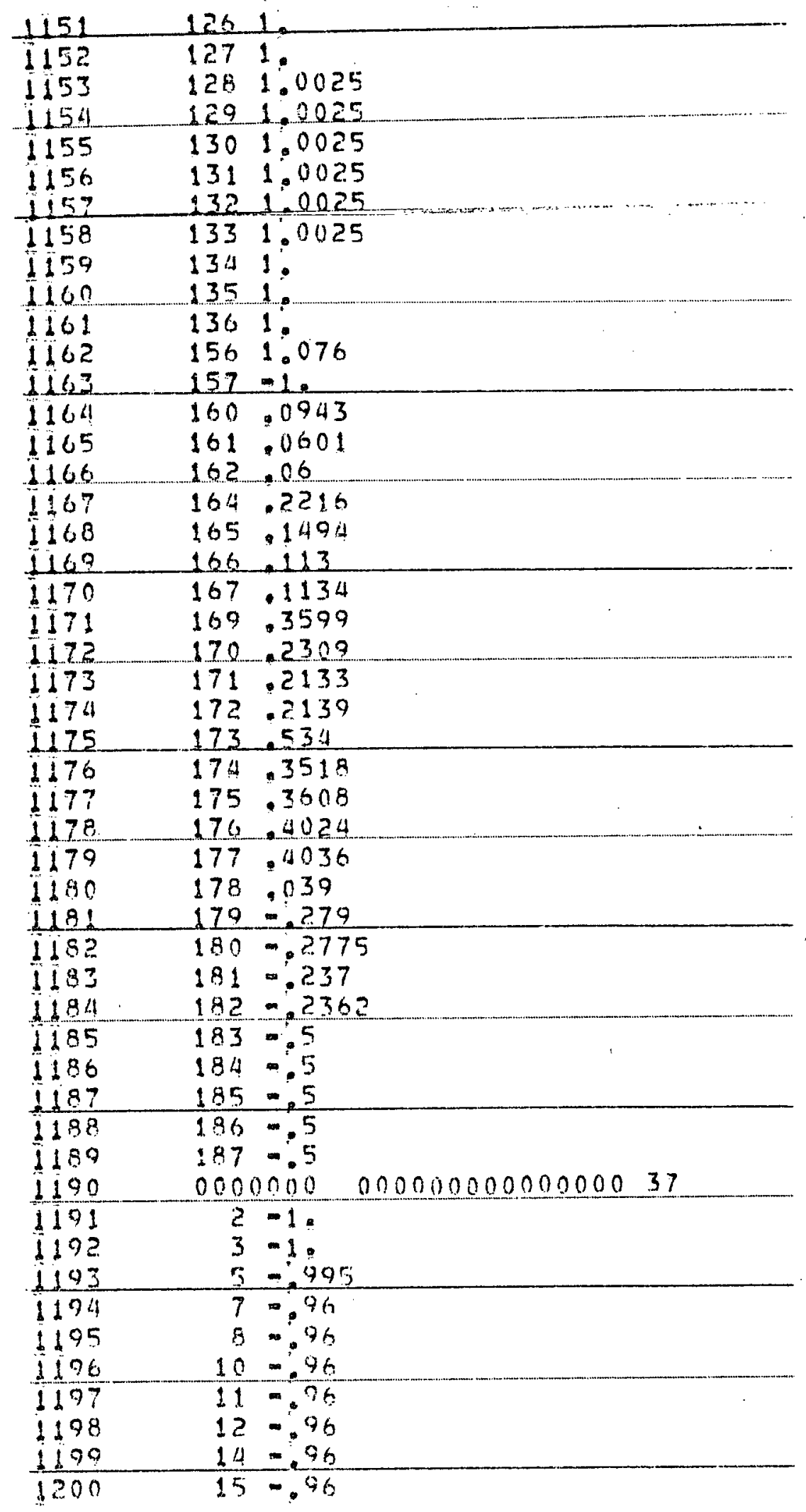




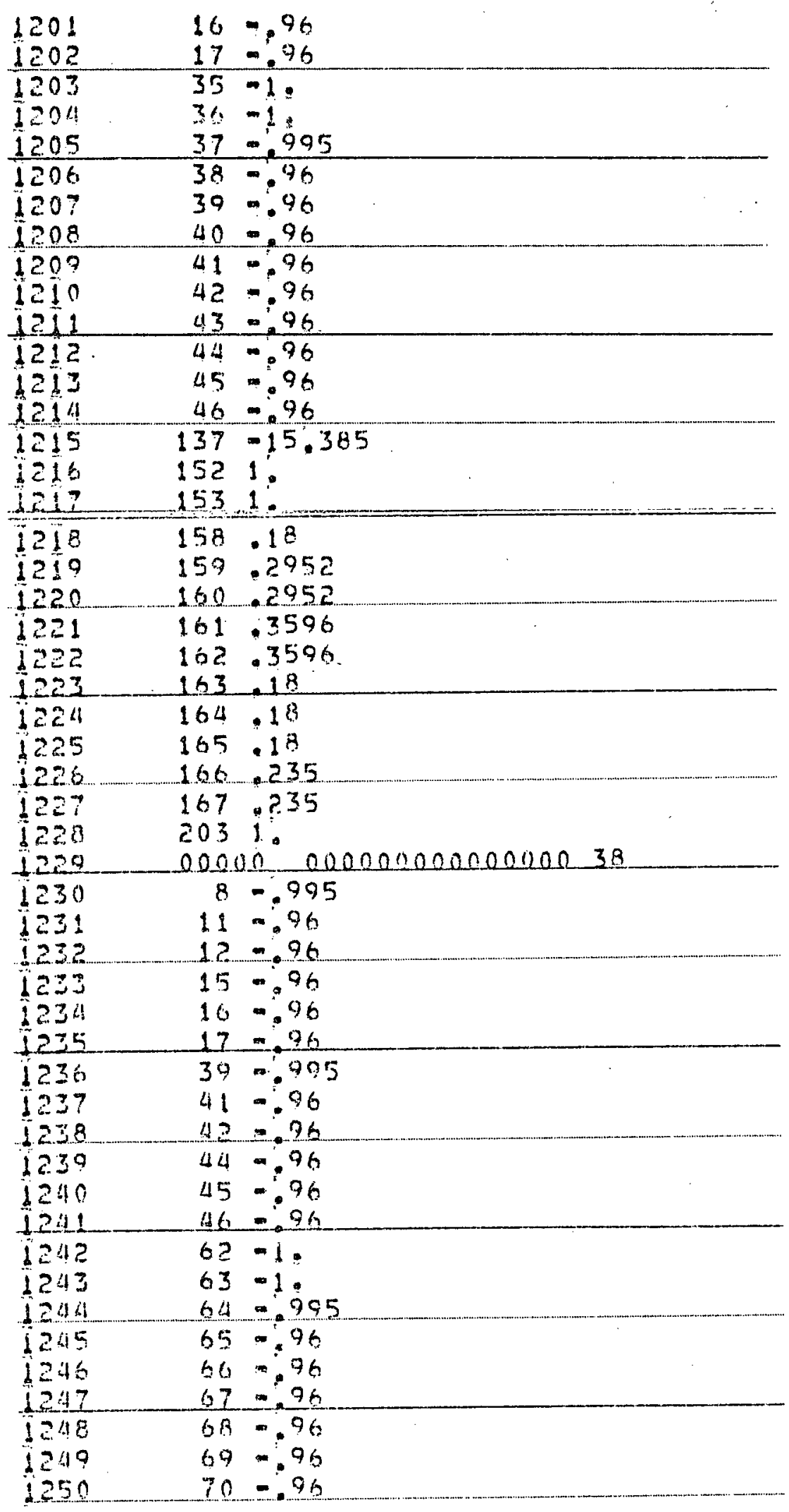




\begin{tabular}{|c|c|c|}
\hline $\begin{array}{l}1251 \\
1252 \\
1253\end{array}$ & $\begin{array}{l}71 \\
72 \\
73\end{array}$ & $\begin{array}{l}\because 96 \\
\therefore 96 \\
\therefore 96\end{array}$ \\
\hline 254 & 138 & $-15,385$ \\
\hline $\begin{array}{r}1255 \\
1256\end{array}$ & 154 & $1: 889$ \\
\hline $\begin{array}{l}1256 \\
1257\end{array}$ & $\frac{159}{150}$ & $\begin{array}{r}1889 \\
.1889\end{array}$ \\
\hline $\begin{array}{l}1257 \\
12258\end{array}$ & $\begin{array}{l}160 \\
161\end{array}$ & .1906 \\
\hline 1250 & 162 & $190 \mathrm{~h}$ \\
\hline 1260 & 163 & .18 \\
\hline $126 !$ & 164 & $\begin{array}{r}2952 \\
2952\end{array}$ \\
\hline$\frac{1262}{1263}$ & $-\frac{165}{166}$ & $\begin{array}{r}.2952 \\
.3596\end{array}$ \\
\hline 1264 & $\begin{array}{l}100 \\
167\end{array}$ & .3296 \\
\hline 1265 & 168 & -18 \\
\hline 1266 & 169 & .18 \\
\hline 1267 & $\begin{array}{l}170 \\
171\end{array}$ & $1 \frac{8}{35}$ \\
\hline$\frac{1268}{1269}$ & 172 & .235 \\
\hline 1270 & 204 & j. \\
\hline 1271 & Q000 & $00 \quad 00000000000000039$ \\
\hline 1272 & 12 & -.995 \\
\hline 1273 & 16 & $=96$ \\
\hline$\frac{1274}{1275}$ & $\frac{17}{42}$ & $\begin{array}{l}-.96 \\
=.995\end{array}$ \\
\hline 1276 & $\begin{array}{l}42 \\
45\end{array}$ & $\begin{array}{l}0.960 \\
0.96\end{array}$ \\
\hline 1272 & $\Delta 6$ & -396 \\
\hline 1278 & 66 & -.995 \\
\hline 1279 & 68 & -.96 \\
\hline$\frac{1290}{1281}$ & 69 & -.96 \\
\hline $\begin{array}{l}1281 \\
1282\end{array}$ & 71 & $\begin{array}{l}=96 \\
=96\end{array}$ \\
\hline 1283 & $\begin{array}{l}72 \\
73 \\
\end{array}$ & -.96 \\
\hline 1284 & 87 & -1. \\
\hline 1285 & 88 & -1. \\
\hline$\frac{1286}{1287}$ & 89 & $\because .995$ \\
\hline $\begin{array}{r}1287 \\
1288\end{array}$ & 90 & $=.76$ \\
\hline $\begin{array}{r}1288 \\
1289 \\
\end{array}$ & 91 & $\begin{array}{l}-96 \\
-96\end{array}$ \\
\hline 1290 & 93 & -.96 \\
\hline 1291 & 94 &. .96 \\
\hline 1292 & 95 & -.96 \\
\hline 1293 & 96 & -.96 \\
\hline 1294 & 97 & -.96 \\
\hline 1295 & 139 & -15.385 \\
\hline 1296 & 155 & 1. \\
\hline 1297 & 150 & .0737 \\
\hline 1278 & 160 & .1209 \\
\hline $\begin{array}{l}1290 \\
1300\end{array}$ & $\begin{array}{l}161 \\
162\end{array}$ & $\begin{array}{r}101 \\
.101\end{array}$ \\
\hline
\end{tabular}




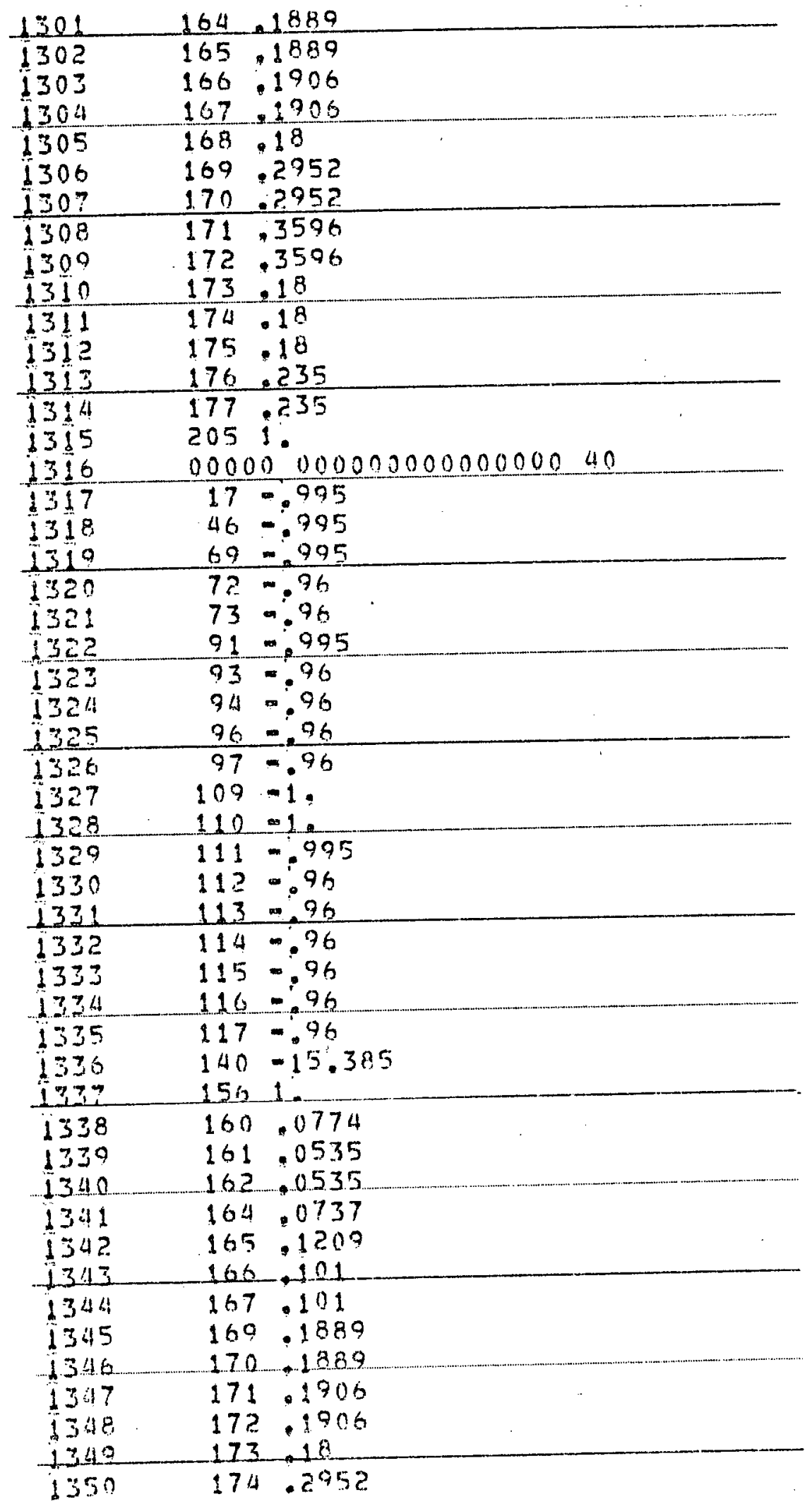




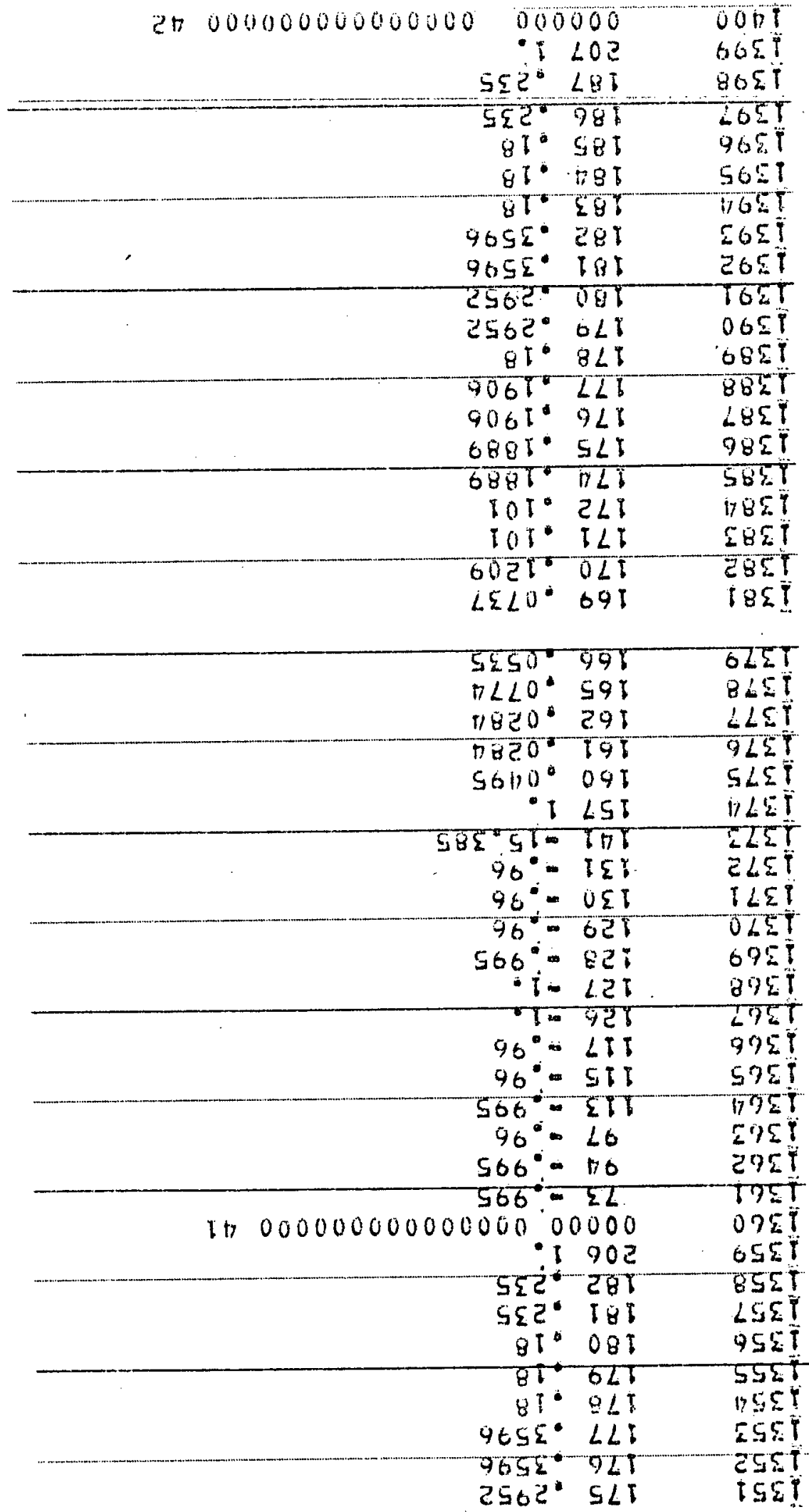




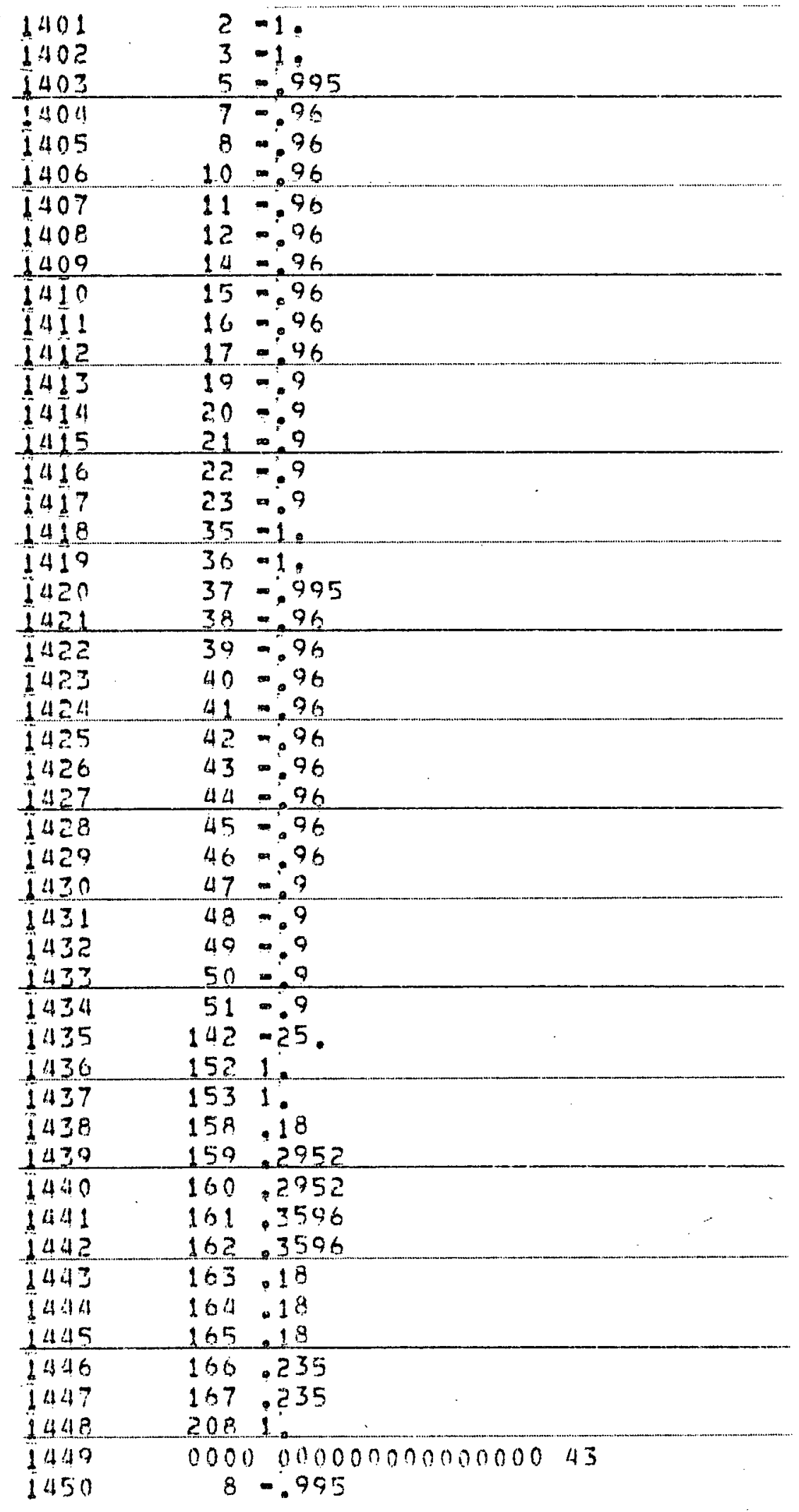




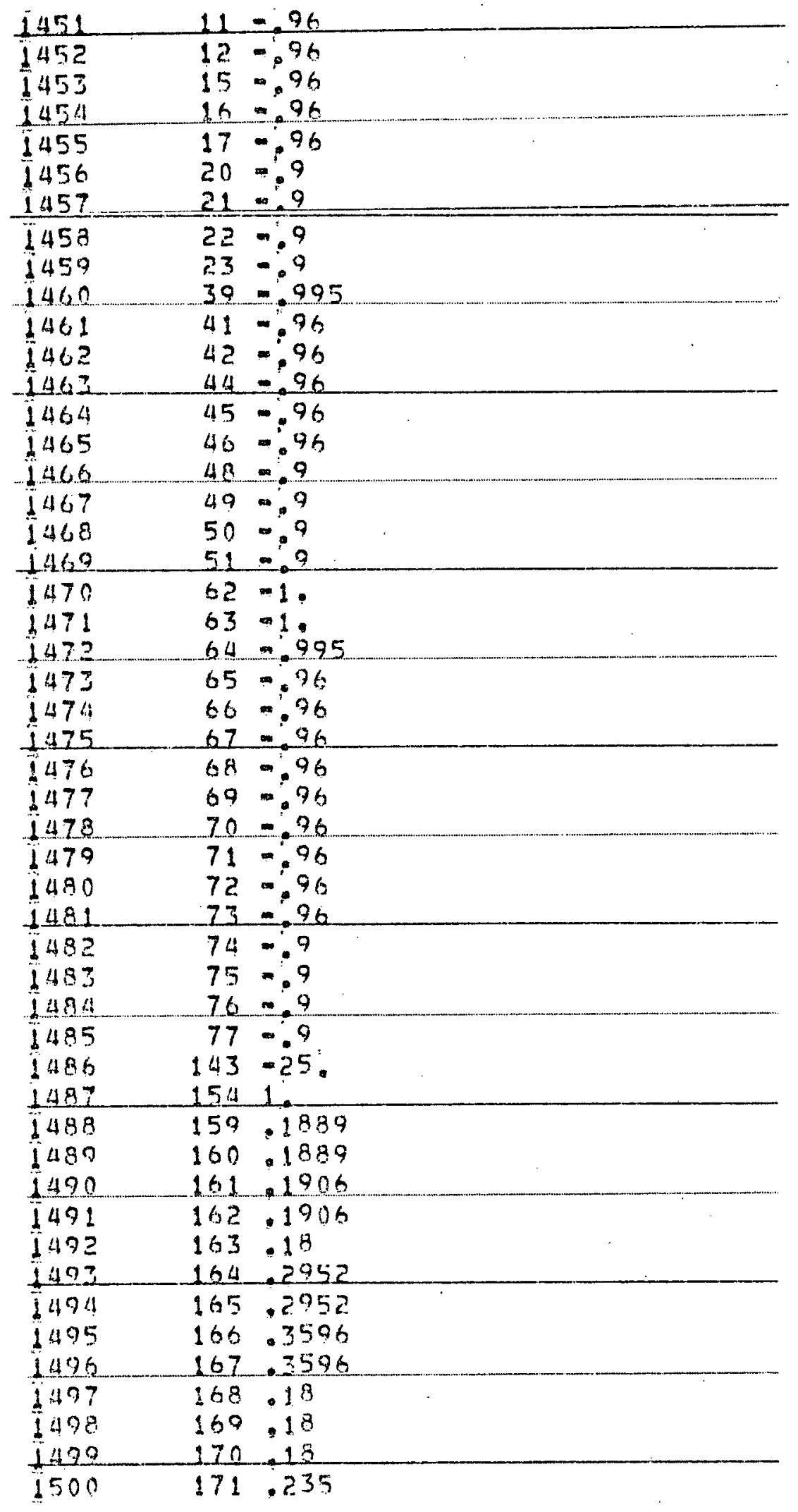




\begin{tabular}{|c|c|c|}
\hline $\begin{array}{l}1501 \\
1502\end{array}$ & $\begin{array}{l}172 \\
209 i\end{array}$ & 235 \\
\hline $\begin{array}{r}1503 \\
1504 \\
1505 \\
\end{array}$ & $\begin{array}{l}00000 \\
12 \\
16 \\
\end{array}$ & $\begin{array}{l}000000000000000044 \\
.995 \\
: 96\end{array}$ \\
\hline $\begin{array}{l}1506 \\
1507 \\
1508\end{array}$ & $\begin{array}{l}17 \\
21 \\
22\end{array}$ & \\
\hline $\begin{array}{l}1509 \\
1510 \\
1511\end{array}$ & $\begin{array}{l}23 \\
42 \\
45\end{array}$ & $\begin{array}{r}.9 \\
-.995 \\
-.96 \\
\end{array}$ \\
\hline $\begin{array}{l}1512 \\
1513 \\
1514\end{array}$ & $\begin{array}{l}46 \\
49 \\
50\end{array}$ & \\
\hline $\begin{array}{r}1515 \\
1516 \\
1517\end{array}$ & $\begin{array}{l}51 \\
66 \\
68 \\
\end{array}$ & $\begin{array}{l}: 9 \\
0.995 \\
-96 \\
\end{array}$ \\
\hline $\begin{array}{l}1518 \\
1519 \\
1520\end{array}$ & $\begin{array}{l}69 \\
71 \\
72\end{array}$ & $\begin{array}{l}=96 \\
-.96 \\
=96\end{array}$ \\
\hline $\begin{array}{r}1521 \\
1522 \\
-1523 \\
\end{array}$ & $\begin{array}{l}73 \\
75 \\
76 \\
\end{array}$ & $\begin{array}{r}.96 \\
.99 \\
.99 \\
\end{array}$ \\
\hline 1521 & 77 & $=.9$ \\
\hline $\begin{array}{r}1525 \\
1526\end{array}$ & $\begin{array}{l}87 \\
88 \\
\end{array}$ & \\
\hline 1527 & 89 & $\because .995$ \\
\hline $\begin{array}{r}1528 \\
1529 \\
\end{array}$ & $\begin{array}{l}90 \\
91 \\
\end{array}$ & $\begin{array}{r}.76 \\
-96 \\
\end{array}$ \\
\hline $\begin{array}{l}1530 \\
1531 \\
1532\end{array}$ & $\begin{array}{l}92 \\
93 \\
94\end{array}$ & $\begin{array}{r}.96 \\
-.96 \\
-.96\end{array}$ \\
\hline $\begin{array}{l}1533 \\
1534 \\
2535\end{array}$ & $\begin{array}{l}95 \\
96 \\
37 \\
\end{array}$ & $\begin{array}{r}.96 \\
-.96 \\
-.96 \\
\end{array}$ \\
\hline $\begin{array}{l}1536 \\
1537 \\
1538\end{array}$ & $\begin{array}{r}98 \\
99 \\
100\end{array}$ & $\begin{array}{r}-9 \\
-9 \\
-99\end{array}$ \\
\hline $\begin{array}{l}\$ 530 \\
1540 \\
1541\end{array}$ & $\begin{array}{l}144 \\
155 \\
159 \\
\end{array}$ & $\begin{array}{r}25 \\
1.737 \\
\end{array}$ \\
\hline 1542 & 160 & .1209 \\
\hline $\begin{array}{l}1543 \\
544\end{array}$ & 161 & .101 \\
\hline$\frac{2}{1545}$ & $\frac{162}{164}$ & $\begin{array}{l}101 \\
.1889\end{array}$ \\
\hline 1546 & 165 & .1889 \\
\hline 1547 & 166 & .1905 \\
\hline $\begin{array}{l}1548 \\
1549 \\
1550\end{array}$ & $\begin{array}{l}167 \\
168 \\
169\end{array}$ & $\begin{array}{l}.1906 \\
.19 \\
.2952\end{array}$ \\
\hline
\end{tabular}




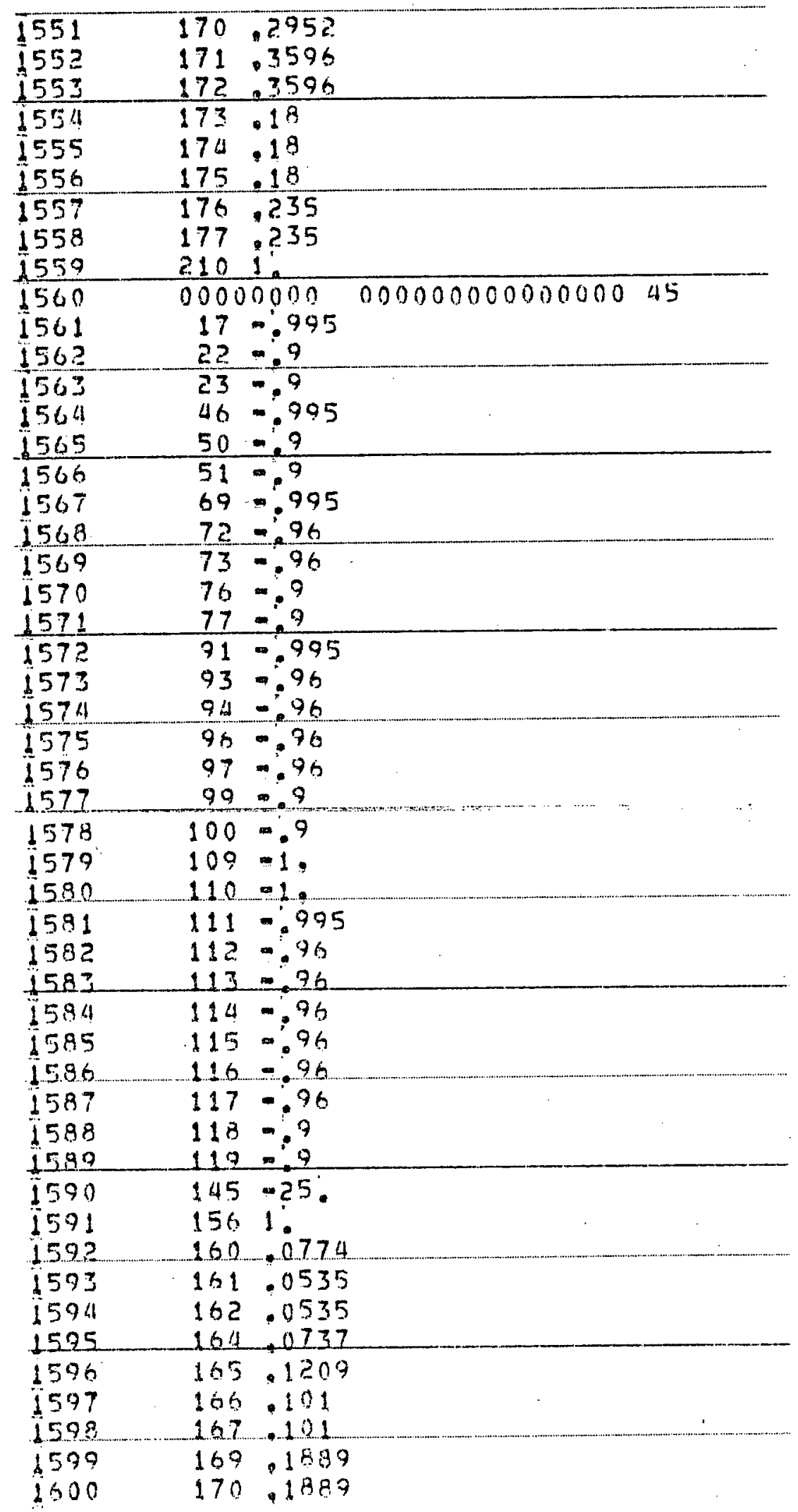




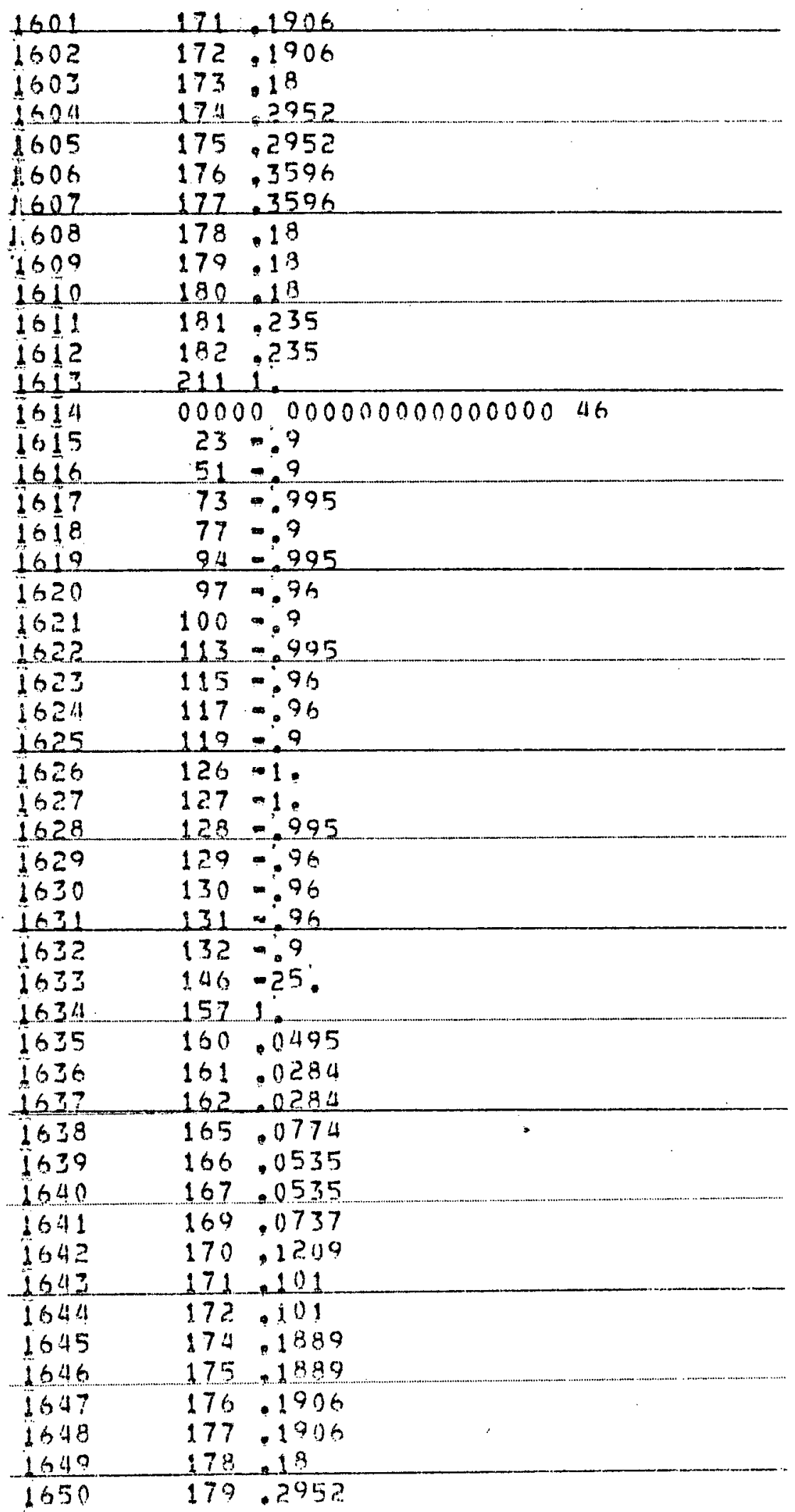




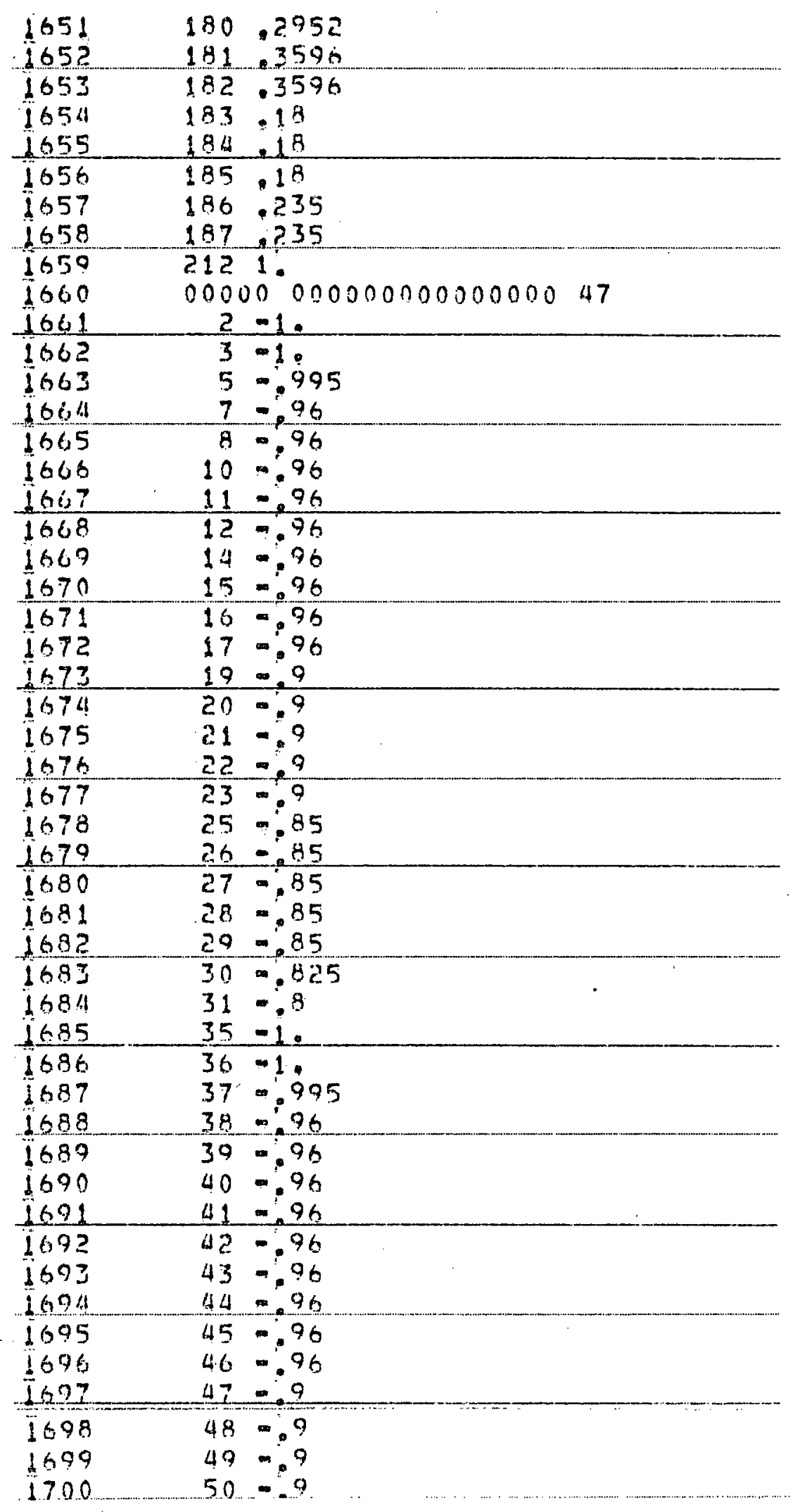




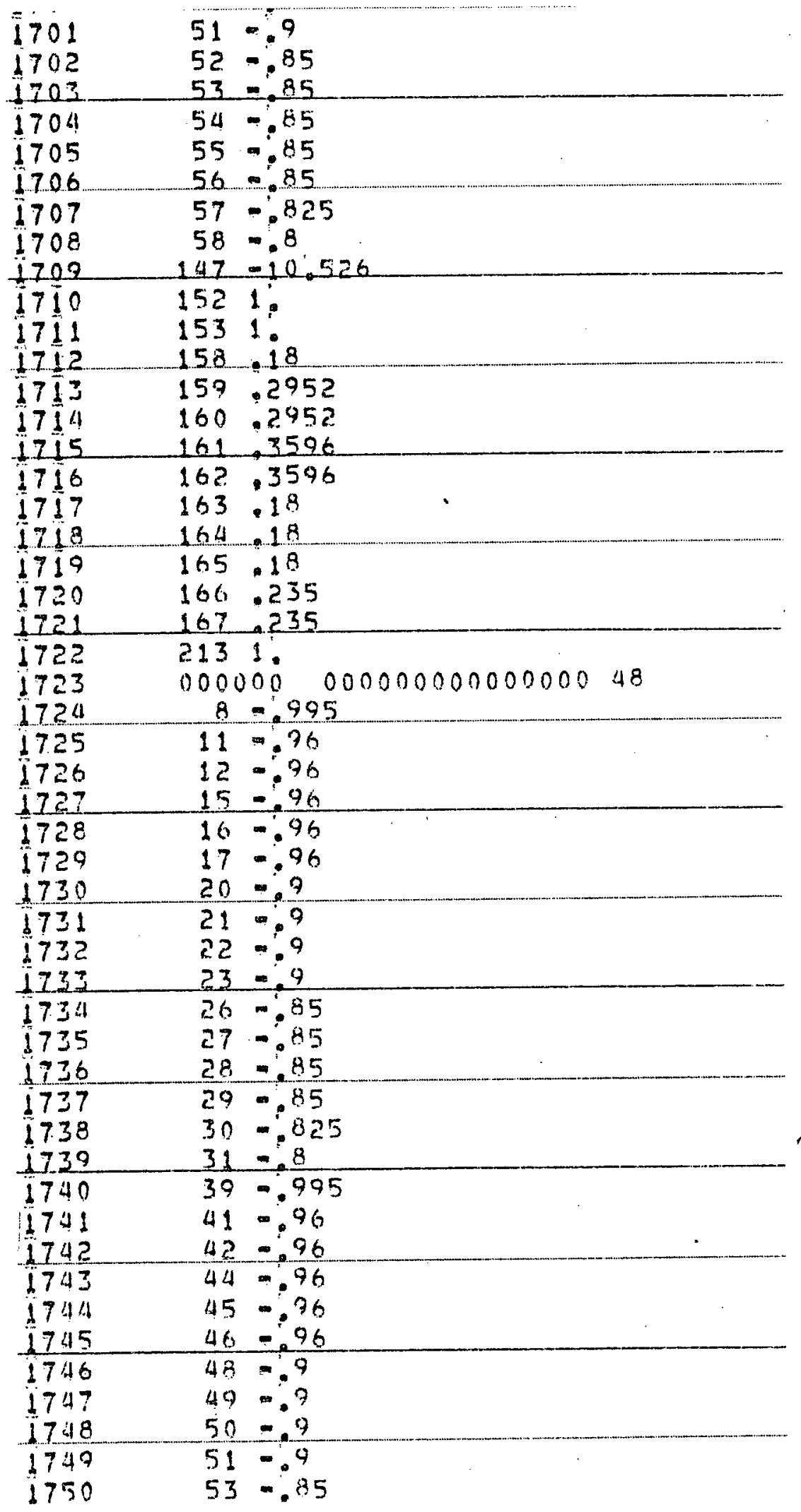




\begin{tabular}{|c|c|c|}
\hline 1751 & 54 & -.85 \\
\hline $\begin{array}{l}1752 \\
1753 \\
1754\end{array}$ & $\begin{array}{l}55 \\
56 \\
57\end{array}$ & $\begin{array}{l}.85 \\
-85 \\
.825\end{array}$ \\
\hline $\begin{array}{l}1755 \\
1756 \\
1757\end{array}$ & $\begin{array}{l}58 \\
62 \\
63 \\
\end{array}$ & $\begin{array}{l}-8 \\
-1 . \\
-1 . \\
\end{array}$ \\
\hline $\begin{array}{r}1758 \\
1759 \\
1760\end{array}$ & $\begin{array}{l}64 \\
65 \\
66\end{array}$ & $\begin{array}{l}=.995 \\
-.96 \\
=.96\end{array}$ \\
\hline $\begin{array}{r}1761 \\
1762 \\
1763 \\
\end{array}$ & $\begin{array}{l}67 \\
68 \\
69 \\
\end{array}$ & $\begin{array}{r}.96 \\
-.96 \\
-.96 \\
\end{array}$ \\
\hline $\begin{array}{l}1764 \\
1765 \\
1766\end{array}$ & $\begin{array}{l}70 \\
71 \\
72\end{array}$ & $\begin{array}{l}-.96 \\
.96 \\
-96\end{array}$ \\
\hline $\begin{array}{l}1767 \\
1768 \\
1769\end{array}$ & $\begin{array}{l}73 \\
74 \\
75 \\
\end{array}$ & $\begin{array}{r}.96 \\
\therefore 9 \\
-9 \\
\end{array}$ \\
\hline $\begin{array}{r}1770 \\
1771 \\
1772\end{array}$ & $\begin{array}{l}76 \\
77 \\
78\end{array}$ & $\begin{array}{l}.9 \\
0.9 \\
. .85\end{array}$ \\
\hline $\begin{array}{l}1773 \\
1774 \\
1775\end{array}$ & $\begin{array}{l}79 \\
80 \\
81\end{array}$ & $\begin{array}{r}-85 \\
-.85 \\
-.85 \\
\end{array}$ \\
\hline $\begin{array}{l}1776 \\
1777 \\
1778\end{array}$ & $\begin{array}{r}82 \\
83 \\
148 \\
\end{array}$ & $\begin{array}{l}-825 \\
-8 \\
-10.526\end{array}$ \\
\hline $\begin{array}{l}1779 \\
1780 \\
1781\end{array}$ & $\begin{array}{l}154 \\
159 \\
100 \\
\end{array}$ & $\begin{array}{r}1889 \\
1889 \\
\end{array}$ \\
\hline $\begin{array}{l}1782 \\
1783 \\
1784\end{array}$ & $\begin{array}{l}161 \\
162 \\
163\end{array}$ & $\begin{array}{l}1906 \\
.1706 \\
.18\end{array}$ \\
\hline $\begin{array}{l}1785 \\
1796 \\
1787\end{array}$ & $\begin{array}{l}164 \\
165 \\
166 \\
\end{array}$ & $\begin{array}{r}2952 \\
.2952 \\
3596\end{array}$ \\
\hline $\begin{array}{l}1788 \\
1789 \\
1790\end{array}$ & $\begin{array}{l}16 \% \\
168 \\
169 \\
\end{array}$ & $\begin{array}{l}.3596 \\
.18 \\
.18\end{array}$ \\
\hline $\begin{array}{r}1791 \\
1792 \\
1793\end{array}$ & $\begin{array}{l}170 \\
171 \\
172 \\
\end{array}$ & $\begin{array}{l}18 \\
235 \\
.235\end{array}$ \\
\hline 7794 & 214 & 1. 00000000000000000 \\
\hline $\begin{array}{l}1795 \\
1796\end{array}$ & $\begin{array}{c}0000 \\
12 \\
\end{array}$ & $\begin{array}{l}00.00000000000000049 \\
\$ 95\end{array}$ \\
\hline $\begin{array}{r}1797 \\
1798 \\
1799\end{array}$ & $\begin{array}{l}16 \\
17 \\
21 \\
\end{array}$ & $\begin{array}{r}-96 \\
-.96 \\
-.9 \\
\end{array}$ \\
\hline 2800 & 22 & -.9 \\
\hline
\end{tabular}




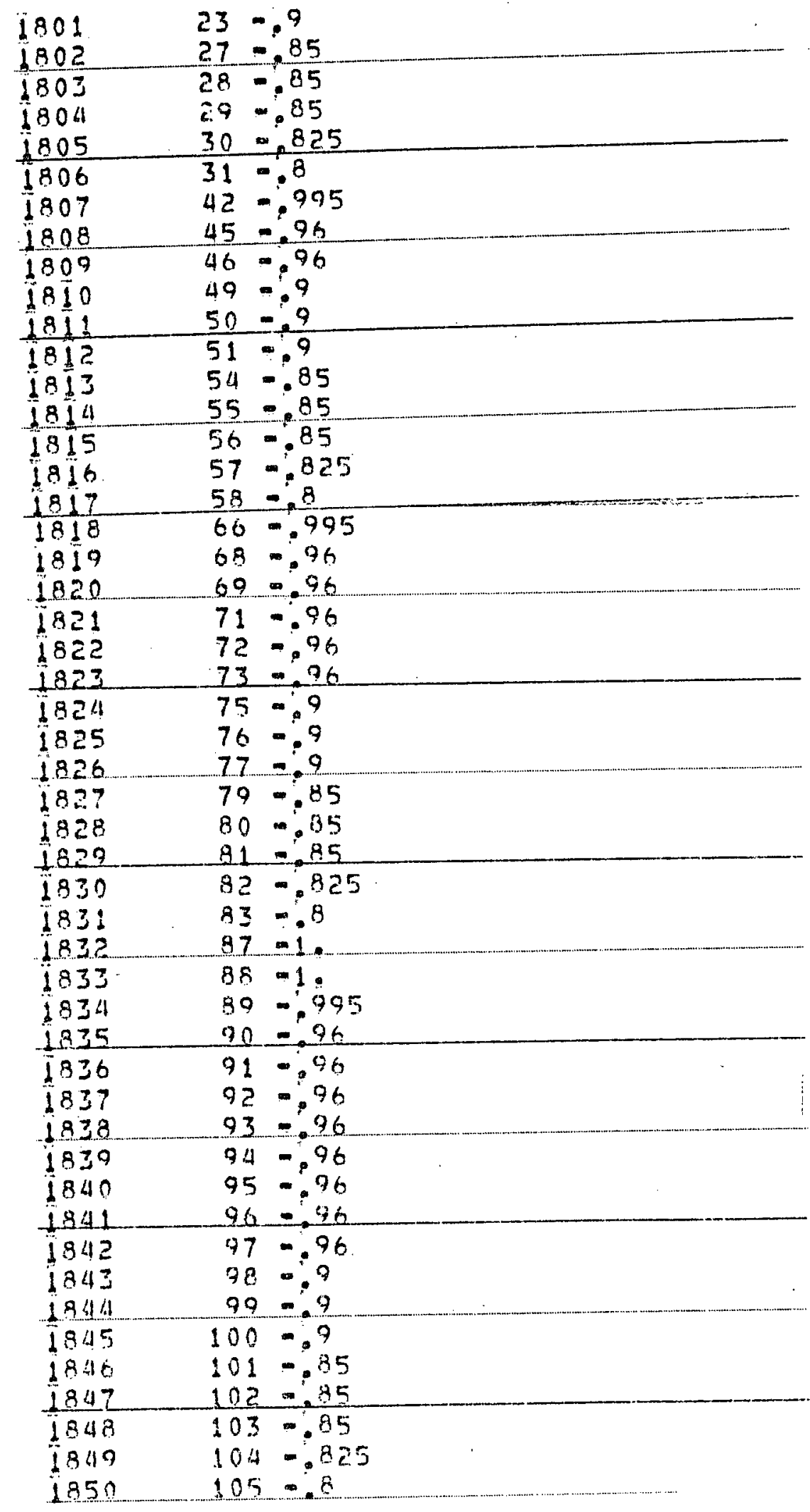




\begin{tabular}{|c|c|c|}
\hline $\begin{array}{l}1851 \\
1852 \\
1853\end{array}$ & $\begin{array}{l}149 \\
155 \\
159\end{array}$ & $\begin{array}{l}-10.526 \\
.0737\end{array}$ \\
\hline $\begin{array}{l}1854 \\
1855 \\
1856 \\
\end{array}$ & $\begin{array}{l}160 \\
161 \\
162\end{array}$ & $\begin{array}{l}.1209 \\
.101 \\
.101 \\
.101\end{array}$ \\
\hline $\begin{array}{l}1857 \\
1858\end{array}$ & 164 & .1889 \\
\hline $\begin{array}{l}1858 \\
1859 \\
\end{array}$ & $\begin{array}{l}165 \\
166 \\
\end{array}$ & $\begin{array}{r}1889 \\
-1906 \\
\end{array}$ \\
\hline $\begin{array}{l}1860 \\
1861 \\
1862\end{array}$ & $\begin{array}{l}167 \\
168 \\
169\end{array}$ & $\begin{array}{l}.1906 \\
.18 \\
.2952\end{array}$ \\
\hline $\begin{array}{l}863 \\
1864 \\
1865\end{array}$ & $\begin{array}{l}170 \\
171 \\
172 \\
\end{array}$ & $\begin{array}{r}.2952 \\
.3596 \\
.3596 \\
\end{array}$ \\
\hline $\begin{array}{l}1866 \\
1867 \\
1868\end{array}$ & $\begin{array}{l}173 \\
174 \\
175\end{array}$ & $\begin{array}{r}.18 \\
.18 \\
.18 \\
\end{array}$ \\
\hline $\begin{array}{l}1869 \\
1870 \\
1871\end{array}$ & & $\begin{array}{l}2 \\
235 \\
235 \\
i\end{array}$ \\
\hline $\begin{array}{l}1871 \\
1872 \\
1873 \\
1874\end{array}$ & $\begin{array}{l}215 \\
0000 \\
17 \\
22\end{array}$ & $\begin{array}{l}1 . \\
000000000000000050 \\
\therefore 995 \\
\therefore 9\end{array}$ \\
\hline $\begin{array}{l}1875 \\
1876 \\
1877 \\
\end{array}$ & $\begin{array}{r}23 \\
28 \\
39 \\
\end{array}$ & $\begin{array}{l}-9 \\
=85 \\
=85 \\
\end{array}$ \\
\hline $\begin{array}{l}1870 \\
1879 \\
1890\end{array}$ & $\begin{array}{l}46 \\
50 \\
51\end{array}$ & $\begin{array}{l}-.995 \\
-.9 \\
-.9\end{array}$ \\
\hline $\begin{array}{l}1881 \\
1882 \\
1882\end{array}$ & $\begin{array}{l}55 \\
56 \\
69 \\
\end{array}$ & $\begin{array}{l}\because 85 \\
-.85 \\
-.995 \\
\end{array}$ \\
\hline $\begin{array}{l}1884 \\
1885 \\
1886\end{array}$ & $\begin{array}{l}72 \\
73 \\
76\end{array}$ & $\begin{array}{l}=96 \\
\because 96 \\
=.9\end{array}$ \\
\hline $\begin{array}{l}8887 \\
1888 \\
1899\end{array}$ & $\begin{array}{l}77 \\
80 \\
81\end{array}$ & $\begin{array}{r}\because 9 \\
\because 85 \\
-85 \\
\end{array}$ \\
\hline $\begin{array}{l}1890 \\
1891 \\
1892\end{array}$ & $\begin{array}{l}82 \\
83 \\
91\end{array}$ & $\begin{array}{l}\because 825 \\
\therefore 8 \\
.925\end{array}$ \\
\hline 1893 & 93 &. .96 \\
\hline $\begin{array}{l}1894 \\
1895\end{array}$ & $\begin{array}{l}94 \\
96 \\
\end{array}$ & $\begin{array}{r}\square 96 \\
-96 \\
\end{array}$ \\
\hline $\begin{array}{l}1896 \\
1897\end{array}$ & $\begin{array}{r}97 \\
99\end{array}$ & $\begin{array}{l}\because 96 \\
\because 9\end{array}$ \\
\hline 1898 & 100 & -.9 \\
\hline $\begin{array}{l}1999 \\
1900\end{array}$ & $\begin{array}{l}102 \\
103\end{array}$ & $\begin{array}{l}\square .85 \\
\because 85\end{array}$ \\
\hline
\end{tabular}




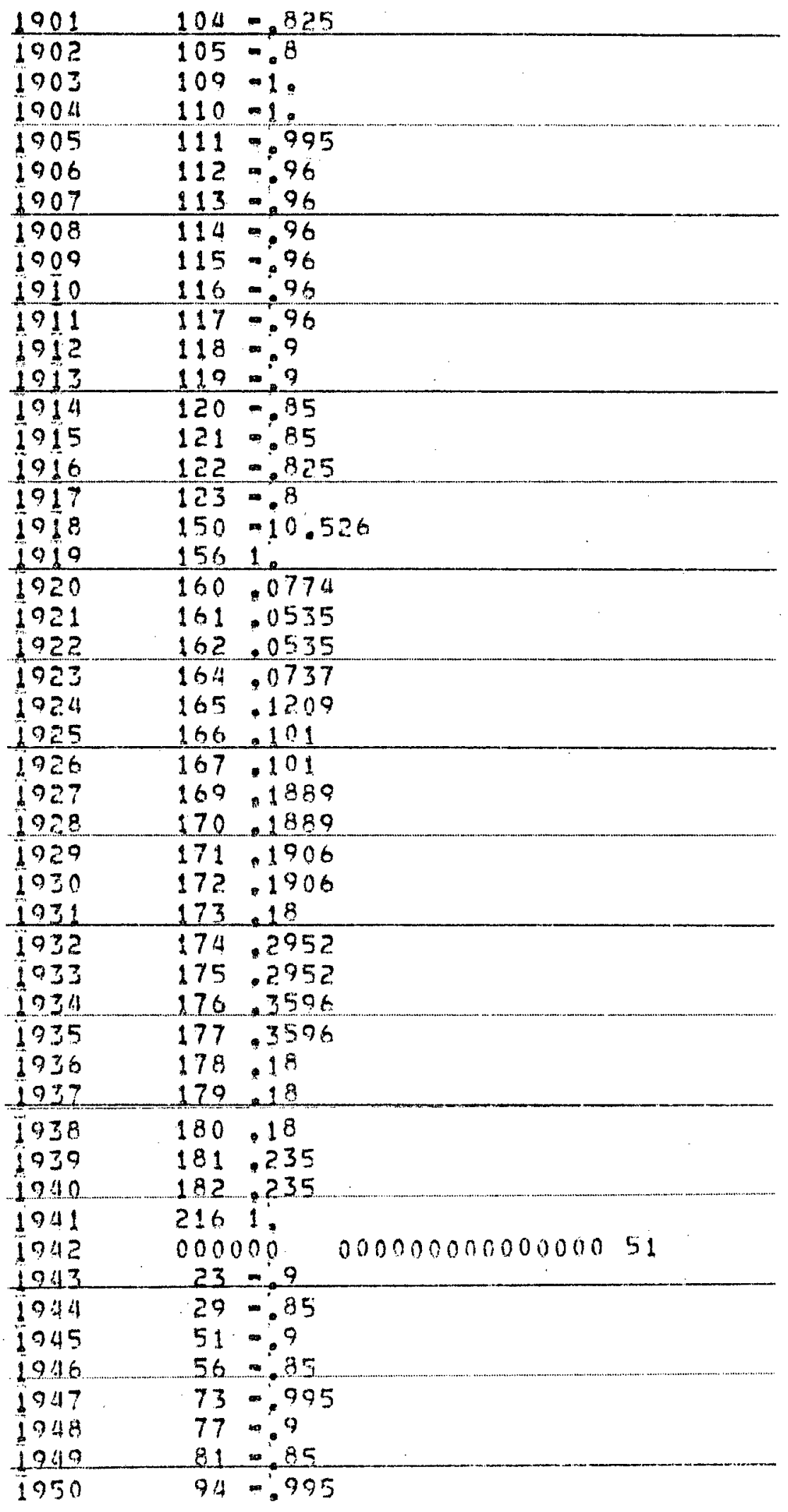




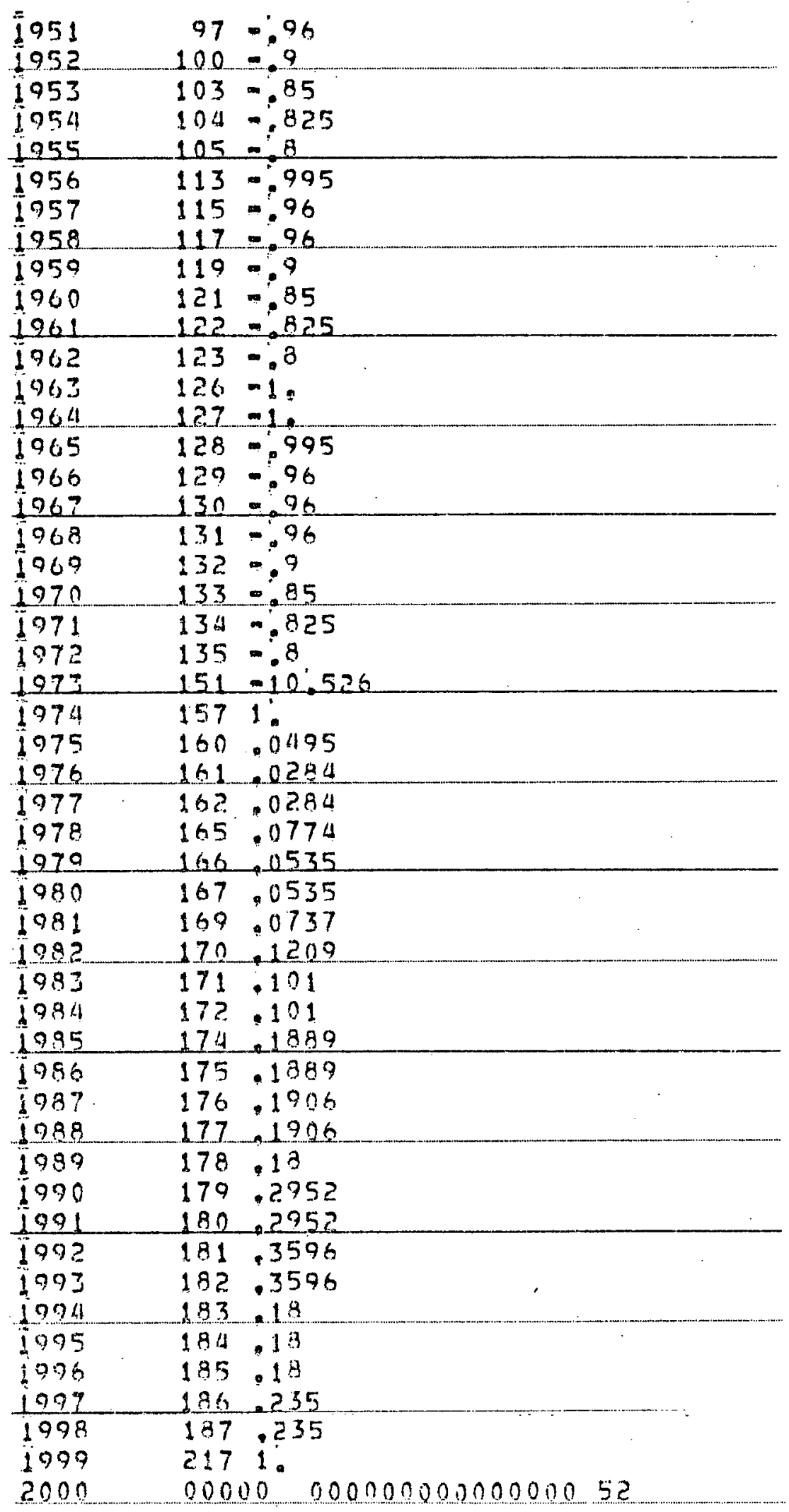




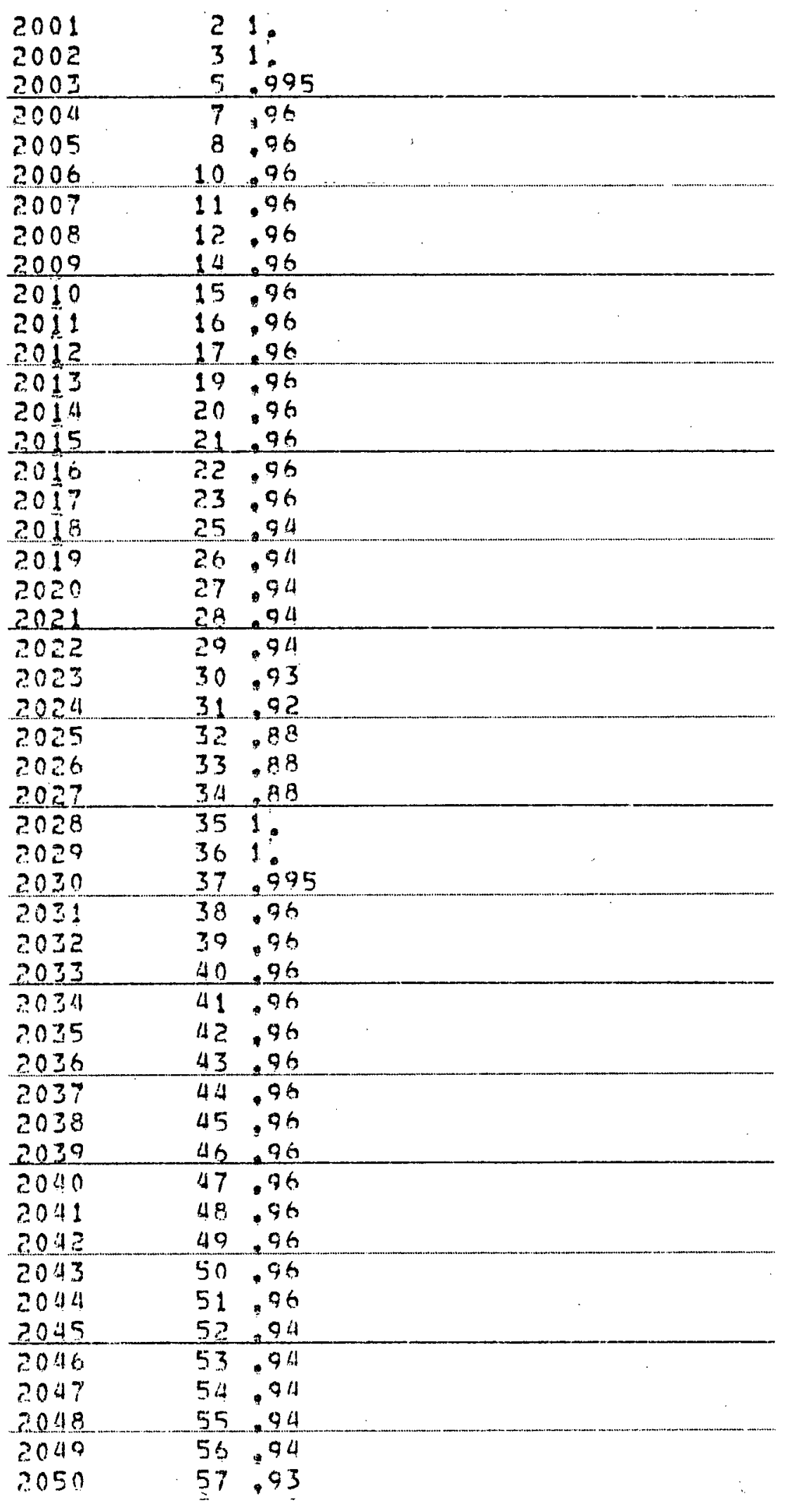




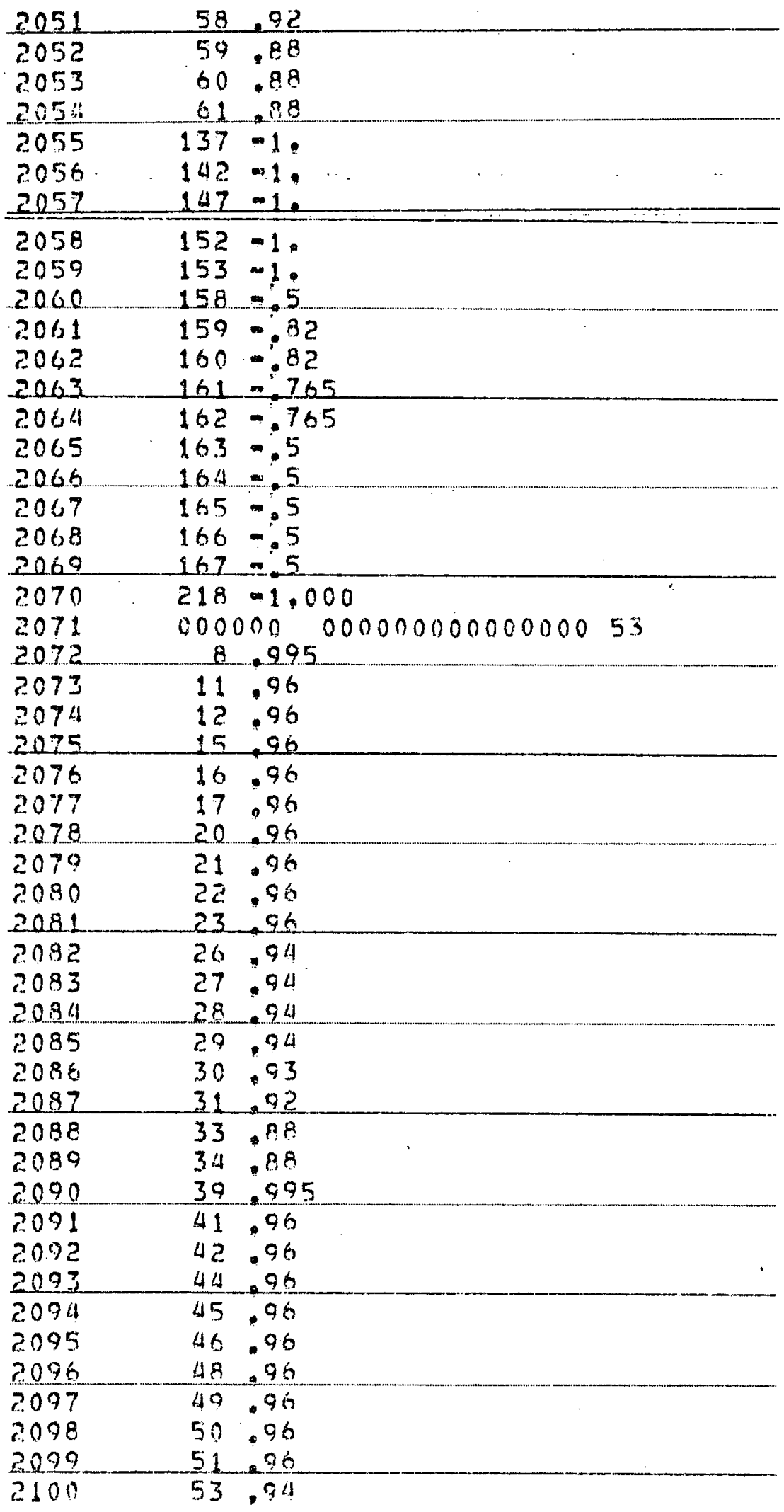




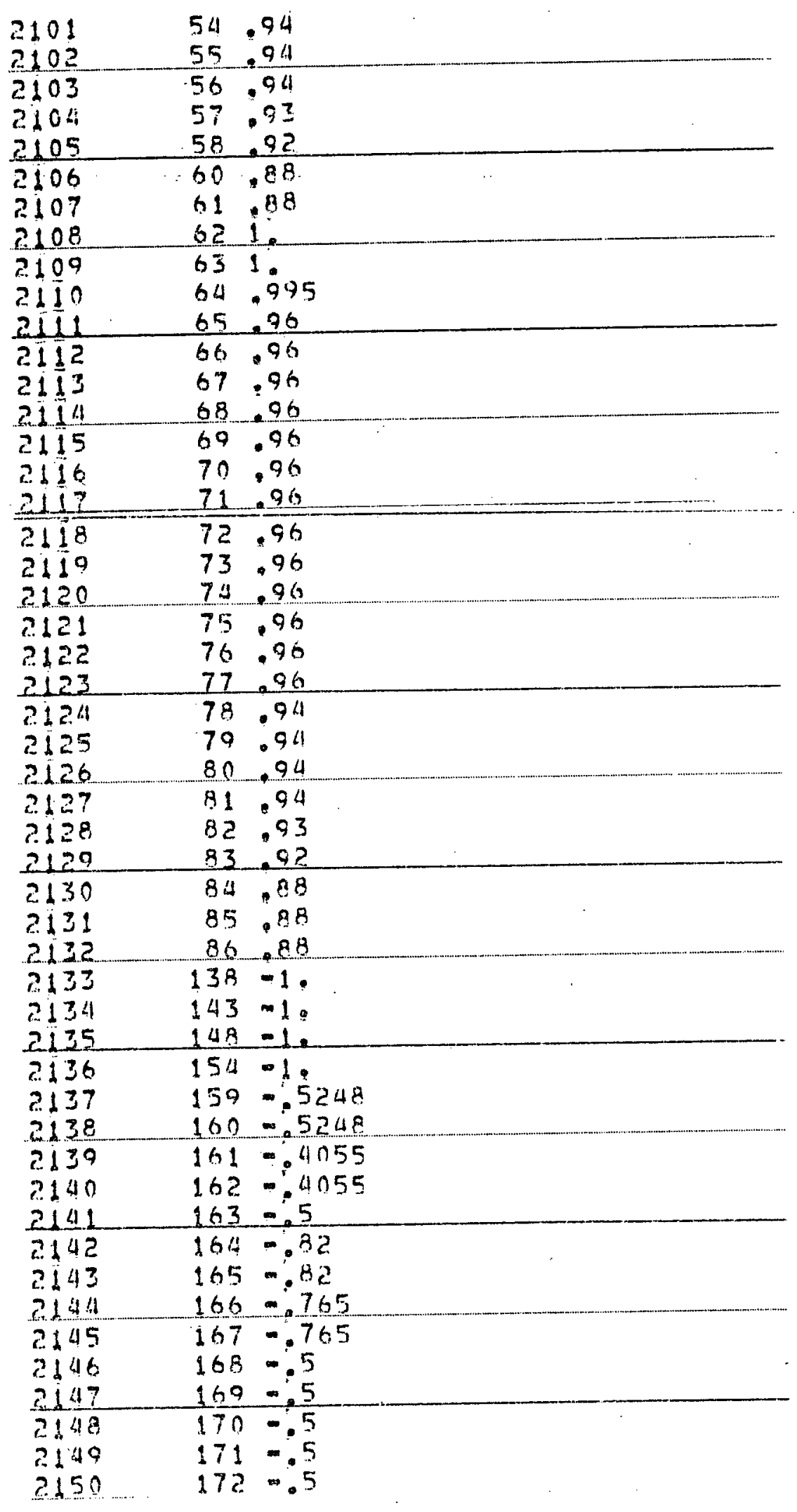




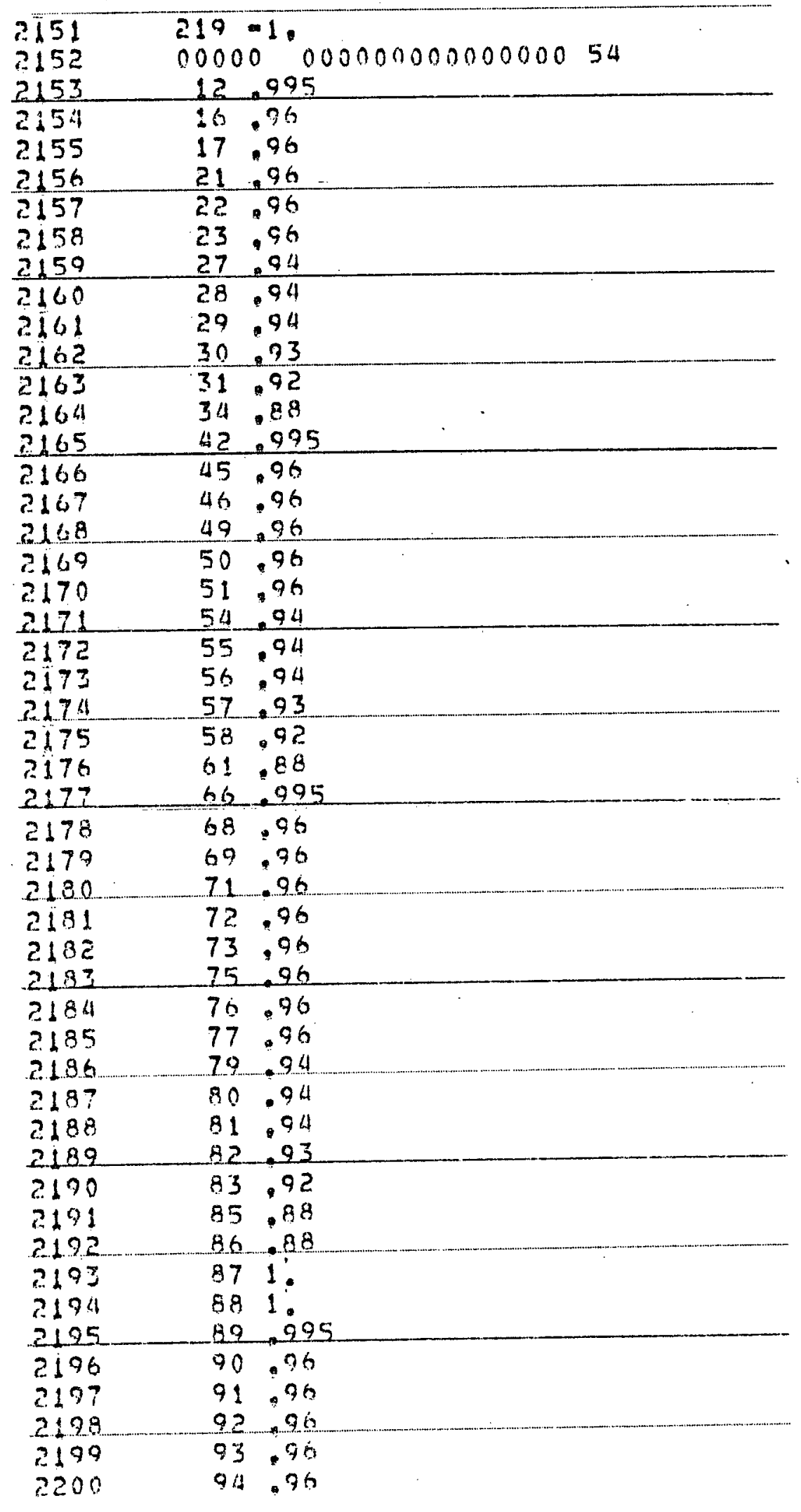




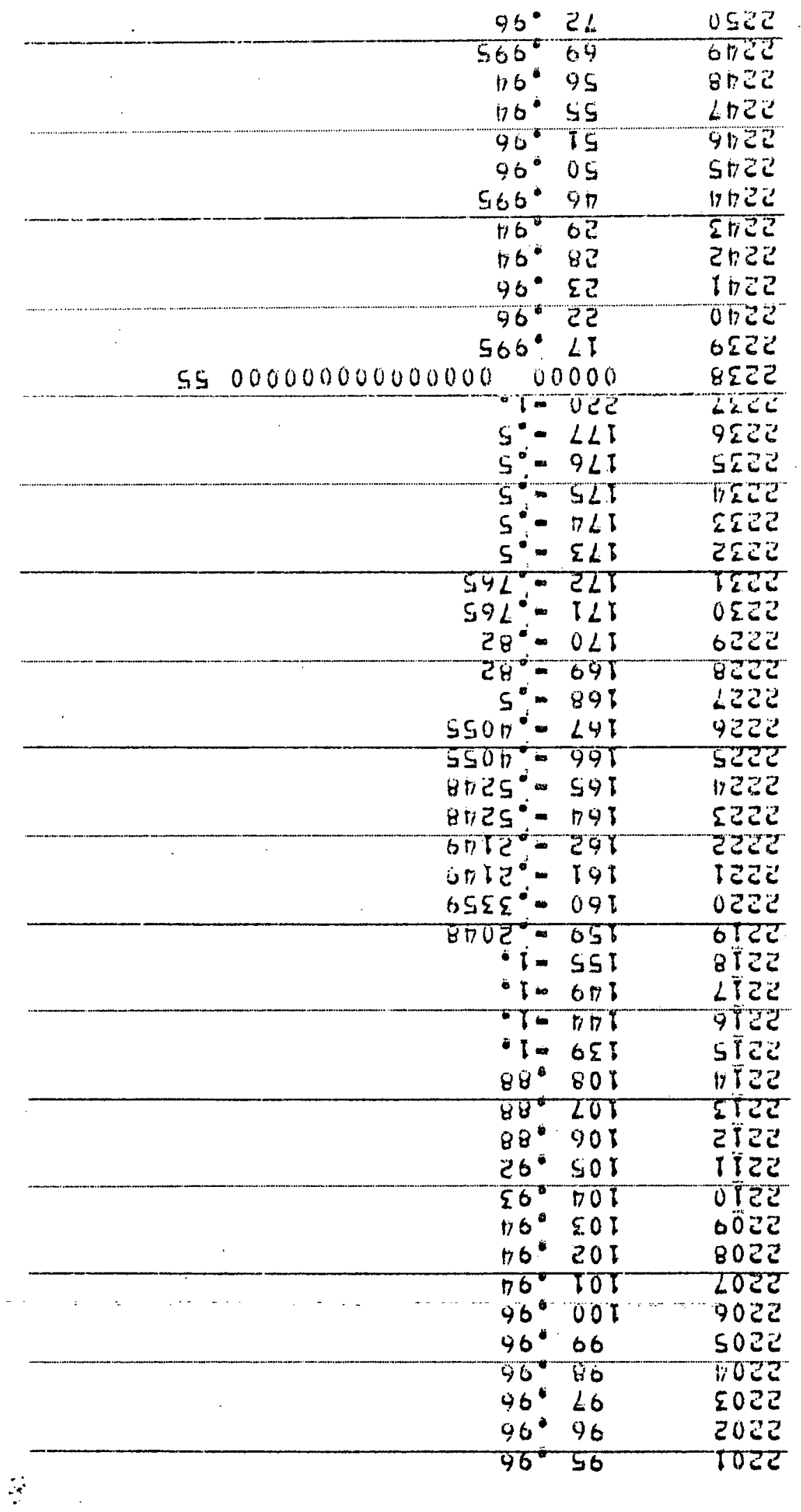




\begin{tabular}{|c|c|c|c|}
\hline $\begin{array}{l}2251 \\
2252\end{array}$ & $\begin{array}{l}73 \\
76\end{array}$ & $\begin{array}{l}96 \\
96\end{array}$ & \\
\hline $\begin{array}{l}2253 \\
2254\end{array}$ & $\begin{array}{l}77 \\
80\end{array}$ & .96 & \\
\hline 2255 & 81 & .94 & \\
\hline 2256 & 82 & .93 & \\
\hline $\begin{array}{l}2257 \\
2258\end{array}$ & $\begin{array}{l}83 \\
86\end{array}$ & $\begin{array}{r}92 \\
88\end{array}$ & \\
\hline 2259 & 91 & .995 & \\
\hline 2260 & 93 & .96 & \\
\hline 2261 & 94 & .96 & \\
\hline 2262 & 96 & .96 & \\
\hline $\begin{array}{l}2263 \\
2264\end{array}$ & $\begin{array}{l}97 \\
90\end{array}$ & 96 & \\
\hline$\frac{2264}{2205}$ & 99 & $\frac{96}{96}$ & \\
\hline $\begin{array}{l}22065 \\
2266\end{array}$ & 100 & .96 & \\
\hline $\begin{array}{l}2266 \\
2267\end{array}$ & 102 & .94 & \\
\hline$\frac{2267}{2268}$ & 103 & $-\frac{.94}{.93}$ & \\
\hline $\begin{array}{l}2268 \\
2269\end{array}$ & 104 & .93 & \\
\hline $\begin{array}{l}2289 \\
2270\end{array}$ & 105 & .92 & \\
\hline$\frac{2270}{3271}$ & $\frac{107}{108}$ & $\begin{array}{r}.88 \\
.88\end{array}$ & \\
\hline 2272 & $\begin{array}{l}108 \\
109\end{array}$ & $i^{\circ}$ & \\
\hline 22273 & 110 & 1. & \\
\hline 2274 & 111 & .995 & \\
\hline 2275 & 112 & .96 & \\
\hline 2276 & 113 & .96 & \\
\hline 2277 & 114 & .96 & \\
\hline 2.278 & 115 & .96 & \\
\hline 2279 & 116 & .96 & \\
\hline 2280 & 117 & .96 & \\
\hline 2281 & 118 & .96 & \\
\hline 2282 & 119 & .96 & \\
\hline 2283 & 120 & .911 & \\
\hline 2284 & 121 & .94 & \\
\hline 2285 & 122 & .93 & \\
\hline 2286 & 123 & .92 & \\
\hline 2287 & 124 & .88 & \\
\hline 2238 & 125 & .88 & \\
\hline 2289 & 140 & 1, & \\
\hline 2290 & 145 & -1, & \\
\hline 2291 & 150 & -1. & \\
\hline 7.292 & 156 & -1. & \\
\hline 2293 & 160 & -215 & \\
\hline 2294 & 161 & $=.1139$ & \\
\hline 2295 & 162 & -.1139 & \\
\hline $\begin{array}{l}2296 \\
22977\end{array}$ & $\begin{array}{l}164 \\
165\end{array}$ & $\begin{array}{r}-2048 \\
-3359\end{array}$ & \\
\hline $\begin{array}{l}2397 \\
2298\end{array}$ & 265 & $\begin{array}{l}=3359 \\
=2149\end{array}$ & $\cdots$ \\
\hline $\begin{array}{l}2298 \\
2299\end{array}$ & 166 & $\begin{array}{r}-2149 \\
2149\end{array}$ & \\
\hline $\begin{array}{l}2290 \\
2300\end{array}$ & $\begin{array}{l}167 \\
169\end{array}$ & $\begin{array}{r}0.2149 \\
\because 5248\end{array}$ & - \\
\hline
\end{tabular}




\begin{tabular}{|c|c|c|}
\hline $\begin{array}{l}2301 \\
2302 \\
2303\end{array}$ & $\begin{array}{l}170 \\
171 \\
172\end{array}$ & $\begin{array}{l}\because 5248 \\
\because 4055 \\
=4055 \\
\end{array}$ \\
\hline $\begin{array}{l}2304 \\
2305 \\
2306 \\
2307 \\
2308 \\
2309\end{array}$ & $\begin{array}{l}173 \\
174 \\
175 \\
176 \\
177 \\
178\end{array}$ & $\begin{array}{l}-5 \\
.82 \\
-.82 \\
.765 \\
-765 \\
-.5\end{array}$ \\
\hline $\begin{array}{l}2310 \\
2311 \\
2312\end{array}$ & $\begin{array}{l}179 \\
180 \\
181\end{array}$ & $\begin{array}{r}.5 \\
-5 \\
-5\end{array}$ \\
\hline $\begin{array}{l}2313 \\
2314 \\
2315\end{array}$ & $\begin{array}{l}182 \\
221 \\
0001\end{array}$ & $\begin{array}{l}-5 \\
-1 . \\
\Omega\end{array}$ \\
\hline $\begin{array}{l}2316 \\
3317 \\
2318\end{array}$ & $\begin{array}{l}23 \\
29 \\
51\end{array}$ & $\begin{array}{r}.96 \\
.94 \\
.96 \\
\end{array}$ \\
\hline $\begin{array}{l}2319 \\
2320 \\
2321\end{array}$ & $\begin{array}{l}56 \\
73 \\
77\end{array}$ & $\begin{array}{r}.94 \\
.995 \\
.96 \\
\end{array}$ \\
\hline $\begin{array}{l}2322 \\
2323 \\
2324\end{array}$ & $\begin{array}{l}81 \\
94 \\
97\end{array}$ & $\begin{array}{l}.34 \\
.995 \\
.96\end{array}$ \\
\hline $\begin{array}{l}2325 \\
2326 \\
2337\end{array}$ & $\begin{array}{l}100 \\
103 \\
104\end{array}$ & $\begin{array}{r}96 \\
.94 \\
.93\end{array}$ \\
\hline $\begin{array}{r}2328 \\
2329 \\
2330\end{array}$ & $\begin{array}{l}105 \\
108 \\
113\end{array}$ & $\begin{array}{l}.92 \\
.88 \\
.995\end{array}$ \\
\hline $\begin{array}{l}2331 \\
2332 \\
2333\end{array}$ & $\begin{array}{l}115 \\
117 \\
119 \\
\end{array}$ & $\begin{array}{r}96 \\
.96 \\
.96 \\
\end{array}$ \\
\hline $\begin{array}{l}2334 \\
2335 \\
2336\end{array}$ & $\begin{array}{l}121 \\
122 \\
123\end{array}$ & $\begin{array}{r}.94 \\
.93 \\
.92\end{array}$ \\
\hline $\begin{array}{l}2337 \\
2338 \\
2338\end{array}$ & $\begin{array}{l}125 \\
126 \\
127\end{array}$ & i: \\
\hline $\begin{array}{l}2340 \\
2341 \\
3342\end{array}$ & $\begin{array}{l}12.8 \\
129 \\
130\end{array}$ & $\begin{array}{r}.995 \\
.96 \\
.96 \\
\end{array}$ \\
\hline $\begin{array}{l}2343 \\
2344 \\
2345\end{array}$ & $\begin{array}{l}131 \\
132 \\
133\end{array}$ & $\begin{array}{r}.96 \\
.96 \\
94 \\
\end{array}$ \\
\hline $\begin{array}{l}2346 \\
2347 \\
2348\end{array}$ & $\begin{array}{l}134 \\
135 \\
136\end{array}$ & $\begin{array}{r}.93 \\
.92 \\
.88\end{array}$ \\
\hline $\begin{array}{l}2349 \\
2350\end{array}$ & $\begin{array}{l}141 \\
146\end{array}$ & $\begin{array}{l}-1 \\
-1\end{array}$ \\
\hline
\end{tabular}




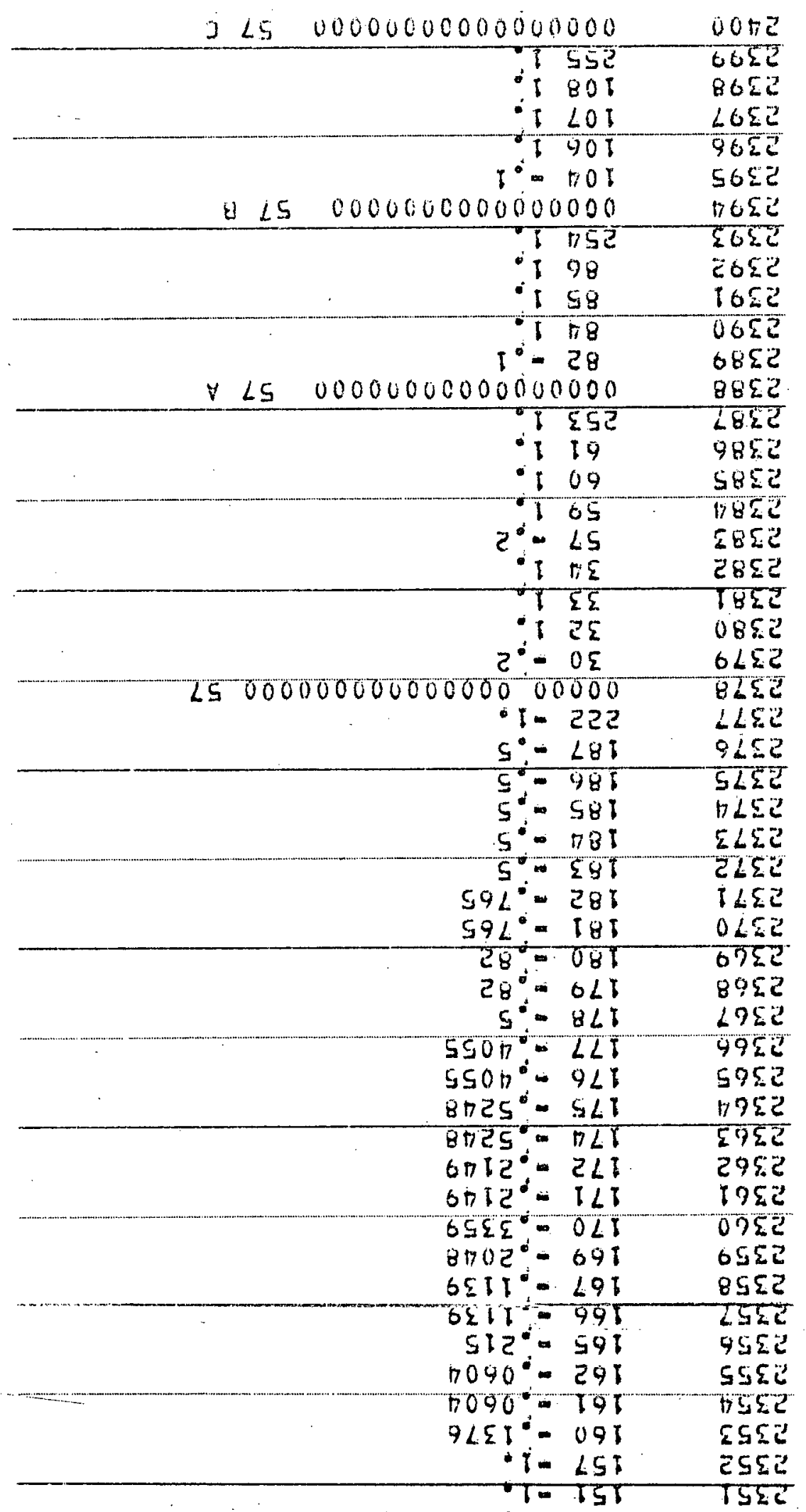




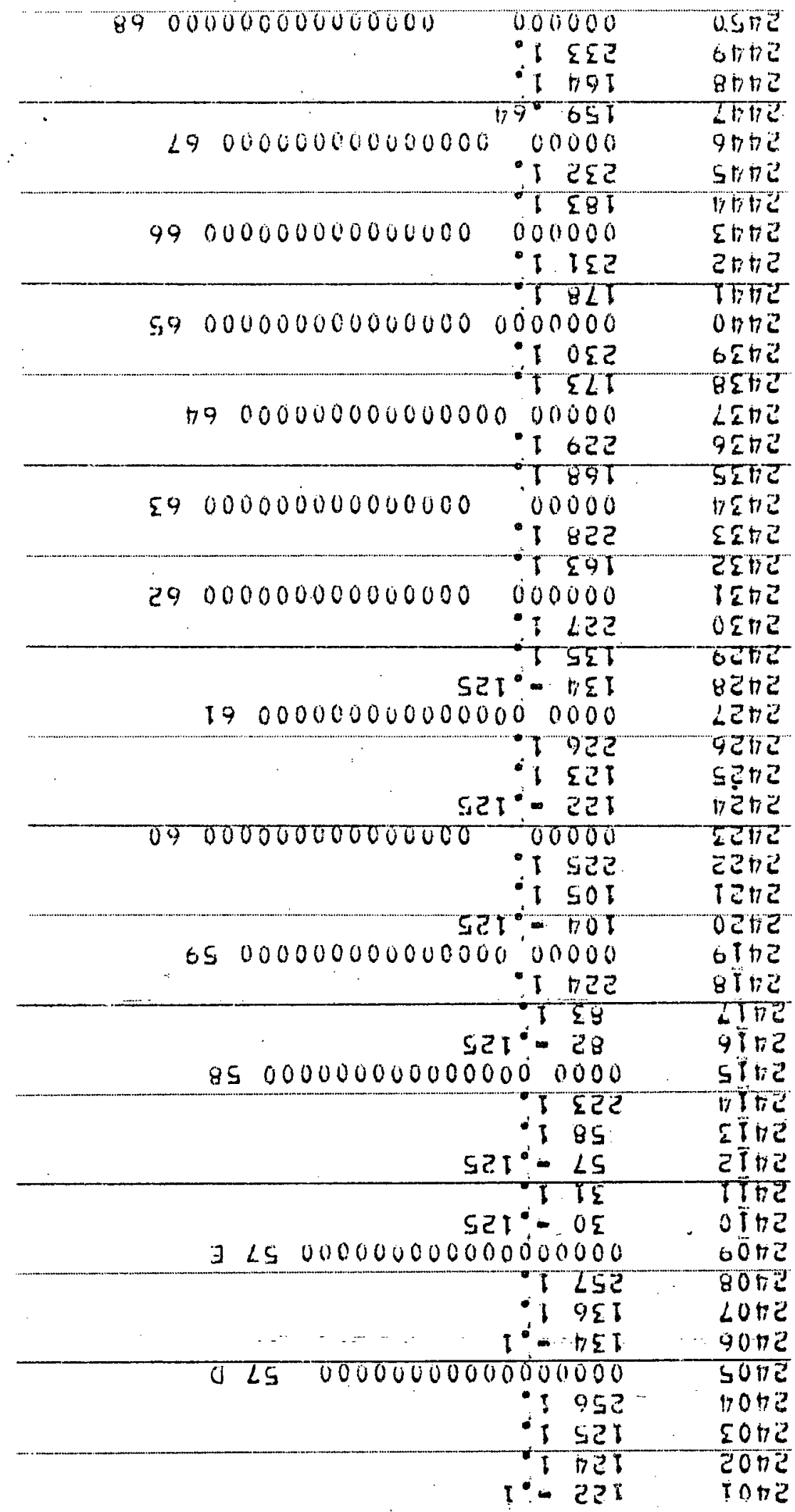




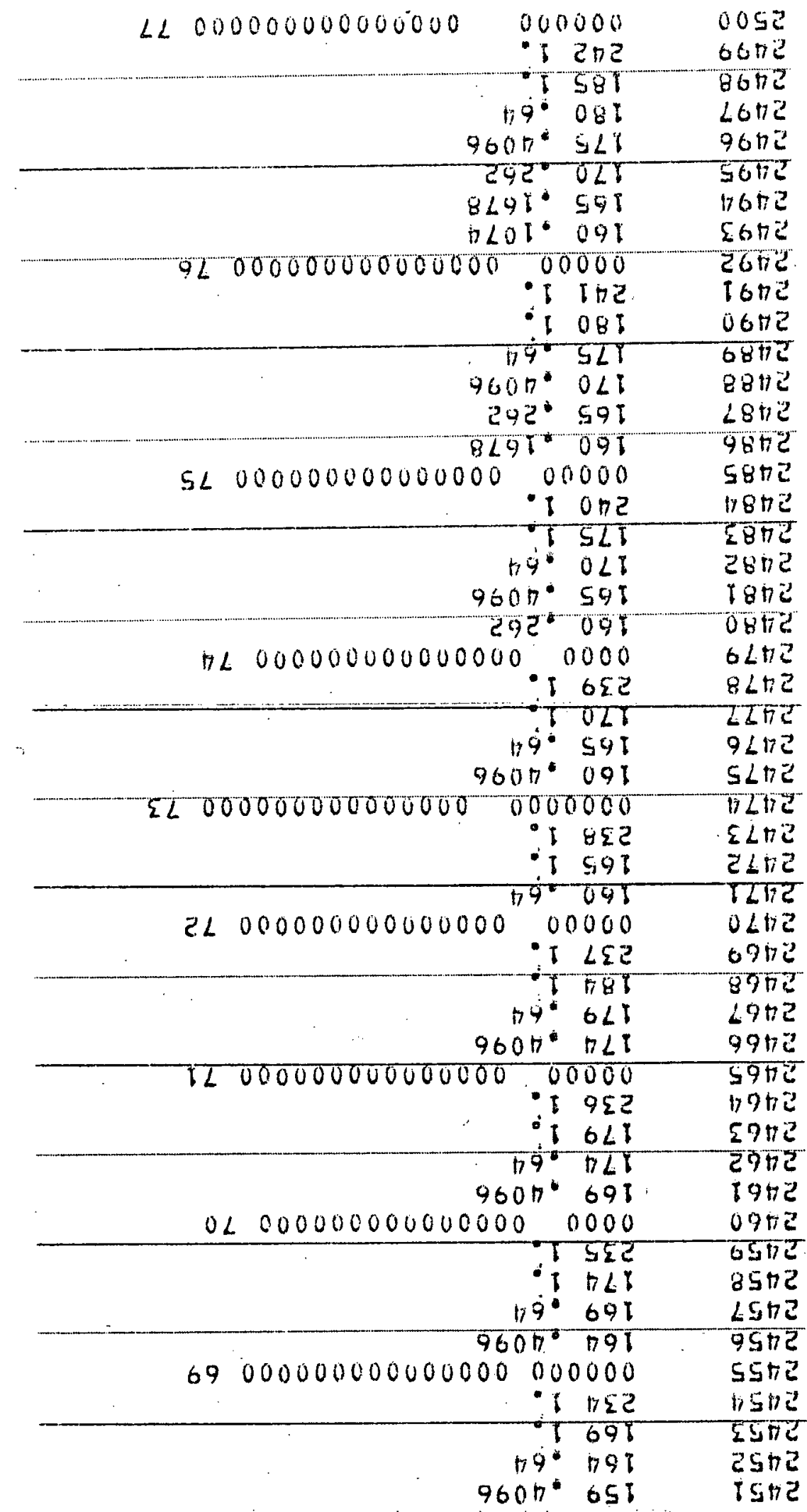




\begin{tabular}{|c|c|}
\hline 2501 & 161.53 \\
\hline $\begin{array}{l}2502 \\
2503\end{array}$ & $\begin{array}{l}1661 \\
2431\end{array}$ \\
\hline .2504 & 000000000000000000078 \\
\hline $\begin{array}{l}2505 \\
2506 \\
2507\end{array}$ & $\begin{array}{lll}161 & .2809 \\
166 & 53 & \\
171 & 1 .\end{array}$ \\
\hline 2508 & 2441. \\
\hline 2509 & 000000000000000000079 \\
\hline 2510 & $161 \cdot 1429$ \\
\hline $25 \frac{11}{25}$ & $\begin{array}{ll}166 & .2809 \\
171 & 53\end{array}$ \\
\hline 2513 & 2761. \\
\hline 2514 & 2451 \\
\hline 2515 & 0000000000000000000080 \\
\hline 2516 & 101.079 \\
\hline 2517 & 160.1489 \\
\hline 2518 & 171.2809 \\
\hline 2519 & $176: 53$ \\
\hline 7520 & 1811 \\
\hline 2521 & 2461 \\
\hline 2522 & 0000000000000000000081 \\
\hline 2523 & 161.0418 \\
\hline 2524 & 166.079 \\
\hline 2525 & 171.1489 \\
\hline 2526 & 176.2809 \\
\hline 2.527 & 181.53 \\
\hline 2528 & 2861 \\
\hline 2529 & 2471. \\
\hline 2530 & 000000000000000000082 \\
\hline 2531 & 162.53 \\
\hline $253 ?$ & 1671. \\
\hline 2533 & 2481. \\
\hline 2534 & $00000^{\circ} 00000000000000083$ \\
\hline 2535 & 162.2809 \\
\hline 2536 & 167.53 \\
\hline 2527 & 1721 \\
\hline 2538 & 2491. \\
\hline $25 \geq 9$ & $00000^{\circ} 00000000000000084$ \\
\hline 2540 & 162,1489 \\
\hline 2541 & 167.2809 \\
\hline 2542 & 172.53 \\
\hline .2543 & $1771:$ \\
\hline 2544 & 2501. \\
\hline 2545 & 00000000000000085 \\
\hline 2546 & 162.079 \\
\hline 2.547 & 167.1489 \\
\hline 2548 & 172.2809 \\
\hline 2549 & 172.53 \\
\hline 50 & 132 \\
\hline
\end{tabular}




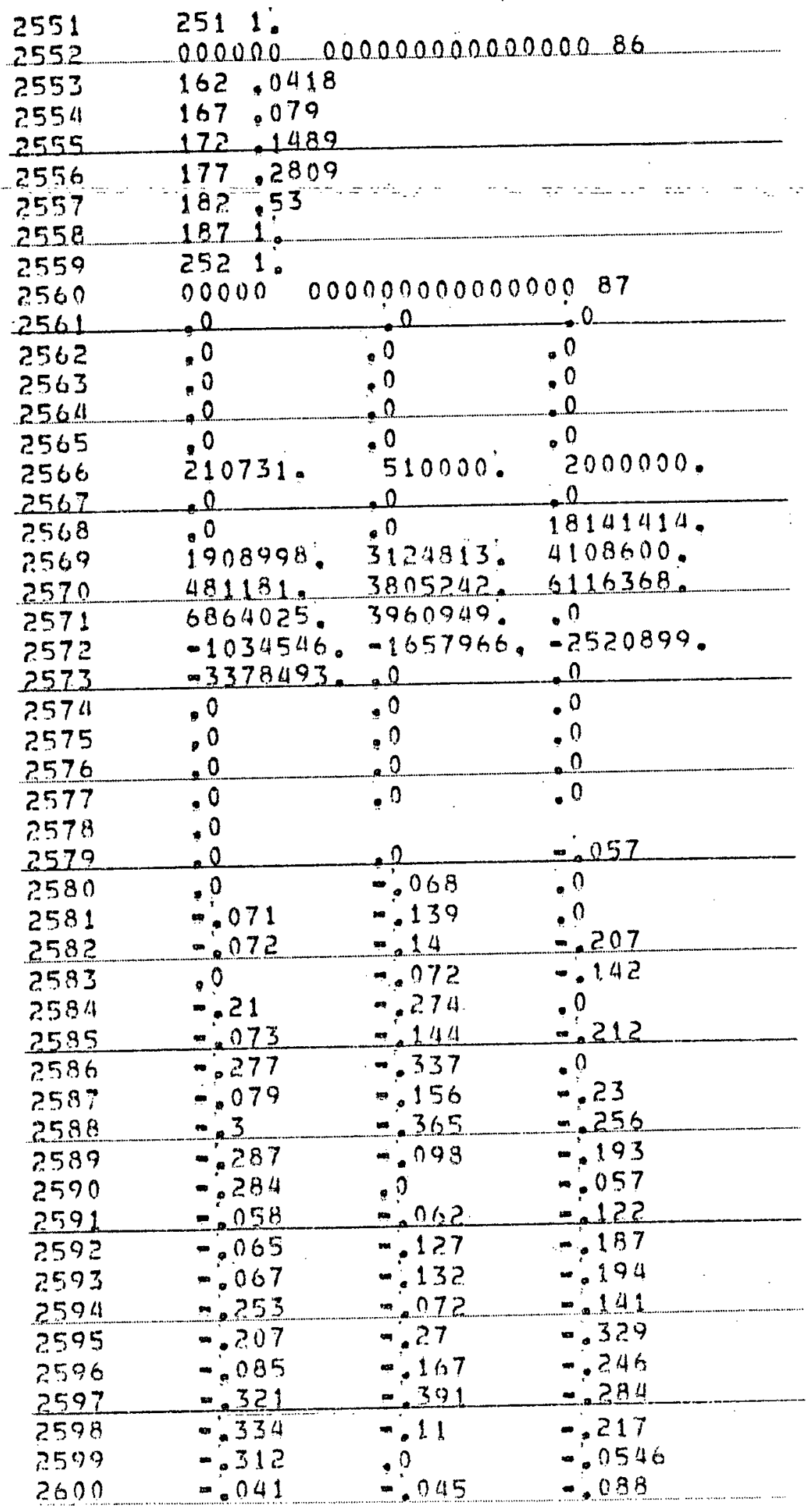




\begin{tabular}{|c|c|c|c|}
\hline $\begin{array}{l}2601 \\
2602 \\
2603 \\
\end{array}$ & $\begin{array}{r}.048 \\
-.051 \\
-.189 \\
\end{array}$ & $\begin{array}{r}.094 \\
-099 \\
-056 \\
\end{array}$ & $\begin{array}{l}-138 \\
-146 \\
-11 \\
\end{array}$ \\
\hline $\begin{array}{l}2604 \\
2605 \\
2606\end{array}$ & $\begin{array}{r}.161 \\
.143 \\
.248\end{array}$ & $\begin{array}{l}.209 \\
=21 \\
=291\end{array}$ & $\begin{array}{r}.073 \\
-.272 \\
-.098\end{array}$ \\
\hline $\begin{array}{l}2607 \\
2608 \\
2609 \\
\end{array}$ & $\begin{array}{r}.193 \\
-.053 \\
-.094 \\
\end{array}$ & $\begin{array}{r}.282 \\
-.045 \\
-052 \\
\end{array}$ & $\begin{array}{l}.0 \\
-.048 \\
-.101 \\
\end{array}$ \\
\hline $\begin{array}{l}2610 \\
2611 \\
2612\end{array}$ & $\begin{array}{r}-147 \\
-156 \\
-168\end{array}$ & $\begin{array}{r}-055 \\
-059 \\
-072\end{array}$ & $\begin{array}{l}=107 \\
-116 \\
=139\end{array}$ \\
\hline $\begin{array}{l}2613 \\
2614 \\
2615 \\
\end{array}$ & $\begin{array}{r}-202 \\
-092 \\
.0 \\
\end{array}$ & $\begin{array}{l}=229 \\
=18 \\
=.058 \\
\end{array}$ & $\begin{array}{r}.269 \\
.261 \\
.049 \\
\end{array}$ \\
\hline $\begin{array}{l}2616 \\
2617 \\
2618\end{array}$ & $\begin{array}{l}-.055 \\
-109 \\
-.06\end{array}$ & $\begin{array}{r}-105 \\
-058 \\
-115\end{array}$ & $\begin{array}{r}.057 \\
. .112 \\
-.07\end{array}$ \\
\hline $\begin{array}{l}2619 \\
2620 \\
2621\end{array}$ & $\begin{array}{l}.134 \\
.09 \\
.054 \\
\end{array}$ & $\begin{array}{r}.154 \\
-173 \\
-.062 \\
\end{array}$ & $\begin{array}{l}.18 \\
.0 \\
0.062 \\
\end{array}$ \\
\hline $\begin{array}{l}2622 \\
2623 \\
2621 \\
\end{array}$ & $\begin{array}{r}.062 \\
-.077 \\
-.098 \\
\end{array}$ & $\begin{array}{l}063 \\
=.087 \\
-9\end{array}$ & $\begin{array}{l}.064 \\
. .102 \\
.0\end{array}$ \\
\hline $\begin{array}{l}2625 \\
2626 \\
2627\end{array}$ & $\begin{array}{l}0 \\
.0 \\
0 \\
\end{array}$ & $\begin{array}{l}0 \\
0 \\
0 \\
\end{array}$ & $\begin{array}{l}0 \\
0 \\
0 \\
0\end{array}$ \\
\hline $\begin{array}{l}2628 \\
2629 \\
2630 \\
\end{array}$ & $\begin{array}{l}.0 \\
.0 \\
.059 \\
\end{array}$ & $\begin{array}{l}0 \\
.075 \\
.053\end{array}$ & $\begin{array}{l}0 \\
.077 \\
.063\end{array}$ \\
\hline $\begin{array}{l}2631 \\
2632 \\
2633\end{array}$ & $\begin{array}{r}.084 \\
.144 \\
.07 ? \\
\end{array}$ & $\begin{array}{l}.034 \\
.065 \\
.169 \\
\end{array}$ & $\begin{array}{r}.108 \\
.073 \\
.181 \\
\end{array}$ \\
\hline $\begin{array}{l}2634 \\
2635 \\
2636\end{array}$ & $\begin{array}{r}.082 \\
.135 \\
.093\end{array}$ & $\begin{array}{l}.095 \\
.15 \\
.058\end{array}$ & $\begin{array}{l}.064 \\
.079 \\
.106\end{array}$ \\
\hline $\begin{array}{l}2637 \\
2638 \\
2639 \\
\end{array}$ & $\begin{array}{r}.122 \\
.063 \\
.069 \\
\end{array}$ & $\begin{array}{r}078 \\
.086 \\
.071 \\
\end{array}$ & $\begin{array}{r}.036 \\
.089 \\
.038 \\
\end{array}$ \\
\hline $\begin{array}{l}2640 \\
2641 \\
2642\end{array}$ & $\begin{array}{l}.04 \\
.031 \\
.0\end{array}$ & $\begin{array}{l}.038 \\
.0 \\
.0\end{array}$ & $\begin{array}{l}.03 \\
.0 \\
0 \\
\end{array}$ \\
\hline 2043 & .0 & 0 & .0 \\
\hline $\begin{array}{l}26411 \\
2645\end{array}$ & $\begin{array}{r}0 \\
.0\end{array}$ & $\begin{array}{l}0 \\
0\end{array}$ & $\begin{array}{r}0 \\
0\end{array}$ \\
\hline 2646 & .0 & .0 & .0 \\
\hline $\begin{array}{l}2647 \\
2648\end{array}$ & .0 & $\begin{array}{l}0 \\
.0\end{array}$ & .0 \\
\hline $\begin{array}{l}2649 \\
2650\end{array}$ & .0 & $\begin{array}{l}.0 \\
.0\end{array}$ & .0 \\
\hline
\end{tabular}




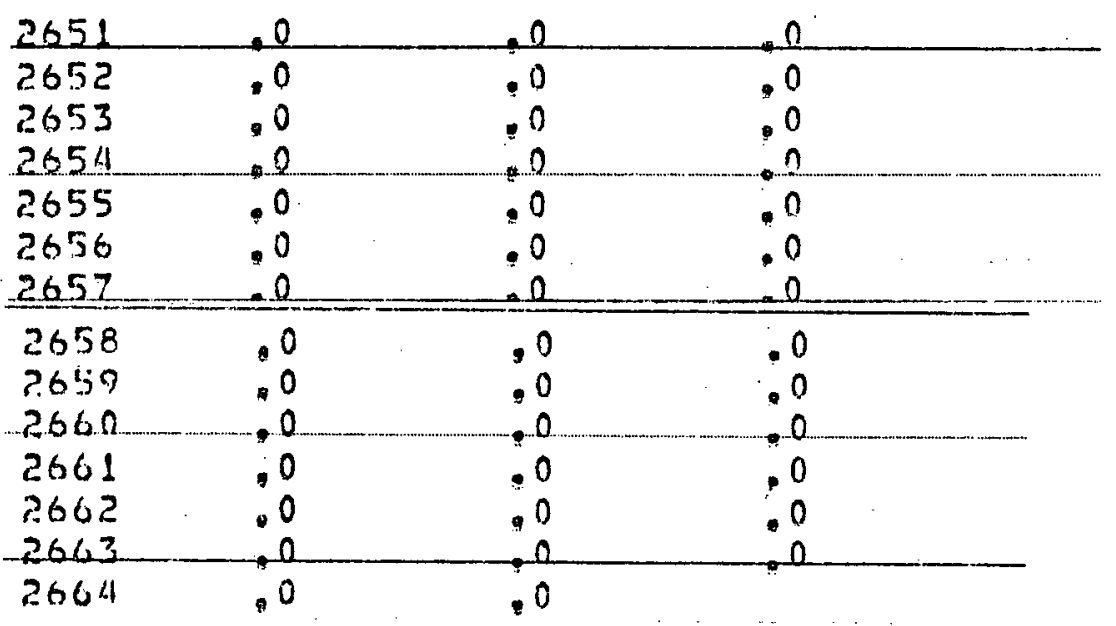




\section{A COMPARISOR OF STOCHASTIC DYHAMIC PROGRAMMING AND STOCHASTIC LINEAR PROGRAMMING WITH SIMPLE RECOURSE MODELS AS DECISION TOOLS}

\subsection{Introduction}

The asset and liability management problem is a continuous decision problem in which actions can be taken at any point in time. At any decision point, the bank has a portfolio of assets and liabilities on hand. Based on forecasts of future interest rates and cash flows, the bank must decide which assets to hold in its portfolio, which assets to sell from its portfolio and which assets to buy for its portfolio. These decisions are made subject to such constraints as cash flows and liquidity. This decision-making process is performed repeatedly. The process is dynamic in that the optimal solution to the immediate problem is dependent on the actions that will be taken at each future decision point (and dependent on the realizations of the random variables).

The best approach to solving the asset and liability management problem would probably be a continuous time stochastic dynamic optimization formulation. Decisions could be made at each point in time conditional on the entire history of events up to and including the present. Such a technique would be able to utilize a greater amount of information than can be summarized in a discrete-time model.

However, computational tractability inhibits the development of an operational model of the continuous type. On the other hand, some operational models have been developed where the time parameter and the probability distribution have been discretized to approximate the more general case. The Bradley and Crane model $[5,6,7]$ described in Chapter 2 is one example. 
The B-C model captures many of the essential features of the asset and liability management problem and achieves a certain amount of computational tractability. However, as was shown in Chapter 2, the B-C model encounters significant computational difficulty as the size of the model is enlarged. Another shortcoming of the B-C model is the inherent problem in the formulation.

To attain an operational model, B-C discretize a continuous probability distribution. So rather than obtaining optimality on the entire support of the random variable, one generates optimality only for a finite set of points in the support. That is, the decision variable must satisfy the constraint set constructed from the representative points. For realizations different from the representative points, the B-C model does not consider the profit foregone or the cost incurred in adjusting the portfolio. Also since the first period feasibility is achieved by the simultaneous satisfaction of the constraints generated from the discrete number of scenarios, the formulation is typical of the fat formulation ${ }^{1}$ for the discrete number of realizations of the random variable.

For example, consider a two-period problem in which an investor faces the following situation: 1) he has $\$ 100$ in period one to invest in either asset $x_{11}$ with a return $r_{11}=.1$ and maturing after one period or $x_{12}$ with a return $r_{12}=.2$ per period and maturing after two periods; 2) in the second period the investor either receives an additional $\$ 50$ to invest with probability .9 or he must return $\$ 50$ with probability .1;

3) in the second period, the investor also has the opportunity to invest in a one-period asset $x_{21}$ with a return $r_{21}=.1$ or to sell a part of his holdings

\footnotetext{
See Appendix 1 in Chapter 3.
} 
in $\mathrm{x}_{12}$ at a $20 \%$ discount; and 4 ) the investor stipulates that his realized capital losses cannot exceed $10 \%$ of the outstanding exogenous funds in any period.

The linear programming formulation of the above problem in the B-C. framework is given in Table 5.1. The optimal solution to this problem is

$$
\begin{array}{cc}
b_{1}^{1}\left(l_{1}\right)=11.11 \\
b_{1}^{2}\left(l_{1}\right)=88.89 \\
b_{2}^{1}\left(l_{21}\right)=80.00 & h_{2}^{1}\left(l_{22}\right)=0 \\
h_{12}^{2}\left(l_{2 \cdot 1}\right)=88.89 & h_{1}^{2}\left(l_{12}\right)=63.89 \\
s_{12}^{1}\left(l_{21}\right)=11.11 & s_{12}^{1}\left(l_{22}\right)=11.11 \\
s_{12}^{2}\left(l_{2,1}\right)=0 & s_{12}^{2}\left(l_{22}\right)=25.00
\end{array}
$$

and the optimal value is $\$ 42.87$.

The final constraint in the model, (which is a bound on realized capital losses), is binding. If the right hand side was increased to 7.5 (maximal loss of $15 \%$ ), then the optimal solution would be to purchase $\$ 100$ of asset $x_{12}$ (and sel1 $\$ 37.50$ of $x_{12}$ at the end of period 1, if the investor has to repay $\$ 50)$. The optimal value to this problem is $\$ 44.11$. Thus, because of the fat formulation used by the B-C model, with respect to the representative points in the support of the random variable, decision flexibility is reduced. This is a result of considering constraints corresponding to realizations with a small probability of occurrence. For example, it is clear from the above problem that in the B-C formulation a number of constraints (such as the capital loss constraints) are not weighted with respect to their profitability. 
Table 5.7

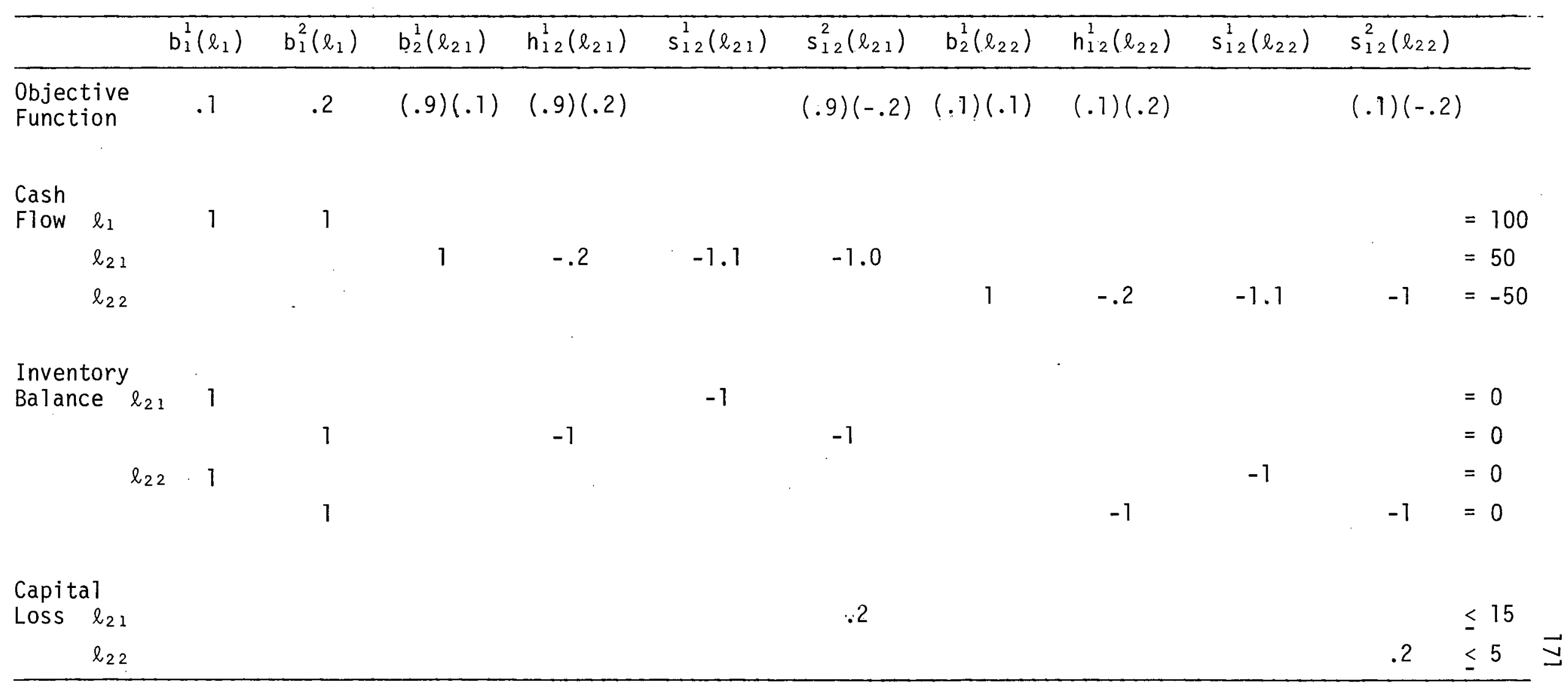


On the other hand, consider the simple recourse formulation described in this dissertation. In the recourse formulation, the right hand sides are not binding on the decision variables. Recourse is allowed and the penalties for the recourse decision compensate for decision infeasibility. Thus there is more first period decision flexibility in the recourse model than in any fat formulation.

The use of representative sample points and the fact that the first period decision is constrained by a11 future economic events may cast doubt on the value of the B-C formulation. In this chapter, in order to uphold the above contentions, a simulation will be performed on a small asset manacement problem. Therefore, coupled with the computational superiority of the recourse model, the ALM model presented in this dissertation should then be considered better operationally than the $B-C$ model.

The simulation utilizes two asset.and liability management models. In one model, a stochastic dynamic programming formulation will be used - the same approach B-C use. In the second model, a stochastic linear program with simple recourse formulation will be used. The simulation can be flowcharted as in Exhibit 5.1 .

This process is repeated for both formulations. After each reconciliation the profit (loss.) for the period is generated and stored. To evaluate the simulation a statistical comparison will be made of the profits generated by the two approaches. 
Exhibit 5.1

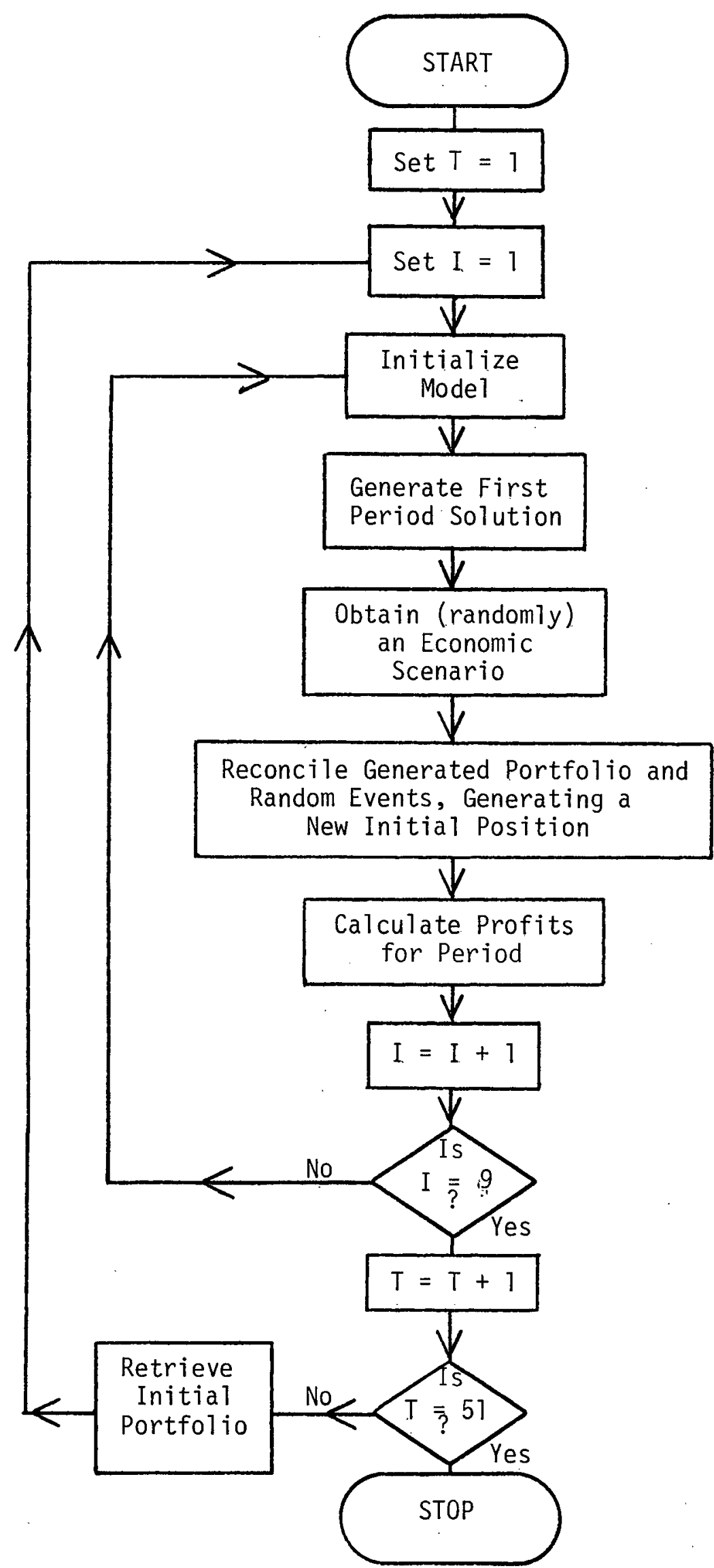




\subsection{Scenario for the Simulation}

The question addressed in this simulation is which formulation technique, SLPR or SDP, can be said to be better in some operational sense? This question must be answered from two points of view. First, which is better from a computational standpoint? And second, which technique is better from a normative standpoint? When one considers the difference in the size of the models for similar problems, ${ }^{1}$ the answer to the first question is selfevident. The answer to the second question is not as clear. Although theoretically SDP should provide a better normative solution, the restrictions inherent in the formulation - few representative sample points and the restrictive constraint set - may reduce the effectiveness of SDP. It is this question of normative effectiveness that the simulation addresses.

To answer the above question, an asset and liability management scenario is created in which the problem will be solved by the two techniques.

Essentially the problem is to determine the optimal portfolio of assets and liabilities, given random future rates of return, costs and cash flows. To maintain computational feasibility for the SDP approach, only 3 planning periods, 3 assets and 1 liability are considered.

The assets considered are: 1) a one period treasury bil1, 2) a term deposit maturing beyond the horizon of the mode1, and 3) a long-term mortgage. The liability used is a demand deposit. The returns and costs of these financial instruments were generated from 26 consecutive observations using data from Central Mortgage and Housing Corporation [10]. To get a

\footnotetext{
' See chapters 2 and 4 for comparisons.
} 
reasonable correlation of interest rates, the returns and costs were made a function of the prime rate. The distribution of the prime rate $(R)$ is

\begin{tabular}{lll}
\multicolumn{1}{r}{$r$} & & $\operatorname{Pr}(\mathrm{R}=\mathrm{r})$ \\
\hline .06 & & $.6 / 26$ \\
.065 & & $3 / 26$ \\
.0675 & & $1 / 26$ \\
.075 & & $2 / 26$ \\
.0775 & & $1 / 26$ \\
.08 & & $2 / 26$ \\
.085 & & $4 / 26$ \\
.09 & & $2 / 26$ \\
.095 & & $2 / 26$ \\
.11 & & $2 / 26$ \\
.115 & & $1 / 26$
\end{tabular}

Distributions were then derived for the difference between the prime rate and the rate of return of each of the four financial instruments. These distributions are

$\begin{array}{cccccccc}\frac{\mathrm{m}}{.0037} & \frac{\mathrm{P}(\mathrm{M} \leq \mathrm{m})}{0.0} & \frac{\mathrm{d}}{-.0104} & \frac{P(D \leq d)}{0.0} & \frac{\mathrm{t}}{-.0388} & \frac{P(T<t)}{0.0} & \frac{\ell}{-.0275} & \frac{P(L \leq \ell)}{0.0} \\ .0088 & 0.2 & -.0072 & 0.2 & -.0306 & 0.2 & -.025 & 0.2 \\ .0198 & 0.42 & +.0008 & 0.44 & -.0253 & 0.5 & -.0225 & 0.31 \\ .0235 & 0.62 & +.004 & 0.5 & -.0225 & 0.77 & -0.2 & 0.92 \\ .0297 & 0.81 & +.0118 & 0.78 & -.0174 & 0.81 & -.0175 & 1.00 \\ .0338 & 1.00 & +.0195 & 1.00 & -.0051 & 1.00 & & \end{array}$

Here the random variables $M, D, T$ and $L$ are defined to be the difference between the prime rate and each of the following: the mortgage rate, term deposit rate, treasury bill rate and the liability rate, respectively. 
At the initial point, the investor has $\$ 100,000$ in demand deposits which is equally invested in the three types of assets. The demand deposits will be assumed to increase (decrease) from one period to the next uniformly in the interval $[-20,000,20,000]$. If the demand deposits decrease so that assets have to be liquidated, then the FRB's parameters for quick liquidation are used. The discounts for treasury bills is .5\%, for term deposits $4 \%$, and for mortgages. $6 \%$.

The constraint set used will be of the B-C type. The constraints on the investor include: 1) cash flows, 2) capital losses, 3) class com-. position and 4) terminal conditions. The capital loss constraints assume that the investor does not want to realize net losses of more than $3 \%$ of the outstanding demand deposits in periods 1 and 2 , and $4 \%$ in period, 3 . The class composition constraints restrain the investor from having more than $\$ 50,000$ in total investments in any asset in periods 1 and 2 , and $\$ 60,000$ in period 3 . The terminal constraints include a discount on the assets in the current portfolio so that all funds are not simply invested in the highest yielding assets and held to the horizon of the model. These discounts are one-half of the normal discounts. The objective of the model is to maximize the net expected returns.

\subsection{Formulation of the Stochastic Dynamic Programming Model}

To formulate the problem posed in Section 5.2 as a stochastic dynamic program, it is necessary to first establish an economic scenario over the three period horizon. This will include obtaining a representative distribution for the cash flows and the rate of return of each of the four financial instruments. As already stated, the use of stochastic 
dynamic programming implies crude approximations of probability distributions, otherwise the computations become unwieldly. So, for the purposes of the simulation the number of possible realizations of the random variables during each time period will be limited to two.

As before, the demand deposits are current1y $\$ 100,000$. At the end of the period the incremental difference will lie in the interval $[-20,000,20,000]$. The two point representative distribution used in the formulation will be $\$ 90,000$ with probability .5 and $\$ 110,000$ with probability .5. Using this distribution the mean of the underlying distribution is maintained although the variance is smaller $\left(1.33 \times 10^{5}\right.$ versus $\left.1.0 \times 10^{5}\right)$. However, the approximation is reasonable as it divides the distribution symmetrically. For the third decision point the distribution will be constructed similarly. Thus the cash flows have the distribution

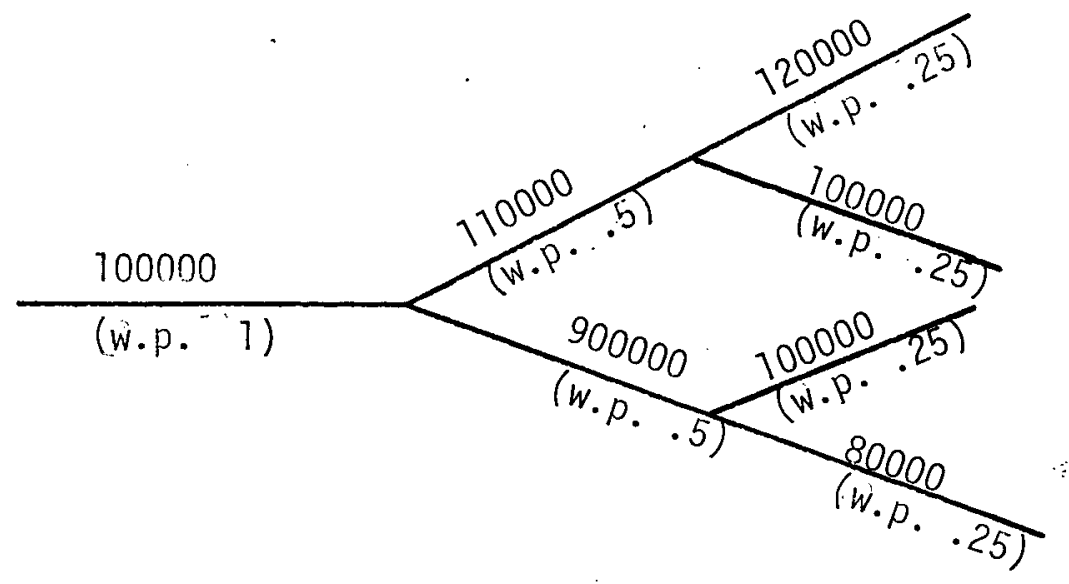


Using the same approach as above, the first period rate of return for a particular financial instrument (assume mortgage rate) is taken to be the median prime rate $(\bar{R})$ plus the median of the difference between the prime rate and the rate of return of the mortgages $(\bar{M})$. The two point estimate in the second period is $\bar{R}$ plus $m$, where $P(M \leq m)=.75$ and $\bar{R}$ minus $m$, where $P(M \leq m)=.25$. The four rates of return in the third period are: 1) $\bar{R}$ plus $m$, where $P(M \leq m)=.875,2) \bar{R}$ plus $m$, where $P(M \leq m)=.625$, 3) $\bar{R}$ plus $m$, where $P(M \leq m)=.375$, and 4) $\bar{R}$ plus $m$, where $P(M \leq m)=.125$.

The actual distributions of the rates of return used in the simulation are:

1) mortgage rate

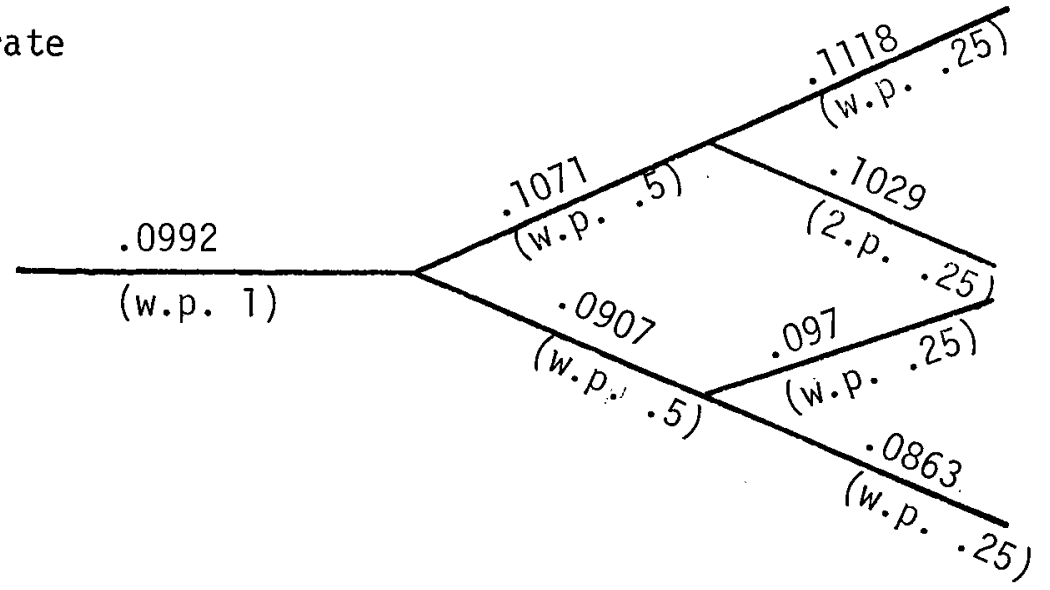

2) term deposit rate

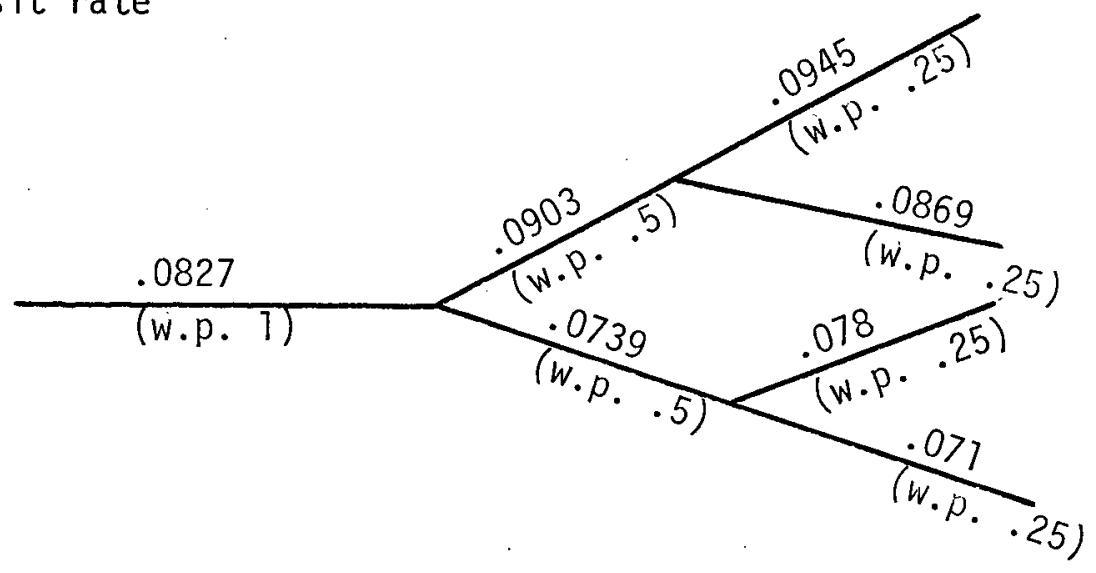


3) treasury bill rate

and 4) nonchequing rate
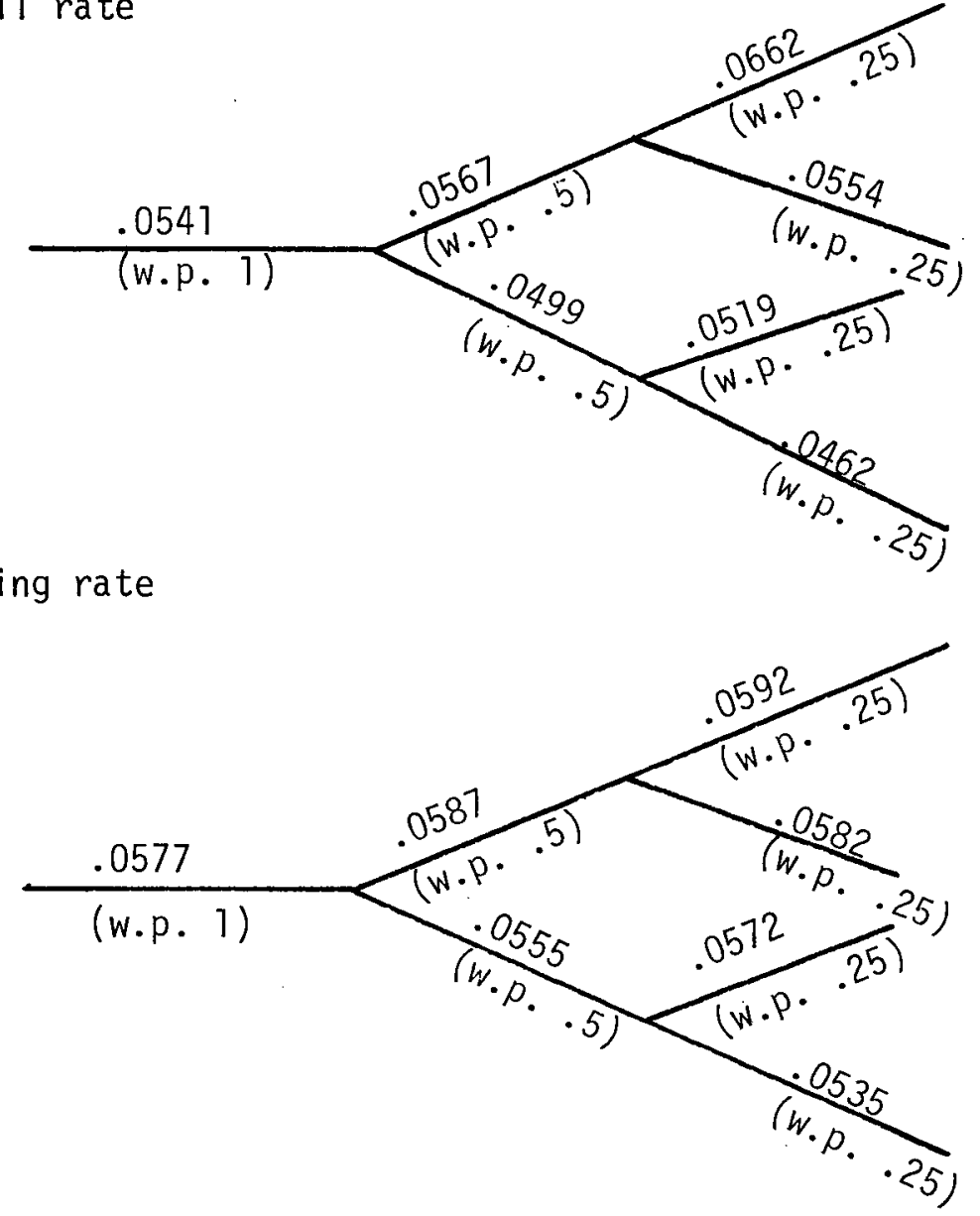

For purposes of the simulation, $70 \%$ of the nonchequing rate was used as the demand deposit rate since the nonchequing rate dominates the treasury bill rate. (This would have precluded investment in treasury bills a priori,) This ad hoc derivation of the demand deposit rate does not impinge on the usefulness of the simulation because the objective is to demonstrate that one solution technique may be operationally better than another.

The decision variables for the B-C model will be the same as defined in Chapter 2. Since treasury bills mature after one period, eighteen variables completely define all potential investment opportunities. Since the term deposits and mortgages mature beyond the horizon of the model, 
42 variables are required to describe all investment opportunities in each of these categories. The variables necessary to define the demand deposits include: the initial position, the demand deposit flows in period one, the two demand deposit flows in period two, and the four demand deposit flows in period three. In a 11, 110 variables define the investment opportunities in the problem.

There are four types of constraints. Constraints 1 to 7 are the cash flow requirements for each period under each economic scenario; namely the uses of funds are equal to the sources of funds. Constraints 8 to 14 require realized capital losses to be less than $3 \%$ of the outstanding demand deposits in period one and two, and $4 \%$ in period three. Constraints 15 to 35 rimit the amount of funds invested in each of the assets as prescribed in the problem. Constraints 36 to 89 (inventory balancing) consist of the initial holdings of each of the four financial instruments and records the transactions in each economic scenario.

The demand deposit flow constraint for period 1. places an upper bound on the funds potentially available for investment. Also the capital loss and the composition constraints add another 28 slack variables to the formulation. Therefore, the total size of the B-C formulation is 89 constraints with 139 variables.

The objective is to maximize the expected value of the net returns from the portfolio over the horizon of the model. That is, the coefficient of each variable is the product of the net return and the probability of its occurrence. 


\subsection{Formulation of the SLPR Model}

The SLPR model uses the same information as the B-C formulation. Also the constraints are of the same type, but the total number of constraints is fewer than in the $B-C$ model; this being the result of the manner in which uncertainty is incorporated in the SLPR model. In contrast to the B-C model, onty the mean rate of interest is used for each of the financial instruments rather than the possible realizations. Also, the SLPR model allows for violations of the constraints by incorporating penalties for recourse in the objective function. The decision variables for the SLPR model will be defined in a manner similar to the variables in the SLM model. The investment opportunities for treasury bi11s, term deposits, mortgages and demand deposits are defined by six, eleven, eleven and four variables, respectively.

The constraints in the SLPR model are comprised of: 1) three constraints to balance the initial holding of an asset with the future buying and selling of the asset, 2) three constraints to equate the cash flows for the three periods, 3) three constraints for each of the three assets for composition requirements, 4) four constraints to describe the initial position of the three assets and one liability, 5) three capital loss constraints of which one (the first period) is deterministic as 1) to 4) above, and the others being stochastic, and 6) three stochastic constraints which describe the flow of demand deposits. In short, there are 25 constraints in total of which five are stochastic. Adding nine slack variables for the class composition constraints and one for the deterministic 
capital loss constraint, the SLPR formulation has 25 constraints and 42 variables.

The right hand sides of the stochastic demand deposit constraints are representative points from the uniform distribution used in the $B-C$ model. However, because of the ability of the Wets' algorithm to handle many realizations without creating computational difficulties, the number of points chosen is larger than in the B-C model. The penalty for violations of any of these constraints is the net return to the horizon of the model, generated by a portfolio consisting of $50 \%$ mortgages and $50 \%$ term deposits, since their portfolio is considered, a priori, to be potentially the highest yielding portfolio. This penalty is calculated as

$$
.5\left[\left(1+\bar{r}_{m}\right)^{4-n}=1\right]+.5\left[\left(1+\bar{r}_{t}\right)^{4-n}-1\right]-\left[\left(1+\bar{r}_{d}\right)^{4-n}-1\right]
$$

where $n=1,2.3 \cdot$ is the period; $\bar{r}_{m}$ is the median return on mortgages; $\bar{r}_{t}$ is the median return on term deposits; and $\bar{r}_{d}$ is the median cost of demand deposits.

The right hand sides of the stochastic capital loss constraints are the representative points used in the $B-C$ formulation. The penalty for violations of these constraints is a loss percentage because these are policy constraints rather than physically or legally restrictive constraints as those in the preceding paragraph. In this particular formulation, a penalty of $4.1 \%$ is used.

The objective is to maximize the net returns minus the expected penalties for constraint violations. The coefficient of each variable is the net return for the first stage variables and the penalty for the second stage variables. 


\subsection{Results of the Simulation}

In most normative financial planning models, the objective is to determine what portfolio changes should be effected immediately. The multi-perodicity characteristic of financial models is to compensate for the shifting economic scenarios across time. However, the purpose of the model is to determine the changes to be implemented immediately. The simulation analyzed in this section determines which technique (SDP or SLPR) yields the superior first period, solution.

In reality, decisions may be made at any point in a period, however, using a discrete time model one aggregates so as to consider all decisions to be made at the start of each period - facing random rates of return. Again, the incremental cash flows are aggregated so that one-half is available at the beginning of the current period. In both formulations the same initial security holdings are given and the cash flows for the next period are random.

A detailed flowchart for the simulation is in an appendix at the end of the chapter. Essentially the process starts with an initial portfolio. Both the SDP and SLPR models determine an optimal solution for the first period. A random cash flow is then generated. If the amount of funds spent during the first period exceeds the random cash flow, then an amount equal to the excess spending must be divested from the present portfolio (.45 of mortgages, .45 term deposits and..1 treasury bi11s). On the other hand, if the random cash flows exceed spending during the first period, then the incremental amount is invested in treasury bills. After this reconcilliation, the realization of the random returns are determined. The revenues are the sum of the (known) returns of the assets held since 
the start of the period and the (random) returns on the assets bought at the start of the period. The costs are the sum of the (random) cost of demand deposits and the discount for selling securities prior to maturity. The reconciled portfolio serves as the new initial portfolio which is then used to generate the new solutions for both the SDP and SLPR models. This cycle is repeated for a total of eight times. This whole process is repeated fifty times for a total of four hundred iterations.

The simulation results for the SDP and SLPR formulations are used to test two hypotheses. The first hypothesis,

$$
H_{0}: \mu_{d}={ }^{\mu} \text { SDP }-{ }^{\mu} S L P R \geq 0,
$$

is used to test whether or not the initial period profit for SLPR is superior to that for SDP.

The first hypothesis is tested by examining the paired differences of the profits for the initial run of the 50 cycles for SLPR and SDP. The specific information used to test the first hypothesis is:

(1) the mean of the paired differences ( $\$ 251.37$ in favour of SLPR),

(2) the standard deviation of the paired differences (\$150.43), and

(3) the correlation between the SDP and SLPR profits (0.958). Given the large sample, the significance of the paired differences is tested using the following test statistic:

$$
\frac{-251.37}{150.43 / \sqrt{50}}=-11.81
$$


Since the test statistic is significant at the 0.001 lever, the null hypothes is is rejected. Thus, the SLPR formulation yields a statistically significant better initial solution than the SDP formulation.

The second hypothesis,

$$
H_{0}: \mu_{d}=\mu_{S D P}-\mu_{S L P R}>0
$$

is used to test whether or not the mean profit for SLPR is superior to that for SDP.

This hypothesis is tested by examining the paired differences of the mean profits of the eight runs of the fifty cycles for SLPR and SDP. The specific information used to test this hypothesis is:

1) the mean of the paired differences ( $\$ 297.26$ in favour of SLPR), 2) the standard deviation of the paired differences $(\$ 308.74)$, and 3 ) the correlation between the SDP and SLPR mean profits (.785). Again, given the sample size, the significance of the paired differences is tested using the following test statistic:

$$
\frac{-297.26}{308.74 / \sqrt{50}}=-6.81
$$

Since this is significant at the .001 level, the null hypothesis is rejected. Thus, the SLPR formulation yields a statistically significant better solution than the SDP formulation.

To test the stability of the above summary statistics, a second simulation using SLPR was run. The results of this simulation are 
analyzed as above: 1) a test of the initial solution of the fifty cycles, and 2) a test of the mean profits for the 8 runs of the fifty cycles. The information necessary to test the first hypothes is is:

1) the mean profits for the first and second SLPR runs ( $\$ 4645.85$ and $\$ 4672.23$ respectively), and 2) the standard deviations for the two runs $(\$ 421.11$ and $\$ 482.15$ respectively). The hypothes is that both samples have the same mean,

$$
H_{0}: \mu_{S L P R}=\mu_{S L P R}
$$

is tested first.

The standard deviation used for the test statistic is the root of the pooled variance. The test statistic is

$$
\frac{4672.23-4645.85}{90.53}=.291 \text {. }
$$

Since the test statistic is not significant at the .1 level, there is no reason to believe that the mean is not stable.

The test statistic for the second hypothesis is established in a similar manner and is

$$
\frac{4783.13-4720.15}{86.84}=.73
$$

Since the test statistic is not significant at the .1 level, there is again no reason to believe that the mean is not stable. 
A CDC 6400 was used to perform the above computations. The total CPU time to perform the 400 iterations for the SLPR formulation was .240 hours and for the SDP formulations was 6.385 hours. This explains why only a limited number of financial instruments, time periods and realizations were used in the simulation. It also further highlights the gap in tractability between the SLPR and SDP techniques. 


\subsection{Appendix 1}

This appendix consists of: 1) a flowchart for the simulation performed in Chapter 5, and 2) a computer code for executing the simulation.

First, the following variables are defined: 1) $X 1(X 19, \times 61)$ is the amount invested in treasury bills (term deposits, mortgages) in the initial portfolio; 2) $\times(2)(x(20), x(62))$ is the amount allocated to purchasing new treasury bills (term deposits, mortgages) in period 1 as generated by the optimal solution to the B-C (SLPR) formulation; 3) $x(3)(x(21), x(63))$ is the amount of initial period treasury bills (term deposits, mortgages) still held in period $1 ; 4) X(4)(X(22)$, $X(64))$ is the amount of treasury bills (term deposits, mortgages) sold in period 1 ; and 5) $\times 103$ is the amount of demand deposits outstanding in the initial portfolio. 


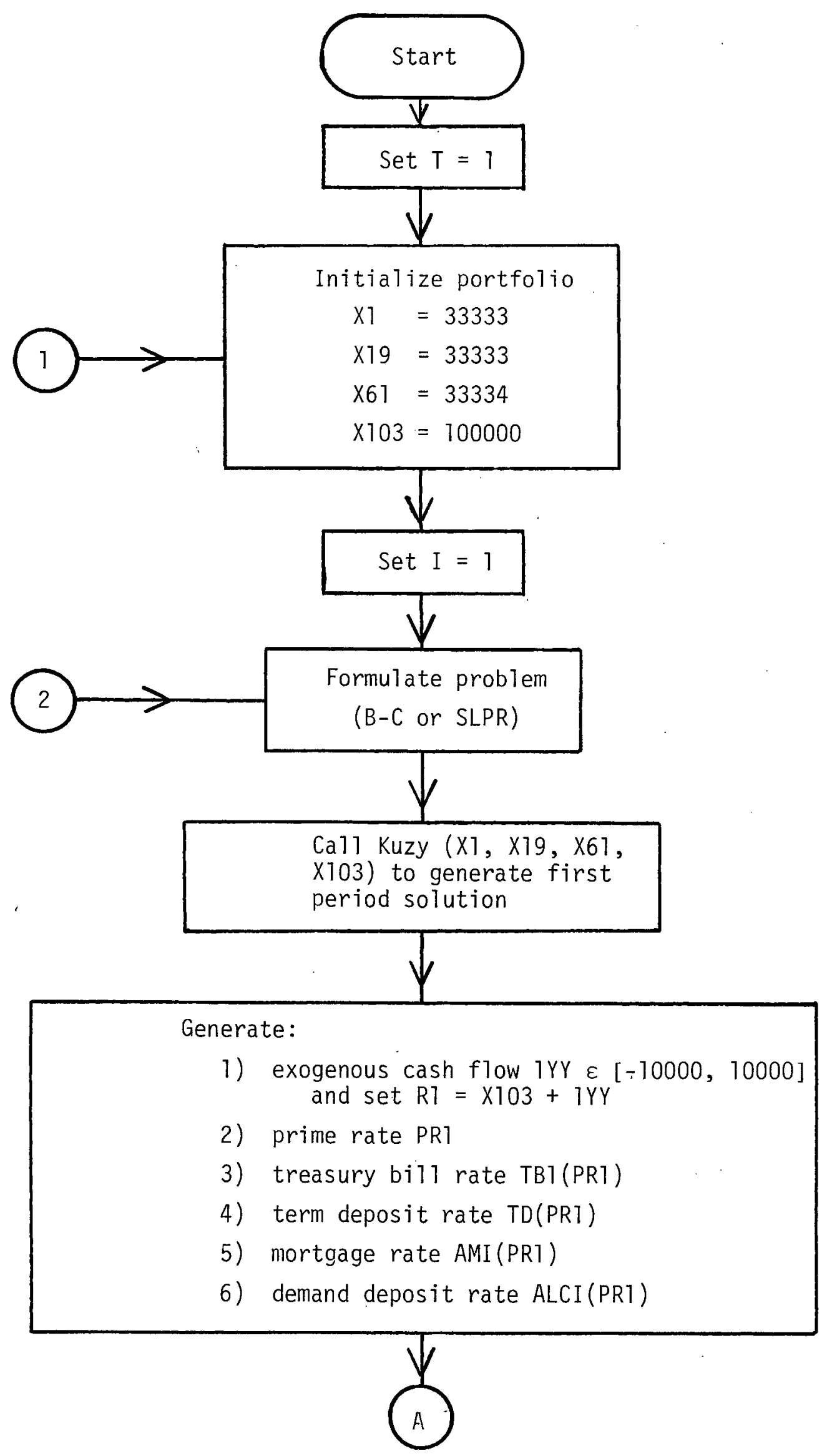




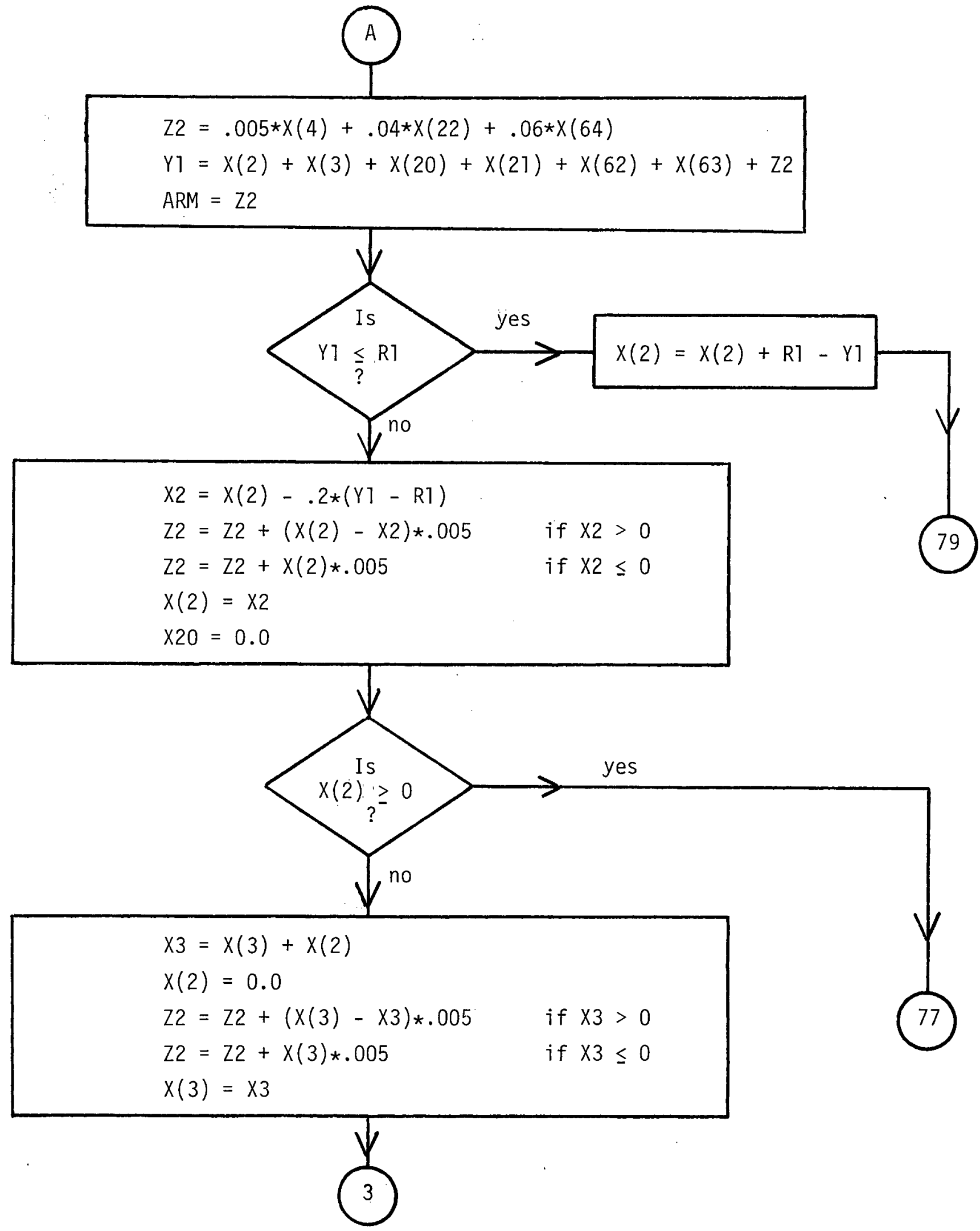




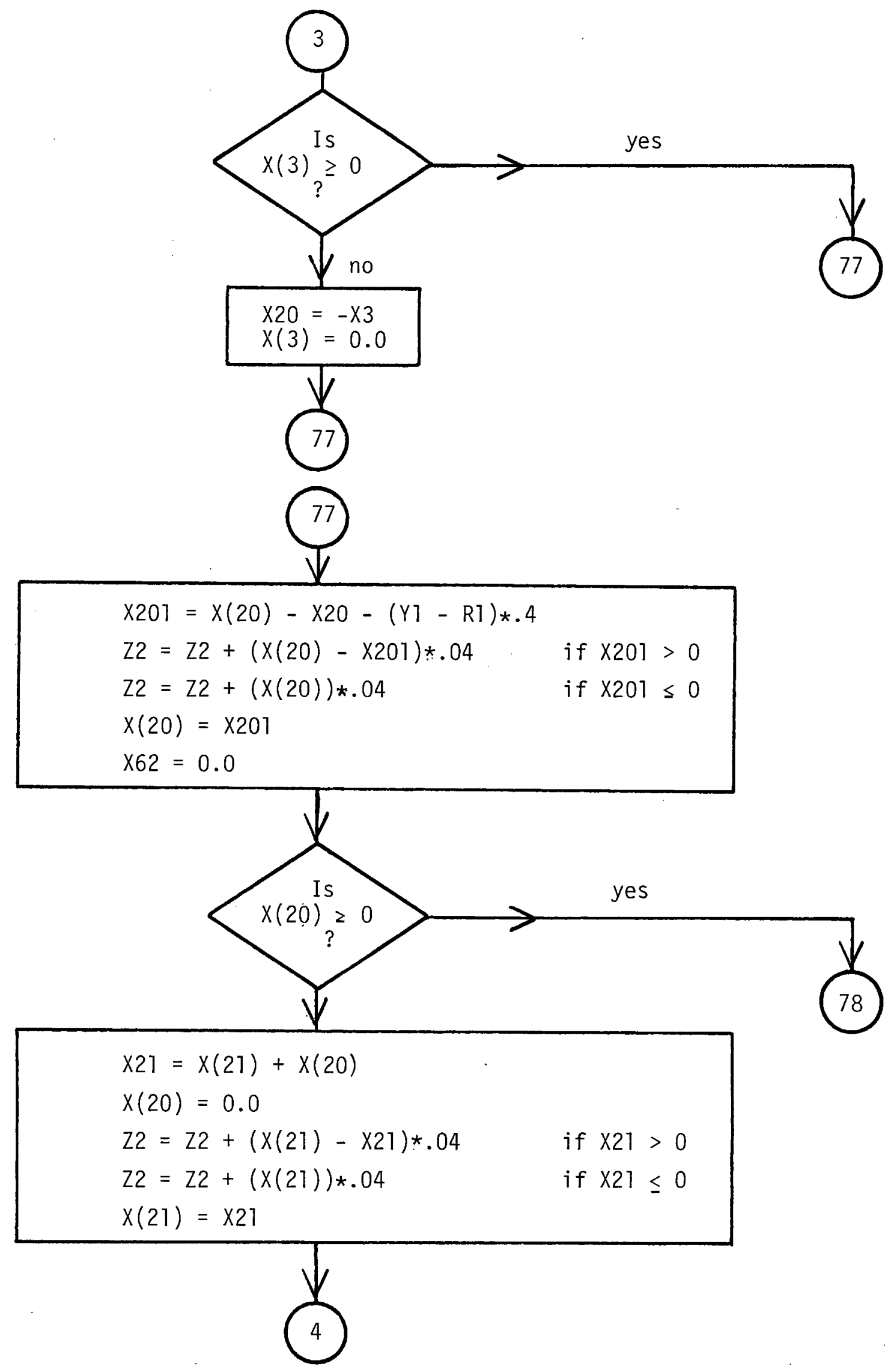



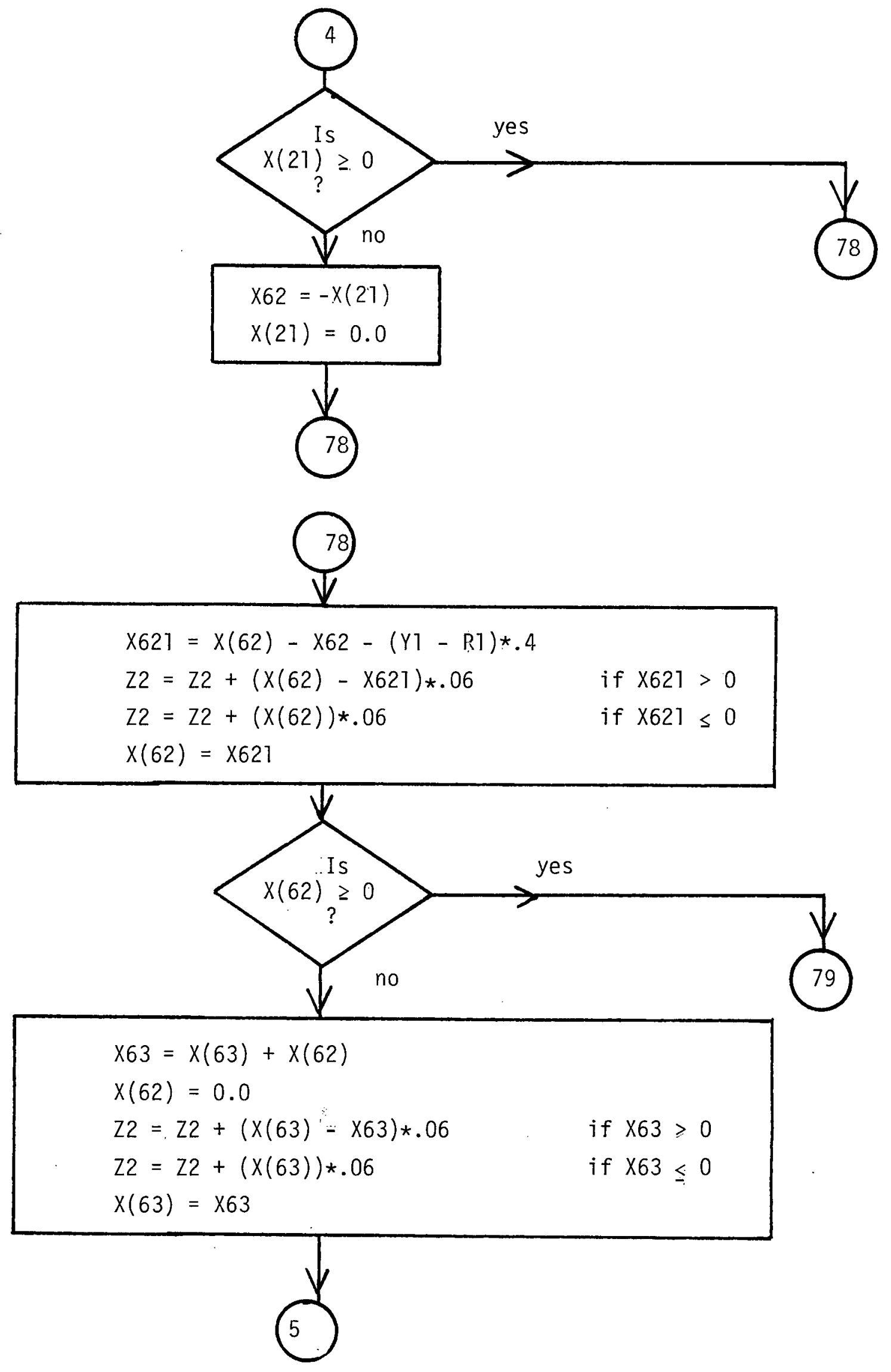


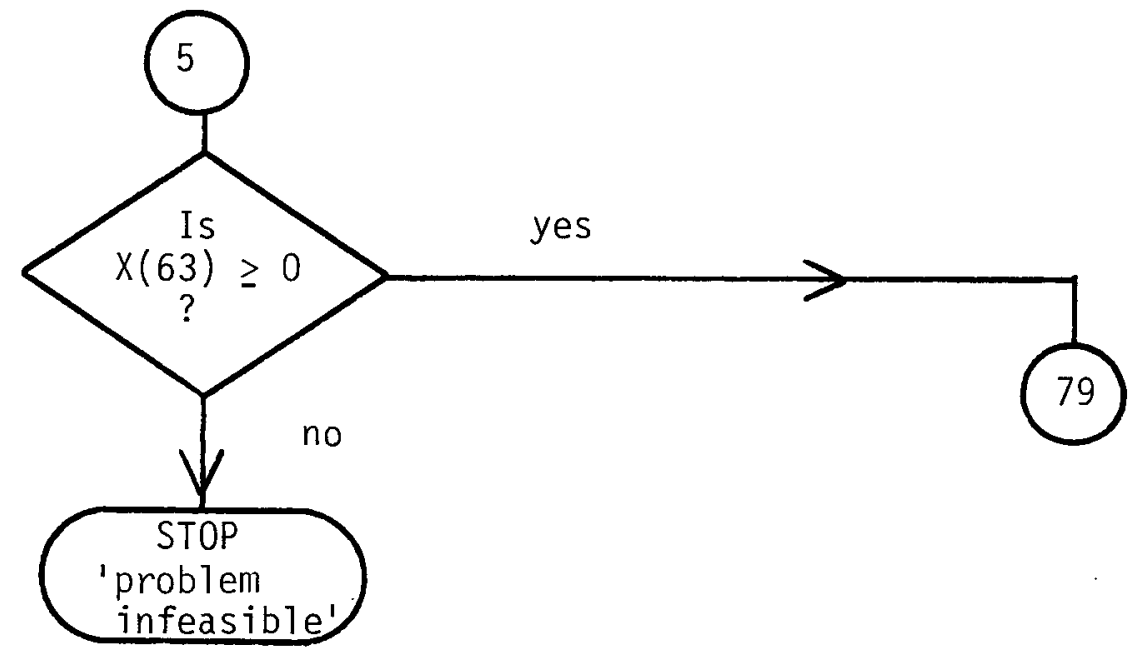

79

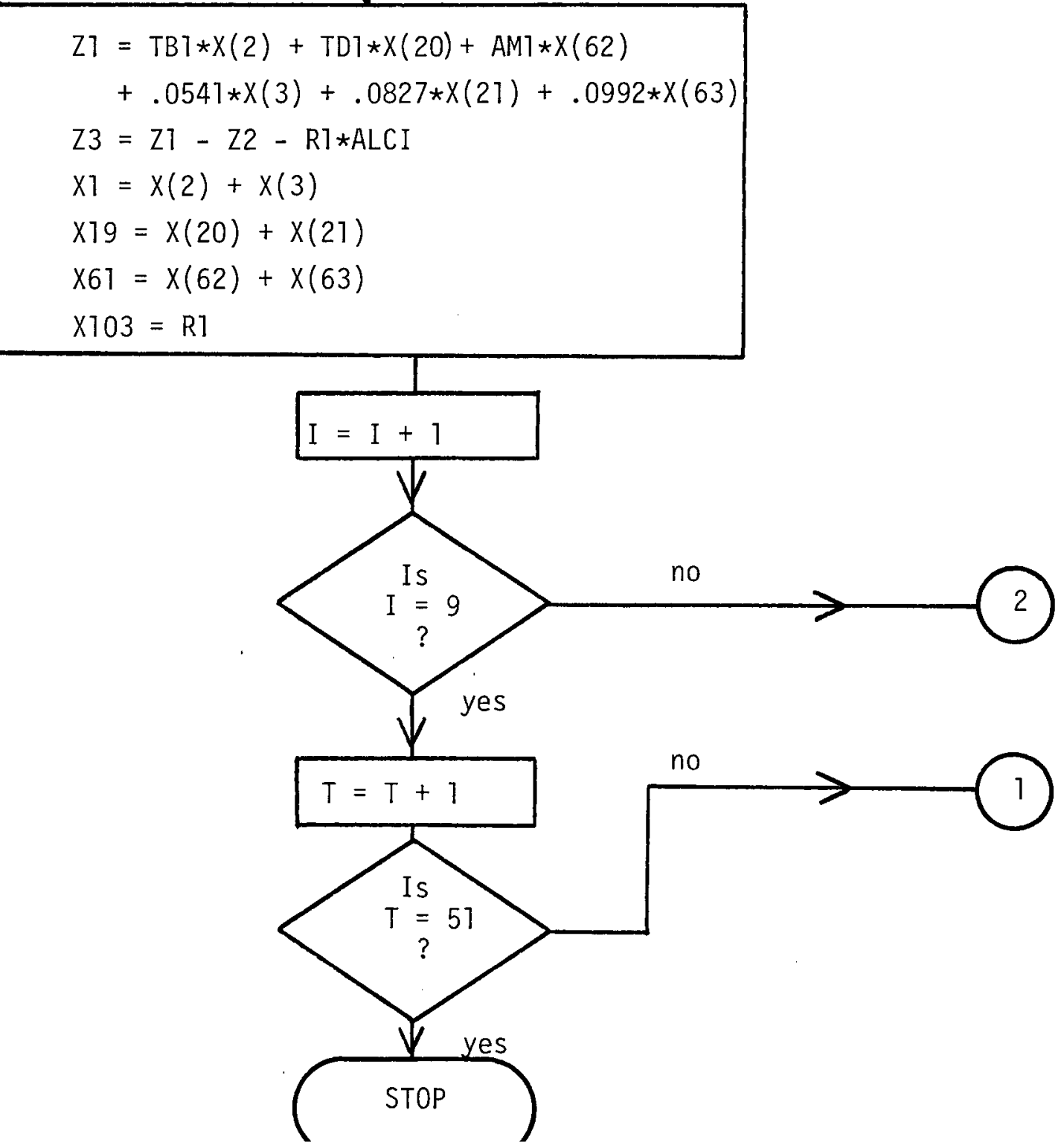


PQPGPAM HAPOY (TAPE5, OUTPIT, TADEj= DUTOUT)

IMOLICIT $=E A L \quad(A-H, O-Z)$

INTEGEO E, E,24T, MAPTY

PEEL TP(70,13),TO(73.13)

PEAL $P(?[, 13), \Pi(7 j, 1 j), A(1) 0.250), H(100), C(25))$

REAL H(1CO,1SE),G(100), DELTA(TO), GAMMA(?J), PI(1ÜU)

OIMENSION TW(IEJ),KADPA(?J),L(7D),K(70)

QEAL $0=(70), O M(70)$

TIMENSION $\times(15$ OS)

COMMON N,M,MI,ME,P,O,A,W, C, H, G, OELTA,GAMMA,PI, IN, KAPPA, L, EOS,

क

K,OP.OM,ZO, MARKER

COMMON /PRINTQ, TP,TD

COMMON IAI $X$

C************* GENERATE CASH FLJW

O) $1234 \quad k K=1.2$

$\times 1$ i $3=100000$

$\times 1=33333$.

$\times 19=3333.3$.

$\times 61=33334$.

DO $1233 \mathrm{KLL}=1,3$

CALL $K U Z Y(X 103, \times 1, \times 19, \times 61)$

REWINO 5

WRITE (6, 1:2)

$1: 2$ FORMAT (1HI)

WRITE $(6,101) \quad K K, K L L$

$10 \pm$ FOPMAT 1 OY,144SIMULATION PUN, I5, 2X,6HPERIOD,I6)

$4 \times 2=x(2)$

$x(2)=x(4)$

$x(4)=A \times 2$

$\triangle \times 20=Y(20)$

$A \times 21=X(21)$

$A \times 22=x(25)$

$x(20)=x(12)+x(13)+x(14)$

$x(21)=x(9)+x(10)+x(11)$

$x(33)=x(8,1)$

$x(52)=x(23)+x(24)+x(25)$

$\times(53)=A \times 20+4 \times 21+A \times 22$

$x(54)=y(19)$

$X(103)=X(29)$

$Y=? A N F(0$

$Y Y=20000 * Y$

$I Y Y=Y Y-20000$

$R:=X(103)+I Y Y$

HRITE $(E, 104)$ P

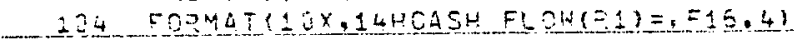

DP1 $1=P$ (DUMMY)

$P P:=.5 * P P 1+.0397$

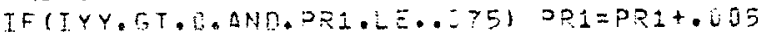

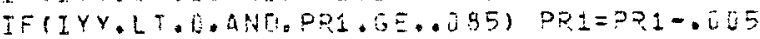

$T 31=P P_{1}+P T B(D U M M Y)$

$T O 1=P P \pm+O T D(D U M M Y)$

$A 41=P R 1+O M(D U M M Y)$

$A L C 1=. ?^{*}(P P 1+P L C$ (DUMMY) 
WPITE $(6,150)$ TP1

L5) EOPMAT(12K.134TREASUPY EILL RATE=, 2X,F15.5)

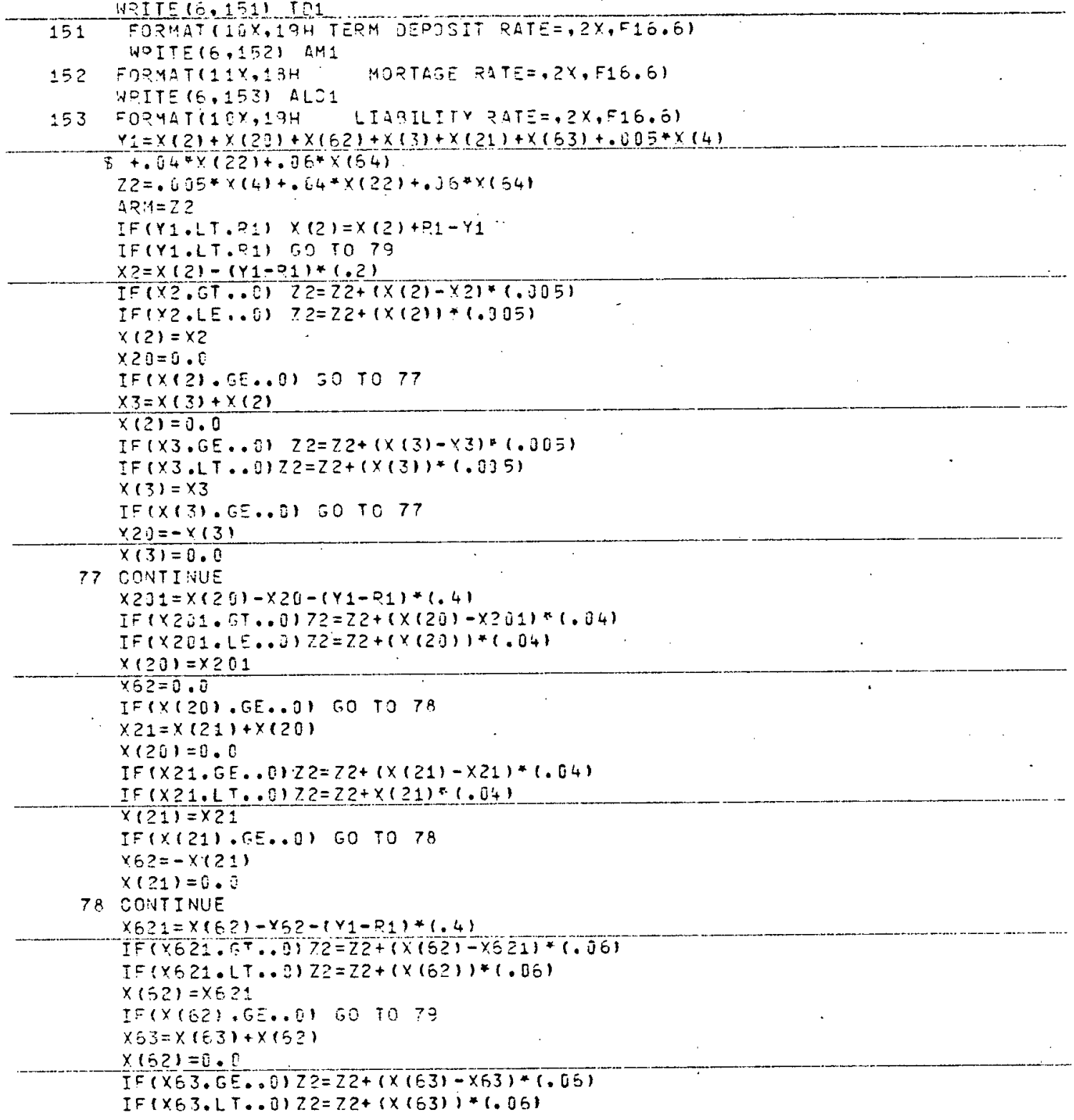
WPITE 6.1511 TO1 
$x(53)=\times 5.3$

IF $(x)(63) \cdot 60.8160$ TO 79

$\operatorname{STOP} 100$

79 CONTINUE

$Z_{1}=T 31 * \times(2)+T \Pi 1 * x(20)+\Delta M_{1} * x(5 \geq 2)$

$5+.3541 * \times(3)+.0327 * \times(21)+.0932 * \times(63)$

$Z 3=Z 1-Z Z Z-P 1 * A ! C I$

सरITE $(5,108) \mathrm{KLL}, 73$

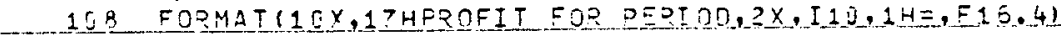

$X(1)=X(2)+Y(\geq)$

$x(19)=x(20)+x(21)$

$x(61)=x(62)+x(63)$

$x(103)=R 1$

$x 13=x(102)$

$x_{1}=x(1)$

$x 19=x(19)$

$\times 51=x(61)$

WRTTE $(6,207) \times 1, \times 19, \times 61, \times 103$

207 FOPMAT $110.2 H X=, 4 F 16.41$

WPITE $(6,160)$

160 FDRMAT $(10 Y, 464 * * * * * * * * * * * * * * * * * * * * * * * * * * * * * * * * * * * * * * * * * * * * * *)$

WRITE $(6,161)$

1E1 FORMAT(16Y,20HS T A T IST I C S )

$S B Z 1=S E Z 1+Z Z$

SBZS $=5 A Z 5+(Z 3) * 2$

WRITE 16,163$)$ Z 1

163 FOPMAT $110 X, *$

GROSS REVEVUES =*,F15.6)

WRITE $(6,168)$ AP:

168 FORMAT $110 \times, *$

WRITE $(6,165) \quad Z 2$

COST OF SA:ES $=*, F 15.6$ )

165 FOPMAT(IEX,* COST OF SALES AND FORCED SALES=*,F15.6)

$A R M I N=P, 1 * A L C 1$

WRITE $(6,156)$ ARYIN

166 FORMAT(1EY,* COST OF EUNJS = *,F16.6)

WPITE $(6,157) \quad 59 Z 1$

167 FORMAT $110 \times, *$

HPITE (E.159) SEZS

159 FOPMATI1jX., CUMMULATIVE OROFITS SQUARED *,FZO.3)

1233 GONTINUE

$\$ 234$ CONTINUE

END 
FUNOTION PP(T)

$Y=$ RAIIF (D)

IF(Y.LE..231) $Q R=.05$

IF(Y.GT. .231.AND.Y.LE..34T) JP=.065

IFIY.GT . . 347. AND.Y.LE. . 335) O2=.3675

IFIY.GT. ZP. AND.Y.LE..462)PZ =.075

IFYY.GT. . LE2.AND.Y.LE..51 DQ =.0?75

IFIY.GT. .5.ANO.Y.LE..57T) DQ =.68

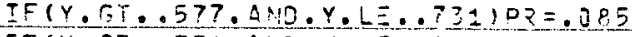

IF $(Y, G T$. PB1.AND,Y,LE..8JB) Jर $=.09$

IF(Y. GT . 9S8.4ND.Y.LE..835)PY =.095

IEIY.GT . P85.ANO.Y.LE..952) PR =.11

WPITE $(6,101)$ DF

101 FORMATQ1LX,11HORIME RATE=,2X,F15.01 RETURI

ENT 
FUVCTION $=$ Ta(n)

$Y=$ DANF (D)

$41=-0.0289$

$42=-.0306$

$13=-.3253$

$14=-.0225$

$45=-.0174$

$100=-.0051$

$I F(Y, 1 E \cdot .2) T T=\Delta 1+(Y) \cdot 2) *(\Delta 2-\Delta 1)$

IE Y. ET . 2. ANB.Y. LE . S T)T $=A 2+((Y-.2) / .3) *(A 3-A 2)$

IF (Y. GT . . . A ND.Y.LE..77) TB=A3+((Y-.5)/.27)*(A4-A3)

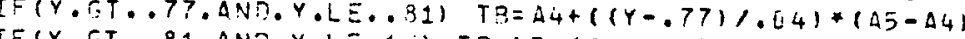

IF $(Y . G T$. R1.AND.Y.LE.1.) TB=A5+((Y-.B1)/.19)*(AD-A5)

$P T B=T M$

RETUON

END 
FUNETION DTOIDI

$Y=$ PANF (D)

$A 1=-.0104$

$A ?=-.0072$

$43=.0013$

$44=.004$

$A 5=.0118$

$A 5=.0195$

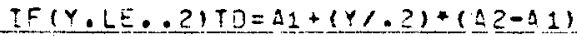

IF(Y.GT. . 2. AND.Y.LE..44)TJ $=A 2+((Y-.2) /(.24)) *(A 3-A 2)$

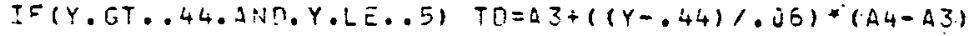

IF (Y.GT. .5.AND.Y.LE..PB) TD $=A 4+((Y-.5) / .23) *(A 5-A 4)$

IF(Y.GT . . Z . ANO.Y.LE.A.) TO $0=45+((Y-.73) / .22) *(A G-\Delta 5)$

$P T D=T O$

RETURN

END 
FUNETION RMIOI

$r=$ RANF(D)

$11=.0337$

$42=.0088$

$43=.0193$

$14=.0235$

$\Delta 5=.0297$

$45=.0338$

IF $(Y . L E \cdot . ?) \quad A Y=A Z+(Y) .2)+(A Z-\{1)$

IF (Y.GT . 2.AND.Y.LE..42) AM $=A 2+((Y-.2) /(.22)) *(A Z-A 2)$

IF (Y.GT. . Z Z.AND. Y.LE..52) QM $=23+(Y Y-.42) / .2) *(A 4-A S)$

IF (Y.GT ..62.AHD.Y.LE.. S1) $A M=A 4+((Y-.62) \%(19) *(A 5-A 4)$

IF(Y.GT..Q1.ANO.Y.LE.1.) AM $A 5+(Y-.81) / .19) *(A 5-\Delta 5)$

$R M=A M$

RETUPN

ENO 
FUNETTON RLCOOH

$Y=P A N F(0)$

IFIV.LE $.1151 P L O=-.0275$

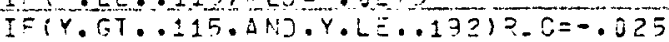

IFIY.GT..192.ANJ,Y.LE..324) ZLC =-.0225

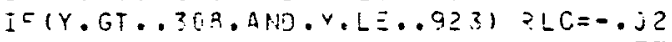

IE Y. GT..923.AND.Y.LE.1.) RLZ $=-.0175$

RETIJPN

END 


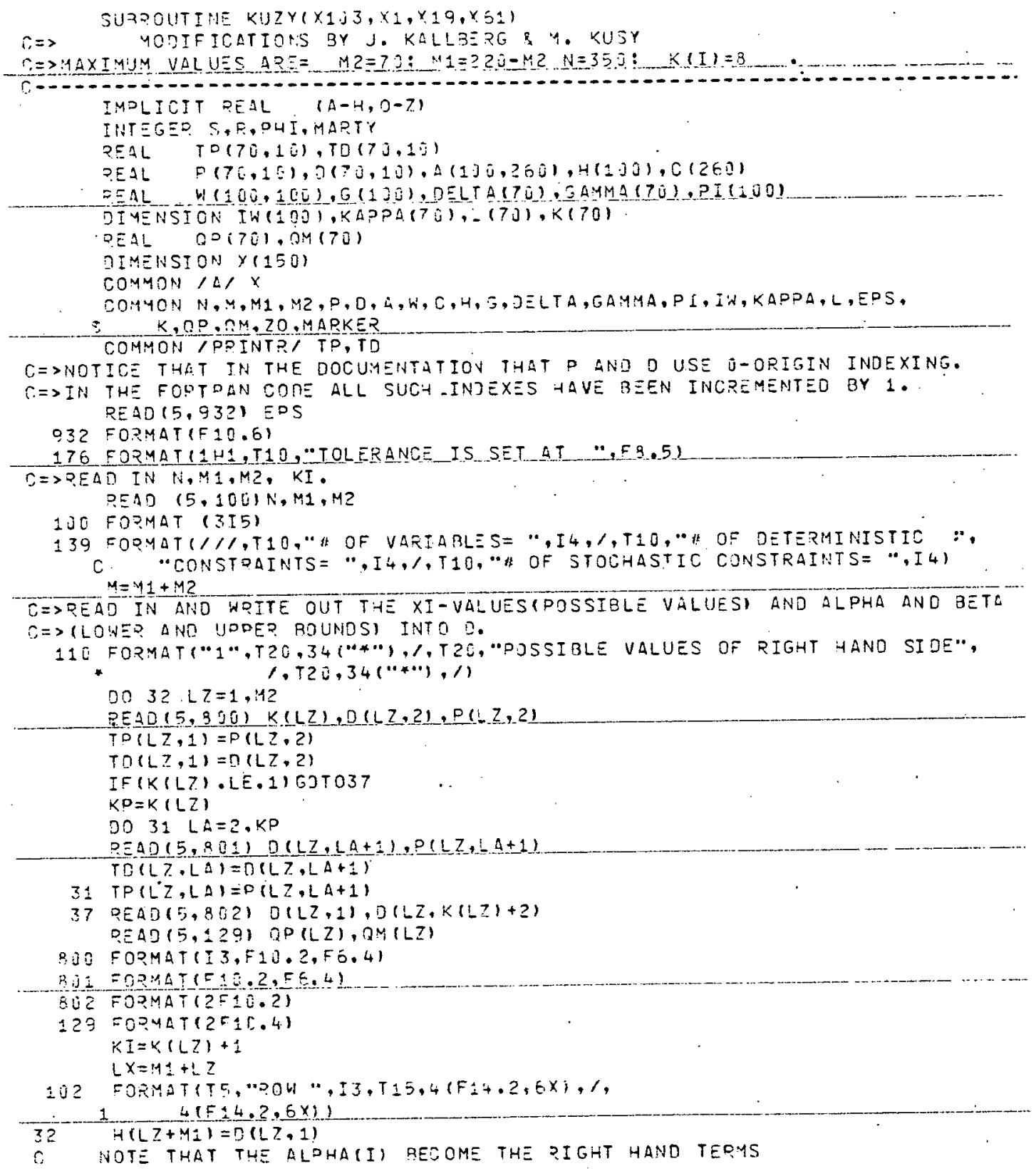


5. FDP THE STOCHASTIC CONSTRATNTS

COWRITE OUT THE LOHER AND UDFFO BJUNOS AND CALCULATE THE O VALUES.

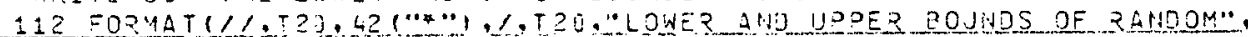

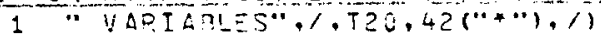

$0035 \quad I=1$, M?

$K I=K(I)+1$

$L X=M I+I$

$3035 \mathrm{~J}=1 \cdot \mathrm{K} T$

$35 \quad 0(I, J)=0(I, j+1)-0(T, J)$

C=2READ IN AND WOITE JUT THE IMITIAL P-VALUES: CALCULATE THE ACEUMULATED

$C=\triangle P-V A L U E S$ ANO WRITE THEM OUT. ALSO WRITE OUT R-PLUS AND 2-MINUS.

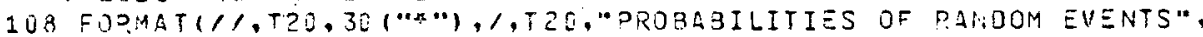

*

, T2 $30,30(\cdot * \cdot), 11$

DO $30 \quad I=1, M 2$

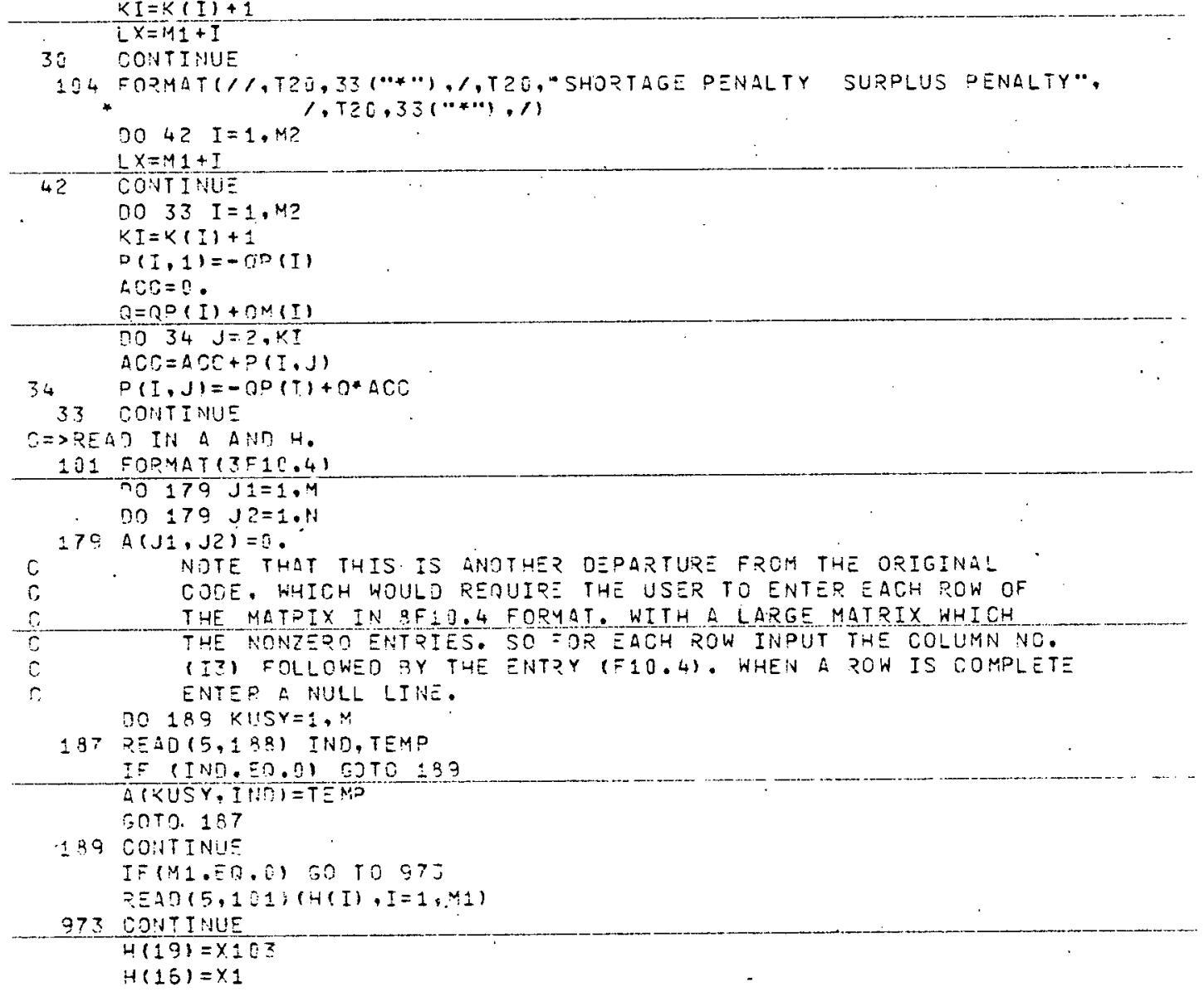

$K I=K(I)+1$ 


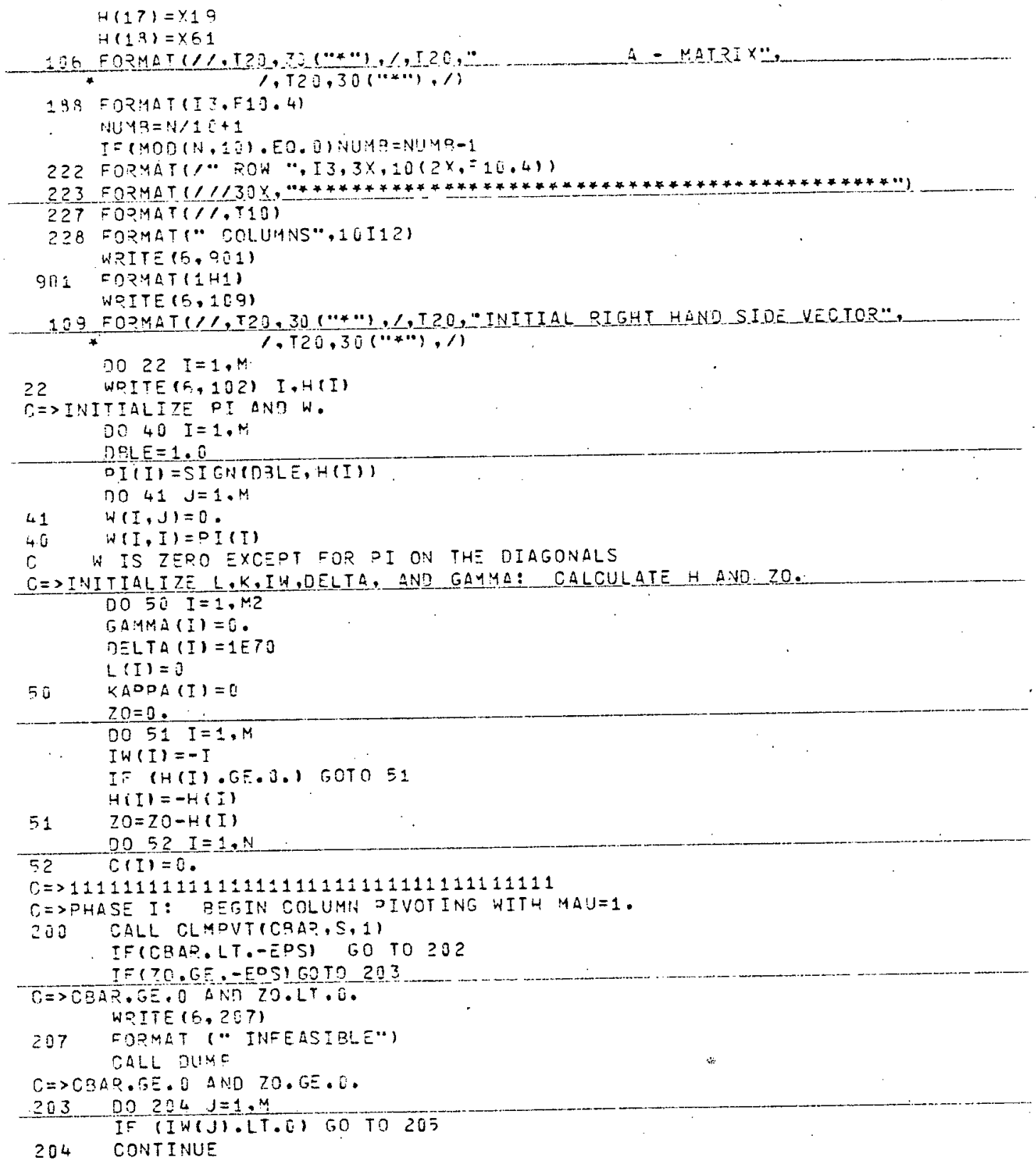




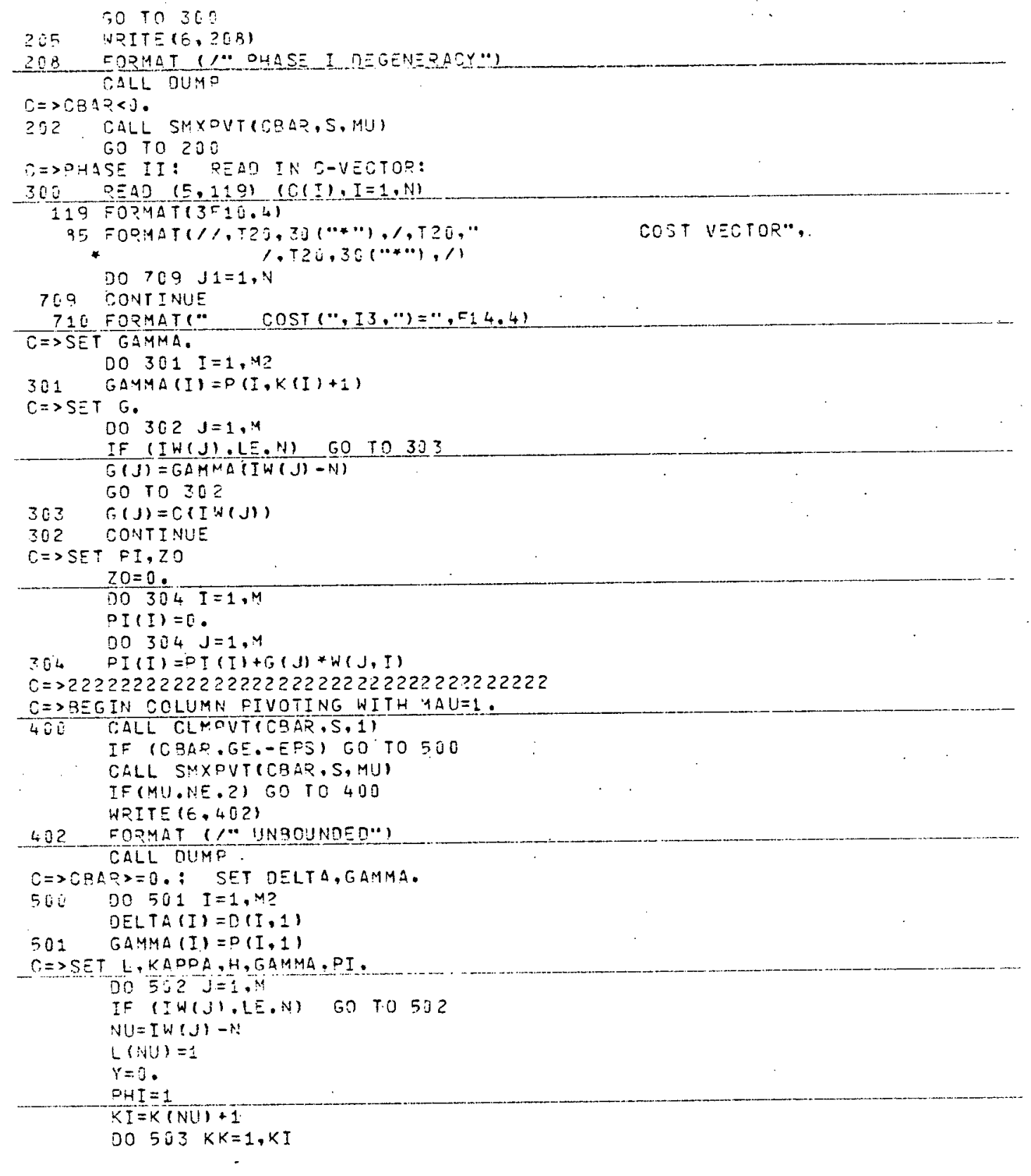




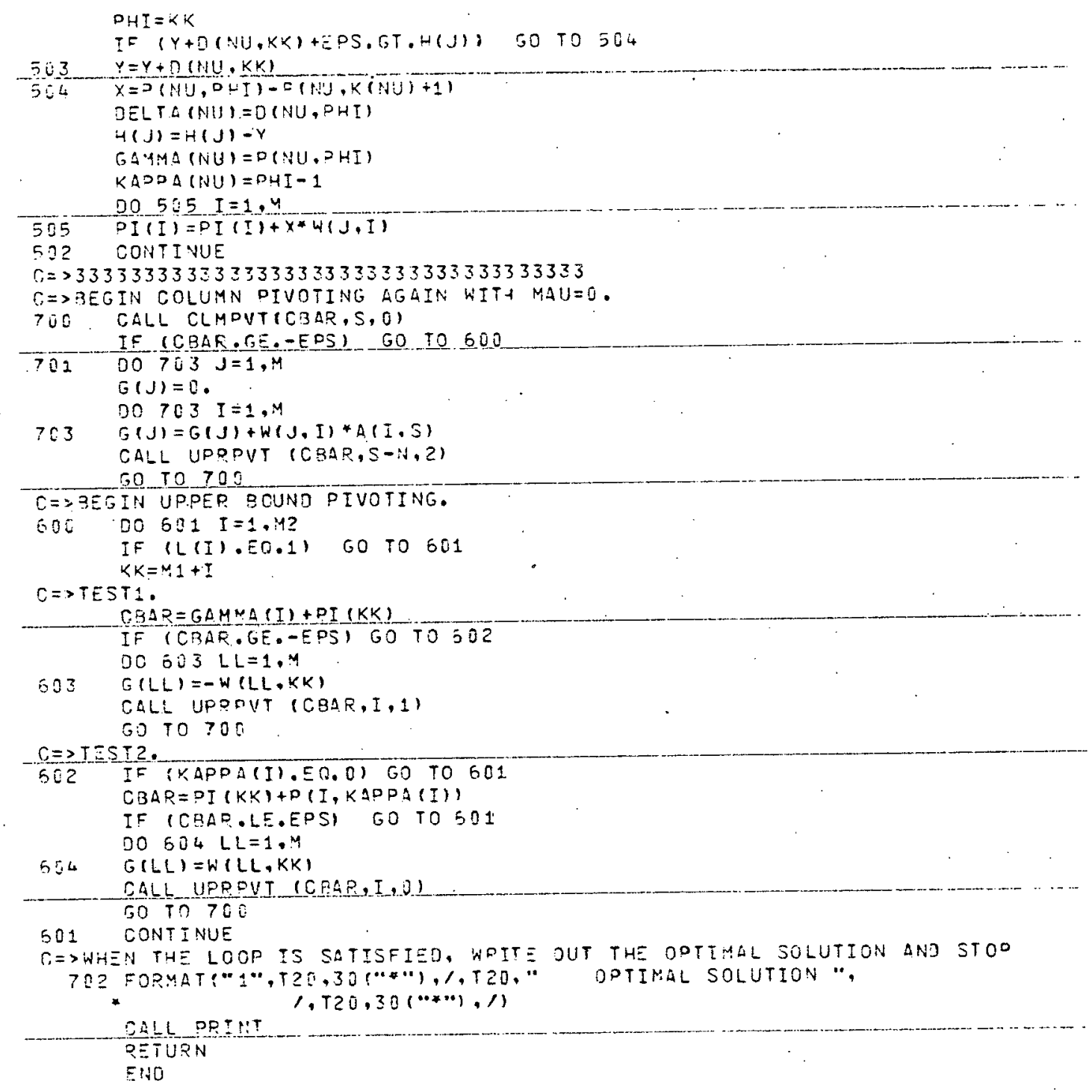




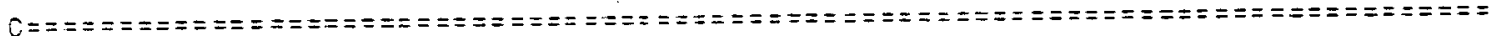
$\mathrm{C}=\mathrm{P}$ SUPPOUTINES

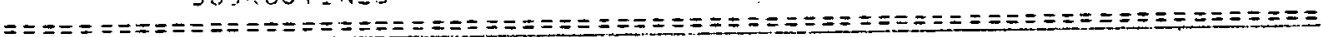
SUPFOUTIKE PIVOT (CRA?, R)

IMPLICIT PEAL $(A-4,0-Z)$

INTEGEP S,P. PHI, MAQTY

REAL $P(7[, 1 J), D(7 j, 10), \Delta(1 j J, 260), 4(100), C(260)$

SEAL W(100.100),G(:0J):DELTA(70), GAMHA(70).PI(10G)

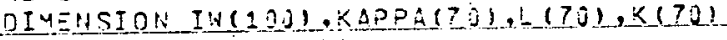

DEAL OD(70).QM(73)

COMMON N,M, M1, M2,P, O, A, H, L, H, G, JELTA,GAMMA,PI, IW, KAPPA,L,EPS,

S K,OP,OM,ZO,MARKE?

$C=\triangle C A L C U L A T E$ DIVOTAL ROW, H(R)

G.S $=1.0 / G(R)$

Q? $10 \quad J=1 . M$

10. $\quad W(2, J)=w(p, j)+6,5$

$H(R)=G S * H(F)$

$C=\rightarrow$ IVOT ON OTHED. ROWS.

DO $11 \mathrm{I}=1, \mathrm{M}$

IF (I.EQ.R) GO TO 11

$G S=G(I)$

$12 \quad W(I, J)=W(I, J)-G S * W(R, J)$

$H(I)=H(I)-G S * H(R)$

11 SONTINUE

$C=>O A L C U L A T E$ PI $\triangle N D Z O$.

DO $13, J=1, M$

$13 \quad P I(J)=P I(J)+C B A R * W(R, J)$

$Z O=Z . O-C 9 \triangle R^{*} H(R)$

976 RETUFN

END 


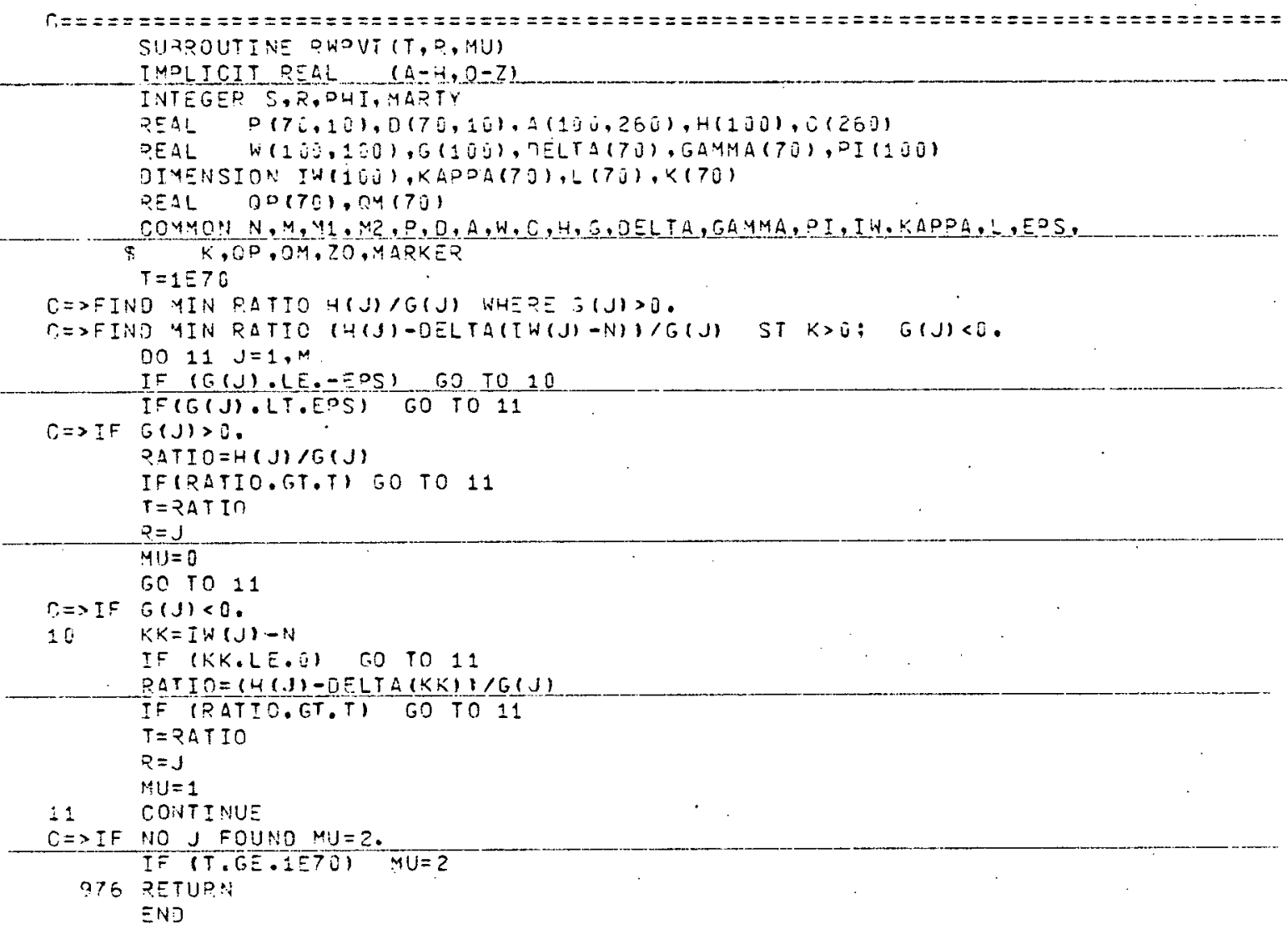




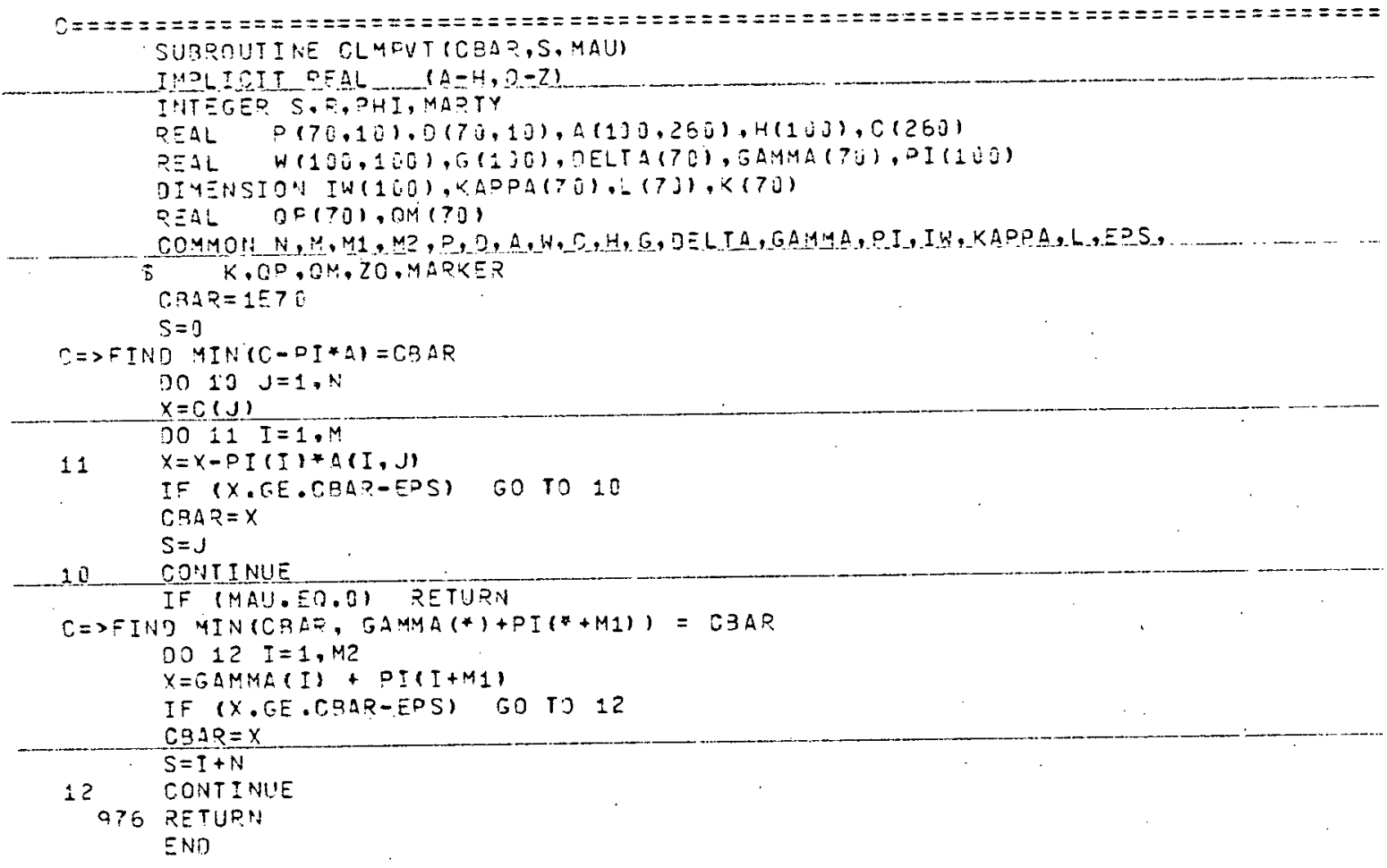




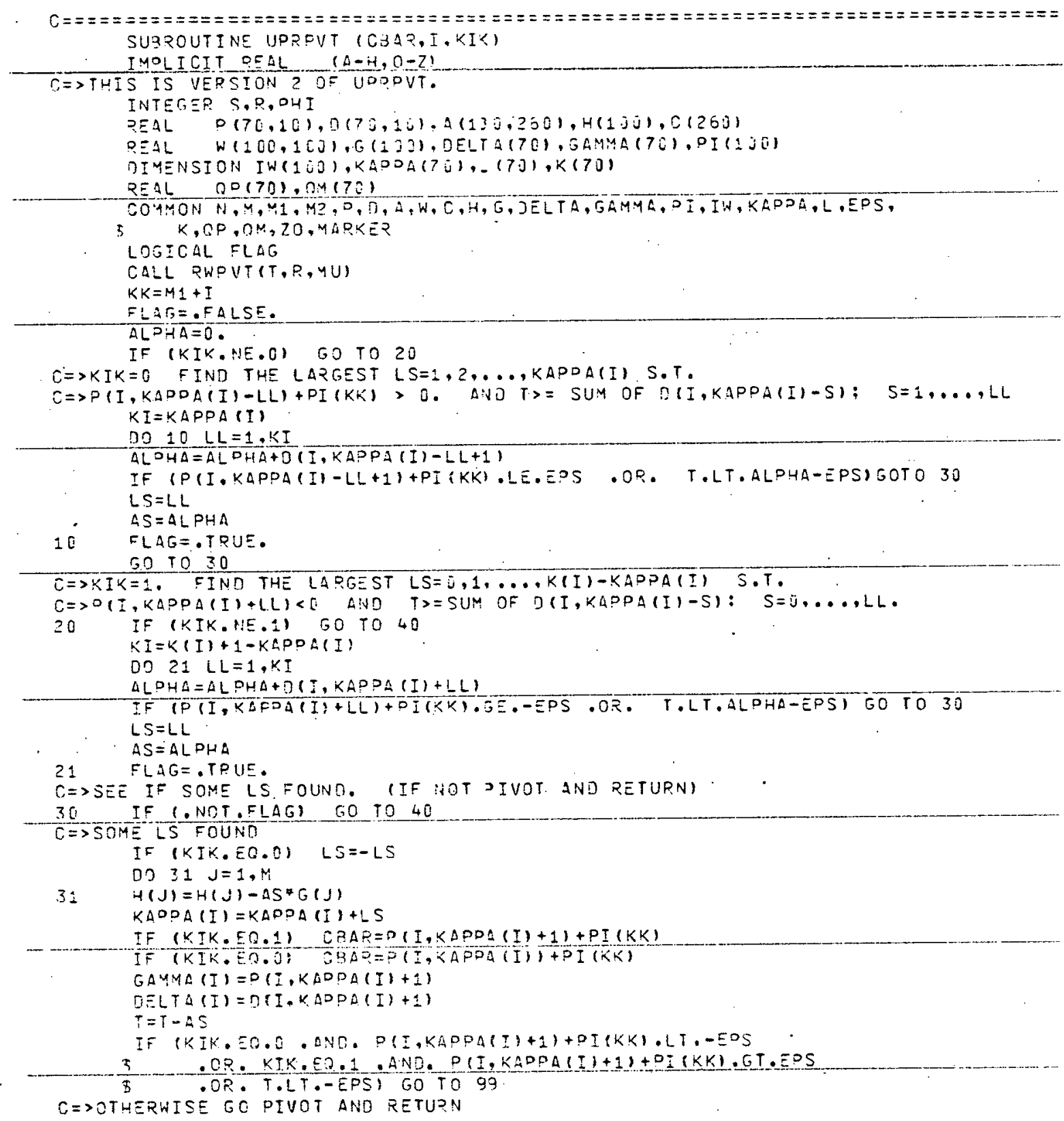




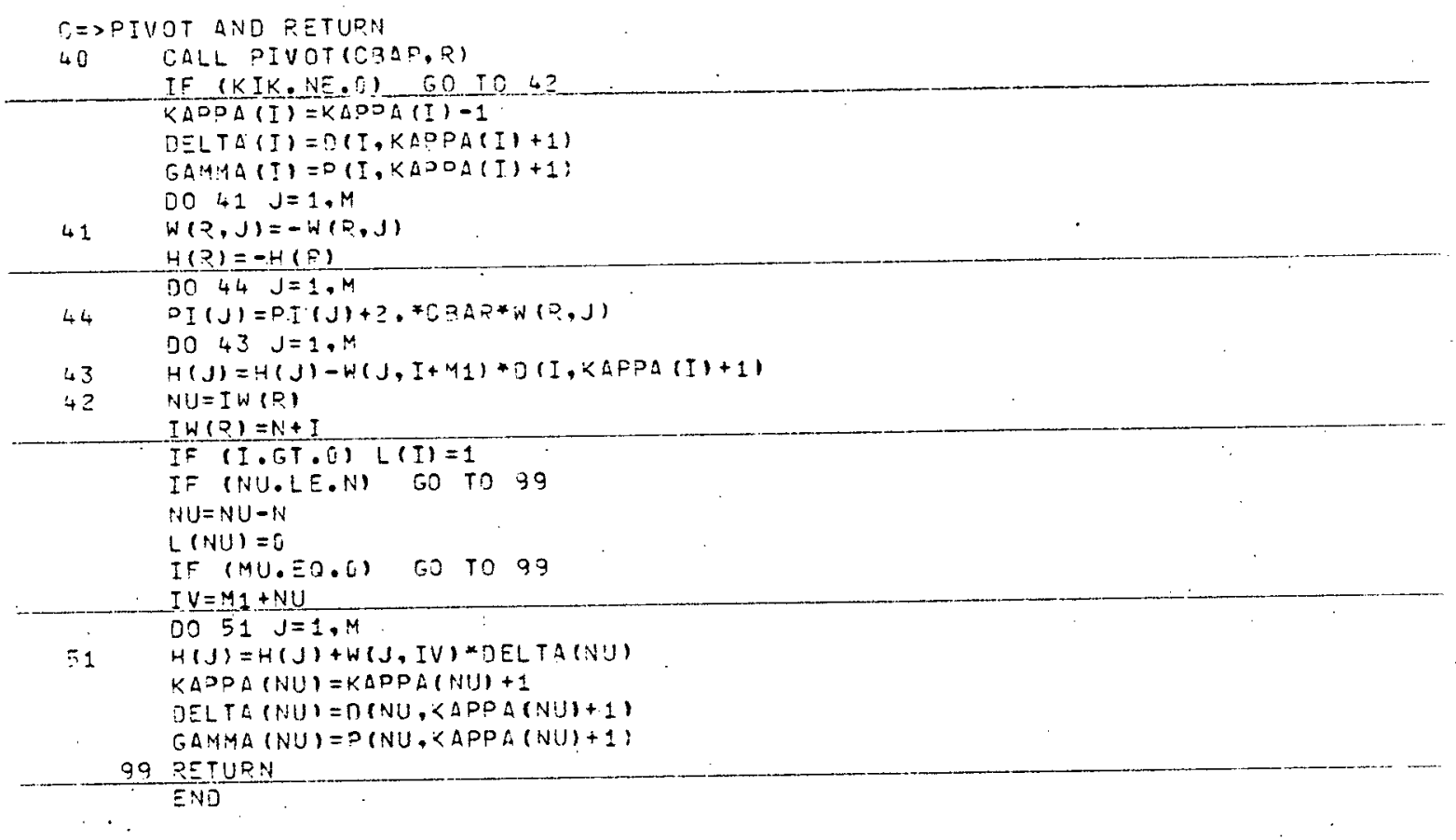




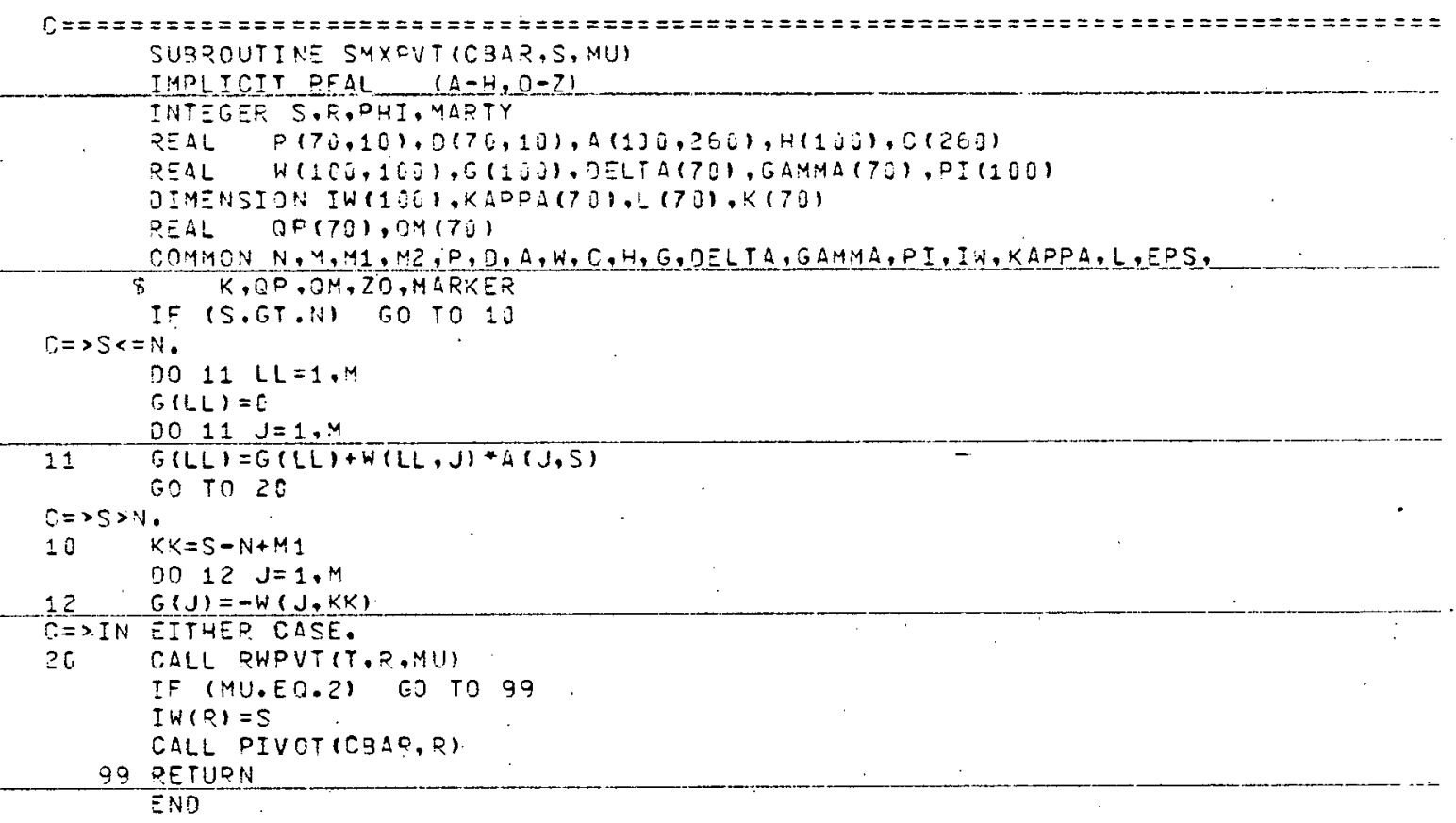




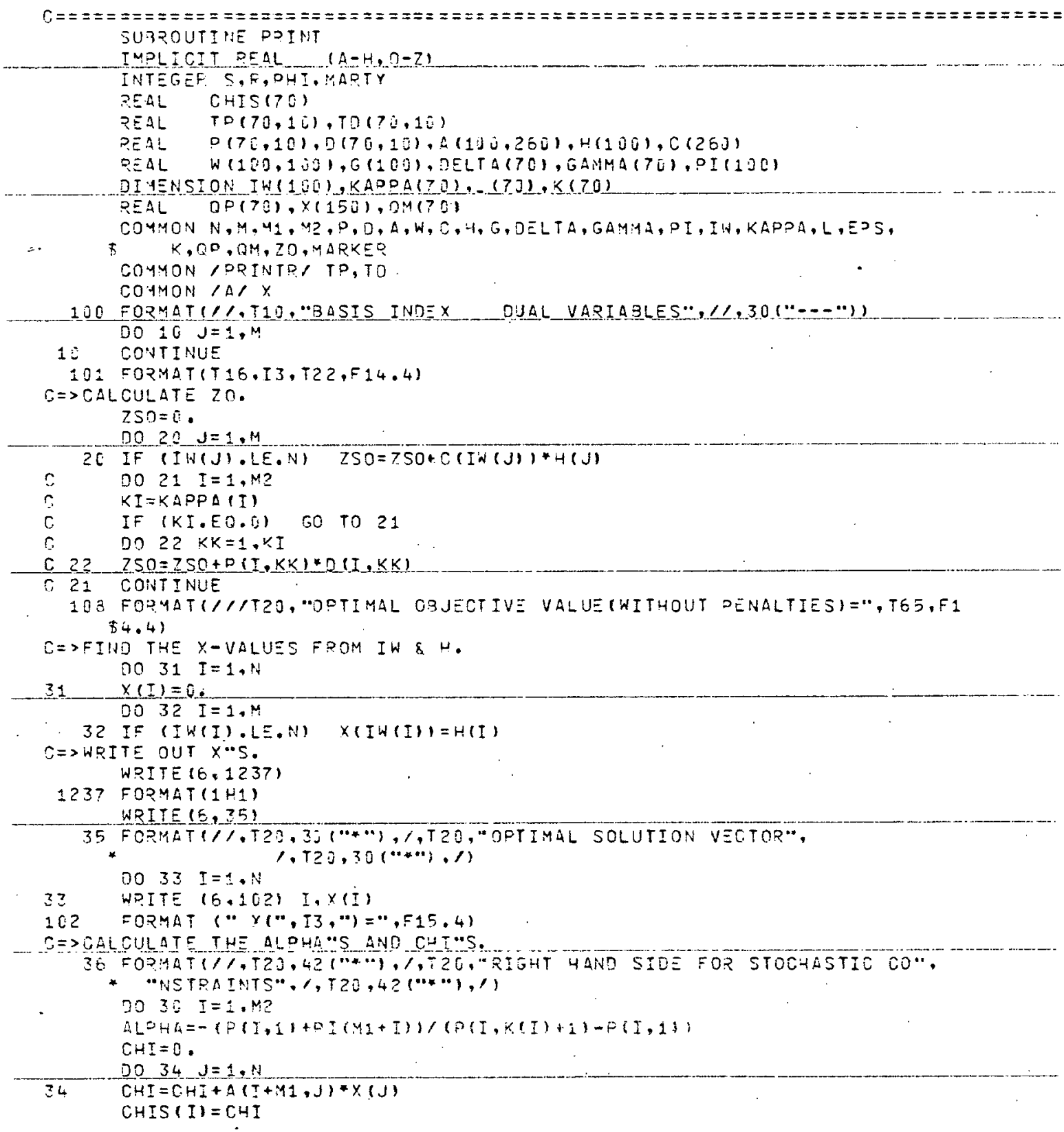




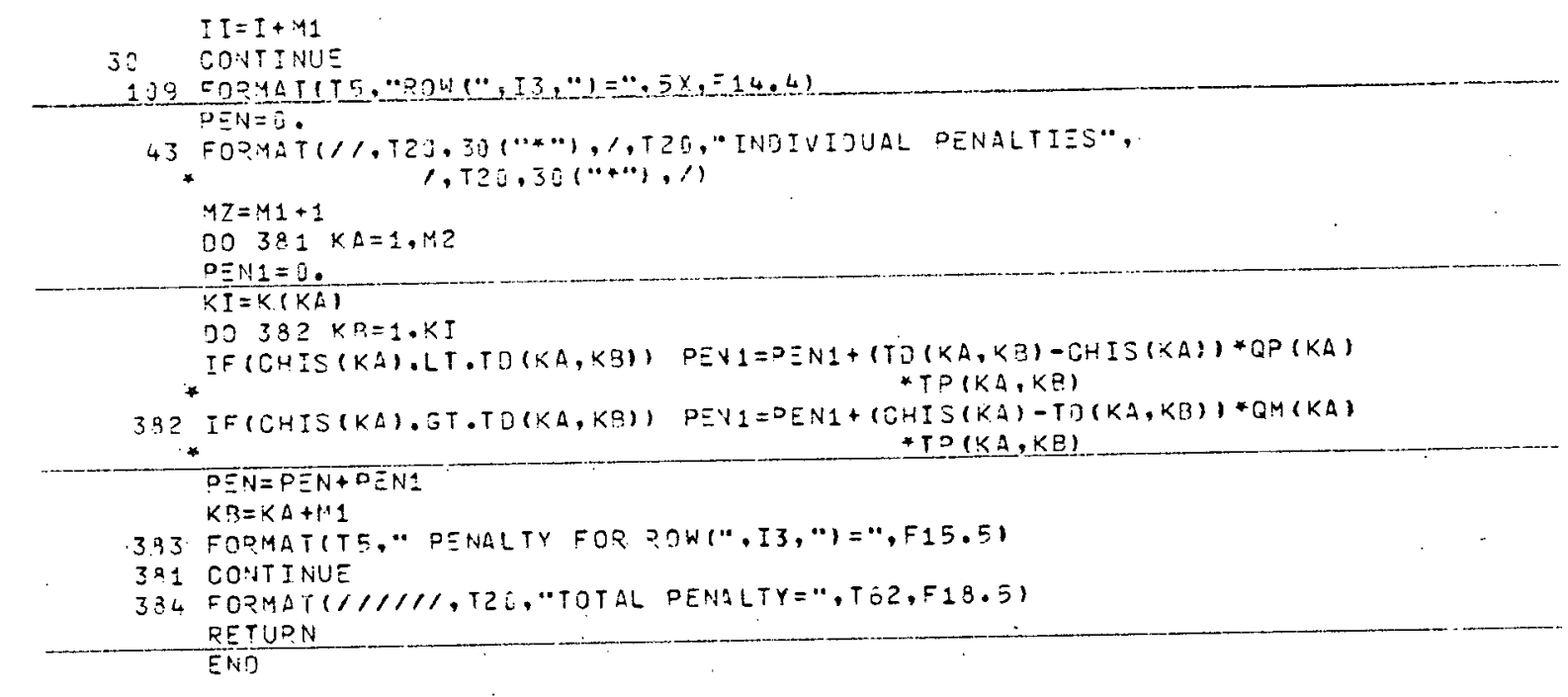




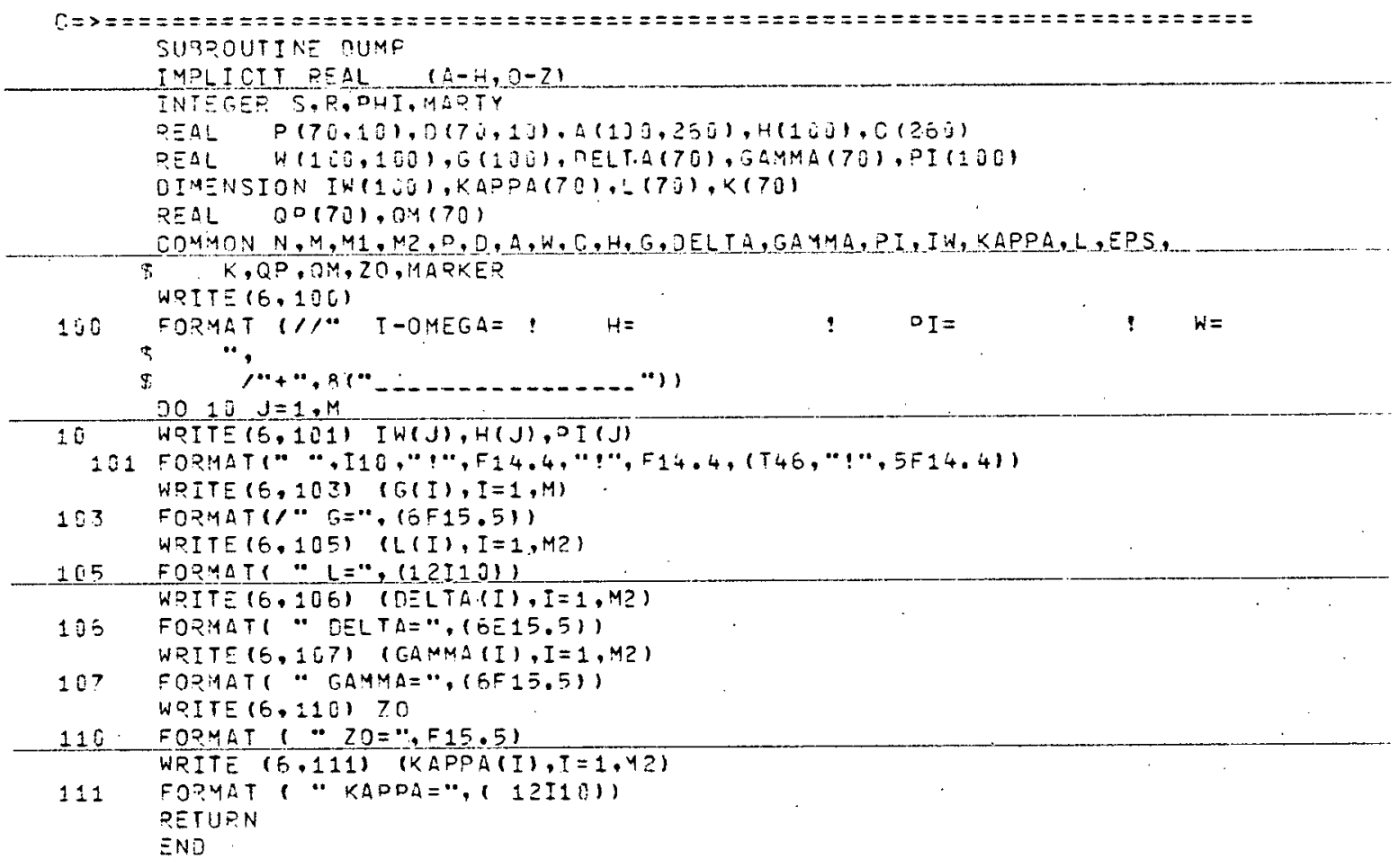


Chapter 6

\section{SUMMARY, MAJOR FINDIHGS AND \\ DIRECTIONS FOR FURTHER RESEARCH}

\subsection{Introduction}

In this chapter a summary of the dissertation (6.2), major findings of the dissertation (6.3), and directions for further research (6.4) are presented.

\subsection{Summary}

In the literature the study of asset and liability management of banks has been approached from two points of view. The first is based upon a mean-variance approach to portfolio selection. The second approach is based on an objective of maximizing net expected returns.

In Chapter 1, by using Myers' criteria [61], it was shown that the appropriate criterion for a financial institution is the maximization of expected net returns. In Chapter 2, deterministic and stochastic models which assumed this criterion were surveyed. In the most comprehensive of these mode1s, Bradley and Crane [5] attempted to overcome the crucial obstacle (to asset and liability management) of incorporating uncertainty while maintaining computational tractability for large problems. Unfortunately, their formulation is not appealing for decision-making because it not only has severe computational limitations but also possesses such undesirable features as arbitrary constraints on capital losses, an absence of portfolio mix constraints and an immediate revision that must satisfy all possible forecasted economic scenarios. 
Given these deficiencies, the purpose of this dissertation was to present an asset and liability management model that is both computationally tractable and realistic for large problems. In Chapter 3, the ALM formulation was developed as an alternative approach to asset and liability management. This model incorporates the inherent uncertainty in asset and liability management, while maintaining computational tractability. In Chapter 4, the ALM formulation was applied to VCS in order to demonstrate the effort necessary to execute the model. The results of this application indicate that: 1) the ALM model is superior to equivalent deterministic models, and 2) the results improve as the information incorporated into model increases. In Chapter 5, by using a simulation to reflect a real (uncertain) environment, the flexibility of SLPR and SDP formulations was compared. The results of the simulation indicate that the SLPR formulation leads to better initial period decisions. This is due to the restrictive nature of having first period portfolios, in the SDP formulation, feasible for all possible forecasted economic scenarios.

\subsection{Major Findings}

The objectives of this dissertation, first, to obtain a computationally tractable asset and liability management model, and, second, to develop a formulation that captures the essence of the asset and liability management problem, are successful.ly achieved.

More specifically, the computational tractability of the ALM model was found to be superior for a number of reasons. First, the CPU time used to solve a SLPR was approximately twice that used to solve 
an equivalent size: linear program. Second, the CPU time used for 500 iterations of the simulation of the stochastic dynamic formulation ( $B-C$ type mode1) was much larger than that needed for 4.00 iterations for the SLPR formulation (6.39 to 0.24 hours). Third, when additional time periods and/or realizations are added, the growth in the size of the stochastic dynamic formulation is approximately exponential while the growth of the SLPR is approximately linear. Clearly these facts demonstrate the superiority of the ALM formulation in terms of computations when compared to the B-C formulation. Fourth, the ALM formulation is easy to operationalize and is equivalent to implementing a linear program while providing superior results. In fact to apply the ALM model, the following information must be determined: 1) an estimate of deposit flows, 2) an estimate of the term structure of interest rates, 3) an estimate of withdrawal rates of deposits under various economic conditions, 4) legal constraints governing the behaviour of the financial institution, 5) policy constraints, 6) the Federal Reserve Board's recommended reserves for maintaining a liquid position, and 7) the initial position of the firm. This is the same information that is necessary to implement an equivalent deterministic mode1. Clearly, these four points indicate that computational tractability is not a constraining factor in the ALM model.

With regard to problem formulation, the ALM model, like the Chambers and Charnes linear programming model, incorporates most of the essential characteristics of the asset and liability management problem. However, unlike the Chambers and Charnes formulation, the ALM formulation overcomes two important drawbacks: 1) the inherent uncertainty of the problem and 2) the conservative nature of the Chambers and Charnes 
formulation. The first drawback has already been discussed. By using stochastic liquidity constraints the second drawback is dealt with effectively. Furthermore, when the ALM formulation is compared to the Bradley and Crane formulation, it has been demonstrated in a simulation that the ALM model is more flexible and thus provides superior results.

\subsection{Directions for Further Research}

Two areas for future research are discussed below.

One shortcoming of the ALM model is that it is not a dynamic formulation due to the lack of efficient algorithms to solve such problems. As Bradley and Crane have shown for a dynamic model, as the number of time periods and possible realizations of the random variables increases the formulation "blows up" in size. Therefore, the development of an efficient stochastic dynamic programming algorithm would be useful for this problem and for optimization problems in general.

Another area that has not been dealt with in the dissertation, is the problem of forecasting. Deposit flows, interest rates and withdrawal rates were taken as given. The problem of forecasting has been the subject of numerous research projects and is viewed as being beyond the scope of this dissertation. However, in order to properly implement the ALM mode1, one would have to estimate the deposit flows, interest rates and withdrawal rates using the available forecasting techniques.

Given the existing state of knowledge in the areas pertaining to asset and liability management, the ALM model formulated in this dissertation appears to be superior to existing models as a normative tool. 


\section{BIBLIOGRAPHY}

[1] Arrow, K.I., "The Role of Securities in the Optimal Allocation of RiskBearing," Review of Economic Studies, Vol. 31 (1964), pp. 91-96.

[2] Baumol, W.J. and Quandt, R.E., "Investment and Discount Rates Under Capital Rationing: A Programming Approach," The Economic Jourmal, Vo1. 75 (1965), pp. 317-329.

[3] Beale, E.M.L., "On Minimizing a Convex Function Subject to Linear Inequalities," Journal of the Royal Statistical Society, Series B., Vol. 17 (1955), pp. 173-184.

[4] Booth, G.G., "Programming Bank Portfolios Under Uncertainty: An Extension," Joumal of Bank Research, Vo1. 2 (1972), pp. 28-40.

[5] Bradley, S.P. and Crane, D.B., "A Dynamic Model for Bond Portfolio Management," Management Science, Vol. 19 (1972), pp. 139-151.

[6] ment Security Portfolios: An Optimization Approach Under Uncertainty," Journal of Bank Research, Vol. 4 (1973), pp. 18-30.

[7] Wiley Inc., New York, 1976.

[8] British Columbia Government, Credit Unions Act of British Columbia, 1973.

[9] Cass, D. and Stiglitz, J.E., "The Structure of Investor Preferences and Asset Returns and the Separability in Portfolio Allocation: A Contribution to the Pure Theory of Mutual Funds, "Journaz of Economic Theory, Vol. 2 (1970), pp. 331-354.

[10] Central Mortgage and Housing Corporation, "Canadian Housing Statistics," 1975.

[11] Chambers, D. and Charnes, A., "Inter-Temporal Analysis and Optimization of Bank Portfolios," Management Science, Vol. 7 (1961), pp. 393410. 
[12] Charnes, A., Cooper, W.W. and Symonds, G.H., "Cost Horizons and Certainty Equivalents: An Approach to Stochastic Programming of Heating 0il," Management Science, Vol. 6 (1959), pp. 73-79.

[13] Charnes, A. and Cooper, W.W., "Chance-Constrained Programming," Management Science, Vol. 6 (1959), pp. 73-79.

[14] Charnes, A. and Kirby, M.J.L.,. "Application of Chance-Constrained Programing to the Solution of the So-Called 'Savings and Loan' Association Type of Problem," Research Analys is Corporation, 1965.

[15] Charnes, A. and Littlechild, S.C., "Intertemporal Bank Asset Choice with Stochastic Dependence," Systems Research Memorandum No. 188, The Technological Institute, Northwestern University, April 1968.

[16] Charnes, A. and Thore, S., "Planning for Liquidity in Financial Institutions: The Chance-Constrained Method," Journal of Finance, Vol. 21 (1966), pp. 649-674.

[17] Chen, A.H.Y., Jen, F.C. and Zionts, S., "The Optimal Portfolio Revision Policy," Journal of Business, Vol. 44 (1971), pp. 51-61.

[18] chastic Cash Demands," Management Science, Vol. 19 (1972), pp. 319-332.

[19] Cheng, P.I., "Optimum Bond Portfol io Selection," Management Science, Vol. 8 (1962), pp. 490-499.

[20] Cohen, K.J. and Hammer, F.S., "Linear Programming and Optimal Bank Asset Management Decision," Journal of Finance, Vol. 22 (1967), pp. $147-167$

[21] Cohen, K.J. and Thore, S., "Programming Bank Portfolios Under Undertainty," Jourmal of Bank Research, Vol. 1 (1970), pp. 42-61.

[22] Collins, H., "A Code for Stochastic Linear Programs with Simple Recourse," Dept. of Mathematics, University of Kentucky, 1975.

[23] Couhault, A., "Quelques méthodes de résolution d'un problème de programmation stochastique linéaire venant de la gestion du stocks," Cahiers de I'I.R.I.A., Vol. 9 (1972), pp. 77-100. 
[24] Crane, D.B., "A Stochastic Programming Model for Commercial Bank Bond Portfolio Management," Journal of Financial and Quantitative Analysis, Vol. 6 (1971), pp. 955-976.

[25] Credit Union Reserve Board, "A Report on the Adequacy of the Financial Capacity of the Credit Union Reserve Board," 1973.

[26] - "Financial Statistics," on the British Columbia Credit Unions," 1970-74.

[27] Crosse, H.D. and Hempel, G.H., Management Policies for Commercial Banks, 2nd Edition, Prentice-Hall Inc., Englewood Cliffs, New Jersey, 1973.

[28] Daellenbach, H. and Archer, S.A., "The Optimal Bank Liquidity: A Multi-Period Stochastic Model," Journal of Financial and Quantitative Analysis, Vol. 4 (1969), pp. 329-343.

[29] Dantzig, G.B., "Linear Programming Under Uncertainty," Management Science, Vol. 1 (1955), pp. 197-206.

[30] - "Upper Bounds, Secondary Constraints, and Block Triangularity in Linear Programming," Econometrica, Vol. 23 (1955), pp. 174-183.

[31] Dantzig, G.B. and Van S1yke, R., "Generalized Upper Bounded Techniques for Linear Programming II," Joumal Comput. Systems Sci., Vol. I (1967), pp. 213-226.

[32] Eisner, M.J., Kaplan, R.S. and Soden, J.V., "Admissible Decision RuTes for the E-Model of Chance-Constrained Programming, "Management Science, Vol. 17 (1971), pp. 337-353.

[33] E1-Agizy, "Two Stage Programming Under Uncertainty with Discrete Distribution Function," Operations Research, Vol. 15 (1967), pp. 55-70.

[34] Eppen, G.D. and Fama, E.F., "Solutions for Cash Balance and Simple Dynamic Portfolio Problems," Joumal of Business, Vol. 41 (1968), pp. 94-112. national Economic Review, Vol. 10 (1969), pp. 119-133. 
[36] Eppen, G.D. and Fama, E.F., "Three Asset Cash Balance and Dynamic Portfolio Problems," Mañagement Science, Vol. 17 (1971), pp. 311-319.

[37] Fama, E.F. and Miller, M.H., The Theory of Finance, Holt Rinehart and Winston Inc., New York, 1972.

[38] Gurley, J.G. and Shaw, E.S., Money in a Theory of Finance, Brookings Institute, 1960.

[39] Haley, C.W. and Schal1, D.W., The Theory of Financial Decisions, McGraw-Hil1, New York, 1973.

[40] Hempe1, G.H., "Basic Ingredients of Commercial Banks' Investment Policies," The Bankers Magazine, Vol. 155 (1972), pp. 59-59.

[41] Hespos, R.F., and Strassmann, P.A., "Stochastic Decision Trees for the Analysis of Investment Decisisons," Management Science, Vol. 11 (1965), pp. B-244-B-259.

[42] Hester, D.D. and Pierce, J.L., Bank Management and Portfolio Behaviour, Yale University Press, New Haven, 1975.

[43] Hillier, F.S., "The Derivation of Probabilistic Information for the Evaluation of Risky Investments," Management Science, Vol. 9 (1963), pp. 443-457.

[44] - "A Basic Model for Capital Budgeting of Risky Interrelated Projects," Engineering Economist, Vol. 20 (1974), pp. 37-49.

[45] Hirshleifer, J., "Investment Decision Under Uncertainty: Choice-Theoretic Approaches," Quarterly Joumal of Economics, Vol. 19 (1965), pp. 509-536.

[46] - "Investment Decision Under Uncertainty: Application of the State-Preference Approach," Quarterly Joumal of Economics, Vol. 80 (1966), pp. 252-277.

[47] - Investment, Interest and Capital, Prentice-Hal1 Inc., Englewood Cliffs, New Jersey, 1970.

[48] Ka11, P., Stochastic Progranming, Springer-Verlag, Berlin, 1976.

[49] Kallberg, J.G. and Kusy, M.I., "A Stochastic Linear Program 'with Simple Recourse," Faculty of Commerce, The University of British Columbia, 1976. 
[50] Komar, R.I., "Developing a Liquidity Management Model, "Joumal of Bank Research, Vo1. 2 (1971), pp. 38-52.

[51] Lasdon, L.S., Optimization Theory for Large Systems, MacMi11an, New York, 1970.

[52] Levy, H. and Sarnat, M., Investment and Portfolio Analysis, John Wiley and Sons Inc., New York, 1972.

[53] Lifson, K.A. and Blackman, B.R., "Simulation and Optimization Models for Asset Deployment and Funds Sources, Balancing Profit, Liquidity and Growth," Journal of Bank Research, Vol. 4 (1973), pp. 239-255.

[54] Luenberger, D.W., Introduction to Linear and Nonlinear Progromming, Addison-Wesley, Reading, Massachusetts, 1973.

[55] Madansky, A., "Methods of Solutions of Linear Programs Under Uncertainty," Operations Research, Vol. 10 (1962), pp. 165-176.

[56] - "Inequalities for Stochastic Linear Programming Problems," Management Science, Vol. 6 (1960), pp. 197-204.

[57] Mao, J.C.T., "Application of Linear Programming to Short-term Financing Decision," Engineering Economist, Vol. 13 (1968), pp. 221-241.

[58] Markowitz, H.M., "Portfolio Selection," Journal of Finance, Vol. 6 (1952), pp. 77-91.

[59] - Portfolio Selection, Efficient Diversification of Investments, John Wiley and Sons Inc., New York, 1959.

[60] Mossin, J., Theory of Financial Markets, Prentice-Hall Inc., Englewood Cliffs, New Jersey, 1973.

[61] Myers, S.C., "Procedures for Capital Budgeting Under Uncertainty," Industrial Management Review, Vol. 9 (1968), pp. 1-20.

[62] Naslund, B., "A Model of Capital. Budgeting Under Risk," Journal of Business, Vol. 39 (1966), pp. 257-271.

[63] Naslund, B. and Whinston, A., "A Model of Multi-Period Investment Under Uncertainty," Management Science, Vol. 8 (1962), pp. 184-200. 
[64] Orgler, Y.E., "An Unequal-Period Mode] for Cash Management Decision," Management Science, Vol. 16 (1969), pp. B-77-B-92.

[65] Cash Management Methods and Models, Wadworth Publishing Co. Inc., Belmont California, 1970.

[66] Orr, D., Cash Management and the Demand for Money, Praeger Publishing Co., Inc., 1970.

[67] Parikh, S.C., Notes on Stochastic Programming, unpublished, I.E.O.R. Department, University of California, Berkeley, 1968.

[68] Pogue, G.A. and Bussard, R.N., "A Linear Programming Model for ShortTerm Financial Planning Under Uncertainty," SZoan Management Review, Vol. 13 (1972), pp. 69-98.

[69] Pye, G., "Sequential Policies for Bank Money Management," Management Science, Vol. 20 (1973), pp. 385-395.

[70] Pyle, D.H., "On the Theory of Financial Intermediation," Journaz of Finance, Vol. 26 (1971), pp. 737-748.

[71] Robichek, A.A. and Myers, S.C., Optimal Financing Decisions, PrenticeHall Inc., Englewood Cliffs, New Jersey, 1965.

[72] Ro11, R., "Investment Diversification and Bond Maturity," Journal of Finance, Vol. 26 (1971), pp. 51-66.

[73] Sharpe, W.F., Portfolio Theory and Capital Markets, McGraw-Hi11, New York, 1970.

[74] Symonds, G.H., "Chance-Constrained Equivalents of Some Stochastic Programming Problems," Operations Research, Vol. 19 (1968), pp. $1152-$ 1159.

[75] Telser, L., "Safety First and Hedging," Review of Economic Studies, Vol. 23 (1955-1956), pp. 1-6.

[76] Thomson, M.R., "Forecasting for Financial Planning," Journal of Bank Research, Vol. 4 (1973), pp. 225-231.

[77] Thore, S., "Programming Bank Reserves Under Uncertainty," Swedish Journal of Economics, Vol. 70 (1968), pp. 123-137. 
[78] Tintner, G., "Stochastic Linear Programming with Applications to Agricultural Economics," Proceedings 2nd Symposium, Linear Prograrming, Edited by H.A. Antosiewicz, 1955.

[79] Tobin, J., "Theory of Portfolio Selection," The Theory of Interest Rates, Edited by F.H. Hahn and R.P.R. Biechling, MacMillan, London, 1965, pp. 7-9.

[80] Tobin, J. and Brainard, W.C., "Financial Intermediaries and the Effectiveness of Monetary Controls," American Economic Review, Vol. 53 (1963), pp. 383-400.

[81] Tuttle, D.I. and Litzenberger, R.H., "Leverage, Diversification and Capital Market Effects on a Risk-Adjusted Capital Budgeting Framework," Journal of Finance, Vol. 23 (1968), pp. 427-443.

[82] Van Horne, J.C., "A Linear-Programming Approach to Evaluating Restrictions Under a Bond Indenture or Loan Agreement," Jourmal of Financial and Quantitative Analysis, Vol. 1 (1966), pp. 68-83. - Function and Anazysis of Capital Market Rates, Prentice-Ha11 Inc., Englewood Cliffs, New Jersey, 1970.

[84] Financial Management and Policy, 4th Edition, PrenticeHa11 Inc., Englewood Cliffs, New Jersey, 1977.

[85] Vancouver City and Savings Credit Union, Financial Statements, 19681975.

[86] Wagner, H.M., Principles of Operations Research, Prentice-Hall Inc., Englewood Cliffs, New Jersey, 1969.

[87] Walkup, D.W. and Wets, R.J.B., "Stochastic Programs with Recourse," SIAM Journal on Applied Mathematics, Vol. 15 (1967), pp. 1299-1314.

[88] Weingartner, H.M., Mathematical Programing and the Analysis of Capital Budgeting Problems, Prentice-Hall Inc., Englewood Cliffs, New Jersey, 1963.

[89] Capital Budgeting of Interrelated Projects: Survey and Synthesis," Management Science, Vol. 14 (1966), pp. 485-516.

[90] Wets, R.J.B., "Programming Under Uncertainty: The Equivalent Convex Program," SIAM JoumaZ on Applied Mathematics, Vol. 14 (1966), pp. 89-105. 
[91] Wets, R.J.B., "Programming Under Uncertainty: The Solution Set," SIAM Journal on Applied Mathematics, Vo1. 14 (1966), pp. 1143-1151.

[92] - "Programming Under Uncertainty: The Complete Problem," z. Wahrsch. verw. Geb., Vol. 4 (1966), pp. 316-339.

[93] - "Characterization Theorems for Stochastic Programs," Mathematical Programming, Vol. 2 (1972), pp. 166-175.

[94] - "Stochastic Programs with Fixed Recourse: The Equivalent Deterministic Program," SIAM Review, Vol. 16 (1974), pp. 309-339.

[95] - "Solving Stochastic Programs with Simple Recourse, I," Mathematical Programming (forthcoming).

[96] Williams, A.C., "On Stochastic Linear Programming," SIAM Joumal Applied Mathematics, Vol. 13 (1965), pp. 927-940.

[97] - "Approximation Formulas for Stochastic Linear Programming," SIAM Journal of Applied Mathematics, Vol. 14 (1966), pp. 669-677.

[98] Wolf, C.R., "A Model for Selecting Commercial Bank Government Security Portfolios," The Review of Economics and Statistics, Vol. 51 (1969), pp. 40-52.

[99] Zangwi11, W.I., Nonlinear Programing: A Unified Approach, PrenticeHall Inc., Englewood Cliffs, New Jersey, 1969.

[100] Ziemba, W.T., "A Myopic Capital Budgeting Model," JournaZ of Financial and Quantitative Analysis, Vol. 6 (1969), pp. 305-327.

[101] - "Transforming Stochastic Dynamic Programs into Nonlinear Programs," Management Science, Vol. 17 (1971), pp. 450-462.

[102] "Solving Nonlinear Programming Problems with Stochastic Objective Functions," Journal of Financial and Quantitative Analysis, Vol. 7 (1972), pp. 1809-1827.

[103] - "Stochastic Programs with Simple Recourse," pp. 213-273, in P.L. Hammer and G. Zoutendijk, editors, Mathematical. Programming: Theory and Practice, North Holland Publishing, Amsterdam, 1975.

[104] Ziemba, W.T.. and Vickson, R.G., editors, Stochastic Optimization Models in Finance, Academic Press Inc., New York, 1975. 